University of Louisville

ThinkIR: The University of Louisville's Institutional Repository

Electronic Theses and Dissertations

8-2017

\title{
Exploring the barriers to effective federal flood mitigation in the Mississippi River region.
}

\author{
Linda Kay Bailey \\ University of Louisville
}

Follow this and additional works at: https://ir.library.louisville.edu/etd

Part of the Public Affairs, Public Policy and Public Administration Commons

\section{Recommended Citation}

Bailey, Linda Kay, "Exploring the barriers to effective federal flood mitigation in the Mississippi River region." (2017). Electronic Theses and Dissertations. Paper 2764.

https://doi.org/10.18297/etd/2764

This Doctoral Dissertation is brought to you for free and open access by ThinkIR: The University of Louisville's Institutional Repository. It has been accepted for inclusion in Electronic Theses and Dissertations by an authorized administrator of ThinkIR: The University of Louisville's Institutional Repository. This title appears here courtesy of the author, who has retained all other copyrights. For more information, please contact thinkir@louisville.edu. 


\title{
EXPLORING THE BARRIERS TO EFFECTIVE FEDERAL FLOOD MITIGATION IN
} THE MISSISSIPPI RIVER REGION

\section{By}

Linda Kay Bailey

B.S., University of Southern Indiana, 2004

M.S., University of Southern Indiana, 2008

\author{
A Dissertation \\ Submitted to the Faculty of the \\ College of Arts and Sciences of the University of Louisville \\ in Partial Fulfillment of the Requirements \\ for the Degree of \\ Doctor of Philosophy \\ in Urban and Public Affairs \\ Department of Urban and Public Affairs \\ University of Louisville \\ Louisville, Kentucky
}

August 2017 



\title{
EXPLORING THE BARRIERS TO EFFECTIVE FEDERAL FLOOD MITIGATION IN THE MISSISSIPPI RIVER REGION
}

\author{
By \\ Linda K. Bailey \\ B.S., University of Southern Indiana, 2004 \\ MPA, University of Southern Indiana, 2008 \\ A Dissertation Approved on
}

August 1, 2017

by the following Dissertation Committee

Dr. David Simpson

Dr. Janet Kelly

Dr. Steven Koven

Dr. Mary Hallock Morris 


\section{DEDICATION}

This dissertation is dedicated to my brother

Mr. Travis Lee Bailey

for promising he would help me reach this goal no matter what happened.

This dissertation is also dedicated to

Breah Bailey, niece

Dax Bailey, nephew

Shae Bailey, niece

who I want to inspire to work hard, play hard, and do good in this world.

And to the memory of my aunt

Gail Johnson

who I lost along this journey

.... for all the doting and sharing the feisty genes with me. 


\section{ACKNOWLEDGEMENTS}

First, I want to sincerely thank my brother, Travis, because I would not have made it this far without his support; and for sharing his dog, Bonnie, who was my major research assistant. I would like to thank my major professor, Dr. David Simpson, for his time and guidance through this process and for the opportunity to study under his supervision. I would also like to thank my committee members, Dr. Steven Koven, Dr. Janet Kelly, and Dr. M.T. Morris for their recommendations and also sacrificing some of their summer to help me finish. I want to thank our program director, Dr. David Imbroscio, for all of his support, guidance, and the opportunity to study under his supervision. I want to thank Hank Savitch for allowing me to study under his supervision and for teaching me to practice my craft every day. I want to express my thanks for the School of Graduate Studies and College of Arts \& Sciences for all their support, plan sessions, and oversight. I especially want to thank the staff at the Department of Urban and Public Affairs for all the help and assistance, the good food, and the good humor provided as needed. I especially want to thank my mentor, Dr. M.T. Morris and her husband, Gary Morris for everything they've done for me--which is more than will fit on this page but includes moving me, visiting regularly, and letting me stay with them. I want to thank my colleague, Sarin Adhikari, for his support and collaboration in all things in the trenches and on the back porch, and his wife, Praktisha Adhikari, for being patient with us. I want to especially thank my aunt, Phyllis Crawford, for helping me during a really difficult period. I want to thank Grant Neeley and Eileen Maloney at the University of Dayton for hiring me and making me feel at home in Ohio. I also want to thank Jennifer Lumpkin at UD for helping me do the ArcGIS maps. Finally, thanks to my friends and family back home for always being there. 


\section{ABSTRACT \\ EXPLORING THE BARRIERS TO EFFECTIVE FEDERAL FLOOD MITIGATION IN THE MISSISSIPPI RIVER REGION \\ Linda Bailey}

August 1, 2017

This dissertation is a comprehensive study of flood mitigation in the Mississippi River region as it is impacted by federal flood policies and programs. The study begins with a historical narrative of flooding events and flood mitigation that provided the impetus for federal flood mitigation in the late $1920 \mathrm{~s}$. The historical narrative sheds light on issues related to federalism, path dependency, dynamic growth, and socio-culture influence during the development of flood mitigation policy. Growth machine theory is used to describe how inequality and disparate access to political power has worked to exacerbate flood disaster outcomes and how this dynamic is legitimately perpetuated via federal policies. The second half of the dissertation is focused on a comprehensive evaluation of current mitigation planning mandates, programs, and planning tools.

The dissertation is divided into six chapters, covering the historical development, theoretical implications, a critique of current practices, and future recommendations for federal flood mitigation. Chapter One provides a basic overview of the issues related to federal flood mitigation and the potential shortcomings of the current system. Chapter Two delves into a historical narrative that provides a rich account of early responses to flooding and how federal flood policy developed from these experiences. Chapter Three discusses the theoretical explanations as to why exacerbated disaster impacts are a result of policy actor influences. It also covers the literature involving present mitigation planning practices. Chapter Four describes the methods used in this study to comprehensively assess mitigation planning and programs. Chapter 
Five discusses the findings and implications derived from the comprehensive assessment of mitigation practices. Finally, Chapter Six provides a discussion of how current federal flood mitigation policy is influenced by growth machine dynamics as evidenced through these findings. It also provides insight for improving current practices and makes recommendations for further study. 
TABLE OF CONTENTS

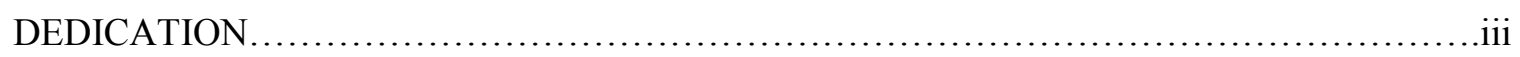

ACKNOWLEDGEMENTS.......................................................

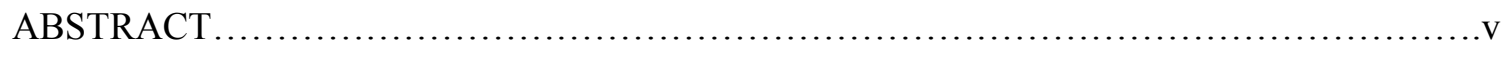

CHAPTER ONE: INTRODUCTION ..............................................

CHAPTER TWO: BACKGROUND OF THE MISSISSIPPI RIVER REGION...............9

CHAPTER THREE: REVIEW OF THE LITERATURE................................

CHAPTER FOUR: METHODS................................................ 58

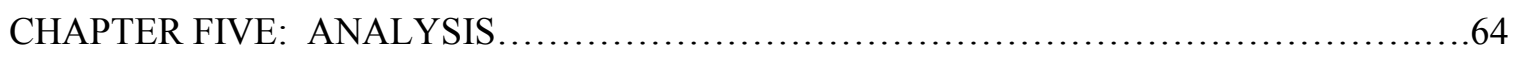

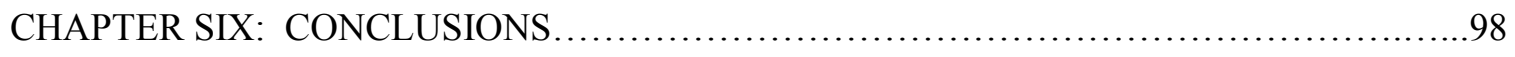

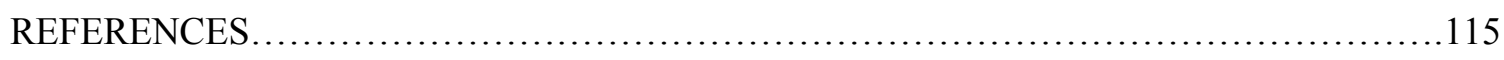

APPENDIX A: TABLES AND FIGURES FOR CHAPTER TWO.........................124

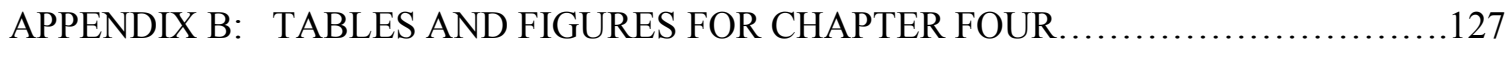

APPENDIX C: TABLES AND FIGURES FOR CHAPTER FIVE $\ldots \ldots \ldots \ldots \ldots \ldots \ldots \ldots \ldots . \ldots \ldots 1$

CURRICULUM VITAE.......................................................... 268 


\section{CHAPTER ONE INTRODUCTION}

The need for federal flood control in the United States originated in the lower region of the Mississippi River in the 1800 s and found legitimacy at the beginning of the $20^{\text {th }}$ Century. Political feasibility for federal flood control has consistently been met with resistance at various levels and by various stakeholders. This resistance basically manifests itself in ways that seem legitimate and there is no resolution that can possibly satisfy everyone. However, a federal flood control system is ineffective if it does not integrate a coordinated effort at all levels of government and with all stakeholders. Lacking a coordinated effort, the flood control system may even contribute to greater vulnerability by providing citizens a sense of false security within the floodplain resulting in higher losses and greater recovery costs.

While floodplain areas are only a small portion of the national landscape as a whole, it commands to be addressed as one of the most concerning and costly areas to mitigate for flooding events. Many hazard researchers will argue that the U.S. government actually does more to contribute to flooding than to mitigate for it. While the federal government sets the guidelines for floodplain management, local jurisdictions are the primary regulators of the floodplain. There are very few constraints on their land use decisions at the state or federal level. Thus, development in the floodplain continues unimpeded and appears to be reinforced within the existing political structure.

Growth machine politics play a strong role in this process. Many claim that local jurisdictions or local elites attempt to secure expensive federal funded structural flood mitigation projects in order to provide these high-dollar project contracts to elite constituents. Secondly, 
these local officials seek to develop the area behind the levees and floodwalls in order to bring in more revenue for local coffers. It is not necessarily the case that these land use decisions are wise choices and in the best interest of the community. Local officials will champion the idea that development is necessary to provide more benefit for the whole community. However, most of the benefit will reside with those elites hawking development contracts and developing these risky areas while the majority of the community is paying the high cost of assuming this risk.

In 1945, Gilbert F. White, often referred to as the "father of floodplain management" wrote a dissertation titled Human Adjustments to Floods, and this became a seminal piece of work that claimed there was too much emphasis faced on structural methods of flood mitigation and not enough consideration of non-structural methods such as land use regulation and insurance (White, 1945). His work echoes the sentiment that large, expensive, structural projects were being appropriated despite evidence that flood costs continued to increase (White, 1945). White (1945) argued for a comprehensive approach to the flood problem with target reduction as a goal and to reduce the need for federal relief. By 1968, his suggestions were being employed through the National Flood Insurance Act of 1968 which was an attempt to provide insurance for structures in the floodplain and incentivize local government to create ordinances enforcing minimum standards of retrofitting structures in the floodplain.

How did this legislation impact the flood problem? Did it reduce flood costs? Karen O’Neil $(2006,173)$ argues that the National Flood Insurance Program (NFIP) actually subsidized construction in the floodplain as a result of this program. Flood costs continue to rise and according to the Government Accountability Office (2013) the NFIP at that time was in debt to the U.S. Treasury to the tune of 24 billion dollars.

This research seeks to answer some basic questions. How does the path dependent development (historical underpinnings) of flood mitigation in this region impact present mitigation initiatives? Does a regional analysis provide a better understanding of persistent 
problems in floodplain management? Does the cost of flooding continue to rise despite implementing both structural and non-structural mitigation? Did non-structural mitigation policies and programs implemented over time reduce the cost of flooding? More specifically, did mandating local governments to create hazard mitigation plans reduce the cost of flooding? Are local governments still too primarily focused on structural mitigation as the answer to flood mitigation?

Mitigation is "the effort to reduce loss of life and property by lessening the impact of disasters" (FEMA, 2015). Flood mitigation is specific to reducing impacts from flood disasters. Structural mitigation encompasses such things as building floodwalls, floodgates, levees, and other major land adjustments or barriers that attempt to control the flow of water away from areas to protect property from flooding. Non-structural mitigation refers to types of strategies or actions that contribute to flood disaster impact reductions such as land use policies, insurance programs, incentive programs, education, outreach, studies, zoning, enforcement and other administrativetype functions. Hazard mitigation plans are planning tools designed to assist state, tribal and local governments identify hazard risks, collaborate with local stakeholders in risk reduction, identify strategies and actions to reduce risk, prioritize mitigation actions, and identify funding sources (FEMA, 2015).

Recently, disaster researchers have honed in on the idea that growth machine dynamics may be the "unifying theoretical paradigm" (Tierney, 2010) explaining how economic and political forces exacerbate our vulnerability to hazards. Looking at flooding specifically, growth machine dynamics seem to be the most plausible explanation for our inability to reduce costs associated with flooding disasters.

Previously, hazard researcher Dennis Mileti $(1999,12)$ advocated the idea of a "global systems perspective" in order to achieve more comprehensive mitigation planning. He explained that three major systems-- the natural environment, the built environment, and the social environment and the interactions among these systems should be our major focus for reducing 
disaster costs (Mileti, 1999, 12). Mileti (1999) expands the systems approach from partially holistic (Easton, 1953) to completely holistic-- highly interconnected and more comprehensive. He believes that by looking from a global systems perspective, there is a shift from the traditional systems model creating an overall system that is "greater than, and different from, the sum of its parts" versus "the whole is equal to the sum of its parts" (Mileti, 1999, 106-107).

Mileti $(1999,13)$ declares that social factors have, for the most part, been overlooked and their power has been underestimated. He claims that change in social values will result in a more effectively mitigated environment (Mileti, 1999, 13). Mileti $(1999,17)$ argues that traditional system theorists" "overemphasis on stability" results in "labeling the change and process as negative". Actually, growth machine dynamics dominate our social culture so significantly that it creates the instability that ultimately causes systems to fail regardless of whether the feedback is negative or perceived as positive. The feedback could be a false positive when the growth machine processes mask vulnerabilities. Therefore, systemic approaches are dependent on eradicating growth machine dynamics from the social culture. Thus growth machine dynamics dominate as the overarching theory in how hazard or flood vulnerability manifests and renders mitigation efforts ineffective.

In sum, along with identifying the most persistent problems in floodplain management, this research contributes to the growing consensus that growth machine theory best identifies how these problems manifest. Hence this research attempts to answer the question: Is it the case that growth machine dynamics are continuing to render the federal flood control system ineffective?

The research study focuses on 10 states and 108 counties that border the Mississippi River from the upper to lower bounds within the United States. Using the Mississippi River region as the region of analysis is very important not only to show how federal flood mitigation policies and programs developed historically; but also this region exemplifies the importance of considering path dependency in this system and how flood mitigation is bounded. Path dependency is best defined as having the condition in which "where we go next depends not only 
on where we are now, but also upon where we have been" (Liebowitz and Margolis, 2000, 981). Historical flooding in the Mississippi River region played an integral role in influencing federal involvement in flood controls. The use of levees was a practice adapted from Europe by early settlers in Louisiana and these early manipulations of flood water are one of several means that created a path dependent condition that impacted the circumstances we have now.

This study will first attempt to describe the historical underpinnings which resulted in a path dependent condition within the region. The path dependent condition specific to this area then influenced the development of federal policy prescriptions for flood mitigation. Path dependency is also symptomatic of growth machine dynamics therefore it is necessary to examine the history of settlement in order to understand how growth machine politics influences overall design and limits to a comprehensive flood mitigation system.

Next, there is a review of the literature associated with flooding, growth machine theory and systems theory as they relate to flooding. Primary to this analysis is a discussion of the works of Gilbert F. White (1945) and his significant contribution to flood mitigation study. White (1945) theorized that as the amount of structural mitigation increased, so did the costs associated with flooding. He argued for a target reduction strategy that focused on non-structural mitigation as the most effective way to reduce the cost of flooding (White, 1945). This research expounds on his work and brings it forward. This study attempts to answer a secondary question: Does the cost of flooding continue to rise despite engaging in both structural and non-structural mitigation initiatives?

In the process of conducting this study, this researcher attempted to collect and evaluate the state and county all-hazard mitigation plans from these ten states and 108 counties. First, a time-series analysis was conducted to determine whether or not flood costs decreased with the implementation of all-hazard mitigation plans under the Disaster Mitigation Act of 2000.

Secondly, this study identifies flood mitigation goals and actions in hopes to gain insight on community preparedness and needs. Looking specifically at flood mitigation goals and actions 
allows us to make determinations on the trends in flood mitigation planning and to explain whether or not these trends are being influenced by growth machine dynamics. Gilbert White (1945) argued that despite all efforts to mitigate flooding using structural methods, the cost of flooding continued to rise. He pointed to the problem of the "status quo" influencing mitigation efforts in a way that was making flood mitigation efforts futile. Today we would describe White's (1945) "status quo" to be growth machine dynamics influence. White (1945) argued that the way forward to reduce flooding would be through target reduction measures in the form of policy and programs rather than large expensive dirt-moving and wall-building structural projects. In this research study, non-structural mitigation action items refer to any action that relates to target reduction such as policies and programs that incentivize identifying and retrofitting or moving repetitive flooding properties in the floodplain; adequately insuring properties within the floodplain; using technology and other tools to identify hazard areas in need of attention; and education and outreach to inform and prepare populations near or within the floodplain.

Using content analysis, each flood mitigation action was evaluated to determine if it was considered a structural or non-structural mitigation action item and then further categorized by the type of action in order to develop a composite picture of flood mitigation actions used within this region. The analysis was intended to determine several things. First, what are the main types of flood mitigation actions used within the whole region within the focus of the study? Second, is there evidence of a structural mitigation preference over non-structural mitigation? Third, are these flood mitigation actions similar across the entire region or do they vary based on geographical location? Fourth, are there any other patterns within these mitigation plan actions that might provide better insight into determining how growth machine dynamics may be impacting the course of mitigation planning? Finally, this data was compared to a national survey of local officials conducted by FEMA regarding their opinions of the flood mitigation needs and overall preparedness. 
In addition, several other types of data were also collected to paint a more comprehensive picture of the region and flooding problems within this region. For one, 50 years of flooding disaster data was collected to determine frequency and costs associated with flooding within the region. The data allowed the researcher to look at flood frequency and property damage costs at the county level and identify counties with greater flooding risks and higher costs.

Demographic and housing characteristics were studied to determine who may live in the floodplain and whether there may be greater vulnerabilities related to these populations. Specifically, we wanted to look at some variables related to greater social vulnerability that were available at both the county level data and census tract level. Based on ad hoc interactions with local emergency managers who claim they are unable to identify who exactly is in the floodplain, GIS mapping more clearly identified this population. The data was contrasted to the SoVI (Clutter et al., 2012), a social vulnerability index created by Susan Clutter and others at the University of South Carolina. The SoVI is a measure of social vulnerability to all hazards at the county level. Therefore, if we looked at the county SoVI scores and county level ACS data and compare it to data available at the census tract level, would we find pockets of vulnerabilities that would not otherwise be identified? Would this be useful information for local emergency managers to distinguish greater social vulnerabilities specifically related to flooding? Secondly, at what level of analysis, e.g. county, census tract, census block, can social vulnerability be measured?

Finally, data associated with the National Flood Insurance Program and Community Rating System gathered from a FEMA database was evaluated for county participation rates. The information was used to make determinations about non-structural mitigation actions specific to program participation and repetitive loss within state and local hazard mitigation plans.

Particularly, is there evidence that counties are participating in these incentivized programs? If not, are there clues to why these programs are under-utilized? Does the growth machine dynamic interfere with program effectiveness? 
Research on mitigation plan quality has continued to grow since the late 1990s.

Evaluating plan quality is challenging due to wide variability and changes in guidance coming from the federal government. The federal government mandated (DMA, 2000) counties to have mitigation plans beginning in 2000 and ordered updates in these plans at five year intervals. It is reasonable to argue mitigation plan standardization could not be realized in the ten year period that we have focused on. On the other hand, after ten years, we should expect greater participation and greater focus on accountability. In fact, we should be accomplished in participation and solely focused on the many ways these plans can be more impactful. This study will recommend the ways we can accomplish this. Not only do we need to be concerned with the internal validity of the plans themselves and the effectiveness of top-down guidance, but also ways in which information from the plans can be gathered and utilized from the bottom-up to create a functional feedback loop for better results. Herein lies great potential to resolve some of disconnects between different levels of government, provide more effective oversight and greater accountability, and diffuse some growth machine influence on the process. 


\section{CHAPTER TWO}

\section{BACKGROUND OF THE MISSISSIPPI RIVER REGION}

\section{The Natural Environment and the Mississippi River}

To understand the enormity of what we are dealing with in terms of flood management on the Mississippi River, it is helpful to provide a comprehensive description of the Mississippi River system, the fourth largest river in the world.

The headwaters begin in a small stream in Minnesota. From here it takes about 90 days for a drop of water to flow out the mouth of the Mississippi River into the Gulf of Mexico. It drains 41 percent of 48 contiguous states, which is a total of $1,245,000$ square miles. It accepts the flows of various rivers and streams in 31 states and two Canadian provinces and serves as the natural border for ten states. In river miles, it extends just over 2,300 miles long given its curviness and meandering nature.

The upper Mississippi River flows through Minnesota, Iowa, and Illinois. The upper portion of the river, or the river head, is fed by waterfalls and cradled within a gorge. This portion of the river is rocky and has higher elevation drops per mile. Here the river cannot be traveled by other means than a canoe or kayak until it reaches the area around Minneapolis, Minnesota.

In the 1930-40s a lock and dam system was built that allows for water to pool in order to make it deep enough for navigation. The lock and dam system is a stair step design where each dam holds back and pools the water rather than allowing to run freely with natural waterfalls and rapids. The upper portion of the river is known for vast wildlife refuges in the natural wetland areas. The wetlands serve as overflow basins for the river when it floods. The dividing point between the upper and lower river is at the confluence of the Ohio River near Cairo, Illinois. 
From Cairo, Illinois the river develops a faster current and has far less elevation slope. This portion of the river is mitigated differently (mainly by levee) because it does not have dams to pool the water. The river, guided by levees, flows faster allowing it to scour the bottom which makes it deeper and heavy with sediment which gives it a muddy appearance. It is an obscure fact that the river's sandy landscape was formed by the river rather than the river actually cutting through the land (Loyola University Wetland Resource Center, 2011). The river has a lower alluvial valley of 35,000 square miles which is 650 miles long and 25-125 miles wide. The lower valley lies within the following seven states: Missouri, Illinois, Tennessee, Kentucky, Arkansas, Mississippi, and Louisiana.

In the delta region of the Mississippi River, the river has a tendency to change course about every 1,000 years. There are five previous recorded changes in the river that actually built Louisiana (Figure 2.1). The first change resulted in the formation of the Atchafalaya River and secondly the Teche region. From here, the river flops to the direction of New Orleans and creates the eastrn region of Louisiana. The third shift created St. Bernard; the fourth created Lafourche, and the fifth shift formed Plaquemine. The river is in the sixth route developing what we call the "bird's foot" and the present mouth of the Mississippi River.

The river attempts to take the shortest and steepest route to the Gulf of Mexico. By the early 1930s, this became a topic of expert discussion (Kelman, 2006) as Old River had established a continuous easterly flow taking on more and more of the Mississippi River and directing this volume into the Atchafalaya River. Presently the Atchafalaya River is about 150 miles shorter and steeper than the Mississippi River's present route towards Baton Rouge and New Orleans; therefore, the river naturally attempted to shift and completely join the Atchafalaya.

Flooding impacts on the Mississippi River by natural forces are due to more frequent and intense rains in both the upper and lower portions but also by higher volumes of snowmelt in the upper river. Therefore, river flooding would also be affected by climate change. If precipitation 
is greater in warmer atmospheres, the lower portion of the river might be more likely to have episodes of flooding. In the 1993 floods, the upper Mississippi experienced massive and catastrophic flooding which would have been detrimental to the lower Mississippi if it were not for drought conditions affecting the area below Cairo, Illinois.

\section{The Human System on the Mississippi River: Settlement, Growth, and Economic Traits}

Dennis Mileti (1999) notes that if people's characteristics were more homogenous, then disaster mitigation would be easier and we would suffer fewer losses. If homogenous conditions were the case, we would have a more simplified and standard way to mitigate because we would only be dealing with the "magnitude" of the natural hazard (Mileti, 1999). However, the human system variables associated with the Mississippi River System are numerous and complex. These include population sizes, socioeconomic conditions, political views, diverse purposes for using or residing near the river, and different cultural perceptions at different areas along the river. Thus, our characteristics and interests are incredibly diverse which makes it far more difficult to create mitigation initiatives satisfactory for everyone. In addition, there will always be a degree of uncertainty that we cannot completely account for in the decision-making process.

There are over 125 established communities on the river's edge and some are more populated than others with heavily populated metropolitan areas such as New Orleans, Louisiana $(1,235,650)$, Memphis, Tennessee (646,889), St. Louis, Missouri $(319,294)$, Minneapolis/St. Paul, Minnesota (891,218) dotting the river landscape (U.S. Census, 2010). In addition, the river is steeped in culture with distinguished differences between the northern and southern ends and rural and urban areas. It can even be said there are cultural differences on opposite sides of the river.

Racial inequality and poverty have plagued regions along the river. Given this fact, politics and wealth influence have made significant impacts on mitigation of the river system. According to the U.S. Commission on Civil Rights (2001) the Mississippi Delta is one of the poorest regions in the United States with a population of 8.3 million and has more counties than 
anywhere else in the U.S. to contain a majority percentage of black population. The Delta has a 17 percent unemployment rate and growing with 50.5 percent of the population living below poverty level (USCCR, 2001). Rural poverty is exacerbated in the lower region of the Mississippi River and can partially be attributed to discrimination against blacks that continues to present day. Black discrimination could not be more accentuated than during the 1927 floods when over 30,000 black plantation workers were forced into concentration camps on the river working day and night to build protection on the levees (Barry, 1997). Many of these men were lost in the flooding as they were stranded and abandoned atop the levees as human sandbags. The official death toll is very misleading and inaccurate given the nature of inequality in 1927 and blacks were not counted in the census of fatalities (Barry, 1997).

Settlement in the southern region of the Mississippi River began with the 1717 French settlement on the crescent shaped land adjacent to the Mississippi River. This ridge was formed by sediment deposits from the river where it takes a sharp turn east to northeast before it flows straight south for 100 miles into the Gulf of Mexico. Thus L'Isle de la Nouvelle Orléans (The Island of New Orleans - at the time believed to be surrounded by water), later became New Orleans. There was speculation among settlers from Indiana and Kentucky territories that travel by river could lead them to the Gulf of Mexico and river trade would be foundational to development of the American Colonies. Unfortunately, Spain declared full control of the Mississippi River cutting northern colonists off from the lower portion of the Mississippi. The 1803 Louisiana Purchase (costing just over 11 million dollars) secured the right to public use for travel the length of the Mississippi without intervention by the Spanish. The purchase prompted increased trade and travel on the river. From this point, New Orleans was on its way to becoming the largest trade route in and out of the U.S. colonies. Living on the delta of the fourth longest river in the world would be profitable and rewarding, but it also meant dealing with many risks and hazards associated with the natural environment. 
Presently, the upper portion of the Mississippi River serves the region's 30 million people as a resource for power plant operations, delivery and export of goods (70-85 million tons of cargo annually), and various other things that enable the public and industry to survive (USGS, 2007). The 1,200,000 acres of floodplains have been adapted for pasture and agriculture use as well. Likewise, the lower Mississippi River has a huge agricultural niche within its basin. The rich and fertile soils left from upstream sediments provide for millions of acres of winter wheat, corn, soybeans, cotton, sugarcane, sorghum and rice. The Atchafalaya basin provides a livelihood for about 1,100 commercial fishermen who provide 82 million pounds of crawfish (McCain et al., 2007) which makes up nearly 95 percent of the national crawfish harvest for the food and restaurant industry. The lower Mississippi River serves to provide fertilizer, chemicals, petroleum, lumber and pulp, gravel, steel, and coal throughout the river system.

Over 400 million tons of bulk cargo is distributed along the river system with 200 million of this tonnage being gasoline and petroleum products (Nienaber, 2007). 448 million tons of cargo is exported annually through the Port of New Orleans accounting for $\$ 37$ billion dollars of the national economy (Stanford, 2011). In grains alone, 1.1 billion bushels of corn, 385 million bushels of soy beans, and 32 million bushels of wheat that make up 90 percent of grain exports are carried down the river (Kruse, 2004). The Mississippi River is a vital link to the economy serving as the most efficient means of transportation. Barges can carry 1,500 tons of bulk products which is far greater capacity than any other method of transportation.

\section{The Constructed Environment}

The constructed environment defined by Mileti (1999) consists of housing, utilities, transportation, technology, communications, critical facilities and engineered structures. Tributaries and river connections making trade possible gave rise to great American cities scattered along its riverbanks. Railroads and automobiles contributed and complicated the American connection with the river. We built bridges, dams, and levees to protect these cities from floods. Within these cities as population densities grew so did the amount of impermeable 
surfaces that allow more runoff into the river system. Pumping stations and holding ponds help manage flooding within cities but poorly maintained infrastructures often leave cities vulnerable when their measures are obsolete or in need of upgrades and repairs.

Dependence on the Mississippi River resulted in the need to make changes by building diversion structures such as levees, carve-outs or canals in order to protect settlements or improve navigation. As a result of these changes, there were unintended consequences that led to an ongoing management system which would monitor and remedy problems arising from those alterations. These conditions makes the system path dependent (Collier and Collier, 1991) which limits the course or changes possible after a previous major action is taken.

\section{Historical Underpinnings: Public Space, Power, and Path Dependency}

The history behind flood control becomes an entertaining story beyond the informative. The historical narrative describing how settlement occurred around the river, how we used the river, and the changes made to the river establishes that the growth machine dynamics have created a path dependent system that also contributes to increasing vulnerability to catastrophic flood disasters. Comprehensive evaluation of the flooding problem, the theories behind flooding problems, and the social influences that perpetuate and exacerbate the flooding problem are examined.

Consider who controlled the river, the space in front of the river and who established where riparian rights end and public space begins? Kelman (2006) argues that these are the main issues that have played a predominate role in flood mitigation since the infancy of the United States. The nation has a culture steeped in individualism and strong respect for private property rights. The role of government in the interest of flood control and public safety has been highly controversial; and over time, there have been many changes depending on the zeitgeist.

Time and path dependency are key elements in developing an understanding of how the federal flood control system originated. The historical to contemporary settlement and development in the Mississippi River provides a rich foundation to overall discussion of 
transformations in addressing flooding problems. Since colonial times, the battle between preservation of nature and development of the riverbanks has ensued. Shortly after the Louisiana Purchase, privatizing the riverfront in New Orleans became an issue that reached national importance. Prior to selling Louisiana, the French had sold parcels of land abutting the riverfront. Here the transition from French governing to U.S. territory and governance was clunky even though U.S. government relied heavily on French and English law. The prevailing attitude in the infant U.S. was one of "reverence for property rights" while the prevailing attitude in New Orleans was one of "committing to civil law heritage" (Kelman, 2006, 41).

Early 1800 s riverfront property deeds contained a covenant that required the landowner to maintain a levee along the riverbank. Levee policy was further codified by state government in Louisiana Act 154 (1813) and Louisiana Act 156 (1817) to ensure the police juries had authority to sue landowners for work performed as a result of levee maintenance negligence (Poe, 2006, 62). In populated areas, this became problematic with owners because they felt too much of the burden was on them to protect not only their own land but those owning land behind them. They felt this should be a shared endeavor.

In rural areas upstream from New Orleans, building or maintaining the levee was even more problematic and complicated. First, the terrain along the riverfront in an undeveloped state was very dense with vines, trees and undergrowth. The river created its own natural levee forming a ridge as it overtopped the banks, then dropped heavy sediment first and cascaded the rest in a graded fashion until the slope gave way to marshy floodplain and backcountry (Poe, 2006). Huge swaths of giant cane or canebrakes within the undergrowth helped sustain the levee as the knotty fibrous root systems formed mats beneath the surface holding the sediment in place (Poe, 2006). The land in an undeveloped state was so dense that settling proved difficult as the only possible access was by the waterway. The land easiest to clear was the land closest to the river that had dried, thus owners built their homes, slave quarters, barns, and livestock pens along the ridge (Poe, 2006). The homes were elevated to allow air circulation and to protect them 
from flooding, snakes and vermin (Poe, 2006). The most difficult laborious land to clear was that of the backcountry which remained damp and heavy and very mineral rich and perfect for cotton farming (Poe, 2006). Flooding occurred often and carried bugs that destroyed crops and stagnated water pools that incubated mosquitos, thus yellow fever epidemics were rampant. Likewise, river erosion often took chunks of the riverbanks forcing settlers to rebuild homes and levees further back on their properties and often at a lower level than previously.

In 1803 New Orleans, as the result of the Mississippi River's sediment building nature, a land mass had formed on the east bank upstream from the crescent "C" (today's French Quarter) between the river and the private property line of Jean Gravier, a wealthy landowner of Faubourge St. Mary (Kelman, 2006). During periods of low water, this muddy sediment bank, the batture, was considered public use and served as a community promenade as it dried out in the summer months. The batture provided an access point for flat boats and fishing and was often used by locals to extract sediment for personal needs on their own property (Kelman, 2006).

Jean Gravier, owner of Faubourge St. Mary (today's New Orleans central business district) had become increasingly territorial over the batture and set up his own barriers to prevent public access (Kelman, 2006). The locals had pretty much disregarded Gravier and attributed much of his behavior as being that of an eccentric old fool. On the other hand, Gravier had decided that this batture held potential profit for him if he could lay claim then market the land for development and improvements (Kelman, 2006). In Gravier's mind, while the river "giveth and taketh away" this was the hazard of owning property that abuts a river. Therefore, he believed the land gifted by nature was solely his riparian property (Kelman, 2006).

In 1807 Gravier had sought out the recently transplanted New York attorney Edward Livingston for collaboration and challenged the local council to acknowledge his riparian rights to the batture (Kelman, 2006). Livingston had left New York in a state of disgrace after his subordinate embezzled $\$ 50,000$ from the city treasury while Livingston was holding public office (Kelman, 2006). Not only did his dealings in New York sour with the city but also ran afoul with 
President Jefferson during the Hamilton-Burr political conflict in New York. Like several of his colleagues and business associates in New York, Livingston has sought refuge in New Orleans to escape his past. In exchange for his legal services, Gravier offered Livingston a parcel of land on the batture to develop for himself (Kelman, 2006, 28).

Up to this point, local law held that the riverbank was owned by the public, therefore, the batture was perceived as public space and Gravier's property right ended at the edge of the batture (Kelman, 2006, 28). Local elites were outraged at Livingston's attempt to privatize the batture and grew infuriated when justices of the territory ruled in favor of Gravier and Livingston (Kelman, 2006, 30). As Livingston attempted to develop his portion of the batture, locals organized into mobs and disrupted the work. The conflict between Livingston and the locals continued to escalate to a dangerous level thus Livingston turned to the territory Governor William Claiborne to enforce his rights established by the territory justices (Kelman, 2006, 31).

In the United States, the Federal Government owns the land beneath navigable waters up to the high water mark. Therefore, while Livingston was arguing for the territory justices to enforce his rights, the local council called on the Governor to help defuse the conflict by establishing the batture as riverbed sediment in federal jurisdiction (Kelman, 2006). President Jefferson then intervened for two reasons. First, was the fact that Jefferson's animosity towards Livingston played a huge role in taking away Livingston's claim to the batture (Kelman, 2006). Second, he took the position that riverbanks are public space trusted to the people of the nation (Kelman, 2006).

Livingston would eventually regain control of this property. Using Manhattan as example of how the local council handed out land grants to develop their waterfront and save their city's beleaguered financial condition, Livingston appealed to locals that it was in their best interest to have someone develop the property and maximize the economic benefit for the public good (Kelman, 2006, 40). Livingston filed two suits, one against Jefferson in Federal Circuit Court for 
ordering him evicted and one in New Orleans district court against the marshal, Le Breton D’Orgenois, that evicted him (Kelman, 2006, 44).

While Livingston lost his case in federal circuit court, he won his case in New Orleans as D'Orgenois had nothing but the merits of the case to stand on. The local government, Counseil de Ville, continued to fight with Livingston creating injunctions against him meanwhile granting other riparian proprietors favor until they haggled Livingston into donating part of the batture to the city, allowed sediment to be removed by citizens for personal use, and forced him to build a levee to protect the property (Kelman, 2006, 47).

The battle over public space on the batture changed the landscape and the "public character" of the riverfront (Kelman, 2006, 49). Losing control of the riverfront led the general public to be extremely concerned about how problems associated with the natural force of the river would be dealt with (Kelman, 2006). They felt that there would be both economic and environmental disasters as a result of losing control of the riverfront. This critical juncture or pivotal point created crucial change and lasting legacy (Collier and Collier, 1991) as power was gained by the growth machine dynamic and diminished for regular citizens.

\section{Historical Underpinnings: River Navigation and Controls}

While serving as Minister to France under the Jefferson administration, Robert Livingston, Edward's older brother was instrumental in the Louisiana Purchase. Basically this purchase included not only Louisiana, but also a large swath of land west of the Mississippi River beyond the region that bordered the river such as Arkansas, Missouri, Iowa, and parts of Minnesota. The Louisiana Purchase allowed the U.S. free and clear access to the Mississippi River. Though the purchase itself was questionable as being unconstitutional, there was little dissent with the rhetoric that this provided all people within the nation free rights to access and use of the river which in turn would provide the economic growth to launch the U.S. into becoming a powerful wealthy nation. 
Contrarily, Robert Livingston then switched his position on a shared public river once he joined forces with Robert Fulton and Nicholas Roosevelt to form the Fulton Group, who successfully invented the first commercial steamboat (Kelman, 2006). The Fulton Group appealed to Governor Claiborne to pass legislation that gave them sole access to the river and its tributaries within the Louisiana territory (Kelman, 2006, 53). Kelman $(2006,54)$ explains that during this time period, granting monopolies allowed the country to develop infrastructure and garner revenue for federal, state, and local government that otherwise was impossible to attain. In this period, monopolies stood for the common good and best use of public space. The private sector provided the capital and groundwork for infrastructure thus spurring economic growth in exchange for healthy profits and exclusive control of that area. Though it seemed hypocritical for Claiborne to support Fulton Group's request for a monopoly, given his previous intervention in the New Orleans riverfront, he championed the cause (Kelman, 2006, 53).

There was reluctance among the citizens and local flatboat traders to embrace the Fulton steamboats as the logistical means to improve upon their present trading conditions. The economic boom promised by the Fulton Group did not materialize (Kelman, 2006, 56). Local people in the Louisiana viewed the Livingston brothers as greedy eastern outsiders and their unpopularity limited their power despite their monopoly on the river (Kelman, 2006, 57). In the meantime, Henry Shreve of Pennsylvania had garnered enough capital to improve upon the Fulton steamboat invention building two steamboats with greater capabilities for upriver travel as far as Louisville, Kentucky in a matter of record time-- 25 days (Kelman, 2006, 58).

Rather than publically and forcefully challenging Shreve's use of the river, Livingston, the ever unpopular outsider, was careful to challenge Shreve's use of the river indirectly. He solicited a retainer from all local attorneys so Shreve would have no representation when Livingston took him in court (Kelman, 2006, 57). The skirmishes between Shreve and Livingston escalated and Shreve's attorney was successful in garnering enough public support for Shreve, that the Fulton monopoly was abolished as the local court ruled they had no jurisdiction 
to enforce Shreve off the river (Kelman, 2006, 59). At this point, commerce on the Mississippi River began to grow exponentially as the river was once again held in common by the public.

\section{Historical Underpinnings: Changes to the Natural Landscape Increase Flooding}

River erosion was exacerbated by the onslaught of steamboats and the enormous amount of wood needed to fuel their engines. Since space was limited given the large cargo holds, the steamboats would carry no more than a day's worth of lumber on board to fuel the engines; therefore, "wood hawks" or loggers would cut and score wood for sale along the riverbanks (Poe, 2006). Flooding was beneficial for wood hawks as they cut wood in lowlands and then during high water, floated their loads and often cut holes in levees to move their wood to the riverside (Poe, 2006, 73).

Flooding brought about more debris, and debris made river navigation hazardous for steamboats, three-fifths of steamboat losses were attributed to debris accidents (Poe, 2006, 53). Therefore, there was a growing need to keep navigation open and deal with debris and natural sediment building that created sandbars and obstructions. Who would be responsible for maintaining navigation? The federal government would eventually step in and assist with navigation mitigation (Klein and Zellmer, 2007; Kelman, 2006) after the Supreme Court affirmed that regulating navigation lies within congressional authority (see Gibbons v. Ogden).

Following the flood in 1825, former Livingston foe and established navigation expert Henry Shreve argued that all the timber from the edge of the riverbank up to 300-400 yards back should be removed in order to prevent tree debris from entering the river (Poe, 2006, 53). The federal government began commissioning Shreve and his crews to do navigation maintenance on the river. Within a span of six months, Shreve's crews had cut 10,000 trees from the riverbanks and this would prove to be devastating and irreversible damage to the Mississippi River by exacerbating bank erosion (Poe, 2006).

In 1831, Shreve was also responsible for cutting a canal at Trumbel's Bend to improve travel time to New Orleans. This canal known as Old River sometimes flowed east to west when 
the Red River was high and then west to east if the Mississippi River level was higher. Shreve's shortcut proved to be problematic as experts learned more about the river later.

Growing trade had increased settlements on the river and individual efforts to build levees provided protections from river flooding. There was little to no coordination on levee building and this protection was not very reliable. By the 1820 s the State of Louisiana had established a comprehensive levee system where landowners were required to maintain their portion of the levee at their own expense within the standards prescribed by law (Poe, 2006). The local Parish Judge provided oversight for the system and police juries who had to construct or repair neglected levees sued the landowner for work and repair costs (Poe, 2006).

Leveeing was a European practice brought over by the French and the most ancient practice in response to flooding (Poe, 2006). Basically it was the only method considered because it was all early settlers knew. However, the more complex the levee system became, the greater the problem of flooding. Levees increased the height of the water within the channel. As a result when they were overtopped, or worse, as they were breached, they created larger disasters. In Louisiana, the velocity of the water was not strong enough to scour and deepen the channel, therefore the higher they built the levee, the higher the water rose as the sediment increased below in the riverbed.

\section{Historical Underpinnings: Increased Flooding and Need for Levee Cooperation}

Locals and especially planters along the riverbanks found themselves in an unsustainable situation with several issues resulting. They often could not afford to maintain the levee or were disgruntled with sacrificing the land. They complained of the lack of cost sharing with neighbors behind them and sacrificing the labor that could be used for planting (Poe, 2006). Levee districts developed within communities but the problems continued to grow. Lack of uniform standards for levee building went across state lines and states were forbidden by the U.S. Constitution from entering into compacts without Congress approval (Poe, 2006). Thus, the levee problem had reached a point where locals wanted federal intervention. 
Federal infrastructure development or internal improvements was a highly controversial issue during national elections throughout the first half of the 1800s and one of the main issues that led us into the Civil War. The South and the Northeast had two very different economies. The Northeast was heavily industrialized and the South was primarily agrarian. Regional competition grew over western expansion, national markets and labor, international trading, transportation links, and Congressional power. Some infrastructure projects were endorsed by Congress under the auspices of national defense and economic development. The South felt slighted by the Northeast and upper Midwest as they made east to west trading routes with federal money that didn't seem to provide enough benefit to the South (O'Neill, 2006, 46-47).

Perhaps these routes potentially limited the South in this growing regional competition (sectionalism) for federal money for internal improvements. It is disputed in various scholarly circles as to whether regional economic differences led to the Civil War or whether it was primarily the issue of slavery. It is hard to extract from the circumstances that the need for free slave labor in order to sustain the Southern economy was a matter of economic disparity. The free labor capitalism movement in the Northeast and Midwest was a progressive ideal.

The South continued to press for federal support to build the levees. They argued that the levees would improve the channel for navigation by scouring and deepening the river bottom thus help rid the river of snags thus improving the economic conditions for the whole country (Poe, 2006). Second, territories in the North and upriver drained into the lower territory causing the flooding. They argued their means for drainage was a negative externality on the South. Therefore, the cost of flood control should be shared by everyone given that this was a national waterway (Poe, 2006). Third, federally owned public lands in Louisiana bordered the river and therefore Congress should be responsible to build levees "in its capacity as a landowner" (Poe, 2006, 56).

Based on these three primary arguments for federal levee support, the South had growing support from business elite, levee districts, state, and local governments throughout the South. 
Advocacy conventions had grown in popularity in the late $1840-50$ s. The most notorious was the 1845 Mississippi River Improvement Convention in Memphis led by John Calhoun which demanded attention to Southern infrastructure to be connected to the upper Midwest including a levee system and a canal to be built from the Great Lakes to the Mississippi River (Kelman, 2006; O’Neill, 2006; Poe, 2006). They were heavily opposed by those in Upper Midwest and the Northeast. Therefore in 1847 in Chicago, they held the largest convention of the time with the intent to snub the South (O’Neill, 2006; Poe, 2006).

The 1849-50 flood created a major levee breach at the Suavé Plantation (also known as Sauvé Crevasse) just 15 miles upriver from New Orleans. High water left over 12,000 people homeless and 200 city blocks in New Orleans flooded for weeks (Kelman, 2006, 162; Klein and Zellmer, 2007, Poe, 2006). The flooding brought about national attention to the levee problem and growing pressure on Congress to do something. In an attempt to appease the South, Congress created the 1850 Swamp Land Act which conveyed all uncultivated federal lands bordering the river to the South. These lands also needed levee protection. Therefore, their intent was for Louisiana to parcel out the lands and build a levee system from the sale profits (Poe, 2006).

Prior to the Civil War, the levee system had started to develop into more than 740 miles (Poe, 2006) and most of this is attributed to the development of levee districts and state oversight. While the levees were pretty much continuous, they were still inadequate and weak. Numerous breaches and repetitive flooding was taxing Louisiana unduly as the State attempted to build a war cache. When the South entered the Civil War, the State did away with public works and all efforts to maintain the levees (Poe, 2006).

\section{Historical Underpinnings: Breaking the Levees to Win the War}

In the beginning of the Civil War, the Union Army quickly took control of most all the Mississippi River and made their way deep into the South rendering Louisiana powerless quite early on. Dominance on the river allowed the Union to maneuver more effectively to take Vicksburg which was a Confederate stronghold. Cutting levees in order to move the Union 
military closer to attack on Vicksburg resulted in hundreds of miles of flooding in Louisiana (Poe, 2006). Within four years of the beginning of the Civil War, the levee system was totally decimated. Adding insult to injury, the Union soldiers had been using the levee to bury corpses (Poe, 2006). The South was wretched and crippled by the end of the war. Devastation from the war had, among things, taken the majority of able bodied men and demolished the economy. With broken levees and fairly continuous flooding, recovery from the war was difficult. It prevented landowners from producing crops and many were losing their lands to debt created from crop failures. Yellow fever and cholera epidemics were rampant. Mindful not to minimize the impact of "violence and racism" on the Reconstruction, Cynthia Poe (2006) argues that flooding dealt a really significant impact as it "exacerbated" effects and conflicts.

Those hit the hardest though were the newly freed people. Sharecropping and wagebased contracts actually made life worse for them than being under the possession and care of plantation owners (Poe, 2006). Under the new labor system both freed people and plantation owners suffered debt and crop failures. However, differential problems resulted and created greater disparity. Landowners were going into greater debt for labor, seeds, failed crops; and at the same time, dealing with major tax increases to rebuild their communities. When crops failed, freed people were broke, homeless, and further destitute than before. If they rented or acquired land to live on, their homes were more likely to be within lower elevation flood prone areas. Freed people also lacked education so they had few options for employment. They lacked credit or suffered disadvantageous terms of credit and where often in competition with white farmers. Overall, they were pushed towards a state of fixed dependency on government aid (Poe, 2006). Many of the freed people began to steal livestock, food, and supplies from white landowners and tore down bridges and used the wood for fuel (Poe, 2006). Thus flooding exacerbated poverty thus created more tension between blacks and whites.

Several state initiatives to build the levees back failed after the war. The states tried generating revenue for levee rebuilding by selling bonds but the program collapsed. The states 
then tried to create a public-private partnership with a local levee building company but then failed to appropriate the money to pay contractors (Poe, 2006).

Political corruption and greed ran rampant as Reconstruction aid never seemed to touch the people. While both Democrats and Republicans alike engaged in corrupt practices in the South, it was all blamed on the Republican North and sectionalist bias (Poe, 2006). As Poe (2006, 183) states, "the experience of flooding and the experience of Reconstruction were one." The attitude in the North was that the South needed to suffer the consequences of their own making.

\section{Historical Underpinnings: Levees Only Policy}

The second recommendation of the 1850 Swamp Act was to authorize two separate studies of the Mississippi River flood problem but completion of these surveys were hampered by the war. Two engineers, Charles Ellet a civil engineer and Captain Andrew Humphreys were commissioned to survey and develop a prescription for flood mitigation. This infamous battle is eloquently presented in John Barry's 1997 book The Rising Tide of a battle between a civil and a military engineer. Ultimately, Humphreys fell behind Ellet due to illness, therefore, Ellet was published first in 1852 (Kelman, 2006; Poe, 2006; Barry, 1997). In his report, Ellet endorsed creating floodways, reservoirs, carve outs and levees as a means to mitigate flooding.

Humphreys actually had arrived at the same conclusions but before he finished his work both he and Ellet were called to duty in the Civil War (Barry, 1997). After the war, Humphreys returned to the task of completing his survey. Humphreys, a rather inflated and bombastic fellow, could not merely support Ellet's findings and allow Ellet to surpass him (Barry, 1997). His contribution had to squash Ellet in order to maintain the notoriety that he felt he deserved (Barry, 1997). Therefore, he "corrupted" his findings and wrote in support of a "levees only policy" based on costs being too great to pursue Ellet's grandiose ideas (Barry, 1997). Ellet was killed in the war therefore he could not defend his work (Barry, 1997). Local government then endorsed 
the "levees only" ideal and made it policy. Humphreys became the Chief of the Corps of Engineers until the power of the Corps was diminished by the Mississippi River Commission.

By 1879 , it was determined that river management needed to be directed from a centralized authority. The Mississippi River Commission was established and consisted of three Corps of Engineers representatives - a president, one from the U.S. Coast and Geodatic Survey and three civilians of which two must be engineers (Barry, 1997). The appointments would be made by the President and confirmed by Congress. Due to lack of funding appropriations, little was accomplished under this initiative (Barry, 1997).

\section{Historical Underpinnings: The 1927 Great Flood Gives Rise to "Project Flood"}

Again major flooding occurred in lower Mississippi and the losses were great in 1882,

1912, 1913 and then most significantly in 1927. The flooding in 1927 devastated the Delta region and is known as the most disastrous in history. Over 600,000 people were left homeless and the disputed death toll is 1,000 (Barry, 1997). Again, death toll numbers can be contested based on racial divisions. The Delta region was a catastrophic mess.

Many felt President Coolidge was hiding from the public when he refused to visit the devastation. Known as "Silent Cal," he was very brooding and quiet, a man of few words. He felt that visiting the devastation would be equal to political grandstanding. At the same time, he also believed that flood recovery was strictly a matter of personal responsibility. Like many presidents before him, President Coolidge's address to the 70th Congress was adamant that the federal government was not in the business of protecting people from "Acts of God" and natural hazards such as floods (70th Congress Digest 46, 1928). Herbert Hoover was sent to the South to direct flood relief operations and deal with racial discord. Hoover gained the confidence of many Southern blacks who remained stranded in refugee camps while many others navigated north to Chicago to find better racial relations and work. Hoover rallied Southern blacks in flood reconstruction efforts and promised them their efforts would not soon be forgotten if they helped elect him to president. He swept the candidacy being highly regarded for his flood relief efforts. 
However, he betrayed the black voters by ignoring civil rights issues and opposing federal antilynching laws and ultimately suffered a loss in reelection.

Headlining in Hoover's highly dignified entrance to the White House, was the Flood Control Act of 1928 that ended the "levees only" policy. The massive and comprehensive mitigation reform would be known as "Project Flood" (Figure 2.2). Project flood provided for the use of levees, floodways, channel improvements/stabilization, and tributary basin improvements. In other words, revetments, cutoffs, dikes and dredging would be used for improvements and stabilization. Dams, reservoirs, pumping plants, and auxiliary channels would provide for tributary basin improvements.

Levees, floodwalls and control structures constructed by the federal government would encompass 2,203 miles with 1,607 miles specifically on the Mississippi River and 596 miles on the Arkansas, Red, and Atchafalaya Rivers (USACE, 2006). These would be maintained by the local governments except when federal assistance would be needed during major floods. Inspections would be conducted by local levee districts and the Army Corps of Engineers.

The Flood Control Act of 1928 was the first major piece of legislation that put the federal government squarely in the middle of protecting the population from natural hazards. The cost would be greater than any undertaking thus far by the federal government besides World War I costing \$325 million (Klein and Zellmer, 2007). The Act also provided protection for the federal government against any litigation resulting from flooding and flood damage. In other words, the federal government provided mainly structural protections against floods and otherwise was not responsible for outcomes associated with flooding. Therefore, if their structures failed or caused a greater flood hazard, they were not held liable.

What is attractive about the 1928 Flood Control Act is that it would centralize efforts to mitigate communities along the riverbank. It provided opportunity to dispel corruption and inconsistencies within local districts where some areas where marginalized for the sake of catering to others that were more influential or wealthy. The goal of Project Flood was to build 
the system at least a foot higher than any known previous flood which would be quite accomplished. On the other hand, it also brought about a false sense of security behind the floodwalls and levees which resulted in increased development and greater issues later.

\section{Historical Underpinnings: Old River Flow Problem}

Also by 1927, the engineers and experts began to realize there was now a constant westerly flow in Old River and the Atchafalaya was taking on more of the Mississippi River (Winer, 2010). Shreve's cut at Trumbel's Bend had allowed the Mississippi to begin the 1,000 year natural shift and take the steepest and shortest route to the Gulf of Mexico (Winer, 2010). Sediment would build and a saltwater wedge would turn the "Birdsfoot" mouth of the Mississippi into a swamp, effectively destroying trade and commerce for New Orleans and along the corridor leading to and including Baton Rouge.

Old River Controls serves as a mechanism to keep the Mississippi River flowing towards New Orleans. This structure provides a 70/30 split sending 30 percent down the Atchafalaya River via Old River and 70 percent to New Orleans and is designed to prevent the river from completely changing course and taking the Atchafalaya to the Gulf of Mexico (Kelman, 2006). It was believed that if the government did not take action soon, the river would be totally consumed by the Atchafalaya by the early 1970s. The Old River Controls structure was completed in 1964 .

Old River controls would first be tested in flooding during 1973. In the aftermath, there was structural damage that scoured out area nearly the size of a football field, but it did hold the river in place (Kelman, 2006). An auxiliary structure, completed in 1986, was built to provide support for Old River Controls. Then, in the early 1990s, a hydroelectric plant was built behind it and some argue that the hydroelectric plant adds protection. However, Harley Winer (2010) claims that the hydroelectric plant has a "sediment lean" system that disrupts the sediment controls and sediment is being shifted disproportionately towards New Orleans and causing a great sediment loss as it falls off the continental shelf into deep waters. The coastal wetlands are disappearing as a result of this misappropriation of sediment. Winer (2010) says that increased 
sediment load in the Atchafalaya River would result in greater delta growth at both the Wax Lake Outlet and mouth of the Atchafalaya River.

Winer (2010) is a strong advocate for detailed engineering studies that support changing legislation to allow the Mississippi River to overtake the Atchafalaya including moving communities, ports, bridges, and industry that would be in the way of the increased flows. Winer's (2010) recommendation would include the entire area of Morgan City and The Port of Morgan City strategically positioned on the Intercoastal waterway. After the 2011 floods, NASA provided satellite images (Figure 2.3) of sediment plumes at the mouth of the Mississippi River beyond New Orleans and at the mouth of the Atchafalaya. These images could possible dispute claims by Winer (2010).

\section{Historical Underpinnings: Flood Insurance Policy and Non-Structural Policy Focus}

The next notable legislation is the creation of the National Flood Insurance Act of 1968. The legislative initiative was led by Gilbert F. White who advocated for a more comprehensive package of flood mitigation including flood insurance and "nonstructural" floodplain management (Platt, 1995). The National Flood Insurance Program (NFIP) was intended to mitigate the cost of disaster assistance during flooding by providing a low-cost flood insurance to floodplain resident. Policy holders would then have a pooled resource in which to draw a benefit for flood repairs. However, there are problems and abuses related to this program and its ineffectiveness.

The 1993 flooding on the Missouri River and upper portion of the Mississippi River brought about a renewed focus on flooding problems along the Mississippi River and specifically brings to light problems with the NFIP. Those most affected by the flood were in poverty stricken areas in flood-prone areas or floodways. Over 100,000 homes were destroyed yet there were only 16,167 claims whereas overall there are 90,000 policies in the nine states affected (Platt, 1995). What is happening here suggests that the majority of these homes did not have flood insurance. The majority of the 16,167 claims were for commercial structures or basement 
flooding outside the floodplains (Platt, 1995). Even if communities participate in the NFIP and make the necessary mitigation requirements, evidence thus far suggests that the NFIP is flawed and ineffective. People within the floodplain are required to have flood insurance in order to obtain a mortgage. However, they often drop the flood insurance soon after purchase because they cannot afford it. If disaster assistance is still made available, these people are often incentivized not to obtain flood insurance.

Gaming the NFIP is also a problem when it comes to waiting periods for flooding; and specifically a problem highlighted in the 1993 Flood at Chesterfield, Missouri were an agricultural levee was "upgraded to a 100 year level of protection" and industry was allowed to build up behind it without forcing them to purchase the mandatory flood insurance, nor did they have proper floodplain controls (Platt, 1995). These corporations bought flood insurance just prior to the five day waiting period so they quickly enjoyed insurance benefits of $\$ 13.2$ million accounting for five percent of the entire NFIP claims in nine states (Platt, 1995). In light of this abuse, the Galloway Report (1984) recommended that the waiting period be extended to 15 days. Currently, the waiting period has been set at 30 days.

The 1993 flooding was called the worst yet to hit the United States claiming 50 lives and forcing the evacuation of tens of thousands and destroying 10,000 homes (Larson, 1996). Flooding was limited to the upper Mississippi River because of severe drought conditions in the lower Mississippi Delta. Having drought conditions in the south was a very fortunate circumstance given the differences in socioeconomic conditions between the populations of the South and North. The flood would have been catastrophic if the entire Mississippi River system had flooded. Nonetheless, the damage was great and crippled the communities as this 300 year flood closed ten airports, shut down barge traffic for two months, destroyed bridges, and effectively halted railroad traffic and destroyed key infrastructure (Larson, 1996).

Discussion of issues and problems resulting from the 1993 flooding is covered in the "Galloway Report" or Sharing the Challenge: Flood-plain Management into the 21st Century 
(1994) generated by the Interagency Floodplain Management Review Committee. The primary cause that "exacerbated" flood levels were nonfederal agricultural levees and other means farmers used to control flooding. In some cases farmers had taken wetlands for agriculture use and prevented the river from overflowing into natural floodplains. Federal levees were nearly overtopped but they held and the U. S. Army Corps of Engineers (USACE) was successful in using reservoirs as intended. Problems included failure of key infrastructure such as wastewater facilities and sewer backup. Flood waters were contaminated by flooding at superfund sites and floodplains containing hazardous waste. Total damage from the 1993 flooding was approximately \$16 billion dollars (Galloway Report, 1994).

\section{Recent Major Mississippi River Flooding}

The 2011 floods left over three million acres of farmland submerged in water. One of the most controversial losses of farmland includes a preliminary cost of $\$ 85$ million (Plume, 2011) to the floodway at Birdspoint, Missouri. When flood levels rose to 59 feet at Cairo, Illinois, the U.S. Army Corps of Engineers placed 115 tons of liquid explosives into 27,000 feet of pipe fuse plugs within levees at Birdspoint; and then blew them to protect Cairo from total flood destruction. This decision forced nearly 200 people residing in 90 homes within the floodway to be evacuated and their property inundated in order to save Cairo (population of 3,000) from total flood destruction (Gay, 2011).

The Birdspoint-New Madrid floodway has been steeped in controversy since the Flood Control Act of 1928 authorized the acquisition of easements for the floodway. Approximately 3,000 residents within the area were paid a one-time indemnity of $\$ 17$ per acre for this land to be flooded if needed in order to save the nearby town of Cairo, Illinois whose population at that time was approximately 15,000 (USACE, 2011). In 1937 a few residents armed with guns still attempted to prevent inundating the floodway. National Guard members were ordered to protect the USACE as they initiated the explosions. 
During the 2011 flood, residents of the area attempted to block USACE from blowing up the levees by filing a law suit in Missouri objecting to the use of the floodway claiming it violated the Missouri Clean Water Act (1981). A federal judge ruled that the USACE was authorized to breech the levee. However, this decision was appealed and two Missouri senators wrote to the president requesting that he block USACE from blowing up portions of the levee (Barrett and Brat, 2011). Flood waters continued to rise steadily and time was a critical element when USACE finally received orders to open the floodway. It was not an issue of clean water that was upsetting the residents. They made it clear to the national news media that they were attempting to block opening the floodway because they felt Cairo, Illinois, a predominately black community, was a dying city plagued with poverty and drug use (Gay, 2011). These white farmers within the floodway felt that allowing an impoverished and drug infested Cairo to flood was more justified that destroying their homes and farmland (Gay, 2011). In a USA Today report on May 18, 2011 (Frank, 2011) residents and farmers in Missouri asked: "Why is it more important to save one side and ruin the other?" In a USA Today editorial, Rep. Jo Ann Emerson, R-Mo. responded, stating currently designed flood control measures and calls for returning the river to natural conditions "is a high ideal for environmentalists who live in safer places and an unthinkable violation of property rights and liberty for Americans who have lived beside the river for more than a century" (see USA Today online edition update 5/18/2011; Frank, 2011).

Once the floodway was inundated, residents then filed a class action lawsuit (Minahan, 2011) against the federal government claiming they were not adequately compensated for their losses. Farmers complained that while they will be compensated for loss of equipment and expense related to planting, they would not be compensated for their lost profits.

Communities in the lower Mississippi River would see record flood levels as a result of what is described as a 500 year flood. Vicksburg flood stage is 43 feet and according to the National Weather Service (2011) it crested at 57.1 breaking the previous record in 1927 of 56.2 feet. Likewise the flood stage at Natchez was 48 feet and it crested at 61.9 feet beating the prior 
record of 58 feet in 1937 (NWS, 2011). Approximately 5,000 people were forced to evacuate from these areas (Branston and Finn, 2011).

The Atchafalaya basin in Louisiana was also threatened during the 2011 floods. As with Birdspoint-New Madrid floodway, the government had purchased easement rights to inundate the area via the Morganza Spillway. This spillway is designed to take pressure off the Old River Controls and levees protecting Baton Rouge and New Orleans. The magnitude of 2011 flooding would have pushed levees beyond their design capacity if not for releasing the water into the Atchafalaya basin. 25,000 residents were prepared and partially evacuated and approximately 11,000 structures within the floodway were at risk for inundation (Robertson, 2011).

For nearly 20 years the people of Louisiana disputed the use of a spillway. However, when faced with the realization that levee structures alone would not likely hold during severe flooding, residents there accepted this realization and scaled back development in the region (Robertson, 2011). According the USACE the Morganza Spillway, five miles wide and 25 miles long, can pass 600,000 cubic feet of water per second off the Mississippi River system.

The Federal Emergency Management Agency (FEMA) response was a bit amazing in some instances. Specifically, there was a well-orchestrated interagency initiative between the Environmental Protection Agency (EPA) and Louisiana Department of Environmental Quality (DEQ) to conduct clean-up ahead of a disaster. Containers of paint, bleach pesticides, oil, antifreeze and other pollutants we effectively removed by residents as they evacuated (Hasten, 2011). Roads were closed and only residents and officials were allowed into the area. Police officers stood guard next to mobile signs which indicated how much longer residents had to retrieve items before the road closed. Widespread police presence was an effective measure to keep sightseers out of the way and prevent further problems.

Coast Guard C-144 aircraft was monitoring the advancing flood waters (Hastens, 2011) while others inspected and raised heights of levees around oil refineries. In Krotz Springs, the Alon USA Refinery was being shut-in with the help of the Louisiana National Guard and the oil 
tank levels were reduced just in case the levees were over-topped. Hasten (2011) reported that 167 oil wells were shut in and the State Department of Natural Resources were keeping tabs on 592 other producing oil and gas wells.

One of the most critical events of the 2011 floods was the discovery of a huge sand boil in the levee near Greenville, Mississippi that threatened to inundate the Yazoo River delta region and thousands of people. The Corps and local officials organized a crew of inmates and created a human chain to build a berm constructed of plywood and sandbags while crews dumped tons of stone into the sand boil to stop erosion (USACE, 2013). Another critical sand boil was discovered at the confluence of the Ohio River at Cairo early on in the flood fight and was immediately remedied before the largest water volume had reached the area. The sand boil appeared to be the largest ever discovered by flood fighting crews in that region (USACE, 2013).

According the USACE (2013) the 2011 floods resulted in 21,203 structures and 43,358 people impacted by the floods and a total loss of 2.8 billion dollars in damages. However, some argue the cost is closer to $\$ 4$ billion as Shelby County, Tennessee reported $\$ 2$ billion in damages alone. The volume of water flow in the Mississippi had never risen as high as 61 feet at Cairo before. Mississippi's Governor Haley Barbour described the flood volume moving through the flood control system comparable to "a pig moving through a python" (Neuman, 2011). The entire flood control system would be tested and there were critical concerns that if the Old River Structure Control did not hold or if there were problems at the Morganza Spillway or Bonnet Carre Spillway, it would result in a catastrophic event where the Mississippi River would entirely shift its course. It was the first time that three of four floodways (Birdspoint, Morganza, Bonnet Carre) were all put into operation together to reduce flood levels. The West Atchafalaya floodway is the only floodway that has never yet been used.

In 2014, flooding on the Upper Mississippi River barely caught national attention; however, areas from St. Paul, Minnesota to the Quad Cities at Iowa and Illinois were impacted by 
what was considered a moderate flood. The damage cost estimate for this flood occurrence was reported to be over one billion dollars (Gerencer, 2015).

Most recently, flooding in the Upper Mississippi River Region in December, 2015 has resulted in 25 fatalities in Missouri and Illinois (Rice, 2016). Federal authorities identified 19 vulnerable levees at risk for failing in the upper region (Smith, 2015). Overall, eleven levees had failed and a levee at West Alton, Missouri about 20 miles north of St. Louis was overtopped by flood waters resulting in the evacuation of 520 residents. 3,700 inmates were moved as flooding threatened a state prison in southern Illinois and twelve (12) Illinois counties were granted a disaster declaration (Smith, 2015). The Mississippi River was nearly 15 feet above flood stage in St. Louis cresting at 42.58 feet which is just shy of the 1993 record. In Missouri, over 7,000 homes were impacted by floods and several wastewater treatment plants were impacted causing a large amount of sewer to enter the floodwaters and continue on downstream (Smith, 2015). There were a total of 33 counties with disaster declarations in Missouri. For the most part, the lower Mississippi Region has fared better with only moderate flooding in Memphis. In Louisiana, the Bonnet Carre spillway was again opened to reduce the risk of flooding in New Orleans. The cost of flooding has yet to be determined but preliminary speculation suggests that over three billion dollars in damages has occurred (Gerencer, 2015). 


\section{CHAPTER THREE}

\section{REVIEW OF THE LITERATURE}

In order to understand the development of flood control in the United States and what influences have contributed to contemporary floodplain management problems, there was a wide range of literature examined to more fully understand the problem. There is a historical pathdependent nature of community development and government efforts towards flood mitigation in the Mississippi River region. The interaction is dynamic and continuously growing in complexity. The story of how populations adapted and how flood policy developed in the Mississippi River region is germane to having a comprehensive picture of the problem.

When we look at theory related to problems associated with flood mitigation, researchers historically used systems theory to explain this phenomenon. However, there is a paradigm shift and growing consensus toward growth machine theory as the best explanation. The focus here is a discussion of systems theory and growth machine theory and whether both are theories of "middle range" or does growth machine theory provide the most comprehensive explanation for continued flooding issues?

Also relevant to this research are the contributions from researchers who have conducted risk evaluation and focused on social vulnerabilities specifically. One of the telling signs here when examining flood mitigation barriers, is how little consideration we give to social vulnerabilities. The lack of consideration is evident in our planning tools and overall efforts to effectively mitigate flood hazards.

\section{Theoretical explanations for flood mitigation failures}

Ultimately failure in flood control results in disaster. The current paradigm in the field of disaster research is that there are two fundamental ideas involved with disasters: 1 ) disasters are 
inherently a social phenomenon; 2) disaster is a social construct that reflects social change (Quarantelli, 2005a, 339). Perry $(2005,11)$ says, "Disaster is characterized as a social disruption that originates in the social structure and might be remedied through social structure manipulations" which results in a social change. Some argue that crisis and disaster are different and should be acknowledged (Boin and Hart, 2006). For example, crisis can occur when social systems encounter a threat but a disaster is actually a crisis with a "devastating ending" (Boin, 2005).

Perry (2005) contends having a clear definition of disaster that is agreeable to everyone in the field of disaster research is not as important as having the researcher make explicit their definition as they begin their work. In this study, the definition of disaster follows Oliver-Smith (1998) in that disaster is a social construct and a result of vulnerabilities within the social structure. Basically, disaster occurs as a result of overwhelming local resources and capabilities in the social structure and disrupts normalcy in the community. What is important to note here is how vulnerabilities within the social structure become key to the problem of flooding disasters. We are potentially creating our own flood disasters or, at the very least, potentially creating more detrimental outcomes by the way we fail to mitigate effectively.

How is it, exactly, that we manage to create circumstances that add to flooding hazards we face? Several theories have offered perspective in how we negatively impact our outcomes. According to Kathleen Tierney $(2010,661)$ most disaster research has been rooted in sociology theories such as functionalism and systems theory. However, in the 1990s disaster research did begin to incorporate sociological perspectives regarding inequality and disparity as this relates to access to political power, but there had yet been a focus on political power as a dynamic force in the production of disasters (Tierney, 2010, 661). Tierney (2010) suggests that growth machine theory may well be the "unifying theoretical paradigm" that moves U.S. disaster research in the same direction as those scientists outside the U.S. who are already focused on political and economic forces as they exacerbate hazard risk. 
Biologist Ludwig Von Bertalanffy (1950) developed the idea of general systems theory through his study of living organisms in the 1940s. By the early 1950s he had determined general systems theory could be applied in sociology to explain social systems. In 1953, David Easton adapted systems theory to political science by describing a political system as a simple organic or living system. Easton (1953) described this step-wise process beginning with inputs (demands or public support) from the environment is fed into the political system. Competition and compromise produces a solution within the political system (Easton, 1953). This solution, usually in the form of policy, is then introduced to the environment creating an impact (Easton, 1953). This impact results in a feedback loop that generates new inputs (Easton, 1953).

Easton's (1953) partially holistic theory of political systems was adapted to disaster studies and expanded upon by in Disasters by Design written by Dennis Mileti in 1999. Mileti $(1999,106)$ emphasizes the increasing complexity of subsystems and their interactions creates a condition where "the system is greater than, and is different from, the sum of its parts". Mileti $(1999,107)$ differentiates from the traditional systems theory model by arguing that due to this complexity, "the laws of additivity do not apply" as in the case where the whole is equal to the sum of its parts. Mileti $(1999,107)$ argues that the traditional systems theory model is "typically linear" and "overemphasizes stability" because they usually only involve one "casual factor". Traditional systems theory is limiting in that it describes change impact resulting in a negative feedback loop to create the input cycle again (Mileti, 1999, 107). Mileti $(1999,107)$ calls for a completely holistic and "non-linear approach" due to the multitude of variables with varying degrees of complexity in their interactions.

There is merit to using systems theory to think about the flood control system itself and the processes within this system. The federal flood protection system contains both hard and soft infrastructure, thus it is a very highly complex interdependent system. Within these systems are self-organizing subsystems and usually these systems are evaluated for normal problems and normal failures. When it comes to risk evaluation, however, there is a problem because these 
systems can "predictably fail in unpredictable ways" which in turn will create "cascading failures" (Little, 2010, 29; see also Perrow, 1999, 212-220). According to Mileti (1999) instead of calculating risk using probability distributions, it is better to think in terms of power law relationships. The failure of only a few subsystems can cause the majority of the damage. Ultimately, when these systems fail, it results in a non-linear outcome and, therefore, a non-linear approach to mitigation is needed (Mileti, 1999).

Mileti (1999) does suggest that a nonlinear approach to mitigation is needed. Each member of the network or subsystem is vital, should be included in mitigation planning, and given innovative empowerment. These networks would have access to all the information and trends at all levels - local, state, national, and global. They would have support in the form of various resources such as technical assistance, information networks, legal authority, political access, and all things related to their function as the institutional memory of that organization or subsystem. Mileti (1999) argues that greater research in planning is needed in order to better understand how planning processes occur within the community and what planning processes would be most effective.

Mileti (1999) explains that interactions occur both within and between systems. He refers to the natural, social, and built environment as the primary systems engaged in these interactions (Mileti, 1999). Systems theory falls short here in that effective flood controls cannot be accomplished where differential power and motivation exists among actors within and between these networks.

Growth machine theory does focus on political power as a dynamic force and the controversies associated with it. Harvey Molotch (1997) coined the word "growth machine" to describe a relationship between local elites and local officials where their motivations and actions to draw revenues into the community and personal profits often create a problem of moral inversion. These partners are constantly vying for external resources and growth-inducing projects to generate more profit and revenue regardless of whether they may do more harm than 
good for local citizens. Note that when it comes to protecting the health and welfare of the community, it is the primary responsibility of local government. Therefore, it should be the priority of the local government to choose projects carefully. However, Freudenburg et al. (2009) argues that this greedy risk-taking behavior among growth machine leaders has become a "politically legitimated process" and is actually fostered from the federal level. Ultimately, federal government enabling results in a "liability crisis" and "circular evasion of responsibility" at the local level (Freudenburg et al., 2009). Regardless of whether these projects actually make good sense for land use and regardless of whether they may do more harm than good, they favor growth machine leaders in three specific ways (Freudenburg et al., 2009, 157). First, the benefits are concentrated to the elites and political players. Second, the costs of these projects are spread out among the citizen tax payers thus they are more likely to behave recklessly given that it is "other people's money." Third, the risks are hidden from public view so that the general public is unaware they're being put in this compromising situation.

Take mapping the floodplain as an example. The federal government mandates states and local officials to map the floodplain. Standards and tools used by local government vary as much as the quality of the maps themselves. Questions and controversies surrounding mapping methods has resulted in claims that some areas identified as having a one percent probability of flooding in 100 years have actually already experienced multiple floods within a 50 year period. Hydrologists actually prefer not to use the term " 100 -year-flood" because it is misleading and does not necessarily mean that flooding has a likelihood of occurring once in 100 years (USGS, 2016). Hydrologists actually refer to it as a reoccurrence interval and flooding the causal pattern for flooding is complicated by various factors and changes in the environment (USGS, 2016). Despite knowing these flaws, local governments continue to allow and subsidize development under the guise that federal mandates were met. In turn, these properties are then sold to the public with no legal recourse against developers when flooding occurs. 
Local growth machine leaders also look for federally funded high-dollar projects such as levees and floodwalls to allow development to occur behind them. These structural fixes have historically provided a false sense of security for the community. Given the government cannot be held liable for failing flood control measures (as established in the Flood Control Act of 1928) the engineering standards for these structures need to be challenged. Freudenburg et al. (2009, 152) point out that the U.S. policy guidance "effectively calls for engineering estimates to have a $50 / 50$ chance of being proved wrong by floods that occur within the period for which they are theoretically designed" which are 100-500 year probability floods. The standard in other countries such as Holland and Germany is based on a 90-95 percent confidence level and are designed to protect for a 10,000 years probability flood (Klein and Zelmer, 2014). The American Society of Civil Engineers (ASCE) warns that while levees may reduce the risk of flood, it is an essential fact that no levee is floodproof (Klein and Zelmer, 2014, 188). Basically, a residence behind a 100 year levee has a 26 percent chance of being flooded over the course of a 30 year mortgage (Klein and Zelmer, 2014, 188).

Flooding vulnerabilities are also exacerbated through policies and programs created as target reduction programs for flooding. Many researchers will argue that the federal government subsidizes floodplain construction through the National Flood Insurance Program (NFIP) brought about in the National Flood Insurance Act of 1968 (NFIA 1968). The measure was intended to promote land-use controls and reduce disaster aid by providing insurance to occupants to cover their losses. In order for communities to engage in the NFIP program, they were required to create zoning restrictions, establish building codes, retrofit existing structures, and develop emergency response plans to respond to flooding. There are no accountability measures or enforcement to actually ensure communities actually meet these standards. The fact that there are no accountability measures is exactly the enabling behavior of the federal government. Gilbert White (1945) who inspired the NFIA 1968, was not oblivious to the problem of growth machine 
dynamics. The problem here is that the NFIP turned out to be much different than White had intended due to influence from growth machine actors.

In summary, when looking at systems theory and growth machine theory as it relates to disaster mitigation, and specifically flood mitigation, it becomes more evident that growth machine has more influence on the process. Growth machine actors are actually creating and influencing all systems and subsystems. Growth machine actors intervene in the systems model at all steps in the process - from inputs to decision-making and policy to outputs and impacts on the environment. Growth machine dynamics have influence within and between these systems and their interactions. These dynamics also hinder the feedback loop in system by discounting the potential hazard risk as an "inevitable by-product of economic expansion" (Freudenburg et al., 2009, 58) and ultimately avoiding responsibility for disastrous outcomes. Thus, Tierney (2010) is correct in that focus on political power as a dynamic force in the production of disasters must be advanced.

\section{Attempting comprehensive assessment for flood mitigation}

Gilbert White (1945) attempted to comprehensively assess the "flood problem" in a very broad analysis of the entire United States. He noted that the scope of his work was not to address the local (White, 1945, 9) or the regional (White, 1945, 102) factors that may be indicative of specificity problems. White's (1945) primary thesis was that while appropriations for structural fixes continued to rise, so did the cost of the flooding problem.

White $(1945,47,128-203)$ theorized there were eight major classes of readjustments to flooding. These eight flood adjustments or mitigation remedies were defined as: 1) land elevation, 2) flood abatement; 3) flood protection; 4) emergency measures; 5) structural; 6) land use; 7) relief; and 8) insurance.

Prevailing policy in 1940 s, according to White $(1945,47)$ was focused only on four primary types of mitigation. These were structural or engineered fixes rather than non-structural adjustments. For one, flood abatement (land adjustments) addressed those areas outside and 
upstream of the inundation areas which include reforestation, reducing debris flows, agricultural contour shifts, bank stabilization, and forest fire controls (White, 1945, 132-140). Secondly, flood protection (White, 1945, 141-163) is defined as engineering devices such as building floodwalls, levees, cut-offs, and channel improvements. Third, emergency measures (White, 1945, 163-176) included evacuation, flood fighting, and recovery. Today, these would be described as response phase and short-term recovery phases in the overall system of response to emergency. Fourth then was the focus on relief (White, 1945, 196-203) measures such as federal grants and loans to the affected population. According to White $(1945,203)$ relief subsidies actually tended to enable flood problems rather than mitigate them.

White $(1945,205-209)$ concluded that there were "four essentials" where prevailing public policy fell short in remedying flood problems. First, policy solutions should take into account all possible types of adjustments that can be made to the flood hazard. Second, a cost benefit analysis should be conducted and evaluated on a consistent basis; and it should recognize costs associated with the best or most appropriate remedial action while also considering benefits such as the welfare of the potentially impacted community (White, 1949). Third, White suggested that any mitigation action created should include of all possible adjustments or readjustments that factor into successfully occupying a structure within the floodplain (White, 1949). Therefore, all possible retrofits must accompany the structure. Fourth, White (1949) suggested that any mitigation action taken should be favorable to the types of land occupancy that "contributes to effective use of floodplain resources". In other words, only those needed to be in the floodplain should be there.

White summarized his findings by saying $(1945,209)$ that, of the eight possible adjustments theorized in terms of mitigation, all remedies with exception to land use management and an insurance program favored preservation of the status quo or enabled the flood problem to continue. While White's (1945) assertion was not an explicit indictment of the growth machine, it clearly points in this direction. 


\section{Moral implications in policy and planning}

David Moss (1999) studied the transformation of disaster relief policy and the problem of taking federal disaster relief for granted. Studying the historical narrative of flooding and flood policy, the public domain becomes increasingly sympathetic to the expansion of federal disaster relief. By the 1960's, Moss $(1999,321)$ described this federal policy expansion as being one of “an intricate patchwork of disparate programs and commitments". Charles Perrow $(2007,45)$ elaborates by saying this "taking for granted" of federal aid is actually "the cause" rather than "the consequence of increased funding". Perrow $(2007,46)$ indicts business and local government for realizing the opportunity to make profits from disasters. As previously addressed, local government and business are primary growth machine actors. Perrow (2007; see also Berke and Campanella, 2006) and other hazard researchers allude to the growth machine dynamic by explaining how federal relief costs are spread to all taxpayers for the concentrated losses of a few. This type of policy prescription will only work when there is reasonable responsibility placed on those individuals and businesses receiving such subsidies to retrofit structures, sufficiently insure property, and limit their presence in flood prone areas. If federal policy does not effectively motivate businesses and individuals to take personal responsibility to reduce flood costs, the result is a "moral hazard" (Klein and Zellmer, 2014; Perrow, 2007; Berke and Campanella, 2006; Moss, 1999).

The discussion of growth machine dynamics throughout this research points to another term and outcome that is somewhat similar to a moral hazard but is slightly distinguished. A moral inversion can be defined as behavior or practice we might mistakenly consider as being good and correct action but in actuality it is very bad (Adams and Balfour, 2014). The problem of a moral inversion is that it creates what Adams and Balfour $(2014,4)$ refer to as evil, and more specifically, as "administrative evil" were the purpose, conditions, and actions resulting in these outcomes are masked and difficult to perceive as potentially wrong and harmful. Those often engaged in a moral inversion believe they are actually doing good and benefitting their 
constituents. Much like a moral hazard, a moral inversion results through growth machine culture and processes result in concentrating the benefit to a few and spreading the risk among the community or population. Growth machine culture or "status quo" generates the false belief that through progress and advances in engineering and technology, we can and should build in hazard risk areas. As Freudenburg et al. $(2009,10)$ point out, "the problem is that, like some twisted variation of the Peter Principle, the growth machine can move relentlessly ahead until it reaches its own level of incompetence" and rarely do the "key" actors concern themselves with what these limitations might be.

Adams and Balfour (2014) elude to this problem as they discuss how a modern culture of technical rationality has upended the policy-making process. Basically, through a technical rationality culture, highly specialized and compartmentalized experts see themselves as ethical because they are professional rather than vice versa. Adams and Balfour $(2014,37)$ argue that ethics education has been marginalized and we face a problem of "moral vacuity" where professionals are over confident in their objectivity and overly reliant on the scientific mindset to solve social problems. Technical rationality culture also cultivates a sense of compliance from subordinates and the general population (Adams and Balfour, 2014, 38) as they grant unconditional regard for professionals; meanwhile support for advocacy and reform has devolved so there are fewer challenges to professional expertise.

Basically, the population views growth machine actors as well-meaning community leaders focused on progress and economic prosperity while holding the community's best interest in mind. (Freudenburg et al., 2009). The population does not realize the ways in which disaster is socially constructed through policies and practices influenced by the growth machine dynamic.

\section{Policy changes and challenges}

Within five years of implementation, NFIA 1968 went through several revisions as Congress realized that flood losses continued to increase and development continued to grow within the floodplain (Klein and Zellmer, 2014). Revisions to the NFIA in 1973 attempted to 
control some of the loss by requiring all mortgage loans and federally insured loans to be contingent on purchasing national flood insurance policies for the property.

Biggert-Waters Flood Insurance Reform Act of 2012 was the strongest attempt to date to reel in the problems associated with the NFIP and provide financial stability to the program. Primarily this legislation brought policy holders to bear the actual cost of flooding and raised premiums accordingly. Some of the main features of Biggert-Waters Flood Insurance Reform Act (2012) included removing businesses and secondary homes from coverage. Basically, those wishing to do business and maintain secondary residences in the floodplain should bear their own costs. Those primary residences in the floodplain would face higher premiums and those previously grandfathered into the NFIP would no longer receive a subsidized premium. Upon sale of these homes, the new buyer would take on the property at current costs rather than the grandfathered rates. However, in the aftermath of Hurricane Sandy (2012), there was such an outcry against the premium increases that the Homeowner Flood Insurance Affordability Act of 2014 has postponed these policy premium increases until further notice. Again, relief was politically motivated and politicians from flood prone areas fought premium increases under the Biggert-Waters Federal Insurance Reform Act (2012).

The problem of premium increases was only the tip of the iceberg following the disaster of Hurricane Sandy. A secondary disaster evolved from systemic issues within the now defective and ineffective NFIP. The National Flood Insurance Act of 1968 established that the most feasible way for the NFIP to be carried out was to establish a public-private partnership with the private insurance industry to implement the program (42 U.S. Code $\S 4001)$. As evidenced in aftermath of Hurricane Katrina in 2005 and Hurricane Sandy in 2012, there are serious flaws in this program and its effectiveness. In fact, after Hurricane Sandy, the problems with the NFIP came to a head with charges of fraud and wide-spread calls for reform (Sullivan, 2016).

In June 2015, Brad Keiserman, FEMA Deputy Associate Administrator for the NFIP, testified before Congress that the NFIP model was no longer effectively providing for flood 
survivors through the public-private partnership (Keiserman, 2015). Keiserman (2015) claimed that the 1983 Write Your Own (WYO) Program established between FEMA and the private insurance industry to allow insurance companies to write and service NFIP policies in their own name had gone awry. The WYO was allowing insurance companies to charge the federal government a fee of 33 percent on every premium dollar paid into the program (FEMA, 2015). In addition, these insurance companies also receive fees for settling claims post-disaster thus profiting even further (Sullivan, 2016). Insurance profiting is a peculiar outcome that defies traditional outcomes; usually insurance companies lose money due to payouts after a disaster event.

Keiserman (2015) argued that there was no possible way the federal government was staffed to provide effective oversight over the WYO and the approximately 82 private insurance companies that managed nearly 6 million flood policies purchased under the NFIP. As a result, the autonomy given to these insurance agencies prevented the NFIP from determining systemic problems and evaluating program effectiveness (Keiserman, 2015). Basically, the NFIP allowed the private insurance industry to operate with a blank check and no oversight. According to Sullivan (2016), in addition to built-in profits from premiums, handling fees, appraisal fees and other expenses, the private insurance companies were making $\$ 3.25$ million annually from flooding disasters (a 29 percent profit margin). Private insurers netted profits of approximately $\$ 400$ million from Hurricane Sandy. In addition to the $\$ 9.3$ billion paid out in claims for Hurricane Sandy, Keiserman (2015) stated that the NFIP was projected to spend over $\$ 1.45$ million in legal fees defending the insurance companies while they attempt to settle claimant court cases that were originally fraudulently denied. Hurricane Sandy victims with NFIP insurance thus have suffered the expense of being out of their homes for four years and paid enormous amounts in legal fees to fight the NFIP to pay the full amount they are owed from their flood policy.

\section{Revisiting comprehensive analysis of the flood problem}


Informed by Meliti (1999) and White (1945) in terms of the idea of comprehensive planning, this study focuses on the Mississippi River Region, a region notorious with flood problems and the primary area of reference from which flood policy has developed. The focus of this study is at a regional level rather than an effort to duplicate White's (1945) national level analysis. Conducting a regional analysis is perhaps a better assessment because it is does bring issues of specificity into focus that White (1945) attempted to avoid. The problem in this study, however, is determining how large this region should be. Should it include only the lower Mississippi area or the entire river and its tributaries? White (1945) indicated in his findings that the lower Mississippi region was one of the two largest regions (urban northeast is the other) identified with high flood costs and this made studying the Mississippi River region even more attractive. Ultimately it was decided that the scope of this study would include both the upper and lower Mississippi in order to examine upper and lower regional differences. Secondly, a regional study of this size would be more manageable than a national study given the various and extensive amount of data that would be required.

White's (1945) analysis also fell short in that all he could measure was federal appropriations for structural mitigation against flood loss data (1902-1941) collected haphazardly by the National Weather Bureau and through federal appropriations data. The Weather Bureau lacked consistency in methods to gather flood loss data as there were often redundancies in counts and estimations via mailed surveys to local government, newspapers, and shared information between agencies (White, 1945). Likewise, as in this study, White (1945) struggled with not being able to differentiate between types of floods such as river, coastal, and flash flooding. The flood data for this study did not differentiate between flash flooding and river flooding but does not include any coastal flooding such as that occurring during Hurricane Katrina. The flood frequency and loss data used in this study was retrieved from a database designed specifically for disaster research called Spatial Hazard Events and Losses Database for 
the United States (SHELDUS). Their latest edition actually does distinguish between flash and river flooding but it was not available at the time of this analysis.

Another opportunity that allows for a more specified focus than that afforded to White in 1945 is the implementation of local planning tools such as the All-Hazard Mitigation Plan mandated via the Disaster Mitigation Act of 2000 (DMA 2000). DMA 2000 required states and counties to have hazard mitigation plans in effect in order to be eligible for post-disaster Hazard Mitigation Grant Program funds, Pre-Disaster Mitigation Program (PDM), or Flood Mitigation Assistance (FMA). Furthermore it tasked the Federal Emergency Management Agency (FEMA) to provide guidelines for state and local plans and holds the state responsible for oversight and coordination of local plans.

In order to make determinations about whether we are closer to effective comprehensive mitigation planning, a key indicator would be to examine these state and local hazard mitigation plans mandated by the federal government since 2000. While the mandate helped steer more state and local governments into participating in mitigation planning, it does not necessarily mean mandated plans are going to bring about effective comprehensive planning. A content analysis of these mitigation plans should tell us a great deal about how prepared we are to manage for flooding and what needs to be done.

If the local level is being empowered and the federal government has created an effective planning tool, then this regional analysis of Mississippi River Region should shed some light on it. It should also support FEMA (2014) findings in the Nationwide Survey of Local Officials (NSLO) conducted annually by FEMA (see http://www.fema.gov/protecting-ourcommunities/local-official-survey-findings-flood-risk). Unfortunately, FEMA did not follow through with this annual survey beyond 2014 and there is only one year for comparison. Nonetheless, it does serve to compare a national study to this regional analysis.

The FEMA NSLO report (2014) provided a mixed analysis of mitigation effectiveness across the nation. The report indicated that three out of four local officials polled believe that 
they have a flooding risk within their community (FEMA, 2014). Findings suggest that local officials are very aware of their risk factors and thus can mitigate effectively. However, less than one in ten of these officials actually believe that their community is truly at risk for flooding (FEMA, 2014). Most local officials reported taking some sort of flood mitigation action regardless of whether they acknowledge there was a flooding risk within their community or not (FEMA, 2014). Most concerning is the fact that one in three communities still did not have a FEMA approved mitigation plan in place (FEMA, 2014). Finally, when it came to determining what they felt were the five most important mitigation needs addressed for their community they reported (FEMA, 2014) building drainage improvements (52 percent); elevation (44 percent); erosion control (41 percent); acquisition (31 percent); and floodproofing (26 percent). According to FEMA (2014) the most sought after mitigation needs from the federal government are funding (73 percent); technical expertise (43 percent); flood maps (29 percent); planning assistance (26 percent); and outreach materials (24 percent).

After review of state and local mitigation plans, it appears that these planning tools can provide insight to principles, processes, choices, and priorities at the local level. These actions can be categorized into both structural and non-structural items that local governments feel are needed in order to adequately mitigate for flooding. Based on a content analysis of the action items, these plans can inform the research as to whether or not FEMA NSLO (2014) effectively describes the need for flooding mitigation. Secondly, mitigation plan analysis would answer questions that White (1945) could not - does a regional analysis of flood mitigation provide a better understanding of what is needed for effective comprehensive mitigation? This research can also shed light on what White (1945) suspected regarding mitigation measures favoring the "preservation of the status quo". Has the status quo changed? If so then the priorities would not be focused on the same things identified by White (1945): land adjusting, structural fixes, grants/aid, and emergency response. If this mitigation plan analysis indicates that the focus is 
still primarily the same as it was in 1940, then this should provide support for the hypothesis that local growth machine dynamics confound the effectiveness of a centralized federal flood system.

Mileti $(1999,144,145)$ says that the nation's culture shapes the "selection of loss reduction strategies" and the focus is primarily on individual preparedness and not at the neighborhood or community level. The problem of "sanctity of private property" and "right to accumulate profits" creates a barrier to the government implementing the proper mitigation initiatives (Mileti, 1999, 145). The problem drills down to local government and what local government wants to acknowledge and address. Mileti $(1999,136)$ says basically the processes that determine what local officials will do is based on who will gain or lose and overall the majority of evidence points to people being unaware or underestimating vulnerability and overestimating their ability to cope with a disaster impact. Basically mitigation decision-making is left to local and state discretion and their attention towards mitigation varies quite a bit. Thus uneven mitigation will likely be the biggest danger of all. As Mileti (1999) stated previously, the system and subsystems have strong interactions to contend with and underestimation, overestimation or lack of awareness can send the entire system into failure-- cascading failures. What Mileti (1999) inadvertently acknowledged is that political influence from growth machine dynamics is the root of these uneven mitigation directives at the local level. Therefore, systems level focus does not fully account for barriers to effective mitigation.

Analyzing mitigation plans and the demographic information of the region can show where there are potential risks that are either not being addressed due to lack of awareness, lacking risk methodology or possibly lack of political feasibility. According to Mileti $(1999,102)$ data needs, and specifically comprehensive data needs regarding the built and social environment, are needed in order to improve mitigation.

\section{Evaluating hazard mitigation planning}

In the 1981, the Reagan administration reorganized FEMA and through top secret security directives (NSDD 26) establishing the National Preparedness Directorate (NPD) which 
established a strong relationship with the Department of Defense (Perrow, 2007). FEMA's focus shifted from natural hazard preparedness to developing classified technology networks with the military and building a nuclear war defense system (Perrow, 2007). The result was that state and local agencies suffered a disconnect from the federal government as top secret planning continued to expand within the federal level but state and local emergency management were denied access to much of the communication networks and technology being developed alongside the military (Perrow, 2007). The shift towards homeland security planning resulted in a roll back on natural hazard mitigation planning (Perrow, 2007). The Integrated Emergency Management System (IEMS) was developed as a streamlined approach to natural hazard mitigation planning focused on commonalities of response to most hazards or "all-hazards mitigation planning" (McLoughlin, 1985). This shift in mitigation planning to an all-hazards approach is the prevailing design for hazard mitigation. Given that this focus has been predominant for many years now, does the DMA 2000 initiative give generously enough to natural hazard mitigation? Secondly, does the commonalities and response focus limit the effectiveness of these plans? Third, does growth machine dynamics limit the effectiveness of these plans?

Lindell and Perry (2007) point out that all-hazards mitigation planning approach allows for a more effective and efficient approach to utilizing resources when emergency managers can identify to what degree each hazard will draw upon these resources. Caruson and MacManus (2011) claim that lack of empirical research on the effectiveness of an all-hazards approach was problematic. They wanted to determine if "perceived commonalities" among local officials were congruent with the "broader theory that where commonality is an organizing principle, emergency management services improve" (Caruson and MacManus, 2011, 348). What they found was that there are commonalities in terms of basic needs such as power, water, transportation, communication health care, etc. but there are differences between metropolitan and rural communities in terms of vulnerabilities to infrastructure and assets (Caruson and MacManus, 2011). MSAs, due to having higher population densities-- thus hazard potential is 
concentrated, have more commonalities and better access to resources such as training and funding but, at the same time, they have greater pressure to utilize resources more efficiently (Caruson and MacManus, 2011). Caruson and MacManus $(2011,366)$ argue that more work needs to be done to determine whether commonality theory actually does save money and produce better results where there is a "high degree of convergence".

Berke and Campanella (2006) argue that barriers to effective local mitigation planning can be blamed on both the federal and state government. The state government does not mandate the development of local comprehensive plans and the federal government does not provide enough support for local planning (Berke and Campanella, 2006).

Covington and Simpson (working paper, 2006) provided a comprehensive overview of all disaster literature focused on disaster preparedness and developed four main categories regarding the role of disaster planning for communities and agencies: 1) fundamental features of disaster preparedness; 2) disaster preparedness metrics; 3) policy issues; and 4) recommendations. They argue that there are two phases of planning that must be achieved (development and implementation) in order to create a comprehensive preparedness measure (Covington and Simpson, 2006). However, in order to accomplish this, consistency and accuracy in data collection must be determined; objective indicators must be agreed upon by both researchers and practitioners; and an agreed upon model design needs to be developed and tested (Covington and Simpson, 2006). Their focus is strictly on the planning tool itself, and not necessarily based on collaboration and competition between policy actors that influence this process.

The federal Disaster Mitigation Act (DMA) of 2000 was an attempt to shift mitigation planning towards a more comprehensive design by integrating various projects, programs, and regulatory initiatives (Godschalk et al., 1999; Burby et al., 1999). These enhancements to the original 1988 Stafford Act was an attempt to bring about greater compliance at the state and local level thus attempting to reign in some of the growth machine politics. In order to be eligible for post-disaster Hazard Mitigation Grant Program funds, Pre-Disaster Mitigation Program (PDM), 
or Flood Mitigation Assistance (FMA) there must be hazard mitigation plans in place at the state and local level (Berke et al., 2009, 5, 26). Furthermore, in the FEMA guidelines for state plans, the state is responsible for oversight and coordination of local plans (Berke et al., 2009, 26).

Since hazard mitigation planning was mandated in 2000 , the literature on plan quality has started to expand. It seems to originate in the mid 1990s with Berke and French (1994) and Burby and May (1997) addressing what should be three basic core components—facts, goals, and their mandates. Since 1999, urban/regional planning scholars have begun to address more in terms of quality of the plans such as organization of the plan (Berke, 1999), plan principles (Berke, 1999), and plan evaluation and monitoring (Berke et al., 1999; Godschalk et al., 1999; Norton, 2005). Others have examined consistency within the plan (Norton, 2005) and linking hazard mitigation plans to other strategic planning mechanisms in place (Brody et al., 2003; Brody et al. 2004; Termorshizen, 2007).

To date, the most extensive work on all-hazard mitigation plan quality has been Berke et al.'s (2009) assessment tool for measuring state hazard mitigation plans and Lyles et al.'s (2012) focus on developing an assessment for local mitigation plans. The Lyles et al. (2012) evaluation method is directed towards evaluating coastal jurisdictions but claim that core principles can be applied across planning domains. They use two conceptual dimensions: direction setting and action-oriented principles (Lyles et al., 2012, 3). Direction setting principles involve establishing a clear plan direction such as developing: 1) facts regarding local conditions and needs; 2) goals; and 3) actions and supportive policies to ensure planning goals are achieved (Lyles et al., 2012). Action oriented principles involve addressing the four main components of the plan: 1) stakeholders participation or all people and agencies impacted; 2) inter-organizational coordination; 3) implementation; and 4) monitoring and evaluation (Lyles et al., 2012). In all, seven principles are evaluated: facts, goals, policies, participation, inter-agency coordination, implementation and monitoring (Lyles et al., 2012, 3). These principles are closely aligned with 
FEMA "Blue Book" guidelines categorized into four main sections: planning; risk evaluation; mitigation strategies; and plan maintenance (FEMA, 2008).

Lyles et al. $(2012,9)$ found that local hazard mitigation plan quality was "moderate to weak overall" and there is wide variability "across the principles of plan quality" and the states involved in the study sample. Their findings support those found by other researchers who have also mitigation plans in other areas (Kang et al., 2010; Berke and Godschalk, 2009). Given this finding, it could be that plan quality and plan enforcement continue to be hampered by the growth machine dynamics and influence by those political actors on the planning process.

\section{Other shortcomings in mitigation planning}

Cutter et al. (2000) argue that the FEMA guidelines for risk assessment falls short in defining hazard vulnerability by only looking at the presence or absence of a natural hazard risk. The best tool available for determining social vulnerability is the Social Vulnerability Index (SoVI) created by Cutter et al. (2003) and through several revisions has developed into a measure that examines 30 socioeconomic variables collected from five year estimates in the American Community Survey and the 2010 Census that contribute to social vulnerability. Interestingly, seven significant components of this measure account for 72 percent of variance in the data: race, class, wealth, elderly, Hispanic, Native American, special needs, and service industry employment (Cutter et al., 2010). This county level data was created using a principle components analysis which reduces the data into statistically significant components for comparison nationwide. The SoVI 2006-10 (Cutter et al., 2013) shows three levels of risk rating based using three quartiles where high and low risk is established as two standard deviations from the mean (medium risk).

While the SoVI 2006-10 (Cutter et al., 2013) could be used by local planners for an improved risk analysis, it does not fall within FEMA requirements. Further, there are limitations to this analysis in that it does not show pockets of social vulnerability down to the census track 
level. County level data can obscure true social characteristics in or near the floodplain when the overall county level demographics are vastly unequal.

Another more recently developed indicator by Cutter et al. (2010) is called the Disaster Resilience Index (DRI) which is a composite score of social, economic, institutional, infrastructure, and community capacities. Overall, there are 36 variables addressing the potential resilience of each community. However, there are assumptions within these variables such as "percent population covered by a recent hazard mitigation plan" that a positive rating could contribute to better resiliency. The DRI (Cutter et al., 2010, 7) does not consider the quality of the mitigation plan, the variables within the subcomponent of "institutional" such as "percent of population covered by Citizen Corps programs" or the variable "percent population participating in CRS for flood" fall within the scope of an effective mitigation plan. A comprehensive evaluation of effective mitigation, reduced vulnerability, or increased resiliency may not be assessed well by this measure especially if the mitigation planning process done at the local level is not robust in the first place.

The Cutter et al. (2010) study also included three community case studies to support the significant of the DRI using the metropolitan area of Memphis, Tennessee for one. The economic and infrastructural resilience of Shelby County was high. Cutter et al. $(2010,17)$ did point out that some limitations to the DRI are that national data sources were often out of date and inadequate to establish true local characteristics. A review of the Shelby County mitigation plan (including Memphis) indicates that there is considerable need for infrastructure improvement for effective flood control. Therefore, if we overlay the region of focus (Mississippi River Region) with indices such as the SoVI or DRI, we still would not have an adequate understanding or comprehensive analysis of flood hazard mitigation needs. We might even be led to believe an area is less vulnerable than it actually is.

When considering the economic resilience of a community as being a positive in accordance with the DRI (Cutter et al., 2010), if the mitigation plan does not account for the 
economic characteristics, does not identify the diversity of those characteristics, or does not include action items within the mitigation plan that address mitigating the private sector, it does not necessarily establish that there is truly economic resilience. Mitigation planning needs to include an analysis of private sector readiness and create action items that promote public-private partnerships in preparedness and private sector outreach initiatives. The economic characteristics and specifically addressing the private sector in mitigation planning is one area where a subsystem failure could potentially be devastating. Looking within the action items of local hazard mitigation plans and determining how many action items address the private sector would indicate whether the economic sector is being considered an integral part of mitigation planning. This study will also establish whether or not local hazard mitigation plans are actively engaging in mitigating the private sector. Absence of this element would be suggestive of growth machine dynamics in play in that these elites are ignoring or refusing to participate in the planning process.

This study considers the institutional subcomponent in the DRI (Cutter et al., 2010) in terms of variables such as the extent the community participates in the Community Rating System (CRS) and promotes the National Flood Insurance Program (NFIP). These programs were based on the recommendations of Gilbert F. White (1945) and legislated into existence through the NFIA (1968) as part of the non-structural mitigation actions that were necessary to reduce flood costs. The primary means of cultivating these programs is through local government and local planning initiatives which would include community engagement activities and other community actions. Local hazard mitigation plans should provide clues as to whether there is community involvement in these programs and the extent to their effectiveness. Also community participation in the CRS and NFIP can be determined based on data obtained from FEMA databases accounting for flood insurance policies and CRS participation. If the community does not seem to be actively participating in these mandates and planning processes, then it seems feasible to question whether or not the growth machine dynamics are exerting influence in this process. 


\section{CHAPTER FOUR}

\section{METHOD}

This study seeks to comprehensively examine the mitigation efforts at the federal, state, and local level to look at the true characteristics of flood mitigation planning, evidence of policy and programs in action or lack of, and describe the social demographics at the census tract level where the population is most at risk in the county. Along with pointing out persistent problems in floodplain management, this research attempts to answer the question: Is there evidence that growth machine dynamics continue to render the federal flood control system ineffective? Secondly, despite implementing both structural and non-structural mitigation does the cost of flooding continue to rise?

This research begins with the following hypotheses:

H1: As the number of flood mitigation actions increased due to the implementation of federal mitigation plan mandates, the costs associated with flooding decreased.

H2: Counties that have followed the federal mandate to implement all-hazard mitigation plans have experienced a greater reduction in flood costs than counties without all-hazard mitigation plans.

H3: Counties with a greater number of non-structural mitigation actions associated with the NFIP have experienced a greater reduction in flood costs than counties without non-structural actions associated with the NFIP.

H4: Counties with a greater number of non-structural mitigation actions associated with repetitive loss reduction have experienced a greater reduction in flood costs than counties without repetitive loss reduction non-structural mitigation actions. 
H5: Counties that participate in the non-structural mitigation CRS initiative have experienced a greater reduction in flood costs than counties who do not participate in the CRS initiative.

H6: Counties whose hazard mitigation plans have a higher the ratio of flood mitigation actions relative to other hazard mitigation actions have lowered damage costs related to flooding. .

H7: Populations near or within the floodplain have higher concentrations of social vulnerabilities than those populations outside the floodplain.

In addition to exploring these hypotheses that are focused on the effectiveness of these mitigation mandates, some exploratory research was done to examine other factors that might contribute to the flooding problem. Exploratory efforts specifically focused on some of the social characteristics that may be present within the region that are correlated to inequality and those populations who have less political power. These selected social characteristics may be confounding any attempts to effectively mitigate the region against disastrous flooding and may create greater vulnerabilities with their presence. In addition, is it possible that these characteristics could be concealed in a way that prevents effective mitigation? Furthermore, if there is evidence that these social characteristics that create greater vulnerabilities are present, then it lends to evidence that growth machine dynamics are at the root of these conditions.

A comprehensive search for all-hazard mitigation plans from ten states and 108 counties bordering the Mississippi River was conducted from August 15, 2013 to April 15, 2014 by online searches in local government webpages, calls, and emails to state and local emergency management agencies. Altogether, ten state plans and 62 county or local multi-jurisdictional plans were retrieved for this study. Even though all-hazard mitigation plans were mandated in the Disaster Mitigation Act of 2000 in order to receive federal funding for post disaster mitigation, not all counties have managed to create mitigation plans or meet the required updating process within five years. For the most part, there have been few changes in these plans during updates. Therefore, using outdated plans still provides sufficient information regarding mitigation actions. In order to capture a more comprehensive picture, if an all-hazard plan has been created and even 
though it may be outdated (usually as a result of lack of available funding), the mitigation plan was included in this analysis. Arkansas is the only state in which there were no county plans available. A comprehensive list of states and their counties within the study and their ratio of flood mitigation actions to overall mitigation actions expressed as a percent is provided in the appendix (Figure 4.1-4.11).

Content analysis was used to evaluate mitigation actions in the mitigation strategy section of each all-hazard mitigation plan. Each mitigation action was first evaluated to determine whether the action was specifically aimed at flood mitigation. The total number of mitigation actions overall and flood mitigation actions specifically to determine the ratio of flood mitigation items to others. Two separate master lists of mitigation actions were made- one for the state plans and one for counties/local level plans. Mitigation actions were then categorized by structural and non-structural actions. Structural actions include building flood walls, levees, widening or enlarging culverts, raising roads, adjusting bridge ramps, and similar actions that involved construction activities or adjusting the natural landscape. Non-structural actions are actions that are achieved through administrative processes and include such examples as technical support and education and outreach.

Non-structural actions were categorized by similar function. A total of 18 types of nonstructural actions were identified (Figure 4.12) and categories (Figure 4.13). Non-structural and structural action items were then calculated and compared in order to make determinations about mitigation needs at local, state, and regional levels. This data will also be compared to the NSLO findings reported by FEMA in 2014.

FEMA has generated a database called Flood Insurance Policies and Community Rating System Participation. This database provides a list of counties and cities within each state that participate in the CRS program, the class rating of that community, and the number of National Flood Insurance policies in effect for that county or community. There is also a state percentage rate for community participation which is measured by total community participation divided by 
total communities available for participation. This data will be gleaned to determine county or community level of participation in non-structural mitigation programs and compared to the jurisdiction repetitive losses information provided within the local hazard mitigation plans.

The Spatial Hazard Events and Losses Database of the United States (SHELDUS) Version 10.0 launched as of August 2012 was used to determine flooding frequency and property damage costs for a period of 50 years for each of the 108 counties in the study. It was determined that the best possible way to manage and present this data would be by ten year period (1960-69, $1970-79,1980-89,1990-99,2000-10)$. This data was used to determine flood frequency and property damage costs to make determinations about the impact of historical policy changes and mandates for mitigation. This database provides data for all natural hazard disaster declarations within the county. Therefore, the number of disaster types will help inform the research as to how much flood hazard is involved in each area in comparison to other natural hazard risks. Further analysis included a comparison of flood frequency and costs in counties with and without mitigation plans in attempt to determine if planning mandates have impacted the cost or frequency of flooding and whether there are local, state or regional differences in flood trends.

Given the disparity of these preliminary results, it was difficult to establish that mitigation planning was having an impact on flood costs. One thought was to return to the raw data and break out the flood costs by each year, rather than by decade, and then run several multiple regression discontinuity models to see if any patterns would emerge.

In the first regression discontinuity model (Model 1), the dependent variable was established as "allcountyyes" which is the reported property damage cost gleaned from SHELDUS from each year in the period 1980 through 2010 (31 total years) for all counties having a mitigation plan $(\mathrm{n}=62)$. The variable "timeline" is coded numerically as one through thirty-one $(1-31)$. The "time-plan" independent variable indicates the two periods in time-zero (0) for the years prior to mandated mitigation planning (1980 - 1999) and one (1) for the years in which these counties had a mitigation plan in place. Third, the independent variable 
"timeafterplan" was created with a value of zero (0) for all time prior to the mitigation planning mandate and the numbers one (1) through eleven (11) for the period $2000-2010$.

The second regression discontinuity model (Model 2) is much similar to the first model but in this analysis, the focus is all counties without a mitigation plan $(\mathrm{n}=46)$. The dependent variable "allcountiesno" is the reported property damage cost using SHELDUS data for each county without a mitigation plan for the same time period as the first model. The "timeline" and "timeafterplan" variables are the same as the first model. The "time-plan" variable indicates the two periods in time - zero (0) for the years prior to mandated mitigation planning $(1980-1999)$ and one (1) for the years in which these counties were mandated to have a plan in place although they do not.

The third (Model 3) and fourth (Model 4) regression continuity models were drafted to explore in greater detail if there were any regional differences between the upper and lower Mississippi River counties. Using the same variables as the first model, plan data from all counties above the confluence of the Ohio River and Mississippi River were used in the third model-Upper Mississippi (Plan-Yes) with the only difference being that the dependent variable is labeled "cost". The fourth model is comprised of all counties with plans below the confluence of the Ohio River and Mississippi River.

Several statistical analysis methods were considered for exploring factors discussed in this study such as the SoVI; CRS classification and participation; and mitigation actions within the mitigation plans to make determinations about their influence on flood costs. Due to the small sample size and variability of flooding, it was not possible to attempt a multivariate or factor analysis of these variables. Even if one of these factors show significance in the years following the 2000 mandate, the variability of flooding by year and when plans were implemented would significantly limit the usefulness of these determinations. Therefore, the most useful way to evaluate this data is merely to quantify and compare their prevalence in mitigation planning; determine whether different areas within the region express different types of 
mitigation needs; and to compare flood mitigation needs in this region to the needs reported by local officials in the from the FEMA national survey.

The 2010 U.S. Census and 2012 American Community Survey (5 year estimates) were used to collect social and housing characteristics on populations within the 108 counties and census tracts bordering the Mississippi River. Arc GIS software was used in order to build maps to visually compare differences between the variables at the county and census tract level to determine if there are pockets of vulnerabilities buffering the river that would not otherwise be observed using county level data. This data can be used to contrast and compare to vulnerability indicators such as the SoVI (Cutter et al, 2012) and to advance the argument that mitigation planning should include a survey of social vulnerabilities in the risk assessment. The variables selected for use in this section of the study were those that could be obtained at both the county and census tract level. These eight variables are poverty (all races), white poverty, black poverty, renter versus owner occupied housing, median income, housing built before 1969, elderly population overall, and elderly poverty. 


\title{
CHAPTER FIVE
}

\begin{abstract}
ANALYSIS

\section{Mitigation Planning Impact on Flood Costs}

Multiple regression discontinuity models were used to determine the accuracy of the independent variables at predicting flood costs. Model 1 (Figure 5.1) in this analysis is focused specifically on counties with mitigation plans and their influence on flooding costs. The dependent variable was established as [allcountyyes] which is the reported property damage cost gleaned from SHELDUS from each year in the period 1980 through 2010 (31 total years) for all counties having a mitigation plan $[\mathrm{n}=62]$. The independent variables are first-- the consecutive years from 1980 through 2010 [Timeline] and coded consecutively [1-31]; second-- plan mandate years [Time-Plan] with zero [0] for the years prior to mandated mitigation planning (1980 $1999)$ and one [1] for the years in which the plan mandate occurs $(2000-2010)$; third-- time as a variable [TimeAfterPlan] with a value of zero [0] for time prior to the mandate and then numbered consecutively [1-11] for the mandate years $(2000-2010)$. Regression results indicate that the overall model does not significantly predict flood cost, $\mathrm{R}^{\wedge} 2=.015, \mathrm{R} \_\operatorname{adj}^{\wedge} 2=-.095, \mathrm{~F}$ $(3,27)=1.36, \mathrm{p} \leq .938$

Model 2 (Figure 5.2) is all counties without a mitigation plan $[\mathrm{n}=46]$. This dependent variable is established as [allcountiesno] again using property damage cost from SHELDUS data for each county in the same period. The independent variables are, again, first - the consecutive years from 1980 through 2010 [Timeline] and coded consecutively [1-31]; second — plan mandate years [Time-Plan] with [0] for the years prior to mandated mitigation planning $(1980-1999)$ and one [1] for the years in which the plan mandate occurs (2000 - 2010); third-time as a variable [TimeAfterPlan] with a value of zero [0] for time prior to the mandate and then numbered
\end{abstract}


consecutively [1-11] for the mandate years $(2000-2010)$. Regression results indicate that this overall model is also does not significantly predict flood cost, $\mathrm{R}^{\wedge} 2=.019, \mathrm{R} \operatorname{adj}^{\wedge} 2=-.090, \mathrm{~F}(3$, $27)=.171, \mathrm{p} \leq .915$

However, the coefficients table for Model 1 (Table 5.1) and Model 2 (Table 5.2), the standardized coefficient for "timeafterplan" for counties that have a plan (plan = yes) and in Model 2 the coefficient for "timeafterplan" for counties that do not have a plan (plan = no) are telling. Both predicted-value curves in the models have similar upwardly slopes. But looking closer at the data, the standardized coefficient for "plan yes" $=.187$ and "plan no" $=.07$ suggests that the coefficient for "plan yes" is 2.5 times greater than the coefficient for "plan no". In terms of real dollars, this result suggests that in counties with mitigation plans the cost of flooding increased by $\$ 3,200,873$ each subsequent year from when planning was mandated. At the same time, counties without mitigation plans after the mandate only had an increase of $\$ 1,920,725$ each subsequent year. We should actually expect this result to be the opposite of what the data indicates or at least these results should be similar. The fact that flooding costs increase at a rate 2.5 times higher in counties with mitigation plans than counties without mitigation plans would lend you to believe that having a mitigation plan actually increased the cost of flooding.

A plausible explanation for this result is that counties with mitigation plans are reporting more flood damage than the counties without plans. Counties with plans in effect are eligible for available FEMA post disaster mitigation funding whereas those counties without plans are not in compliance and, therefore, post disaster funding would not be approved.

In Model 3 (Figure 5.3) and Model 4 (Figure 5.4), the discontinuity design was also used to explore if there were differences between counties with plans in the upper and lower regions of the Mississippi River. Both designs have significant challenges due to the limitations of smaller sample size and also, potentially, flooding behavior itself.

Model 3 is a multiple regression discontinuity model exploring the upper region of the Mississippi River, specifically the area above the confluence of the Ohio and Mississippi River at 
Cairo, Illinois. Regression was conducted to determine the accuracy of the independent variables at predicting flood costs. The dependent variable was established as [cost] which is the reported flood property damage cost gleaned from SHELDUS from each year in the period 1980 through 2010 (31 total years) for all counties having a mitigation plan in the upper region $[\mathrm{n}=37]$ of the Mississippi River. The independent variables are first-- the consecutive years from 1980 through 2010 [Timeline] and coded consecutively [1-31]; second-- plan mandate years [Time-Plan] with zero [0] for the years prior to mandated mitigation planning $(1980-1999)$ and one [1] for the years in which the plan mandate occurs (2000 - 2010); third-- time as a variable [TimeAfterPlan] with a value of zero [0] for time prior to the mandate and then numbered consecutively [1-11] for the mandate years $(2000-2010)$. Regression results indicate that the overall model does not significantly predict flood cost, $\mathrm{R}^{\wedge} 2=.011, \mathrm{R} \_\operatorname{adj}^{\wedge} 2=-.099, \mathrm{~F}(3,27)=1.43, \mathrm{p} \leq .255$.

Model 4 (Figure 5.4) is also a multiple regression discontinuity model exploring the lower region of the Mississippi River which is defined as the area below the confluence of the Ohio River and Mississippi River at Cairo, Illinois. Again, regression was conducted to determine the accuracy of the independent variables in predicting flood costs. The dependent variable was established as [cost] which is the reported flood property damage cost gleaned from SHELDUS from each year in the period 1980 through 2010 (31 total years) for all counties having a mitigation plan in the lower region $[\mathrm{n}=25]$ of the Mississippi River. The independent variables are first-- the consecutive years from 1980 through 2010 [Timeline] and coded consecutively [131]; second-- plan mandate years [Time-Plan] with zero [0] for the years prior to mandated mitigation planning (1980 - 1999) and one [1] for the years in which the plan mandate occurs (2000 - 2010); third-- time as a variable [TimeAfterPlan] with a value of zero [0] for time prior to the mandate and then numbered consecutively [1-11] for the mandate years $(2000-2010)$. Regression results indicate that the overall model does not significantly predict flood cost, $\mathrm{R}^{\wedge} 2=$ $.012, \mathrm{R} \_\operatorname{adj}^{\wedge} 2=-.099, \mathrm{~F}(3,27)=.101, \mathrm{p} \leq .958$. 
It was anticipated that the models again would lack significance given the wide variability of flooding and sample size (See Table 5.3, 5.4). Comparing the slopes of Model 3 (Figure 5.3) and Model 4 (Figure 5.4), there were some major differences. The slope in Model 3 (Figure 5.3) in the mandated period was very similar to the slope in Model 1 (Figure 5.1) which suggests that flooding costs increased at the beginning of the mandate period. However, the slope in Model 4 (Figure 5.4) showed a drastic decline in flood cost in the mandated period. In real dollars, counties with plans in the upper region reported a cost increase of $\$ 5,195,403$ each subsequent year (standardized coefficient $=.721$ ) whereas the lower region counties with plans had a yearly decrease of $\$ 1,994,530$ (standardized coefficient $=-.127$ ). How might this discrepancy be explained?

Model 3 and Model 4 discontinuity design have significant challenges due to the limitations of smaller sample size and also potentially flooding behavior itself. There were more counties identified with plans $(n=37)$ in the upper region than the lower region $(n=25)$ in the sample. The upper and lower regions do not necessarily flood at the same time or in the same frequency. For example, in the 1993 Great Flood, the upper region experienced catastrophic flooding while the lower river region, in a state of drought, was not impacted at all. Secondly, when flooding occurs in the lower region, it can be due to receiving higher volume flood waters from the upper region and/or from the Ohio River. A large volume of water from the Ohio River pouring in to the Mississippi River alone will often create flood conditions in the lower region.

\section{Analysis of Flood Costs and Flood Mitigation}

\section{$\underline{\text { State Flood Costs }}$}

Using the SHELDUS data provided from 1960 - 2009, the ten states within the sample were evaluated for property damage costs due to flooding (Table 5.5). Iowa has the highest flood costs over the 50 year period, primarily due to the Great Flood of 1993 (\$702 million). The second and third highest flooding states were Illinois $(\$ 363,993,661)$ and Louisiana 
$(\$ 363,770,517)$. Kentucky has the lowest cost $(\$ 13.8$ million) over the 50 year period and remains the lowest during the 2000-2009 period which is after mitigation planning was mandated.

What is alarming here is that after mitigation planning was mandated, over half of these states have suffered the majority of their overall 50 year flood costs in the $2000-2009$ period. For example, Minnesota has a total 50 year flood cost of $\$ 267$ million and the losses suffered in 20002009 totaled $\$ 242$ million or 91 percent of all costs; Tennessee had a 50 year overall loss of $\$ 131$ million and \$115 million (88 percent) in the 2000-2009 period; Wisconsin has a total 50 year flood cost of $\$ 183$ million and $\$ 146$ million (80 percent) in the 2000-2009 period; Arkansas's 50 year flood cost totaled \$23 million and had \$15 million (65 percent) flood cost in the 2000-2009 period.

Also using SHELDUS data, the total amount of flood disaster declarations could be evaluated from the same 50 year period from 1960-2009 (Table 5.6) The total amount of flood disaster events increased most dramatically in Wisconsin (50 to 160 disasters), Minnesota (29 to 89 disasters), Tennessee (51 to 80 disasters), and Mississippi (78 to 125 disasters) from the $1990 \mathrm{~s}$ decade to 2000-09.

Overall, disaster declarations (Table 5.6) and property damage (Table 5.5) due to flooding on the Mississippi River border has continued to increase despite the mitigation planning mandates of Disaster Mitigation Act of 2000. Two specific exceptions, Iowa and Illinois did see a decrease in both disaster declarations and property damage due to flooding in their Mississippi River border counties (MRBCs) from the ten year period 1990-1999 prior to the enactment of the Disaster Mitigation Act period from 2000 to 2010. In Missouri, the number of disaster declarations in border counties went down but property damage costs increased; meanwhile the opposite occurred in Kentucky MRBCs - two more disaster declarations but a decrease in the cost of property damage.

\section{$\underline{\text { State Mitigation Planning Overview }}$}


A content analysis of state hazard mitigation plans (Table 5.7) revealed that the majority of state plans do have specific flood action items and these action items range from zero to 57 percent of total action items. Iowa has the best ratio of flood action items (57 percent) in their mitigation plan, followed by Minnesota (56 percent) and Mississippi (43 percent). Louisiana did not have any mitigation actions related to flooding in their state plan.

State plans were evaluated for structural mitigation (Table 5.8) and non-structural mitigation (Table 5.9) action items. Minnesota and Iowa has evenly distributed the number of structural and non-structural flood mitigation actions, while the majority of states focus solely on non-structural mitigation. These results suggest that states perhaps see their role as providing administrative and technical support to their counties and not one that focuses heavily on structural improvements. It appears that the state relies heavily on funding non-structural mitigation actions either through the general fund, or as part of the administrative role of county emergency managers.

Given that structural mitigation actions are usually high dollar construction projects, it appears that the states leaves it up to the local government to barter with the federal government for structural project funding. While this is not stated explicitly in state plans, this assumption is made based on looking at county plans to see where they indicate their potential funding resources for all mitigation actions.

It also suggests that states view their role in mitigation planning in terms of broad strokes. Mainly, their action strategies lack specificity in terms of non-structural mitigation projects outside of promoting awareness of the National Flood Insurance Program (NFIP) and Community Rating System (CRS). Every state but Louisiana specifically addressed promoting the NFIP, and all states but Wisconsin, Illinois and Louisiana mentioned the CRS in their non-structural mitigation action items (Table 5.9). Also notable is the fact that six out of ten states addressed repetitive loss properties in the action items; the four states that did not address repetitive loss are: Illinois, Wisconsin, Louisiana, and Mississippi (Table 5.9). 


\section{County/Parish Mitigation Planning Overview}

A content analysis was conducted on 64 all hazard mitigation plans from counties bordering the Mississippi River. A total of 2,562 all hazard mitigation items were evaluated and 1,062 flood mitigation specific action items were identified. These flood mitigation action items were then divided into structural action items (509) that accounted for 48 percent of flood mitigation actions (Table 5.10) and non-structural action items (553) that accounted for 52 percent of flood mitigation actions (Table 5.11).

Structural mitigation need in MRBCs (Table 5.10) was most prevalent in Illinois (236 items) followed by Louisiana (121 items). All MRBCs showed the greatest need for road repairs and elevation ( 81 items) followed by widening culverts (75 items), fixing sewers (45 items), stabilizing banks with armour (33 items), repair/replace bridges (32 items) and building floodwalls and levees (30). Illinois specifically seemed to skew the data for the most prevalent types of structural mitigation. Specific to Louisiana, there is a critical need for building pumping stations (25 items) and retrofitting structures (18 items); and Tennessee specifically needs retention ponds and reservoirs (18 items). The number one issue by State differs somewhat: Wisconsin (stabilizing banks); Minnesota (floodwalls and levees); Iowa (fix sewers); Illinois and Missouri (road repair/elevation); Kentucky and Mississippi (move buildings out of floodplain); Tennessee (retention ponds/reservoirs); Louisiana (pumping stations).

Non-structural mitigation needs (Table 5.11) are also skewed by the high number of item needs in Illinois. The highest non-structural mitigation need (in all states) is conducting studies on the floodplain to determine what can be done to mitigate issues (92 items). In fact, all state MRBCs indicate the top three issues are 1) conducting studies, 2) promoting the NFIP, and 3) trying to get maintenance approved (clean debris from waterways and drains). All state MRBCs, with exception to Tennessee, show a need to address repetitive loss property issues (ranked fourth as an issue) and specifically they indicate this need is to identify these properties in the floodplain. Working towards policy remedies was another popular non-structural item (ranked 
fifth, total 48) with exception to Kentucky and Tennessee (no need reported). Overall, education and outreach ranked sixth with a total of 45 action items related to this initiative (no need:

Tennessee, Mississippi). The most concerning items noted during the analysis, because they are foundational for mitigation, are the needs for warning improvements (Wisconsin, Illinois, Missouri, and Mississippi); evacuation and shelter planning (Wisconsin, Iowa, Illinois, Missouri) and make response plans (Wisconsin, Illinois, Missouri). The CRS program as an MRBC action item (total 12) only had relevance in three states (Illinois, Missouri, and Louisiana).

\section{Content Analysis: State \& County Profiles of Flooding Costs and Mitigation Planning $\underline{\text { Minnesota \& Counties }}$}

The total amount of flood costs for the fifty year period (1960-2010) in the Minnesota counties bordering the Mississippi River was 266.8 million dollars (Table 5.12). The period from 2000 to 2010 accounts for 91 percent (\$242.3 million) of this total. Flooding in August, 2007 accounts for 34 percent (over $\$ 82$ million) of this period and is confined to three countiesHouston, Winona, and Wabasha. The second worst year for flooding occurred in 2001 (\$77.7 million) accounting for 32 percent of flooding in this decade with 13 counties reported flood damages primarily in the months of April and May.

Comparisons were made between counties with and without mitigation plans to the amount of total disaster declarations per decade (Table 5.13) and also total property damage (Table 5.12) by decade. Minnesota had an increased amount of flood disaster in the 13 MRBCs from 29 flood disasters in the 1990s to 89 total flood disaster from 2000 to 2010 (Table 5.13). Of the total number of disasters in the 2000 to 2010 period, 46 of these declarations were in counties with no mitigation planning. The three counties with the most flooding frequency, flood disaster declarations, and highest cost for flooding from 2000 - 2010 are Houston County (21 disaster declarations/\$54.1 million), Winona County (17/\$49 million), and Wabasha County (16/\$25.1 million) accounting for over half (53 percent) of all flood costs within this decade. Houston and Wabasha are two of six counties without a hazard mitigation plan. Overall, Minnesota counties 
without mitigation plans experienced 53 percent (1.28 million) of flooding costs in this $2000-$ 2010 decade. Counties with plans also reported more flooding disasters and more total flooding costs than the total of all previous years combined. The average flood cost per disaster was $\$ 74,000$ prior to the year 2000 , from here costs jumped $\$ 2.65$ million to an average $\$ 2.72$ million per occurrence. Counties in specific where it is alarming to see such an increase in the average cost per disaster declaration is: Winona County, \$2.88 million; Houston, \$2.58 million; and Wabasha, \$1.57 million.

Looking at the Minnesota state and counties mitigation plans, in the state plan there were a total of 18 mitigation actions listed and flood mitigation actions (10) accounting for 56 percent of total actions. This suggests the state does pay ample attention to the problem of flooding. The state evenly divided the need for structural (5) and nonstructural mitigation (5). Counties plans overall have a lower ratio (15 percent) with 61 flood mitigation actions out of an overall total of 416 total mitigation actions. Of these actions, the counties reported 17 structural actions and 44 nonstructural actions.

Does the state plan and county plans appear to agree on the priority mitigation needs (see Table 5.14)? Both agree that they need structural mitigation actions such as culverts, levees, dams, and floodwalls. The State identified bank stabilization, bridges, and reforesting/greening as a need while the counties indicated a strong need for warning systems, elevating structures in the floodplain, and flood gates. The State and counties agree on studies, NFIP, and repetitive loss funding being top five priorities. The State cited the community rating system and education and outreach being among the top five while the counties asked for technical support and equipment funding. The State seems to be more cognizant of flooding problems and is encouraging counties to adapt the Community Rating System, however none of the counties have flood mitigation action items related to this federal initiative.

Counties indicate that they would seek funding for structural projects primarily from the federal government while providing a 25 percent matching from their local funds. Funding for 
nonstructural mitigation actions would be requested from federal, state, and local governments. Overall the counties cited 19 actions seeking federal funding sources; eight (8) actions seeking state funding sources; and 32 actions seeking local funding. In some actions, all levels of government were listed as possible funding sources.

\section{Wisconsin \& Counties}

In Wisconsin, 80 percent of flooding from the entire 50 year period of study (1960 2010) can be attributed to the 2000 - 2010 period, or after the DMA 2000 mandate for mitigation planning began (Table 5.15). Flooding jumped to $\$ 146.1$ million from $\$ 8.2$ million in the previous decade (18 times higher). Vernon County (\$53.5 million - no mitigation plan) makes up 37 percent of the total for that period, followed by Crawford County ( $\$ 35.5$ million, 24 percent, with mitigation plan) and Grant County (\$18.3 million, 13 percent, with mitigation plan).

Grant and Crawford counties have flooded every year in this last decade except for 2005 and 2006. The majority of flooding occurred in 2001 (\$25.5 million), 2007 (\$73.8 million), and 2008 ( $\$ 26.8$ million). Those Mississippi River border counties without plans account for $\$ 88.5$ million (\$35 million excluding Vernon County) of the total \$146 million in property damage costs from 2000 to 2010. Those Wisconsin MRBCs that do not have mitigation plans have historically had more property damage losses. Comparing 1990s to the 2000s period, flood costs increased in mitigated river border counties by 96 percent and 93 percent in unmitigated river border counties. The cost of flooding (Table 5.15) and number of disaster declarations (Table 5.16) increased significantly in both mitigated and unmitigated MRBCs in Wisconsin. The average cost per disaster occurrence increased by $\$ 1.05$ million in the $2000-2010$ period from $\$ 40,000$ per occurrence to $\$ 1.09$ million average per disaster declaration. In Vernon County, the average cost per disaster declaration is $\$ 6.69$ million followed by $\$ 1.25$ million in Crawford County.

The Wisconsin state plan has 17 flood related mitigation actions (17 percent) of a total 98 mitigation actions overall. None of those flood mitigation actions are structural in nature. Three 
counties have mitigation plans with a total of 32 percent of mitigation actions related to flooding. Pepin County, second lowest flooding county, seems to concentrate the greatest efforts towards flooding with 21/37 (57 percent) of mitigation actions oriented to flooding (Crawford - 6/23, 26 percent; Grant -5/40, 13 percent).

In terms of structural mitigation, counties rank the need for culverts, sewers, bank stabilization, road elevation, and bridges repair/reconstructed/constructed as their primary need (Table 5.17). They are primarily focused on obtaining funding from the federal government for structural projects but also indicate asking at all levels on some actions, including nonstructural actions. They reported seeking funds from the federal government- 16, state government- 8 , and local government- 34 (Pepin making 28 requests from the local government).

The State plan ranked the need for education and outreach as its first priority followed by technical support, training, NFIP, and repetitive loss funding (Table 5.17). Counties ranked the NFIP as the priority need, followed by maintenance work (cleaning/checking for debris), repetitive loss funding, influencing local policy, and education/outreach (Table 5.17). Neither the state nor counties mention the Community Rating System in their mitigation plans.

\section{$\underline{\text { Iowa \& Counties }}$}

Iowa had a significant decrease (348 to 154 ) in the amount of flood disasters from the period 1990 - 1999 to $2000-2010$ (Table 5.19). The property damage flood costs for the Great Flood of 1993 alone was reportedly \$ 59.9 million or 94 percent of the flooding cost for that decade (Table 5.18).

In the period 2000 - 2010 significant flooding increases have occurred when you remove 1993 from the equation. The highest repetitive flooding occurrences and flooding costs can be attributed to Allamakee (\$12.9 million) and Clayton (\$16.6 million) counties. These counties alone account for 50 percent of the flooding in the $2000-2010$ period.

Clayton County, the highest flooding county, has a mitigation plan. This plan has a total of 15 mitigation actions with two of those actions being flood related. The actions specifically 
are to provide increased flood mitigation efforts and enhancements to structural mitigation and provide an increased awareness to NFIP participation. These are very broad actions that would be expected within a state plan but more exact in a county plan.

In Iowa, Mississippi River border counties (MRBCs) without plans accounted for 154 of the total 207 flood disasters in the $2000-2010$ period (Table 5.19). The total cost of property damage due to flooding was 59.8 million dollars which is just slightly higher that the cost of the 1993 Great Flood (Table 5.18). Counties with plans averaged \$7.56 million per county and those without plans $\$ 8.55$ million in flood costs for the 2000 to 2010 period. On the surface, it seems to indicate that those counties with mitigation plans have less property damage on average. Comparing data from 1990 to 1999 and 2000-2010, unmitigated counties have experienced a flood cost loss reduction of 91.1 percent whereas mitigated counties have a 61.2 percent average loss reduction. Therefore, it seems that hazard mitigation plans have had little, if any, effect on reducing property damage on MRBC's in Iowa.

Flood mitigation actions make up 57 percent (29 of 51) of the total mitigation actions in the Iowa state plan signaling that the state is very aware of flooding risks. Out of the 10 counties in Iowa bordering the Mississippi River only three (Clayton, Jackson, and Scott) have mitigation plans. Since we already know Clayton has only two total flood actions, Jackson (33) and Scott (56) primarily provide for the 33 percent ratio (91 of 279) of flood actions.

Comparing the state plan to county plans in terms of mitigation need (Table 5.20), both state and counties identify a structural mitigation need for culverts, levees, dams, and floodwalls in the top five mitigation needs. The state cites a need for road elevation and repair; bank stabilization, and bridge improvements such as repair/construction/reconstruction. The counties number one primary need reported is improved sewer infrastructure and that they need to move/build/rebuild properties that are in the floodplain.

In terms of nonstructural mitigation, both the state and counties report a need to address repetitive loss property funding and promote the NFIP. The State includes mention of the 
Community Rating System but there was no mention the CRS in any of the county plans. Their primary nonstructural mitigation action is "policy influence" or to play a role in moving local government in terms of shaping land use/regulating the floodplain and other flood related subjects. Their second ranked action was to enforce regulations related to floodplain management. Finally, the other highly ranked action for Iowa counties was "maintenance" which relates to checking and cleaning debris from various sources flowing into the Mississippi River.

Iowa counties look to the federal government (five requests) and state government (four requests) for funding. Only Clayton county sought funding (twice) from the local government. These counties are very vague about seeking funding overall, but efforts would be concentrated at the federal and state level. It is assumed that they believe the majority of nonstructural actions would be funded through their operations budget.

\section{Illinois \& Counties}

In Illinois, there was an overall reduction of property damage costs (Table 5.21) and flood disasters (Table 5.22) in both mitigated and non-mitigated counties bordering the Mississippi River. The average loss per MRBC is $\$ 2,659,987$ overall. Mitigated MRBCs claimed on average $\$ 2,806,443$ while unmitigated county property damage claimed, on average, half that amount $(\$ 1,488,335)$. Mitigated MRBCs accounted for nearly 45 million of the 47.9 million in property damage. The total amount of flood costs in the mandated period (2000 2010) was $\$ 47.4$ million dropping from $\$ 210.2$ million in the 1990 s. There are only two counties on the Mississippi River border without mitigation plans (Randolph County and Whiteside County). The highest flooding county during the $2000-2010$ period is Mercer County $(\$ 16.4$ million) making up 35 percent of overall flooding and \$11 million of this total was reported in 2003. The majority of flooding during this period occurred in 2010 ( $\$ 21.4$ million) with $\$ 10$ million attributed to Carroll County and $\$ 5$ million to Mercer. Overall, the cost of flooding has gone down since 2000 from an average $\$ 570,000$ per disaster declaration to $\$ 400,000$ average per occurrence. 
The Illinois state plan has 41 flood mitigation actions (20 percent) out of a total of 207 mitigation actions. None of the flood mitigation actions are of the structural type (Table 5.23). Counties (16 of 18 with plans), on the other hand, have 220 (57 percent) structural mitigation actions. Road elevation and repair ranked first with 44 total actions specifically focused on this problem. Culvert building/widening followed as a close second with 42 total actions. Bridges (23), bank stabilization (22) and sewers (19) are the remaining structural actions within the top five.

Counties had a total of 187 nonstructural items and cited a tremendous need for studies (52 total actions) followed by equipment funding (24), maintenance, education/outreach, and warning improvements. The State, however, ranks training as the first priority followed by repetitive loss funding, technical support, studies, and NFIP (Table 5.23). The State plan does mention promoting the Community Rating System; however there were three action items from the counties sample. These findings suggest that the CRS is very low priority in Illinois.

Funding sources identified by the counties were primarily geared toward the federal government for structural projects and the state for nonstructural actions. The overall funding breakdown was federal (92), state (55), and local (131).

\section{Missouri \& Counties}

Missouri's MRBCs experienced very little change in total number of flooding disasters (Table 5.25) from the 1990 s to 2000 s but does show a slight decrease overall (124 to 116). Those two counties without hazard mitigation plans (Clark and Lewis County) reported an increase from seven to 31 flood disasters and accounted for 27 percent of flood disaster declarations. Overall the two counties that did not have mitigation plans claimed twenty percent of the flooding property damage cost (Table 5.24). Despite a decrease in number of flood events, the cost of flooding continues to rise. Actually it more than doubled (\$25.4 million to $\$ 66.1$ million) from the 1990 - 1999 period to 2000 - 2010 decade when mitigation plans were mandated by DMA 2000. The average per disaster occurrence has increased in the 2000 period by $\$ 170,000$, or from 
$\$ 120,000$ to $\$ 290,000$ per disaster occurrence. The highest flooding counties presently are Marion County (\$7.3 million, has plan), Clark (\$4.4 million, no plan), and Cape Girardeau County (\$3.6 million, has plan). Most concerning is Marion County previously had an average $\$ 192,000$ average per disaster occurrence, and since 2000 , this has increased to $\$ 3.65$ million per occurrence.

The Missouri state plan has six of 17 mitigation actions related to flooding (29 percent). None of these flood actions are structural in nature (Table 5.26). The State is focused on repetitive loss issues, NFIP, CRS, education/outreach, and technical support. Counties actually look pretty decent with 14 of 16 having plans and 28 percent of their mitigation actions $(136 / 480)$ are focused on flooding. The overall total of structural actions reported by counties is 13 while nonstructural mitigation actions amounted to 123 total. In their detailed funding sections, they sought government funding as follows: federal- 62, state- 53, local- 90 . All structural projects had federal funding requests; often the counties noted asking all three levels of government for funding.

Their primary structural action needs are road elevation/repair, reforest/greening, bank stabilization, levees, dams, and floodwalls. They ranked nonstructural actions as 1) influencing local flooding policy, 2) enforcing present floodplain regulations, 3) maintenance (check/clean debris in local stream outputs), 4) NFIP, 5) environmental considerations. While the State acknowledges the CRS to be a high priority, this action was only mentioned once out of all 123 nonstructural actions indicating it is not a very popular initiative in the Missouri counties. Interestingly, counties made 16 actions related to influencing local policy and 16 actions regarding enforcing local regulations. This suggests that counties are highly motivated to impact land use and floodplain management while the state does not acknowledge such things at all.

\section{$\underline{\text { Kentucky \& Counties }}$}

Kentucky appears to have an overall reduction in property damage losses (from $\$ 4$ million to \$2.8 million) with a marginal increase in flood disasters (23 to 25 declarations) in 
MRBCs (Table 5.27 and Table 5.28). However, the average cost per disaster declaration has gone up \$60,000 per occurrence after the 2000 mandate. Kentucky has the smallest overall increase in flood cost average per disaster out of the five states $(n=10)$ seeing an increase within this focus of this study. MRBCs have the lowest overall property damage rate of all ten states examined on the Mississippi River border. It is the only state within the sample that has active mitigation plans in place for all MRBCs.

The state plan for Kentucky has a total of 24 flood mitigation actions (34 percent) out of a total 67 mitigation actions. The counties have a ratio of 47 percent with 43 flood mitigation actions out of 92 actions total. It is very evident that both the State and counties take flood mitigation planning seriously.

In terms of structural mitigation, Kentucky cited elevating structures as their primary need followed by any "not yet identified" water reduction projects (two total). The counties appear to be building their plans from state guidance (Table 5.29) as their second ranked action item is the same as the state "not yet identified" water reduction projects. Their main priority in a total of 13 structural actions is to move/rebuild or build out of the floodplain, third is road elevation/repair, fourth-- bank stabilization. The fifth ranked priority for the counties is retention ponds and reservoirs. This is interesting because this structural action item is starting to become prevalent within the areas above Louisiana and below the confluence of the Ohio River and Mississippi River.

The State plan views nonstructural mitigation as the priority (22 actions) with influence policy decisions ranking first; and the followed by repetitive loss funding, NFIP, education and outreach, and technical support (Table 5.29). Counties (25 nonstructural actions) ranked promoting the NFIP first, followed by education/outreach, maintenance, repetitive loss funding, and exploring environmental considerations. There was no mention of the Community Rating System by any counties within Kentucky. 
Counties indicated funding sources from the federal government are a priority for structural projects supplemented by a local government match. Overall, the requests to the federal government total 17 and local requests total 21 . The counties seek state funding for nine nonstructural actions.

\section{$\underline{\text { Tennessee \& Counties }}$}

Flood costs in Tennessee climbed from $\$ 7.5$ million in the 1990 s to $\$ 114.7$ million in the 2000s (Table 5.30). $\$ 80.4$ million can be attributed to Shelby County and $\$ 20.6$ million to Tipton County. Mississippi River border counties with mitigation plans (Shelby, Tipton) had considerable more property damage costs and flood disaster declarations (Table 5.31) than river border counties without mitigation plans (Dyer, Lake, Lauderdale). The average loss in the 20002010 for mitigated river border counties was $\$ 50.5$ million in comparison to $\$ 4.5$ million average loss per MRBC without mitigation planning. Tennessee has the second largest increase in the average cost per disaster declaration $(\$ 940,000)$ from $\$ 490,000$ to $\$ 1.43$ million per incident.

The Tennessee state plan had a total of six (10 percent; nonstructural) flood actions out of 57 total mitigation items (Table 5.32). Tennessee counties had a ratio of 61/113 (54 percent) of mitigation items directed toward flooding. Tennessee counties have 49 structural actions and the main priority is building retention ponds and reservoirs (18 actions). Counties complete ranking their structural priorities as 2) culverts, 3) channel improvements, 4) roads elevated/repaired, and 5) construct/reconstruct bridges.

Tennessee state plan prioritized nonstructural mitigation as follows: 1) repetitive loss, 2) studies, 3) NFIP, 4) CRS, and 5) training. The counties concentrate their need on four priority nonstructural mitigation actions: 1) studies, 2) NFIP, 3) technical support, 4) maintenance. None of the counties mention the Community Rating System. All structural items were dependent on receiving federal funding ( 57 requests) followed by nonstructural funding requests from the state (12) and local (28) governments.

\section{$\underline{\text { Arkansas \& Counties }}$}


The cost of flooding and number of flooding disaster declarations continues to rise in Arkansas MRBCs (Table 5.33 and Table 5.34). The change in property damage between the 1990s ( $\$ 1.7$ million) to 2000 s (15.1 million) is a bit alarming. The overall flood cost average increase per disaster declaration in the $2000-2010$ period is $\$ 150,000$ per occurrence which has doubled from $\$ 150,000$ to $\$ 300,000$ per disaster reported. While Crittenden County has the highest flood cost overall, Desha County's cost of flooding since the $2000-2010$ period from 1990s had the most significant average increase. Flooding costs have grown from an average $\$ 209,000$ to $\$ 680,750$ per disaster declaration.

There were no county mitigation plans available to evaluate in Arkansas MRBCs. However, the State plan has a total of eight (13 percent, nonstructural) flood mitigation actions out of a total 62 mitigation action items (Table 5.35). These are ranked as 1) NFIP, 2) repetitive loss, 3) technical support, 4) CRS, 5) training.

\section{Mississippi \& Counties}

Mississippi counties bordering the Mississippi River experienced a rise in flood costs from the 1990s (\$17.2 million) to the 2000s (\$25.9 million) with the highest flooder consistently being Warren County (Table 5.36). Disaster declarations (14) in Warren County in the 1990s yielded a total flood cost of $\$ 13.7$ million, and then jumped to $\$ 53.9$ million in the $2000 \mathrm{~s}$. The change in average cost per disaster for Warren County is \$2.19 million, moving from an average $\$ 980,000$ per flood disaster to $\$ 2.19$ million per flood disaster. Flooding in April, 2003 accounted for $\$ 10$ million in Warren County which was 39 percent of the total flood costs in all border counties for the 2000 to 2010 period. Mississippi MRBCs had considerable increase in flood disaster declarations ( 78 to 125 ) from the 1990s to 2000s (Table 5.37). However, property losses were on the decrease in MRBCs overall. The seven MRBCs with plans averaged $\$ 492,615$ per loss compared to unmitigated MRBCs average $\$ 4.28$ million per loss.

The Mississippi state plan concentrates 43 percent of total mitigation actions (63) towards flooding (27). Two structural actions identified are levees, dams, and floodwalls improvements 
and installing warning systems. The top priorities for nonstructural flood mitigation are: 1) NFIP, 2) technical support, 3) enforcing regulations for floodplain management, 4) communication (networking); and 5) conduct studies. Promoting the Community Rating System is within the action items, as well as promoting the NFIP, and seeking funding for repetitive loss.

Counties (7) with plans have a total 22 flood mitigation actions out of 108 mitigation actions total (20 percent) ranked promoting the NFIP first; followed by maintenance (checking and clearing drainage); technical support; repetitive loss funding; and warning improvements. It is clear that both the counties and State understand they have a need for improving/acquiring warning systems (Table 5.38). The primary structural mitigation needs for counties are to move, rebuild and build out of the floodplain, and focus on culverts, road elevation/repair, and sewer infrastructure.

Counties primarily look to the federal government ( 7 requests) to provide funding for structural mitigation projects and depend heavily on local funding (10 requests) to match federal funds and support nonstructural mitigation. Only Desoto County sought funding from the State for nonstructural mitigation projects.

\section{Louisiana \& Parishes}

Property damage (Table 5.39) due to flooding has dropped considerably in Louisiana MRBCs in the 2000 to 2010 period while flood disaster declarations (Table 5.40) were on the rise (2000s - \$14.1 million; 1990s - \$257.2 million). However, these results do not give any indication that having a hazard mitigation plan is reducing these costs. Actually, the cost of flooding for the 11 MRBCs without plans averaged \$700,253 whereas the average for mitigated river border counties was $\$ 1,065,333$. Flooding over the 50 year period of study was highest during the decade 1990 to 1999 with a total \$257.2 million in flood costs. In January, 1990, six counties-West Feliciana, West Baton Rouge, East Baton Rouge, Pointe Coupee, and Ascension each reported $\$ 41.6$ million in property damage costs, which is approximately $\$ 250$ million total. 
The Louisiana state mitigation plan has 16 total mitigation actions that are very broadly based and do not mention flooding specifically at all. Three specific items focus on developing mitigation planning towards historical preservation efforts. Three actions are aimed at analyzing and developing education and outreach strategies. Four actions emphasize a need to develop technical support initiatives. Two action items are directed at identifying cost effective projects at various levels of government (state, local, municipal). The remainder has to do with improving mitigation planning and focusing on legislative and regulatory activities. This plan is remarkably underdeveloped and does not provide much guidance for local planning initiatives which is the primary focus of state plans. There is no mention of the primary federal initiatives towards flooding such as the NFIP or Community Rating System.

Louisiana MRBC's (17 total) have six parishes engaged in mitigation planning. There were 197 flood actions identified out of a total 256 mitigation actions overall. These Louisiana parishes have the highest ratio of flood mitigations (77 percent) of all states within the study sample. Their first ranked structural mitigation item is the need for pumping stations in 25 different identified locations (Table 5.41). They also identified elevation structures, installing culverts, improving sewer infrastructure, and making channel improvements as high priorities. Their main priorities for nonstructural mitigation were tied with needs for education and outreach as well as influencing flood related policies. Studies, repetitive loss funding, and participation in the Community Rating System (8 actions) are the other three primary needs. Interestingly, Louisiana MRBC's have the highest amount of participation in the CRS. There are six parishes within the sample that have achieved a CRS classification.

The parishes look to the federal government primarily for funding their structural mitigation actions (144 requests) and expect matching funds to come from their local government. In all, the local government (174 requests) is sought out to supplement federal funding and provide for nonstructural mitigation. Orleans (4 requests) and Iberville (1 request) 
have indicated they would solicit funding from state government related to their mitigation actions.

\section{State and County Profiles Summary Analysis}

While Mississippi and Kentucky MRBCs may have improved outcomes related to mitigation planning, the overall analysis suggests that having mitigation plans does not decrease the number of flood disasters or cost of flooding. Looking at the overall results, there seems to be no improvement in flood disaster mitigation as a result of non-structural program initiatives as recommended by White (1945) or after the DMA 2000 took effect. White (1945) argued that despite more spending in structural mitigation, the cost of flooding continued to rise. These findings suggest that despite both structural and non-structural mitigation initiatives, the cost of flooding continues to rise.

Less than eight percent (nine counties total) of the 108 counties/parishes evaluated in this study participate in the Community Rating System (CRS). None of the Mississippi River border counties within Wisconsin, Minnesota, Iowa, Kentucky, Tennessee, Mississippi and Arkansas are actively participating in the CRS (FEMA, 2012). Of these seven states there are cities bordering the Mississippi River that do participate: LaCrosse, Wisconsin (class 8); Davenport, Iowa (class 8); West Memphis, Arkansas (class 7); and Greenville, Mississippi (class 8).

In Illinois, the river border counties of Whiteside (class 8), Rock Island (class 7) participate in the CRS and the City of Moline (class 8). Within the State of Missouri only St. Charles County (class 7) participates in the CRS. Louisiana has the most river border parishes participating in the CRS (total of 6 parishes) which are East Baton Rouge (class 6); Ascension (class 8); St. Charles (class 8); St. John the Baptist (class 8); Orleans (class 8); and Jefferson (class 6).

\section{Content Analysis Findings Compared to 2014 FEMA Local Official Survey}

Comparing this analysis of mitigation planning to the FEMA Local Official Survey (2014), there are differences in what FEMA LOS (2014) believes to be the most sought after 
mitigation needs and also concerning the extent of mitigation planning. FEMA OLS (2014) reports that one in three counties have mitigation plans and the "perception persists" that there is no flooding risk in their community. Analysis of mitigation plans in this study indicates that flooding is the top natural hazard risk and 57 percent this sample has mitigation plans. Giving generously to the FEMA OLS (2014) claim that "perceptions persists" among local officials that there is no flood risk in their community, states and counties are somewhat capricious in focusing on flood mitigation. According to FEMA LOS (2014) the primary mitigation action being taken by communities is storm water planning but it is unclear what exactly this may entail as it is a very vague and abstract strategic action.

An attempt was made to compare and contrast the action items from this study to the FEMA LOS (2014). Structural and nonstructural mitigation items were evaluated together in order to rank the overall need and compare findings. The state plan rankings are based upon how many states cited the mitigation action and the county rankings are based upon how many states had their counties report a mitigation action.

FEMA LOS (2014) has identified ten action items as the top needs for local flood mitigation efforts. The actions would all be very useful to both the states and counties. Specifically 60 percent of the FEMA LOS 2014 mitigation actions are indeed in the top priorities of the states and counties even if they have not been coded exactly the same as the FEMA LOS 2014. These are: funding; addressing repetitive loss (acquisition); erosion control; expertise (studies); technical support (mapping/building data bases); and education and outreach development.

States and counties have a strong agreement that NFIP promotion needs to be addressed. The federal government could be very instrumental in addressing this need and providing support for this endeavor. Second, both the states and counties see a need to influence policies related to flooding and floodplain management. There is an obvious awareness by the state and local mitigation planning officials that federal initiatives cannot effectively be achieved until state and 
local governments align themselves with the federal government. Finally, both states and counties identify the need for expansion and/or improvements with levees, dams, and floodwalls. It is abundantly clear that they seek funding help from the federal government to satisfy this need.

Particular to the state priorities and not addressed by FEMA LOS 2014 (federal) or counties in the top priorities is the need to promote the Community Rating System. In fact, this action item is not prevalent in county plans. The states also prioritize training and communication networks. Counties identified road elevation and repairs; maintenance-- checking and cleaning debris from obstructing streams and waterways; and improvements to sewer infrastructure. These action items are not acknowledged as priority needs by either the federal or state government.

\section{Social Vulnerabilities: Populations and households potentially in the floodplain}

In order to make determinations about social vulnerabilities in the floodplain, it is important to try to identify who might be in the floodplain and why. Thus far, social vulnerability indexes have depended on county level data in order to make inferences about hazard vulnerabilities. The problem here is that measuring vulnerability at the county level may not reveal concentrations of vulnerability in higher risk areas. This effort is beset by the limited amount of data available for study at the census tract level. In this study, available population and housing data was selected at the census tract level from 2012 American Community Survey five year estimates and compared to the same data at the county level. The use of Arc GIS to map this enormous amount of data served to provide a better visual aid for analysis. The total area of study was divided into four mapped segments: Upper Mississippi River Region; Upper Middle Mississippi Region; Lower Mississippi River Region; and Louisiana Region (Figure 5.5). There are eight side by side maps within each segment that identify the specified social vulnerability variables at the county and census tract level. These maps are accompanied by pullouts for six high density urban areas: Minneapolis/St. Paul, Quad Cities, St. Louis, Memphis, Baton Rouge, and New Orleans. The variables are as follows: overall poverty (Figures $5.6-$ 
5.15); white poverty (Figures 5.16 - 5.25); black poverty (Figures 5.26 - 5.35); elderly poverty (Figures 5.36 - 5.45); elderly population overall (Figures 5.46 - 5.55); median household income (Figures 5.56 - 5.65); renter versus owner occupied housing (Figures 5.66 - 5.75); and housing built in 1969 or prior (Figures $5.76-5.85$ ).

The total population of all counties within this study is $10,243,374$ and the total population within the census tracts bordering the Mississippi River is $2,264,845$. It is estimated that 22 percent of the total population in this study is considered to potentially be within the floodplain (Table 5.42). Total households for this population is $4,011,674$ and potentially 896,807 (also 22 percent) of these households are within the floodplain (Table 5.42). Looking at the region overall, large population centers are most evident in Minnesota, Iowa, and Louisiana (Table 5.42). The lowest population density lies in the middle region just below the confluence of the Ohio River with exception to the metropolitan area of Memphis, Tennessee (Table 5.42).

One of the most interesting findings in this study is the fact that poverty is pushed up against the Mississippi River thus exposing a more vulnerable population to a potentially more risky area to live (Table 5.42). Poverty conditions become increasingly prevalent in the lower Mississippi region and within urban areas (see Figures 5.6-5.15). Breakdowns for each state provide an idea of what percent of populations and households may be in the floodplain and also what the highest level of poverty is within poverty pockets obscured by much lower overall county poverty levels (Table 5.42).

Race does have significance in the overall poverty characteristics along the Mississippi River. Black poverty along the Mississippi River is highest in urban areas and more prevalent in the middle and southern regions. There is a large section of black poverty on the Illinois border in the Quad Cities region and a large section of white poverty in Baton Rouge. Even though black poverty is much more pronounced, both white and black poverty is similarly situated by region. 
What is most concerning about the poverty population are the small dense pockets of elderly poverty along the entirety of the river and especially in Illinois. There are large sections of elderly poverty in urban areas especially in St. Louis and Memphis and one glaringly large area at the tip of the bird's foot in Louisiana. Elderly population overall should be a concern for mitigation planning. The upper region, upper middle, and lower middle region especially on the Arkansas side of the river have large elderly populations. In urban areas, the most prevalent areas for elderly populations are in the Quad Cities region, Memphis, and Baton Rouge.

In addition to high concentrations of poverty, over 30 percent of households are rental units. The counties in the lower Mississippi River region have even higher pockets of rental housing buffered up against the river than the upper region. The urban areas all have a large presence of rental housing buffered along the river, especially in Memphis and Baton Rouge.

Furthermore, housing built prior to 1969 , which would be grandfathered into the National Flood Insurance Program and Community Rating System, is extremely dominant on the river border. The most dense areas are within the urban centers and in the lower region along the Arkansas side and upper Louisiana. This housing stock would less likely be retrofitted and more vulnerable to flooding.

Mapping these social vulnerabilities at the regional level using Arc GIS provided an opportunity to scan the region for problem areas. Greater analysis within each state then provided further evidence of social vulnerability characteristics and these are explained in greater detail below.

\section{Minnesota Characteristics:}

Minnesota counties have the largest population $(3,179,161)$ bordering the Mississippi

River. Within these counties, the census tracts bordering the river make up a total of 437,001 people (14 percent). Household totals are 1,247,595 with 167,229 (13 percent of total households) potentially within the floodplain. There are approximately 21,000 structures (44 percent) in or near the floodplain dating prior to 1969 and would likely be grandfathered in to the 
NFIP program. Rental homes make up 28 percent of the total households within these census tracts and, for the most part, poverty levels are far greater than their county average with exception to Houston, Wabasha, and Wright County. Higher levels of poverty, as much as 56 percent (Winona County) are evident in census tracts bordering the Mississippi River. These findings suggest that high pockets of poverty are being pushed up to the river's edge and creating greater vulnerabilities.

\section{Wisconsin Characteristics:}

The population within the MRBCs in Wisconsin is 302,974 which ranks this state as eighth overall in terms of population and total households $(119,384)$. Census tracts bordering the Mississippi River within the Wisconsin MRBC's have a population of 121,233 (40 percent) with a total of 50,624 households (47 percent) that could be potentially at risk for flooding or be within the floodplain. Approximately 29 percent of these housing structures are rentals which creates greater vulnerability to hazard risk. There are two counties that have high poverty pockets (Crawford, 16.6 percent; LaCrosse, 31.1 percent) buffered against the river borders and these two most populated counties within the Wisconsin sample. Structures built in 1969 or earlier make up 44 percent of the housing stock.

\section{Iowa Characteristics:}

Iowa MRBC's have a huge vulnerability in the high level of poverty buffering the Mississippi River. The population of the Iowa counties within this study is 490,616 and total households equal 198,055 which ranks Iowa sixth overall in terms of population density but it has the highest percentage of population (90 percent) potentially within the floodplain and has the second highest population of all states within the potential floodplain area. Poverty pockets along the river range from 15.1 percent to 49 percent (Scott County) and include all counties with exception to Jackson County. The population within these census tracts totals 440,858 (90 percent) and is within a total of 177,101 households ( 89 percent) that are potentially at flood risk or within the floodplain. Rental housing makes up 27 percent of households. There are 105,642 
structures (60 percent) that predate 1969 and therefore are grandfathered into the NFIP program. These findings show that the overall housing stock is very dated along the river's edge.

\section{Missouri Characteristics:}

Missouri ranks second in total population density in MRBCs (population 1,909,143) and a total of 748,535 households. There are potentially 189,894 people (10 percent) at risk of being in the floodplain (72,483 households) in the counties bordering the Mississippi River in Missouri. Some census tracts that buffer the edge of the river have high poverty pockets such as St. Louis County (16.35 percent), New Madrid (17 percent), Pemiscot (20 percent), Cape Girardeau (29 percent), and Ste. Genevieve (64 percent). Rental properties make up 25 percent of the housing stock and 40 percent of the housing stock was built before 1969.

Most interesting about Missouri is that while this state has the second largest population in this study, it has the second lowest population rate (10 percent) within the potential floodplain area. Missourians, given the proper resources, can potentially further reduce their population within the floodplain.

\section{Illinois Characteristics:}

Census tracts bordering the Mississippi River in the MRBC's show high concentrations of poverty buffering the river. Ten counties have poverty levels of 21 percent to 65 percent with Alexander County being the highest, followed by St. Clair County with 50.3 percent. The housing stock is dated with 55 percent of these structures being built prior to 1969 . The population at risk of being within the floodplain is 177,454 (16 percent) out of an overall MRBCs population of $1,088,248$. The total amount of households within the Illinois MRBCs is 472,217 with 87,431 households (also 16 percent) potentially within the floodplain and 21 percent of these households are occupied by renters.

\section{Kentucky Characteristics:}

There are 17,764 people and 7,311 households which accounts for 71 percent of the total population/households $(25,064 / 10,356)$ within the census tracts bordering the Mississippi River 
in Kentucky making them potentially within the floodplain. These figures reflect a broad estimate of who might be in the floodplain given that census tract borders in lower populated counties cover far more terrain than those with higher population density. Kentucky has the lowest population density of all states within this study. Kentucky's border counties show poverty levels ranging from 13.2 to 24.2 percent but two of these counties have border census tracts with poverty levels six percent higher: Ballard County (13.2 overall; 19.6 census tract) and Fulton County ( 24.2 overall; 30.4 census tract). Rental housing in the bordering census tracts accounts for 20 percent of overall households with exception to Fulton County (38 percent). Over half the structures within census tracts bordering the Mississippi River were built prior to 1969 (51.4 percent) which is much higher than the overall average of the four counties (23 percent).

\section{Tennessee Characteristics:}

Nine census tracts border the Mississippi River in the five MRBC's and there is an overall higher poverty rate in some of these census tracts that should be noted: Shelby County (20.2 percent overall; 44 percent in census tract) and Tipton (14 percent overall; 21 percent in census tract). All of Lake County is included within the two census tracts reported and has a poverty rate of 30 percent (32.5 percent in one census tract). The counties overall have poverty ranging from $14-30$ percent which is rather high overall.

When looking at population density within these census tracts, there are potentially 30,565 people living within 10,557 households (three percent) that may potentially be within the floodplain. Rental units make up over 40 percent of this housing stock. In Shelby County, rental properties make up 67 percent of total households within the census tracts bordering the Mississippi River. Upon further inspection of the Shelby County census tracts bordering the river, one tract (CT 43) shows a very low poverty rate ( 5 percent) and the median household value is $\$ 80,000$ compared to the overall county average of $\$ 25,465$ suggesting that a more 
affluent community is pocketed within the riverfront. Approximately 25 percent of the housing stock within these census tracts was built prior to 1969 .

Overall, Tennessee has the lowest percentage population within the floodplain, however, Memphis, Tennessee (Shelby County) has a high density overall, thus Tennessee ranks fifth out of the ten states in terms of population. Therefore, this three percent is still a significant number of people (total population/household is $1,064,261 / 390,461$ ) potentially within the floodplain.

\section{Arkansas Characteristics:}

The population within the census tracts bordering the river totals 43,000 or 28 percent of the total population $(153,763)$. Findings show that this includes 15,000 households which is 26 percent of total households $(57,508)$ that may potentially be within the floodplain. Arkansas is the second lowest density state within the study sample.

The Arkansas MRBCs have a poverty rate of $25-32$ percent and there are concentrations of poverty within the census tracts bordering the river as high as 50.4 percent (Chicot County). Rental housing makes up 38 percent of the housing stock with exception to Phillips County (58 percent) and Mississippi County (59 percent) and approximately 10 percent of the housing stock was built prior to 1969 .

\section{Mississippi Characteristics:}

Mississippi MRBCs have a total population of 393,168 with a total of 142,445

households. The population within the census tracts bordering the river is 103,404 with a total of 38,629 households (27 percent) at risk of being within the floodplain. Mississippi MRBCs have a poverty rate of $23-38$ percent with poverty pockets within the census tracts as high as 51 percent (Washington County - CT 4). Rental housing makes up 39 percent of the housing stock with exception to higher rental percentages in Bolivar County (53 percent), Warren County (58 percent), and Washington County (66 percent). Seven percent of structures were built prior to 1969 which is rather low in comparison to other states/counties.

\section{Louisiana Characteristics:}


Louisiana's 16 parishes have a poverty rate ranging from 11 (Ascension, Plaquemines) to 45 percent (East Carroll). However, to further explore at the census tract level bordering the Mississippi River, Ascension Parish (11 percent) has a 35 percent poverty rate buffering the river. The actual county poverty rate hides the higher poverty pockets buffered against the Mississippi River and this pattern is very predominant in Louisiana: East Baton Rouge Parish (18.5 - 56.4 percent); Jefferson (15 - 44 percent); Pointe Coupee (19 - 37 percent); St. James (16 - 41 percent); St. John the Baptist (16 - 30 percent).

The total population within these census tracts bordering the Mississippi River and potentially within the floodplain is 703,672 , with a total of 264,442 households. The population in the floodplain represents 43 percent of the total Louisiana parish population/households $(1,636,976 / 625,118)$. While Louisiana ranks third overall in terms of total population, it has the highest number of population/households potentially within the floodplain. Of these households over 94,000 or 36 percent are rental properties and 46 percent $(122,223)$ total households built prior to 1969. The highest pockets of rental housing are found within census tracts in East Baton Rouge Parish (99 percent); Jefferson Parish (99 percent); West Feliciana Parish (84 percent); Plaquemines Parish (78 percent); and Orleans Parish (72 percent).

\section{Summary analysis of social characteristics}

In the overall Arc GIS analysis (see Figures 5.5 through 5.84) there are several concerning factors to consider. This analysis shows the potential population and households at risk in the floodplain (Table 5.42) in each state. Potentially 22 percent of all households $(896,806)$ within this study are near or within the floodplain (Table 5.42) Louisiana $(703,672)$, Minnesota $(437,001)$, and Iowa $(440,858)$ all have nearly double the amount of people potentially in the floodplain (Table 5.42) in comparison to the other seven states within the study. In terms of percent of population and households within the floodplain in each county (108) analyzed, those ranked in the top three are: Iowa (89 percent), Kentucky (71 percent), and Louisiana (43 percent). 
Other interesting trends in housing demographics include median household incomes (Figures 5.55 - 5.64) are much lower and more prevalent in the middle to southern region and all urban areas regardless of region. The greatest volume of dated housing (Figures 5.75 - 5.84), such as those units built in 1969 and or before (grandfathered into the NFIP), are actually in the north and upper middle regions of the river. The most dated housing density is located in Iowa and Illinois and within urban centers such as the Quad City area and Minneapolis/St. Paul Minnesota. In the southern region, dated housing exists primarily in urban centers such as St. Louis, Missouri; Memphis, Tennessee; and Baton Rouge, Louisiana with exception to a few areas along the Arkansas border and upper Louisiana.

Those who rent property within the floodplain are also more vulnerable to disasters. Over 30 percent of properties located within the floodplain are rental units. In some places this number goes as high as 99 percent (East Baton Rouge Parish). Rental households trend higher in the southern region, the top ranking states with high rental volumes are Louisiana, Mississippi, and Tennessee.

When looking at poverty in these counties overall, there is a higher concentration of poverty bordering the river (Figures $5.5-5.14$ ). These pockets of poverty range upwards of 50 percent in most cases and can go as high as 65 percent in some areas. The most concerning are the following: Illinois (65 percent), Missouri (64 percent), Arkansas (59 percent), (Louisiana (56 percent) and Minnesota (56 percent).

Overall, the ArcGIS analysis shows that white poverty (Figures 5.15 - 5.24) has a high prevalence in the south and urban areas with a large pocket present specifically in Baton Rouge, Louisiana. Black poverty (Figures $5.25-5.34$ ) is more widely distributed with higher density in urban areas and south, but also much higher on the Illinois side of the Quad Cities.

Elderly populations (Figures $5.45-5.54$ ) are significantly distributed in the upper and middle regions bordering the Mississippi River and in the southern region along the Arkansas border and within Louisiana. There are greater pockets of elderly (Figures $5.35-5.44$ ) within 
Quad Cities, Memphis, Baton Rouge and New Orleans. High concentrations of elderly poverty (Figures $5.35-5.44$ ) can be found in the most southern region of Louisiana at the tip of the Bird's Foot; along the entire border of the State of Mississippi; and within counties bordering the river in upper Louisiana. Other elderly poverty pockets are also concentrated in urban areas such as Rock Island, IL; St. Louis, Missouri; Memphis, Tennessee; Baton Rouge and New Orleans, Louisiana.

Ultimately, Arc GIS analysis shows that urban areas have the highest density for social vulnerabilities but potentially the greatest value of this analysis is the revelation of pockets of vulnerabilities that would otherwise be undetected. As more data becomes available at the census tract and block level, this tool will prove beneficial to exposing more hazard vulnerabilities and provide a more comprehensive analysis.

\section{Overall vulnerability summary}

In the 2000 to 2010 period following the DMA (2000) mandates for mitigation planning, this study shows Wisconsin, Iowa, and Mississippi had the most disaster declarations within the sample of this study. Therefore, flooding events occurred most often within these three states. The highest flooding costs were attributed to Minnesota, Wisconsin, and Tennessee (Table 5.5). Also troubling here is that the cost of flooding per event was much higher in these same states; and property damages costs per event were upwards of three to five times higher in comparison to other states in the study. The majority of these costs can be attributed to the four Minnesota counties of Houston, Wabasha, Winona, Wright; Wisconsin counties of Crawford, Vernon, Grant, LaCrosse; and Shelby and Tipton counties in Tennessee. In terms of populations within the floodplain, the states of Iowa, Kentucky, and Louisiana have the highest concentrations. These attributes - highest number of flood events, highest cost per event, and population within the floodplain, are strong indicators for concern.

This study also concludes that despite DMA (2000) mandates for hazard mitigation, the cost of flooding has continued to rise. In addition, regardless of engaging in both structural and 
non-structural mitigation, these costs continue to increase. There is low participation in federal programs associated with the DMA (2000) mandates with only 64 of 108 counties actually having mitigation plans. Furthermore, only nine counties actually participate in the CRS program. Out of 2,562 total mitigation actions identified in these 64 counties, 41 percent $(1,062)$ were related to flooding. That figure is rather impressive compared to state plans where the overall ratio of flood actions to all other actions was 25 percent. One very disturbing observation was that less than one percent of all mitigation plans considered mitigation actions related to the private sector.

Most mitigation actions listed within the mitigation plans are unfunded. Basically this is a list of action items that are nothing more than a wish list unless an actual disaster occurs prompting the federal government to make appropriates for these needs. Counties that do not have mitigation plans are not supposed to receive any federal funds. The main findings from the content analysis determine two things: 1) where local officials have focused their efforts on mitigation and 2) where they intend to seek funding. Structural mitigation is very high on their priority list as was observed by White (1945). Local officials also believe that the federal government is the primary resource for funding along with a small match by local governments. Non-structural mitigation actions are expected to be funded by both federal and state government when it comes to things such as technology support and education and outreach. Otherwise, nonstructural mitigation efforts appear to fall in line with regular duties assigned to the local emergency manager's office.

Mitigation needs within the scope of the study varied according to region. The most alarming needs that should be addressed are those actions related to warning improvements, evacuation and shelter planning, and creating emergency response plans (Wisconsin, Iowa, Illinois, Mississippi). There is demand across the board for infrastructure repairs such as road elevation, culvert alteration, bridge repair, levee, and floodwall improvements. There are needs based on regions from the top to the bottom of the river. The northern region needs warning and response capabilities; the middle region needs resources to move structures out of the floodplain 
and funding to build retention ponds and reservoirs; and the lower southern region has a demand for structure retrofits and pumping stations.

Finally, Arc GIS analysis shows a considerable percentage of people near or within the floodplain, especially in Minnesota, Iowa, Kentucky, and Louisiana. This analysis shows more poverty overall lower household median incomes in the urban areas and lower Mississippi River regions. There are high poverty pockets on the river edge that are concealed from analysis by overall county rates. There are also significant populations of elderly and poor elderly along the river edge that should be caution for emergency planning. Arc GIS analysis of social vulnerability risk provides a missing piece of the overall risk analysis. 


\section{CHAPTER SIX}

\section{CONCLUSIONS}

Do these findings provide support for the original research question: Is there evidence that growth machine dynamics continue to render the federal flood control system ineffective? Secondly, despite implementing both structural and non-structural mitigation does the cost of flooding continue to rise?

This study does provide evidence that growth machine dynamics are negatively impacting mitigation efforts within the federal flood control system; and despite both structural and non-structural mitigation, the cost of flooding continues to rise. Kathleen Tierney (2010) argued that since the 1990s disaster research has started to shift from sociology's systems theory or functionalist paradigms toward growth machine theory as the "unifying theoretical paradigm". This study actually suggests that growth machine dynamics were evident in flood control far earlier than we realize. Harvey Molotch (1997) coined the term "growth machine" to describe the relationship between local elites and officials where their motivation is to consistently attempt to draw large revenues into the community to create growth-inducing projects that will general more profit and revenue for elites and political coffers regardless of whether it is actually good for the community. It is easy now to identify what Gilbert White (1945) was referring to as the "status quo" as actually growth machine dynamics in play.

Growth machine theory incorporates the element of political power and issues such as disparity and inequality as it relates to political power influence on the construction of disaster (Tierney, 2010). Freudenburg et al. (2009) argue that growth machine behavior is actually fostered at the federal level and has become a "politically legitimated process" resulting in a 
"circular evasion of responsibility" and creates a problem of concentrating the benefits and spreading risk among the unwitting population.

In this study we see various examples, not only through the historical development and focusing events that created path dependencies but in the policy mandates themselves. American culture grew from the belief in manifest destiny which is heavily steeped in exceptionalism and expansionism. From the beginning, the way we altered the river and its natural environment is evidence of growth machine dynamics in play. Steamboat development accelerated this process through river erosion, a result of cutting timber to fuel steamboats and then to prevent timber snags during navigation.

Early settlers brought with them the European practice of using levees to protect their land from flooding. However, levees alone were no match for the Mississippi River. What is true in growth machine dynamics presently was also true in early development, there were no limits and many errors made related to incompetence in river hydrology and engineering. As settlement grew and experiments in navigation continued, demand increased for a centralized system of flood control. A federal system for flood control (Project Flood) was then realized after the devastating flood in 1927.

Project Flood was structurally designed to protect against flooding equal to one foot higher than any previous flooding occurrence. Along with this mandate, the federal government exempted itself from any potential legal action related to structural failures. The legislation was paramount to the progression of growth machine dynamics and principal evidence in explaining how growth machine theory becomes the predominant theory providing explanation for how political power serves as the dynamic force that ultimately explains disaster as a social construct (Tierney, 2010). Political power is the force that creates the system, and is a force on or input to the system; it operates as a force within and between subsystems; and it also impacts outputs and feedback that becomes further input. The political power of the growth machine weakens systems theory explanations. 
In 1945, Gilbert White then observed growth machine processes in play as he claimed the flood control system was designed based on the "preservation of the status quo"-- through processes such as dirt moving, structural fixes, and grants/aid (White, 1945, 209). White (1945) found that as funding increased for structural mitigation, so did the cost of flooding. Perrow (2007) further charges growth machine actors as being profiteers from disaster. White's (1945) influence on non-structural mitigation policy was manipulated by growth machine actors to result in a "patchwork of disparate programs" (Moss, 1999, 321); thus, costs continued to increase. Increasing costs could then be attributed to the myriad ways in which growth machine actors gamed the system, especially through the NFIP.

Mitigation planning mandated by DMA 2000 has become a tool to perpetuate "growth machine" dynamics. These plans are designed explicitly to maximize funding opportunities from the federal government on high dollar structural projects. This study concluded that cost of flooding continues to increase despite the creation of all-hazard mitigation plans mandated through DMA 2000; and even more shockingly, findings indicate flood costs have increased as a result of mitigation plan mandates. Counties with mitigation plans report more flood costs than counties without mitigation plans perhaps because they are in compliance with mandates for mitigation funding. Compliance mandates potentially create conditions where localities may over-report in order to generate more funding. If disaster strikes in counties without mitigation plans, they are dependent on media attention which generates disaster sympathy phenomenon from the general public. In turn, this behavior generates federal leniency and emergency aid appropriations. The "status quo" is that congressional representatives will respond quickly to provide aid or they will experience negative exploitation if they vote against emergency appropriations.

Disaster aid as a result of political manipulation creates another example of a moral hazard, a condition where localities behave in a more risky manner and expect all federal taxpayers to incur the cost. Even counties with mitigation plans are engaging in behavior that 
creates a moral hazard; as substantiated in this analysis - there are low participation rates in federal programs (CRS, NFIP) designed to reduce flood risk and flood costs.

Speaking of lower participation rates in these federal programs, consider what is in the guidance of the DMA 2000 on mitigation planning as it relates to the NFIP. Within the plans themselves, the circular pattern of evasiveness is evident. For example, what actually happens when the local mitigation plan states as a non-structural action "promote the NFIP program"? They guide citizens to the FEMA website on the NFIP and flooding where they are directed to call their local insurance provider for all information regarding this matter. Here they fall into the trap of the NFIP and WYO program.

As Keiserman (2015) testified before Congress, the Write Your Own (WYO) program had created a scenario where insurance companies were drawing a 33 percent fee against every premium dollar that was paid into the NFIP program. They profited even further on the back end drawing more fees in claims settlements. Then, the WYO program was not finished here with egregiously frauding customers. These folks were actually paying the NFIP to provide millions of dollars in legal defense for insurance companies in their fraudulent claims denials (Keiserman, 2015). Generating participants for the NFIP program resulted in profitability for elite insurance corporations both at policy creation and then again during the claims period should disaster occur. The benefit falls largely on these corporations while the program participants invest to cover risk and then struggle to collect enough return to restore their property. The disaster impacts and lengthy claims process eventually produces far more losers than winners. This non-structural federal mitigation initiative is faulty by design yet continues to be a major component in mitigation.

As reiterated throughout this study, mitigation plans are very steeped in taking actions related to structural fixes of which White (1945) cautioned were not actually addressing the flooding problem. High dollar projects such as levees and floodwalls are strongly coveted by primary growth machine actors-- local officials and elites. Nowhere in the foreseeable future do 
we see any suggestion that policy guidance in the United States might be strengthened to provide for greater security in structural designs beyond the 50/50 chance of failure (Freudenburg et al., 2009). Given the federal government cannot be held liable (as established in the Flood Control Act of 1928) we continue to throw money at projects designed to fail and provide a false sense of security to residents.

\section{Reform Federal Mitigation "All-Hazard" Planning}

Local hazard mitigation plan actions, in general, are primarily focused on emergency response actions; and then, specific to flooding, they are concerned primarily with funding and structural mitigation or dirt moving/land adjusting projects. What is most concerning is that, even 71 years after White (1945) addressed poor performance in emergency response; there are still inadequacies in emergency response planning. There are six items identified within local mitigation plans that specifically focus on the need to develop emergency response plans and establish first responders. There were ten items requesting improvements to/or the development of warning systems. There are 19 items focused specifically on the need to develop emergency evacuation and sheltering plans. This need is primarily based in the upper Mississippi region and specifically, counties within Wisconsin, Missouri, and Illinois. A serious concern here is that, even though these plans go through an approval process at the state and federal level, there is no oversight process that would alert the state or federal government to quickly dispatch aid to resolve this immediate need.

This study, focused specifically on flood mitigation within the local hazard mitigation plan, also exposes potential weaknesses within the planning process. As stated previously, the State plans have actions that are basically painted in very broad strokes. Therefore, one would expect that local plans would be far more detailed and specific. In conducting the content analysis of these plans, it became clear that the low quality of local mitigation plans offer support to previous research findings especially Lyle et al. (2012) in terms of wide variability and weaknesses in organizing principles. 
Intriguingly, though, this analysis led to further consideration of the all-hazards approach to mitigation planning and its effectiveness. It appears the "all-hazards approach" to mitigation is inherently flawed in that while it guides the planning process toward commonalities, it creates the dilemma of moving it away from identifying and addressing needs that are hazard specific. These conditions create a state of aporia where the closer one moves toward one goal, the farther he moves from another equally important goal (Boin and Nieuwenburg, 2011). The result is an irresolvable contradiction that impedes effective comprehensive planning. There is a problem of bounded rationality at the federal level in creating an "all-hazard" model guideline and then placing a planning mandate at the local level as a matter of frontline discretion. Boin and Nieuwenburg (2011) explains how mandating a plan from the higher level creates "hard to predict" outcomes. In this case, the federal government lacks the information to create feasible plans and prioritize conflicting goals and create feasible terms. Rather the federal government is quite ambiguous in establishing directives and providing feedback beyond addressing commonalities. Lacking specificity, we have problems such as states and local governments not implementing land-use planning that would effectively eliminate dangerous development within the floodplain. Local planning officials tend to write plans geared toward federal funding opportunities which are steeped in ambiguity and lacking feasibility—basically it is a "wish list". State guidance is also quite ambiguous and they basically play an interceding or mediating role between the federal and local government.

The most glaring problem is there is no process during the mitigation plan approval stage where the state or federal government should be accountable to address immediate needs for emergency response action items. If a county declares they have no emergency response plan, no means to organize emergency responders, no evacuation plan, no sheltering plan, or no warning system, it should invoke an immediate response from the federal and state government followed by an expedited resolution. Here is where the top-down centralized approach to mitigation becomes flawed. If the county does not have a mitigation plan, the state should be accountable to 
the federal government via their mitigation plan approval. The "all hazards" mitigation plan crafted by the state should reflect analysis of each risk reported by counties and an analysis of mitigation need reported by each county. Thus, in addition to top-down directives for local "all hazard" mitigation, the federal government should employ a procedure where the assessment results in a bottom-up assessment that guides the state and federal government on mitigation needs and planning.

This study refutes Lindell and Perry's (2007) claim that all-hazard mitigation is the most effective and efficient. The findings within this study suggest that "all-hazard" mitigation planning directives from the federal government need to provide more regional specificity and improved standardization. Emergency response capabilities, which primarily address commonalities, should be designated as a stand-alone section which would indicate risks or shortages to capabilities followed by mitigation actions to alleviate this risk. Each hazard risk should have a section regarding risk evaluation followed by a mitigation action plan. This practice allows the planning community to focus more specifically on each primary hazard risk and assess what resources and capabilities are on hand for this specific risk and what is needed specifically for managing this hazard impact. These suggestions provide a remedy for Caruson and MacManus's (2011) concerns regarding commonality theory and commonality as the primary organizing principle. It is highly likely that over time, a consistent set of best practices for each hazard would be tethered out from this process and captured through the process of top down and bottom up feedback.

Action items should be further evaluated to determine priority level and cost. Each action item should have a strategic plan proposal and itemized cost analysis. The state "allhazard" mitigation plans should then be designed from a bottom-up assessment of county needs and provide regional specificity. Federal "all-hazard" plans should then identify need by region, establish response priorities, and direct mitigation appropriations to the appropriate regions. This new mitigation planning approach would allow for a continuous dynamic process of reporting 
and feedback, thus incentivizing local and state governments to monitor their need more diligently in order to influence federal priorities. The regional specificity element moves state and federal governments to address hazard risk regionally, thus avoiding the pitfall of equity distributions over efficiency distributions of funding.

It was very clear within this analysis that flood mitigation needs had both commonalities and differences based on regional location. All counties showed needs for road repairs and elevation; culvert alterations; bridge repairs/alterations; and levee and flood wall improvements. Specific to the southern region of the river is a need for structure retrofits, and specific to Louisiana there is a need for pumping stations. The middle river region has a demand for moving buildings out of the flood plain, retention ponds and reservoirs; and the upper region needs to develop their emergency response plans, warning improvements and evacuation/sheltering assistance. Effective mitigation, then, at the federal level, would be to focus on directing mitigation funding to the critical regions first for items that will significantly improve flood disaster outcomes.

\section{Nonstructural Mitigation and Federal Programs}

Digging deeper into the content analysis and evaluating the state role in mitigation planning, their action strategies are focused primarily on providing nonstructural mitigation in the form of administrative and technical support to counties. State mitigation plans overall are focused on promoting awareness of the NFIP, the CRS, and identifying and addressing repetitive loss properties. Their method of promoting these federal programs is to direct the local government to develop education and outreach initiatives on these topics or develop their own ideas of addressing these topics. The directives follow a centralized top-down approach but they are not accompanied by funding appropriations.

For example, the federal government says promote the NFIP, the state government says promote the NFIP, and then the local government says promote the NFIP. From the content analysis, it was very clear that there was a need for education and outreach development. 
However, what should a NFIP education and outreach initiative require? Reverting to federal guidance, the primary strategy is to refer the individual to their local insurance agent so the local insurance agent can provide this service. As the Hurricane Sandy saga continues over the WYO program and lack of oversight within the NFIP administration, this is a real conundrum. State and local governments both agree that NFIP promotion needs to be addressed. The federal government's public-private partnership with the insurance industry basically disconnects the state and local government from the process. This ambiguous directive from the federal government for NFIP promotion results in a circular directive where no action actually occurs.

\section{Reform or Revoke the National Flood Insurance Program}

Biggert-Waters Flood Insurance Reform Act provided for necessary changes in the NFIP that brought flood insurance policy premiums closer to their true cost of risk and would make the program solvent. It allowed for certain circumstances to trigger the removable of discounted rates for grandfathered properties. When claims reached a certain level of market value (50 percent), the homeowner would need to either make structural retrofits or pay higher premiums.

Following Hurricane Sandy, there were so many properties meeting these criteria, the government balked at enforcing this legislation. In this case, the economic consequences would have been so severe, that these areas could not recover. Little did they know that systemic failures within the WYO program and the federal public-private partnership would ultimately create a comparable disaster.

The NFIP is now 47 years old and beyond its usefulness. The intent at this zeitgeist was to be equitable and provide affordable insurance through government subsidy for properties built prior to 1968. This intent did not arise without consideration to future target reduction planning. At some point moving toward efficiency should have been established as a goal in order to avert the moral hazard of concentrating the benefit and passing the high cost of subsidizing risk to all taxpayers. A roll-back in subsidized flood insurance is needed in order to bring local government in line with the federal mitigation initiatives. 
In 2007, U.S. Representatives Ginny Brown-Waite and Vern Buchanan proposed a National Catastrophe Insurance Program that would establish coverages against natural hazards for earthquake and hurricane prone residents and dissolve the NFIP into this plan. Critics argued that the same issues impacting the NFIP would just increase in scale and cost to the federal government. Ultimately this initiative was rejected. In the late 2000s Congress started to only approve short extensions for the NFIP and at times allowed the program funding to lapse. These changes prompted the private insurance industry to offer a Natural Catastrophe Insurance Program underwritten by affiliates with Lloyds of London to NFIP policy holders. Individual natural catastrophe insurance might be an attractive solution if the federal government would mandate all U.S. citizens to purchase a policy. In this scenario, each policy premium would be based on regional risk factors and the consumer could select additional coverages for relocation expenses, lost wages, and other miscellaneous expenses. A policy solution of this nature could potentially thwart the tendency for Congress to appropriate large sums of disaster relief money for individual needs. Instead, more money could be directed towards rebuilding infrastructure and post-disaster mitigation needs.

\section{Reform the Community Rating System Program}

There are very low participation rates within the Community Rating System program which was established along with the NFIP. Communities participating in the CRS program receive flood insurance discounts by retrofitting their flood prone structures and regulating landuse within the floodplain. The CRS has four different classifications or series, with 19 objectives total. Each mitigation action has a minimum and maximum point values range to be assigned for CRS credit to reduce insurance premiums. Class 10 is the lowest classification with points ranging from 0 to 499 and has no insurance discount. Insurance premium discounts begin at five percent in Class 9 and increase in five percent increments through to Class 1 (4,500 points, 45 percent discount). 300 series has seven objectives (maximum 981 points) addressing public information (e.g. elevation certificates, mapping information, outreach, hazard disclosure etc.) ; 
400 series has five objectives addressing floodplain mapping and regulation (5,841 points); 500 series addresses flood damage reduction $(4,692)$ which includes acquisitions, retrofits, drainage improvements and floodplain management planning; 600 series (790 points) has three objectives directed at flood preparedness which covers levee and dam safety and flood warning systems.

The CRS program is not popular within this study sample, there is little movement towards participation and those that do participate (nine counties total) have low classifications. There are several things to consider. First, are citizens who are required to have flood insurance unaware of CRS incentives? Second, do they lack the ability to collectively organize to move the local government to be more proactive? Do community leaders believe that meeting these objectives is not feasible? Further research is needed to determine why there are such low participation rates and why participating community ratings are heavily skewed towards the lowest classification levels.

The primary weakness of this program is incentivizing premium holders as a means to garner participation. Given that growth machine dynamics are in play, premium holders lack the power to be an effective change agent. Federal mitigation funding should be synchronized to the objectives within this program in order to effectively incentivize local communities and increase participation.

\section{Improve FEMA Nationwide Survey of Local Officials (NSLO)}

Looking at the FEMA NSLO (2013), the first concerning factor is whether or not the survey sample is truly representative of the nation or, even more specifically, flood risk communities such as the region of focus in this study. Secondly, 64 percent of respondents $(\mathrm{n}=$ 1,710) identified their jurisdiction to be rural communities thus skewing the results to represent small population centers. Third, 41 percent of these local officials fall into a category designated as "other", 34 percent are local emergency managers or floodplain managers, and 25 percent are mayors or city managers; therefore, the role of the local official for nearly half the study cannot 
be identified and qualified. Fourth, it is uncertain how many respondents actually came from the same community, therefore the summary data reported by FEMA may be confounded.

In this FEMA NLSO (2013) survey, three out of four local officials believe they have a flood risk in their community, yet only one in ten of these officials actually believe their community is at risk (FEMA, 2013). These local officials reported that only one in three of these communities actually have a FEMA approved mitigation plan in effect. This report does not distinguish the differences in results between communities with a plan and those without a plan.

Comparing the FEMA NLSO (2013) to this study, there were 108 total counties in this sample and 64 plans available for evaluation thus 59 percent of this region have mitigation plans in place. This study relies on the content analysis of these 64 mitigation plans to determine what the primary mitigation needs are for their communities. FEMA NLSO (2013) reported that the top five mitigation (structural) needs reported by local officials are building drainage improvements (52 percent), elevation (44 percent), erosion control (41 percent), acquisition (31 percent), and flood-proofing (26 percent). In this study, the top structural mitigation needs are 1) road repairs and elevation, 2) widening culverts, and 3) fixing sewers, 4) stabilizing banks, and 5) repairing or replacing bridges. In terms of what sort of support is needed from FEMA, the local officials reported 1) funding (73 percent), 2) technical expertise, 3) flood mapping, 4) planning assistance, and 5) outreach materials (FEMA NLOS, 2013). In this study, the top five nonstructural mitigation needs are 1) conducting studies, 2) promoting the NFIP, 3) debris maintenance/drainage funding, 4) repetitive loss (acquisition), and 5) policy remedies for floodplain management.

FEMA NLOS (2013) states that CRS participation is rising with 76 percent of respondents reportedly $(n=1,296)$ actively participating. However, looking at the Mississippi River border counties, less than eight percent or nine counties in three states are participating in the CRS program. States and counties in this study strongly agree that NFIP promotion needs to be addressed though it is not mentioned at all in the FEMA NLOS (2013). States and counties in 
this study appear very aware that state and local mitigation planning is limited without policy changes at the state and local level that will align them with the federal policies and programs. FEMA NLOS (2013) makes no mention of this need. There are commonalities between FEMA NLOS (2013) and this study; but a regional analysis such as this study does provide more insight.

Therefore, as stated earlier, a better way to evaluate the need at the local level is for the federal government to critically assess mitigation plans during the approval process and set their mitigation objectives from local mitigation plan data. Covington and Simpson (2006) noted there are two phases of planning that must be achieved- development and implementation. This study speaks to the problem that we are stuck within the first phase without a clear path to reach the second phase. If the federal government cannot effectively accomplish this, then its mitigation efforts will remain as problematic as herding kittens.

Clearly the greatest weakness in the way we do flood control is that policy makers only want to go so far as to recommend to local governments what they should do, but ultimately yield to local government to decide whether or not they wish to comply with these recommendations. Upon experiencing a flooding disaster, the status quo behavior of the federal government is a two-fold response. First, federal relief arrives based on the stipulations within flood policy. Secondly, federal relief arrives based upon public pressure on Congress and disaster sympathy phenomenon. Therefore, if the first relief is not sufficient because the local governments failed to be proactive, the second relief enables this behavior to continue.

\section{Mitigation Planning and Potential Social Vulnerabilities for Populations within the}

\section{Floodplain}

Results of this study indicate there is a potential for 22 percent of the population and nearly 900,000 households to be located within the floodplain. Even more concerning is the risk associated with high concentrations of poverty pushed up against the Mississippi River and a high volume of rental housing (30 percent). As noted by Cutter et al. (2000) risk assessment guidelines created by FEMA for all hazard mitigation plans does not include factors beyond 
presence or absence of natural hazard risk. Therefore, determinations about social vulnerability and factors that increase risk such as high poverty levels are not included in the planning process. This shortcoming alone usurps the aim of effective and comprehensive planning. Thus, the next question is: How can social vulnerability analysis be incorporated into all hazard mitigation planning?

The most recent iteration of Cutter et al.'s (2013) social vulnerability index (SoVI) would not be an effective tool for flood hazard mitigation planning given that the social and economic characteristics were evaluated by using county level data. The problem is that measuring socioeconomic characteristics at the county level may conceal concentrated pockes of social vulnerabilities that could negatively impact outcomes in flooding disaster. Even using census tract level data, which as not as robust as county level data, would be problematic because census tracts can be quite large in lower density rural areas. Despite this limitation (as noted within this study), mitigation planners are overlooking a source of vital information and a significant consideration in flood hazard risk. Local officials must incorporate social vulnerabilities in local hazard mitigation planning and it must be done in a manner that couples social vulnerability to different types of natural hazard risk.

The primary reason for coupling social vulnerability and natural hazard vulnerability is moving mitigation planning toward a better understanding of differential impacts on certain populations in response and recovery. For example, Clutter et al. (2010) points out, those communities that have a high volume of service industry employment are at greater risk given they are traditionally lower wage type jobs, and the businesses themselves are more vulnerable in recovery. Populations occupying rental housing often face greater constraints than traditional homeowners when it comes to being able to recover and resettle because they have greater dependency on affordable housing availability.

Secondly, those populations in poverty will often behave differently during a disaster threat and impact because their resources are more limited. It is important to consider how 
community emergency response capabilities, resources, and the population needs intersect. Areas with higher density or extreme poverty pockets would be more difficult to accommodate than other areas especially when it comes to evacuation. Local mitigation planners can be more effective if they have a greater understanding of their population. The all-hazard mitigation planning process, therefore, should include an evaluation of the social, economic, and house characteristics of their population.

Previously, Arc GIS software has been used by some mitigation planners to plot such things as critical infrastructure and building inventories owned by local governments. Arc GIS software offers even greater potentially to create an overall comprehensive assessment with the capability to add and subtract layers of data and perform analyses that were previously limited to Excel software. Not only can planners take stock of critical infrastructure and building inventories, it can also be used catalog the types of hazard risks. It also has the capability to allow the planner to assess social vulnerability characteristics with the Census Bureau and American Community Survey data. Mapping these characteristics would offer planners a comprehensive visual aid to detect problematic areas and further assess the need for resources or redistribution of resources. One of the most notable advantages of using Arc GIS for analysis is that a high volume of data can be organized and manipulated in a variety of ways to explore vulnerabilities. Furthermore, the increasing availability of Census and American Community Survey data gathered for census tract and block level is promising. In this study, the use of Arc GIS at a regional level helped provide greater insight to the differences between regions along the Mississippi River. It also exposed a pattern of social vulnerabilities being buffered against the river and hidden pockets that would likely otherwise go unnoticed.

\section{Future Research Recommendations}

Evaluating all-hazard mitigation planning through a content analysis method opens possibilities to look at the plans in a variety of ways and can offer valuable insights to improve mitigation planning. However, there are several challenges to this process. The plans are not 
easily obtainable and often previous plans are not available for comparison. FEMA directives for plan changes occur more often than the actual plan updates. Despite attempts by FEMA to direct these plans toward a more standardized format, they have such wide variation it is difficult to collect quantitative data. Plan quality is so low, that there will likely need to be several plan iterations and studies over the next decade to help improve this planning process.

Also missing from the planning process is a way to capture what this planning has accomplished. Once a project is completed, in most cases, it is removed from the next plan. If the plan could be designed as a living document, a register showing what has been completed would be useful for evaluation. Archiving completed work would allow us to make determinations about what has been addressed and whether or not these changes impact disaster costs. Specific to flood disasters, we may be able to determine what types of mitigation actions need to be repeated and within what time frame this should occur. We could also determine whether we are effectively balancing a healthy distribution of both structural and nonstructural flood mitigation actions.

There is an opportunity to look at these plans based on the "all-hazard" model and attempt to make determinations as to how useful or limiting this model may be. With the "allhazard" plan in mind, we can also make better determinations about how we are distributing mitigation resources based on the level of hazard risk. Does this model allow for better prioritizing of resources? At the other end of the spectrum, does this model run the risk of weakening the focus needed to comprehensively address hazard specificities?

Another research consideration should be whether there is a benefit to creating regional plans versus individual county plans. Not only might this be a more cost effective method, but also more collaborative. One of the most concerning issues regarding the mandate for mitigation plans is the lack of compliance. It would be interesting to explore this issue further to see if this is due to lack of funding, lack of planning expertise, or some other issue that prevents county participation. Secondly, it would be interesting to see how state oversight of this process may be 
improved. Would a regional planning process allow states to better assess mitigation needs and respond more efficiently with funding and resources?

One of the most useful practices in terms of non-structural mitigation is education and outreach and it appears that it would be useful for further study on this topic. What types of education and outreach methods as a non-structural mitigation strategic action is effective? How can local emergency management be more effective in reaching out to the population to prepare them for hazard threats? Are the plans that specifically mention education and outreach in broad terms actually achieving deliverables? What are these deliverables? What are the most feasible methods?

Finally, one of the most concerning discoveries in this research is the fact that the population, socio-economic and housing characteristics are missing in the risk assessments in all all-hazard mitigation plans. In order to respond better to hazard threats, it seems that knowing exactly what issues and challenges within the population may impede effective mitigation and emergency response. Does the population in the area change (increase or decrease) during day shift working hours? Does the housing stock appear to be resilient? What is the ratio of special populations? What about the pet population? Does the region have a plan to manage for pets in the event of an evacuation, sheltering, or extraordinary need for medical support? What are the local business characteristics and what vulnerabilities exist here? These are the sort of questions that should be addressed in mitigation planning and more research is needed to explore opportunities for more comprehensive planning. 


\section{REFERENCES}

Adams, G. \& Balfour, D. (2014). Unmasking Administrative Evil. Taylor \& Francis: New York, NY.

American Society of Civil Engineers (2009). So You Live Behind a Levee!: What You Should Know to Protect Your Home and Loved Ones from Flood. Bklt Edition.

Ball, R. (1978). Sociology and General Systems Theory. The American Sociologist. 13(1). 65-72.

Barry, J. (1997). Rising Tide: The Great Mississippi Flood of 1927 and How it Changed America. Simon \& Schuster: New York, NY.

Barrett, J. \& Brat, I. (2011). Missouri to Appeal Levee Ruling. Wall Street Journal (Online) Retrieved November 17, 2011 from http://proquest.mi.com/pqdweb? index $=18 \&$ sid $=1 \&$ vinst $=$ PROD \&fmt $=3 \&$.

Bates, F. \& Pelanda, C. (1994). An Ecological Approach to Disasters. In Russell R. Dynes and Kathleen J. Tierney (Eds.) Disasters, Collective Behavior, and Social Organization. Cranbury, NJ: Associated University Presses.

Berke, P. \& French, S. (1994). The Influence of State Planning Mandates on Local Plan Quality. Journal of Planning Education and Research. 13, 237.

Berke, P., Crawford, J., Dixon, J. \& Ericksen, N. (1999). Do cooperative environmental Planning mandates produce good plans? Empirical results from the New Zealand experience. Enviroment and Planning B: Planning and Design. 26: 643-664.

Berke, P. \& Campanella, T. (2006). Planning for Postdisaster Resiliency. The ANNALS of the American Academy of Political and Social Science. 604: 192-207.

Berke, P., Smith, G. \& Lyles, W. (2009). State Hazard Mitigation Plan Evaluation and Model Practices: Analysis of Federal Mitigation Policy in the U.S.: Mitigation Plans, Expenditures, Civic Engagement, and Local Capacity. Center for the Study of Natural Hazards and Disasters, Department of Homeland Security Center of Excellence - Disasters, Coastal Infrastructure, and Emergency Management, Institute for the Environment, and Department of City and Regional Planning at the University of North Carolina at Chapel Hill, Chapel Hill, NC. 
Bertalanffy, L. (1950). An Outline of General Systems Theory. British Journal of the Philosophy of Science. 1. 134-165.

Biggert Waters Flood Insurance Reform Act of 2012. Public Law 112-141.

Boin, A. (2005). From crisis to disaster: Towards an integrative perspective. In R. W. Perry \& E. L. Quarantelli (Eds.), What is a disaster? New answers to old questions. (pp.153-172). Philadelphia: Xlibris.

Boin, A. \& 'tHart, P. (2006). The Crisis Approach. In H. Rodriguez, E. L. Quarantelli, \& R. Dynes (Eds.), (pp. 42-54) Handbook of Disaster Research. New York, NY: Springer Science + Business Media, LLC.

Boulding, K. (1956). General Systems Theory; the skeleton of science. Management Science. 2(3). 56-68.

Branston, J and Finn, K. (2011). Mississippi River flood passes record at Natchez retrieved May 15, 2011 from http://www.reuters.com/article/2011/05/11/usflooding.

Brody, S. (2003). Are We Learning to Make Better Plans?: A Longitudinal Analysis of Plan Quality Associated with Natural Hazards. Journal of Planning Education and Research. 23(2). 191-201. Retrieved from jpe.sagepub.com at Univ of Louisville August 21, 2013.

Brody, S., Carrasco, V. \& Highfield, W. (2004). Measuring the collective planning capabilities of local jurisdictions to manage ecological systems in southern Florida. Journal of Planning Education and Research. 25. 294-310.

Burby, R. (2006). Hurricane Katrina and the Paradoxes of Government Disaster Policy: Bringing About Wise Governmental Decisions for Hazardous Areas. The ANNALS of the American Academy of Political and Social Science. 604. 171-191.

Burby, R. \& French, S. (1990). Sharing Environmental Risks. Boulder, CO: Westview Press.

Burby, R., Beatley, P., Berke, R., Deyle, S., French, D., Godschalk, E. Kaiser, J., Kartez, R., Patterson, R., \& Platt, R. (1999). Unleashing the Power of Planning to Create Disaster-Resistant Communities, Journal of the American Planning Association, 65(3): 247-258.

Burton, I., Kates, R., \& White, G. (1978). The environment as hazard. New York, NY: Oxford University Press.

Burton, I. \& Kates, R. (1964) The perception of natural hazards in resource management. Natural Resources Journal. 3. 412-441. 
Campanella, R. (2010). Delta Urbanism. Washington, D.C.: The American Planner Association.

Caruson, K. \& MacManus, S. (2011). Gauging Disaster Vulnerabilities at the Local Level: Divergence and Convergence in a "All-Hazards" System. Administration \& Society 43: 346-371.

Changnon, S. (1996). The Great Flood of 1993: Causes, impacts, and responses. Stanley Changnon (Ed.). Boulder, CO: Westview Press, Inc.

. (2009). The Historical Struggle with Floods on the Mississippi River Basin. Water International. 23(4). 263-271.

Chen, D. \& Stroup, W. (1993). General Systems Theory: Toward a Conceptual Framework for Science and Technology Education for All. Journal of Science Education and Technology. 2(3). 447-459.

Collier, D. \& Collier, R. (1991). Shaping the political arena: critical junctures, the labor Movement, and regime dynamics in Latin America. Princeton, NJ: Princeton University Press.

Covington, J. \& Simpson, D. (2006). An Overview of Disaster Preparedness Literature: Building Blocks for an Applied Bay Area Template. Center for Hazards Research and Policy Development. Working Paper 06-02.

Cutter, S., Mitchel, J. \& Scott, M. (2000). Revealing the Vulnerability of People and Places: A Case Study of Georgetown County, South Carolina. Annals of the Association of American Geographers, 90(4). 713-737.

Cutter, S., Boruff, B., \& Shirley, W. (2003). Social Vulnerability to Environmental Hazards. Social Science Quarterly, 84(2), 242-261.

Cutter, S., Emrich, C, Morath, D. \& Dunning, C. (2013). A Method for Including Social Vulnerability into Flood Risk Management Planning. Flood Risk Management. 6(4): 332-344.

Daniel, P. (1977). deep'n as it come: The 1927 Mississippi River Flood. New York, NY: Oxford University Press.

Day, J. \& Boesch, D. et al (2007). Restoration of the Mississippi Delta: Lessons from Hurricane Katrina and Rita. Science, 315 (5819), 1679-1684.

Disaster Mitigation Act of 2000. Public Law 106-390.

Easton, D. (1979). A Framework for Political Analysis. University of Chicago Press. 
Chicago, IL.

Elazar, D. (1966). American federalism. New York, NY: Harper \& Row.

. (1994). The American mosaic: The impact of space, time, and culture on American Politics. Boulder, CO: Westview.

FEMA (2004). Multi-Hazard Mitigation Planning Guidance Under the Disaster Mitigation Act of 2000 (Blue Book). Washington, D.C. . (2008). Multi-Hazard Mitigation Planning Guidance Under the Disaster Mitigation Act of 2000 (Blue Book). Washington, D.C.

. (2011). A Whole Community Approach to Emergency Management: Principles, Themes, and Pathways for Action. Washington, D.C.

. (2014). Local Official Survey Findings on Flood Risk. Retrieved February 21, 2015 from https://www.fema.gov/local-official-survey-findings-flood-risk.

. (2015). What is Mitigation? Retrieved from https://www.fema.gov/whatmitigation

Flood Control Act of 1928. Seventieth Congress Digest 46, 1928.

Frank, T. (2011). Changes Urged in Flood Control: Designed to protect, system is destroying. USA Today. Retrieved November 17, 2011 from http://web.ebscohost.com.

Fremling, C. (2005). Immortal River. Madison, WI: The University of Wisconsin Press.

Freudenburg, W., Gramling, R., Laska, S. \& Erikson, K. (2009). Catastrophe in the Making: The Engineering of Katrina and the Disasters of Tomorrow. Washington, D.C. Island Press.

Gay, M. (2011). Levee Breach Moves One Step Closer. NY Times (Online). Retrieved June 10, 2011 from http://www.nytimes.com/2011/05/01/us/01flood.html.

Gerencer, T. (2015). U.S. Floods Cost \$34 Billion - Money Nation. Retrieved February 12, 2016, from http://moneynation.com/u-s-floods-cost-34-billion/.

Gibbons v. Ogden. 22 U.S. 1 (1894).

Gibbs, K. (2004) Mississippi River and Tributaries Project. Army Corp of Engineers retrieved June 6, 2011 from http://www.mvn.usace.army.mil/pao/bro/mrc_mrc map.gif. 
Godchalk, D., Beatle, T., Brower, D. \& Kaiser, E. (1999). Natural hazard Mitigation: Recasting disaster policy and planning. Washington, D.C.: Island Press.

Hall, B. \& Wood, C. (1992). Big Muddy. New York, NY: Penguin Group.

Houck, O. (2011). Floodway into the Atchafalaya Basin Saves New Orleans. Nola.com Retrieved May 6, 2011 from http://www.nola.com.

Hasten, M. (2011). Coast Guard, EPA search for Pollution. The News Star.com. Retrieved June 6, 2011 from http://www.thenewsstart.com/aritcle/201105.

Heller, P. (2011). The Mississippi River Flood and the Katrina Risk. Bloomberg Businessweek Magazine. Retrieved from the internet June 09,2011from http://www.businessweek.com/magazine/content/11_25/b4233068017336.htm.

Homeowner Flood Insurance Affordability Act of 2014. Public Law 113-89.

Johnson, C. (1976). Political Culture in American States: Elazar's Formulation Examined. American Journal of Political Science. 20(3). 491-509.

Kang, J., Peacock, W., \& Husein, R. (2010). An Assessment of Coastal Zone Hazard Mitigation Plans in Texas, Journal of Disaster Research. 5(5): 520-528.

Keiserman, B. (2015). The National Flood Insurance Program: Oversight of Superstorm Sandy Claims. Statement of FEMA Deputy Associate Administrator for Federal Insurance to Committee on Financial Services. Retrieved from: https://www. fema.gov/media-library-data/1434230264592-556e64c75275ca5acc56c6956 f8adb30/NFIP-Sandy-Claims-Testimony-6-2-15.pdf.

Kelman, A. (2006). A River and Its City: The nature of landscape in New Orleans. University of California Press: Los Angeles, CA. . (2009). Even Paranoids Have Enemies: Rumors of levee sabotage in New Orleans's Lower 9th Ward. Journal of Urban History. 35. 627-639.

Klein, C. \& Zellmer, S. (2007). Mississippi River Stories: Lessons from a century of unnatural disasters. College of Law, Faculty Publications Paper 12. Retrieved December 10, 2011 from http://digitalcommons.unl.edu/lawfacpub/12.

Kruse, J. (2004). Testimony on the Value of Mississippi River for U.S. Agriculture. FAPRI-UMC Briefing Paper \#06-04. Mississippi River Caucas, Washington D.C.

Larson, L. (1996). The Great USA Flood of 1993. NOAA/National Weather Service. Retrieved December 10, 2011 from http://www.nwrfc.noaa.gov/floods/papers/ oh_2/great.htm. 
Liebowitz, S.; Margolis, Stephen (2000).Encyclopedia of Law and Economics. p. 981.

Lieske, J. (1993). Regional subcultures of the United States. Journal of Politics. 55. 888913.

. (2010). The Changing Regional Subcultures of the American States and the Utility of a New Cultural Measure. Political Research Quarterly. 63(3). 538-552.

Loyola University (2011) American's Wetland Resource Center. Retrieved December 10, 2011 from http://www.americaswetlandresources.com/_facts/detailedstory/ mississippiformd.html.

Lindell, M. \& Perry, R. (2007). Planning and preparedness. In W.L. Waugh Jr. \& K. Tierney (Eds.), Emergency management: Principles and practice for local government. $2^{\text {nd }}$ ed., Washington, DC: ICMA Press.

Little, R. (2010). Controlling Cascading Failure: Understanding the Vulnerabilities of Interconnected Infrastructures. Journal of Urban Technology. 9(6). 109-123.

Lyles, W., Berke, P. \& Smith, G. (2012). Evaluation of Local Hazard Mitigation Plan Quality. Center for Sustainable Community Design UNC Institute for the Environment, Coastal Hazards Center, DHS Center of Excellence-Natural Disasters, Coastal Infrastructure and Emergency Management. University of North Carolina at Chapel Hill.

MacDonald, N., Chester, D., Sangster, H., Todd, B. \& Hooke, J. (2012). Progress in Physical Geography. 36(1). 125-133.

McCain, W., Romaire, R., Lutz, C. \& Shirley, M. (2007). Louisiana Crawfish Production Manual. Louisiana State University AG Center, Publication 2637.

McCarthy, B. (2011). Army chief says levee system is holding up amid historic flooding. Times-Picayune, May 21, 2011. Retrieved from the internet on May 25, 2011 from http://www.nola.com.

McLoughlin, D. (1985). A framework for integrated emergency management. Public Administration Review 45 (special issue): 165-172.

Mileti, D. (1999). Disasters by Design: A reassessment of natural hazards in the United States. Joseph Henry Press. Washington, D.C. 105-133.

Minahan, S. (2011). Flood the Farm or the City: The Army Corps of Engineers' Tough Question. Midwest Agriculture Law Guide. Retrieved from the internet on June 12, 2016 from www.midwestagriculturelawguide.com. 
Molotch, H. (1976). The city as growth machine: toward a political economy of place. American Journal of Sociology, 82: 309-332.

Mowbray, R. (2011). Property owners in the path of Mississippi River flooding are taking out mortagages to beat the 30-day waiting period on insurance. Retrieved May 22, 2011 from http://www.nola.com.

National Flood Insurance Act of 1968. 42 U.S. Code $\S 4001$.

National Weather Service (2011). Advanced Hydrologic Prediction Service. Retrieved on June 12, 2011 from water.weather.gov.

Neuman, S. (2011). Along The Mississippi, An Old Sense of Dread Arises. NPR. Retrieved May 15, 2011 from http://www.npr.org/2011/05/10/136174860/alongthe-mississippi-an-old-sense-of-dread-rises.

Nienaber, D. (2011). America's Artery of Commerce: The Mighty Mississippi. Retrieved December 10, 2011 from http://cnhi.com/archive/x1753194701.

Norton, R. (2005). More and better local planning: State-mandated local planning in coastal

North Carolina. Journal of the American Planning Association. 71(1). 55-72.

Oliver-Smith, A. (1998). Global challenges and the definition of disaster. In E.L. Quarantelli (Ed.) What is disaster: Perspectives on the question. London: Routledge.

O’Neill, K. (2006). Rivers by Design: State Power and the Origins of U.S. Flood Control. Durham, N.C.: Duke University Press.

Perrow, C. (1999). Normal accidents: Living with high risk technologies. Princeton, N.J.: Princeton University Press. . (2007). The Next Catastrophe: Reducing Our Vulnerabilities to Natural, Industrial, and Terrorist Disasters. Princeton, N.J.: Princeton University Press.

Perry, R. (2005). Disasters, definitions, and theory construction. In R. W. Perry \& E. L. Quarantelli (Eds.). What is a disaster? New answers to old questions. Philadelphia, PA: Xlibris.

Platt, R. (1995). Sharing the Challenge: Floodplain Management into the 21st Century. Report on Reports 37(1). 25-28.

Plume, K. (2011). Once in a Lifetime Flood Submerges Farmland. Retrieved Oct. 22, 2011 from http://www.reuters.com. 
Poe, C. (2006). Reconstructing the Levees: The Politics of Flooding in NineteenthCentury Louisiana. (Doctoral dissertation, University of Wisconsin-Madison, 2006). ProQuest Dissertations and Theses.

Pope J. (2011). Morganza Floodway Flow Underestimated: Several bays closed to adapt. The Times-Picayune, May 25, 2011. Retrieved June 6, 2011 from http://www.nola.com.

Quarantelli, E.L. (2005a). A social science research agenda for the disasters of the $21^{\text {st }}$ century. In R.W. Perry \& E.L. Quarantelli (Eds). What is disaster? New answers to old questions. Philadelphia, PA: Xlibris.

Rice, D. (2016). Wintertime floods among costliest ever. Retrieved January 09, 2016, from http://www.usatoday.com/story/weather/2016/01/08/mississippi-river-flood$\operatorname{cost} / 78366942 /$.

Robertson, C. (2011). Louisiana Spillway Opened to Relieve Flooding. Retrieved November 17, 2011 from http://www.nytimes.com/2011/05/15/us/spillway.html.

Rojecki. A. (2009). Political culture and disaster response: the Great Floods of 1927 and 2005. Media, Culture \& Society, 31(6). 957-976.

Scallen, M. (2011). With the Bonne Carre Spillway closed, it's time to assess damage to Lake Pontchartrain. Retrieved November 17, 2011 from http://www.nola.com.

Sharing the challenge: Floodplain management into the 21st century: Report of the Interagency Floodplain Management Review Committee to the Administration Floodplain Management Task Force (1993) The Galloway Report.

SHELDUS (2011). Spatial Hazard Events and Losses Database for the United States. Retrieved on January 2011 from Hazard and Vulnerability Research Institution at the University of South Carolina. http://hvri.geog.sc.edu/SHELDUS/index.cfm? page $=$ products.

Smith, A. (2015). 'Historic' Floods Threaten 19 Levees Along Mississippi River. Retrieved December 30, 2015, from http://www.nbcnews.com/news/weather/ historic-missouri-floods-threaten-19-levees-along-mississippi-river-n487776.

Stanford, D. (2011). Trade Slows as Mississippi River Floods. Retrieved December 2, 2011 from http://www.businessweek.com/magazine/content/11_23/ b4231012667675.htm.

Sullivan, L. (2016). Business of Disaster: Insurance Firms Profited \$400 Million after Sandy. NPR News Investigations. Retrieved on July 13, 2016 from http://www.npr.com. 
Tierney, K. (2010). "Societal Dimensions of Earthquakes and Other Hazards: Findings in Search of Theory." Proceedings of the 9th U. S. National and 10th Canadian Conference on Earthquake Engineering. Oakland, CA: Earthquake Engineering Research Institute.

Termorshizen, J., Opdam, P. \& Van Den Brink, A. (2007). Incorporating ecological sustainability into landscape planning. Landscape and Urban Planning 79. 374384.

U.S. A.C.E. (2006). The Mississippi River \& Tributaries (MR \& T) Project. Retrieved from the internet Mar 3, 2011 from http://www2.mvn.usace.army.mil/pao/bro/ misstrib.htm.

. (2013). The Mississippi River \& Tributaries System 2011 Post Flood Report. Retrieved from the internet on September 14, 2013 from http://www.mvd. usace.army.mil.

U.S. Census Bureau (2010). State and County Quick Facts. Retrieved May 8, 2013 from http://quickfacts.census.gov.

. (2013). 2008 - 2012 Selected Housing and Population Characteristics, American Community Survey 5 year estimates. Retrieved on August 2016 from http://factfinder.census.gov.

U.S. Commission on Civil Rights (2001). Racial and Ethnic Tensions on American Communities: Poverty, Inequality, and discrimination. Volume VII: The Mississippi River Delta Report. Retrieved October 22, 2011 from http://www.usccr.gov/pubs/msdelta/main.html.

U.S. Government Accountability Office (2013). National Flood Insurance Program: Continued Attention Needed to Address Challenges. GAO-13-858T. Washington, D.C.

U.S.G.S. (2007). About the Upper Mississippi River System. Retrieved June 6, 2011 from http://www.umesc.usgs.gov/umesc_about_umrs.html.

. (2016). Floods: Reoccurrence intervals and 100 year floods. Retrieved January 5, 2017 from http://water.usgs.gov/edu/100yearflood.html.

White, G. F. (1945). Human Adjustment to flood. Research Paper 29. Department of Geography, University of Chicago.

Winer, H. (2010). Re-Engineering the Mississippi River as a Sediment Delivery System. Roberts, T, Rosati, J., and Wang, P. (eds.). Proceedings, Symposium to Honor Dr. Nicholas C. Kraus, Journal of Coastal Research, Special Issue, 59. 229-234. 


\section{APPENDIX A}

\section{CHAPTER 2 FIGURES}

\section{Figure 2.1}

Mississippi River Historical Course Changes

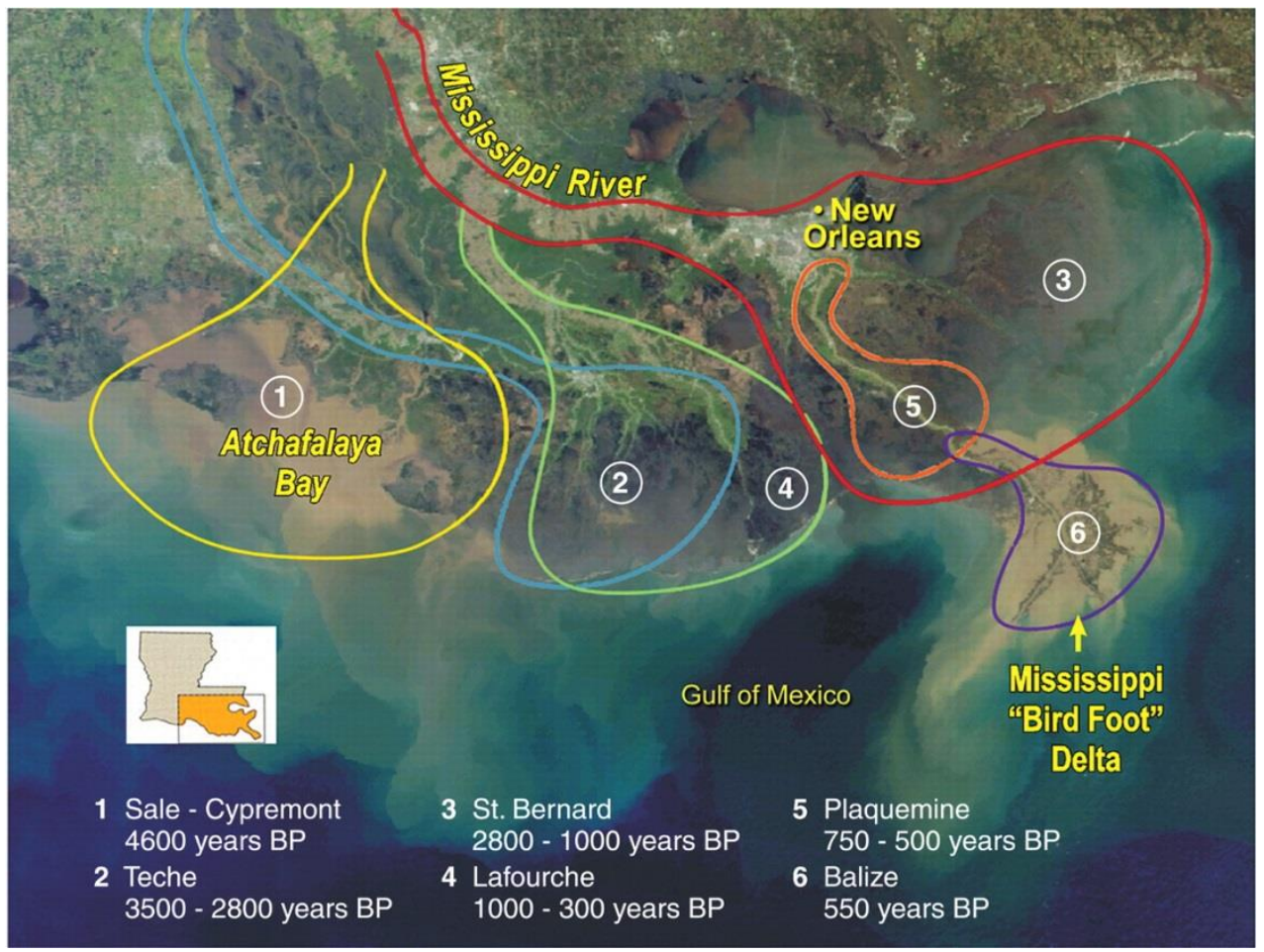

http://geologycafe.com/class/chapter11.html 


\section{Figure 2.2}

Project Flood

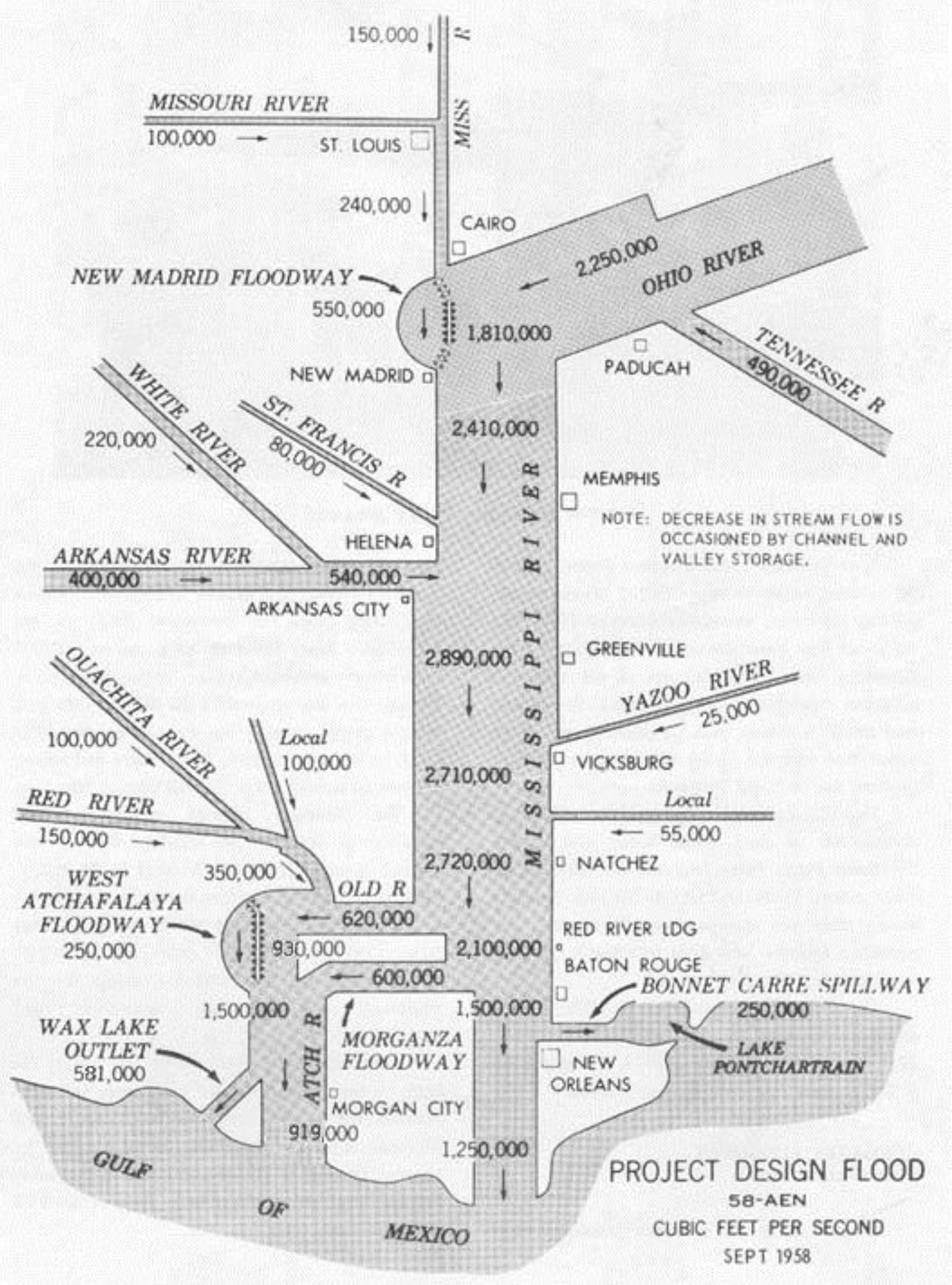

http://www.americaswetlandresources.com 


\section{Figure 2.3}

Mississippi River sediment plume in May 2011

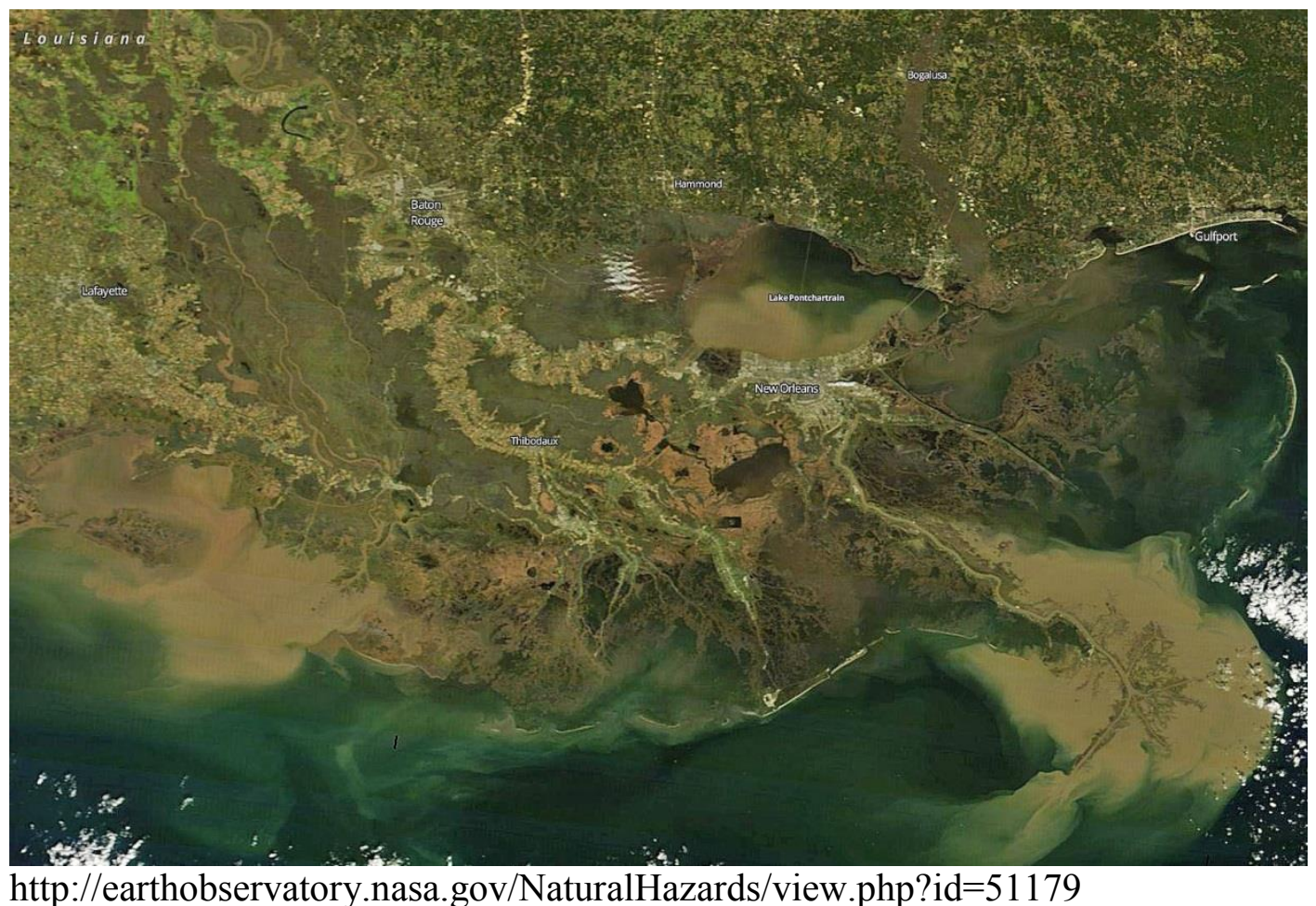


APPENDIX B

\section{CHAPTER FOUR TABLES AND FIGURES}

Table 4.1

Minnesota and Counties: Ratio of Flood Mitigation to All Mitigation Actions

\begin{tabular}{|l|l|r|r|r|}
\hline State & County & $\begin{array}{l}\text { Flood Mitigation } \\
\text { Actions }\end{array}$ & $\begin{array}{l}\text { Total } \\
\text { Mitigation } \\
\text { Actions }\end{array}$ & $\begin{array}{l}\text { Ratio } \\
(\boldsymbol{\%})\end{array}$ \\
\hline MN & Anoka & 10 & 60 & 17 \\
\hline MN & Benton & 4 & 73 & 5 \\
\hline MN & Dakota & 7 & 94 & 7 \\
\hline MN & Goodhue & 14 & 27 & 52 \\
\hline MN & Hennepin & no plan available & & \\
\hline MN & Houston & no plan available & 35 & 11 \\
\hline MN & Ramsey & 4 & & \\
\hline MN & Sherburne & no plan available & & \\
\hline MN & Stearns & 3 & & \\
\hline MN & Wabasha & no plan available & 56 & 34 \\
\hline MN & Washington & no plan available & & \\
\hline MN & Winona & 19 & $\mathbf{4 1 6}$ & $\mathbf{1 5}$ \\
\hline MN & Wright & no plan available & & \\
\hline MN & Total & $\mathbf{6 1}$ & & \\
\hline
\end{tabular}




\section{Table 4.2}

Iowa and Counties: Ratio of Flood Mitigation to All Mitigation Actions

\begin{tabular}{|r|l|r|r|r|}
\hline State & County & Flood Mitigation Actions & Total Mitigation Actions & Ratio (\%) \\
\hline IA & Allamakee & no plan available & 15 & 13 \\
\hline IA & Clayton & no plan available & & \\
\hline IA & Clinton & no plan available & & \\
\hline IA & Des Moines & no plan available & & \\
\hline IA & Dubuque & no plan available & & \\
\hline IA & Jackson & no plan available & & \\
\hline IA & Lee & no plan available & & \\
\hline IA & Louisa & 56 & & \\
\hline IA & Muscatine & $\mathbf{9 1}$ & $\mathbf{2 7 9}$ & \\
\hline IA & Scott & & & \\
\hline IA & Total & & & \\
\hline
\end{tabular}




\section{Table 4.3}

Missouri and Counties: Ratio of Flood Mitigation to All Mitigation Actions

\begin{tabular}{|l|l|r|r|r|}
\hline State & County & $\begin{array}{l}\text { Flood Mitigation } \\
\text { Actions }\end{array}$ & $\begin{array}{l}\text { Total } \\
\text { Mitigation } \\
\text { Actions }\end{array}$ & $\begin{array}{l}\text { Ratio } \\
(\mathbf{\%})\end{array}$ \\
\hline MO & $\begin{array}{l}\text { Cape } \\
\text { Girardeau }\end{array}$ & 11 & 33 & 33 \\
\hline MO & Clark & no plan available & & \\
\hline MO & Jefferson & 30 & 37 & 81 \\
\hline MO & Lewis & no plan available & & \\
\hline MO & Lincoln & 9 & 37 & 24 \\
\hline MO & Marion & 10 & 50 & 20 \\
\hline MO & Mississippi & 5 & 21 & 24 \\
\hline MO & New Madrid & 5 & 18 & 28 \\
\hline MO & Pemiscot & 10 & 37 & 19 \\
\hline MO & Perry & 2 & 32 & 31 \\
\hline MO & Pike & 6 & 34 & 6 \\
\hline MO & Ralls & 4 & 31 & 19 \\
\hline MO & Scott & 15 & 43 & 9 \\
\hline MO & St. Charles & 13 & 37 & 41 \\
\hline MO & St. Louis & 9 & 38 & 34 \\
\hline MO & St. Genevieve & $\mathbf{1 3 6}$ & 32 & 28 \\
\hline MO & Total & & $\mathbf{4 8 0}$ & $\mathbf{2 8}$ \\
\hline
\end{tabular}




\section{Table 4.4}

Wisconsin and Counties: Ratio of Flood Mitigation to All Mitigation Actions

\begin{tabular}{|l|l|l|r|r|}
\hline State & County & $\begin{array}{l}\text { Flood Mitigation } \\
\text { Actions }\end{array}$ & $\begin{array}{l}\text { Total } \\
\text { Mitigation } \\
\text { Actions }\end{array}$ & $\begin{array}{l}\text { Ratio } \\
(\boldsymbol{\%})\end{array}$ \\
\hline WI & Buffalo & no plan available & & \\
\hline WI & Crawford & 6 & 23 & 26 \\
\hline WI & Grant & 5 & 40 & 13 \\
\hline WI & La Crosse & no plan available & 37 & 57 \\
\hline WI & Pepin & 21 & & \\
\hline WI & Pierce & no plan available & & \\
\hline WI & Trempealeau & no plan available & & \\
\hline WI & Vernon & no plan available & & $\mathbf{3 2}$ \\
\hline WI & Total & $\mathbf{3 2}$ & & $\mathbf{1 0 0}$ \\
\hline
\end{tabular}




\section{Table 4.5}

Illinois and Counties: Ratio of Flood Actions to All Mitigation Actions

\begin{tabular}{|l|l|r|r|r|}
\hline State & County & $\begin{array}{l}\text { Flood Mitigation } \\
\text { Actions }\end{array}$ & $\begin{array}{l}\text { Total } \\
\text { Mitigation } \\
\text { Actions }\end{array}$ & $\begin{array}{l}\text { Ratio } \\
(\boldsymbol{\%})\end{array}$ \\
\hline IL & Adams & 1 & 12 & 8 \\
\hline IL & Alexander & 8 & 23 & 35 \\
\hline IL & Calhoun & 12 & 28 & 43 \\
\hline IL & Carroll & 90 & 107 & 84 \\
\hline IL & Hancock & 8 & 40 & 20 \\
\hline IL & Henderson & 6 & 39 & 15 \\
\hline IL & Jackson & 15 & 36 & 42 \\
\hline IL & Jersey & 3 & 10 & 30 \\
\hline IL & Jo Daviess & 192 & 212 & 91 \\
\hline IL & Madison & 23 & 52 & 44 \\
\hline IL & Mercer & 9 & 37 & 24 \\
\hline IL & Monroe & 2 & 15 & 13 \\
\hline IL & Pike & 6 & 38 & 16 \\
\hline IL & Randolph & no plan available & & \\
\hline IL & Rock Island & 15 & 38 & 39 \\
\hline IL & St. Clair & 10 & 12 & 83 \\
\hline IL & Union & 9 & 21 & 43 \\
\hline IL & Whiteside & no plan available & & \\
\hline IL & Total & $\mathbf{4 0 9}$ & $\mathbf{7 2 0}$ & $\mathbf{5 7}$ \\
\hline
\end{tabular}




\section{Table 4.6}

Arkansas and Counties: Ratio of Flood Actions to All Mitigation Actions

\begin{tabular}{|l|l|r|l|l|}
\hline State & County & $\begin{array}{r}\text { Flood Mitigation } \\
\text { Actions }\end{array}$ & $\begin{array}{l}\text { Total } \\
\text { Mitigation } \\
\text { Actions }\end{array}$ & $\begin{array}{l}\text { Ratio } \\
(\boldsymbol{\%})\end{array}$ \\
\hline AR & Chicot & no plan available & & \\
\hline AR & Crittenden & no plan available & & \\
\hline AR & Desha & no plan available & & \\
\hline AR & Lee & no plan available & & \\
\hline AR & Mississippi & no plan available & & \\
\hline AR & Phillips & no plan available & 0 & 0 \\
\hline AR & Total & 0 & & 0 \\
\hline
\end{tabular}




\section{Table 4.7}

Louisiana and Counties: Ratio of Flood Actions to All Mitigation Actions

\begin{tabular}{|c|c|c|c|c|}
\hline State & County & $\begin{array}{r}\text { Flood Mitigation } \\
\text { Actions }\end{array}$ & $\begin{array}{l}\text { Total } \\
\text { Mitigation } \\
\text { Actions }\end{array}$ & $\begin{array}{l}\text { Ratio } \\
(\%)\end{array}$ \\
\hline LA & Ascension & no plan available & & 0 \\
\hline LA & Concordia & no plan available & & 0 \\
\hline LA & $\begin{array}{l}\text { East Baton } \\
\text { Rouge }\end{array}$ & 22 & 22 & 100 \\
\hline LA & East Carroll & no plan available & & 0 \\
\hline LA & Iberville & 16 & 20 & 80 \\
\hline LA & Jefferson & 2 & 7 & 29 \\
\hline LA & Madison & no plan available & & 0 \\
\hline LA & Orleans & 40 & 63 & 63 \\
\hline LA & Plaquemines & no plan available & & 0 \\
\hline LA & Pointe Coupee & no plan available & & 0 \\
\hline LA & St. Bernard & 15 & 16 & 94 \\
\hline LA & St. Charles & 102 & 128 & 80 \\
\hline LA & St. James & no plan available & & 0 \\
\hline LA & $\begin{array}{l}\text { St. John the } \\
\text { Baptist }\end{array}$ & no plan available & & 0 \\
\hline LA & Tensas & no plan available & & 0 \\
\hline LA & $\begin{array}{l}\text { West Baton } \\
\text { Rouge }\end{array}$ & no plan available & & 0 \\
\hline LA & West Feliciana & no plan available & & 0 \\
\hline LA & Total & 197 & 256 & 77 \\
\hline
\end{tabular}




\section{Table 4.7}

Louisiana and Counties: Ratio of Flood Actions to All Mitigation Actions

\begin{tabular}{|c|c|c|c|c|}
\hline State & County & $\begin{array}{r}\text { Flood Mitigation } \\
\text { Actions }\end{array}$ & $\begin{array}{l}\text { Total } \\
\text { Mitigation } \\
\text { Actions }\end{array}$ & $\begin{array}{l}\text { Ratio } \\
(\%)\end{array}$ \\
\hline LA & Ascension & no plan available & & 0 \\
\hline LA & Concordia & no plan available & & 0 \\
\hline LA & $\begin{array}{l}\text { East Baton } \\
\text { Rouge }\end{array}$ & 22 & 22 & 100 \\
\hline LA & East Carroll & no plan available & & 0 \\
\hline LA & Iberville & 16 & 20 & 80 \\
\hline LA & Jefferson & 2 & 7 & 29 \\
\hline LA & Madison & no plan available & & 0 \\
\hline LA & Orleans & 40 & 63 & 63 \\
\hline LA & Plaquemines & no plan available & & 0 \\
\hline LA & Pointe Coupee & no plan available & & 0 \\
\hline LA & St. Bernard & 15 & 16 & 94 \\
\hline LA & St. Charles & 102 & 128 & 80 \\
\hline LA & St. James & no plan available & & 0 \\
\hline LA & $\begin{array}{l}\text { St. John the } \\
\text { Baptist }\end{array}$ & no plan available & & 0 \\
\hline LA & Tensas & no plan available & & 0 \\
\hline LA & $\begin{array}{l}\text { West Baton } \\
\text { Rouge }\end{array}$ & no plan available & & 0 \\
\hline LA & West Feliciana & no plan available & & 0 \\
\hline LA & Total & 197 & 256 & 77 \\
\hline
\end{tabular}




\section{Table 4.8}

Kentucky and Counties: Ratio of Flood Mitigation to All Mitigation Actions

\begin{tabular}{|l|l|l|l|r|}
\hline State & County & $\begin{array}{l}\text { Flood Mitigation } \\
\text { Actions }\end{array}$ & $\begin{array}{l}\text { Total } \\
\text { Mitigation } \\
\text { Actions }\end{array}$ & $\begin{array}{l}\text { Ratio } \\
(\mathbf{\%})\end{array}$ \\
\hline KY & Ballard & 8 & 24 & 33 \\
\hline KY & Carlisle & 18 & 24 & 75 \\
\hline KY & Fulton & 9 & 22 & 41 \\
\hline KY & Hickman & 8 & 22 & 36 \\
\hline KY & Total & $\mathbf{4 3}$ & $\mathbf{9 2}$ & $\mathbf{4 7}$ \\
\hline
\end{tabular}




\section{Table 4.9}

Tennessee and Counties: Ratio of Flood Mitigation to All Mitigation Actions

\begin{tabular}{|l|l|l|l|r|}
\hline State & County & $\begin{array}{l}\text { Flood Mitigation } \\
\text { Actions }\end{array}$ & $\begin{array}{l}\text { Total } \\
\text { Mitigation } \\
\text { Actions }\end{array}$ & $\begin{array}{l}\text { Ratio } \\
(\boldsymbol{\%})\end{array}$ \\
\hline TN & Dyer & no plan available & & 0 \\
\hline TN & Lake & no plan available & & 0 \\
\hline TN & Lauderdale & no plan available & & 0 \\
\hline TN & Shelby & 43 & 72 & 60 \\
\hline TN & Tipton & 18 & 41 & 44 \\
\hline TN & Total & $\mathbf{6 1}$ & $\mathbf{1 1 3}$ & $\mathbf{5 4}$ \\
\hline
\end{tabular}




\section{Table 4.10}

Mississippi and Counties: Ratio of Flood Mitigation to All Mitigation Actions

\begin{tabular}{|c|c|c|c|c|}
\hline State & County & $\begin{array}{l}\text { Flood Mitigation } \\
\text { Actions }\end{array}$ & $\begin{array}{l}\text { Total } \\
\text { Mitigation } \\
\text { Actions }\end{array}$ & $\begin{array}{l}\text { Ratio } \\
(\%)\end{array}$ \\
\hline $\mathrm{MS}$ & Adams & 6 & 23 & 26 \\
\hline MS & Bolivar & no plan available & & 0 \\
\hline MS & Claiborne & 6 & 23 & 26 \\
\hline MS & Coahoma & 2 & 6 & 33 \\
\hline MS & DeSoto & 2 & 8 & 25 \\
\hline MS & Issaquena & no plan available & & 0 \\
\hline $\mathrm{MS}$ & Jefferson & 3 & 22 & 14 \\
\hline $\mathrm{MS}$ & Tunica & 1 & 6 & 17 \\
\hline MS & Warren & no plan available & & 0 \\
\hline $\mathrm{MS}$ & Washington & no plan available & & 0 \\
\hline MS & Wilkinson & 2 & 20 & 10 \\
\hline MS & Total & 22 & 108 & 20 \\
\hline
\end{tabular}




\section{Table 4.11}

State and Counties: Overall Total - Ratio of Flood Mitigation to All Mitigation Actions

\begin{tabular}{|l|l|l|l|l|}
\hline $\begin{array}{l}\text { States } \\
10\end{array}$ & $\begin{array}{l}\text { Counties } \\
108\end{array}$ & $\begin{array}{l}\text { Total Mitigation Flood } \\
\text { Actions }\end{array}$ & $\begin{array}{l}\text { Total Mitigation } \\
\text { Actions }\end{array}$ & \\
\hline & Total & $\mathbf{1 0 5 2}$ & $\mathbf{2 5 6 4}$ & $\mathbf{4 1 \%}$ \\
\hline
\end{tabular}




\section{Table 4.12}

Non-structural Action Item Category

\begin{tabular}{|c|c|c|}
\hline Coded & Non-Structural Mitigation Action & Count \\
\hline Replos & $\begin{array}{l}\text { Actions that specifically address the problem of repetitive } \\
\text { loss properties }\end{array}$ & 50 \\
\hline CRS & $\begin{array}{l}\text { Actions that specifically address participating in the } \\
\text { Community Rating System }\end{array}$ & 59 \\
\hline NFIP & $\begin{array}{l}\text { Actions that specifically address the National Flood } \\
\text { Insurance Program }\end{array}$ & 12 \\
\hline Policy & $\begin{array}{l}\text { Actions related to influencing policies related to flood } \\
\text { mitigation }\end{array}$ & 48 \\
\hline Eduout & $\begin{array}{l}\text { Actions related to education and outreach to community } \\
\text { stakeholders such as private industry, government, general }\end{array}$ & 45 \\
\hline Study & $\begin{array}{l}\text { Actions related to conducting studies, evaluating } \\
\text { processes, or developing plans }\end{array}$ & 92 \\
\hline Tech & $\begin{array}{l}\text { Actions that involve technical work such as building } \\
\text { databases, creating map products, creating inventories, and }\end{array}$ & 36 \\
\hline Train & Actions that identify training needs & 5 \\
\hline Equip & $\begin{array}{l}\text { Actions related to purchasing items and equipment such as } \\
\text { sandbags, signage, boats, portable generators }\end{array}$ & 39 \\
\hline Maint & $\begin{array}{l}\text { Actions related to maintaining equipment, performing } \\
\text { inspection and maintenance on structural elements and }\end{array}$ & 50 \\
\hline Warn & Actions involving improving warning systems & 18 \\
\hline Evacshel & $\begin{array}{l}\text { Actions involving developing evacuation routes and } \\
\text { sheltering sites }\end{array}$ & 19 \\
\hline Enforce & $\begin{array}{l}\text { Actions related to enforcing policies associated with } \\
\text { floodplain management }\end{array}$ & 32 \\
\hline Enviro & $\begin{array}{l}\text { Actions related to promotion and protection of the natural } \\
\text { environment }\end{array}$ & 15 \\
\hline Comm & $\begin{array}{l}\text { Actions related to improving communication and } \\
\text { networking between agencies }\end{array}$ & 10 \\
\hline Leveeacc & Actions related to levee accreditation & 4 \\
\hline Resp & $\begin{array}{l}\text { Actions that involve creating response plans and } \\
\text { establishing first responders }\end{array}$ & 6 \\
\hline \multirow[t]{2}{*}{ Other } & Actions otherwise specified & 9 \\
\hline & Total Non-Structural Mitigation Items & 549 \\
\hline
\end{tabular}




\section{Table 4.13}

Structural Action Item Categories

\begin{tabular}{|l|r|}
\hline Structural Action Item & Total \\
\hline Culverts & 75 \\
\hline Roads Elevate/Repair & 67 \\
\hline Reorganize Sewers & 47 \\
\hline Bank Stabilization & 33 \\
\hline Build Bridges & 32 \\
\hline Build Pumping Stations & 30 \\
\hline Elevate Structures & 29 \\
\hline Build Levees Dams Flood Wall & 30 \\
\hline Build Retention/Reservoirs & 28 \\
\hline Move/Rebuild/Build Structures & 26 \\
\hline Channel Improvements & 26 \\
\hline Otherwise Specified & 23 \\
\hline Build Perm Generators & 12 \\
\hline Build Warning Systems & 10 \\
\hline Reforest/Green & 9 \\
\hline Reorganize Electric Grid & 6 \\
\hline Build Shelters & 6 \\
\hline Flood Gates & 8 \\
\hline Build Potable Water Store & 4 \\
\hline Build Roadway Gates & 2 \\
\hline Totals & 503 \\
\hline
\end{tabular}




\section{APPENDIX C \\ CHAPTER FIVE TABLES AND FIGURES}

\section{Table 5.1}

Model One: Coefficients Table

\begin{tabular}{|c|c|c|c|c|c|}
\hline Model & $\begin{array}{l}\text { Unstandardize } \\
\text { B }\end{array}$ & $\begin{array}{l}\text { Coefficients } \\
\text { Std. Error }\end{array}$ & $\begin{array}{l}\text { Standardized } \\
\text { Coefficients } \\
\text { Beta }\end{array}$ & t. & Sig. \\
\hline Constant & 28226526.24 & 28969839.27 & & .974 & .339 \\
\hline Timeline & 304007.04 & 2418355.45 & .046 & .126 & .901 \\
\hline Time-Plan & -28853442.31 & 48463198.30 & -.235 & -.595 & .557 \\
\hline TimeAfterPlan & 3200873.20 & 6419107.43 & .187 & .499 & .622 \\
\hline
\end{tabular}

a. Dependent Variable: AllCountyYes 


\section{Table 5.2}

Model Two Coefficients Table

\begin{tabular}{|c|c|c|c|c|c|}
\hline Model & $\begin{array}{l}\text { Unstandardize } \\
\text { B }\end{array}$ & $\begin{array}{l}\text { Coefficients } \\
\text { Std. Error }\end{array}$ & $\begin{array}{l}\text { Standardized } \\
\text { Coefficients } \\
\text { Beta } \\
\end{array}$ & t. & Sig. \\
\hline Constant & 19470479.90 & 45429224.40 & & .429 & .672 \\
\hline Timeline & 2117653.74 & 3792358.38 & .206 & .558 & .581 \\
\hline Time-Plan & -48455542.00 & 75997850.30 & -.252 & -.638 & .529 \\
\hline TimeAfterPlan & 1920725.49 & 10066161.20 & .072 & .191 & .850 \\
\hline
\end{tabular}

a. Dependent Variable: AllCountiesNo 


\section{Table 5.3}

Model Three Coefficients Table

\begin{tabular}{|c|c|c|c|c|c|}
\hline Model & $\begin{array}{l}\text { Unstandardize } \\
\text { B }\end{array}$ & $\begin{array}{l}\text { Coefficients } \\
\text { Std. Error }\end{array}$ & $\begin{array}{l}\text { Standardized } \\
\text { Coefficients } \\
\text { Beta }\end{array}$ & t. & Sig. \\
\hline Constant & 18477323.50 & 11309277.43 & & 1.634 & .114 \\
\hline Timeline & -725399.48 & 944080.24 & -.265 & -.768 & .449 \\
\hline Time-Plan & -19484673.88 & 18919116.18 & -.381 & -1.030 & .312 \\
\hline TimeAfterPlan & 5195403.22 & 2505898.15 & .729 & 2.073 & $.048^{*}$ \\
\hline
\end{tabular}

a. Dependent Variable: Cost $* \mathrm{p} \leq .05$ 


\section{Table 5.4}

Model Four Coefficients Table

\begin{tabular}{|c|c|c|c|c|c|}
\hline Model & $\begin{array}{l}\text { Unstandardize } \\
\text { B }\end{array}$ & $\begin{array}{l}\text { Coefficients } \\
\text { Std. Error }\end{array}$ & $\begin{array}{l}\text { Standardized } \\
\text { Coefficeints } \\
\text { Beta }\end{array}$ & t. & Sig. \\
\hline Constant & 9749202.74 & 26789600.81 & & 1.634 & .114 \\
\hline Timeline & 1029406.89 & 2236352.67 & -.265 & -.768 & .449 \\
\hline Time-Plan & -9368768.43 & 44815910.91 & -.381 & -1.030 & .312 \\
\hline TimeAfterPlan & -1994530.02 & 5936012.41 & -.127 & -.336 & .739 \\
\hline
\end{tabular}

a. Dependent Variable: Cost 
Figure 5.1

Regression Discontinuity Model One "PLAN YES"

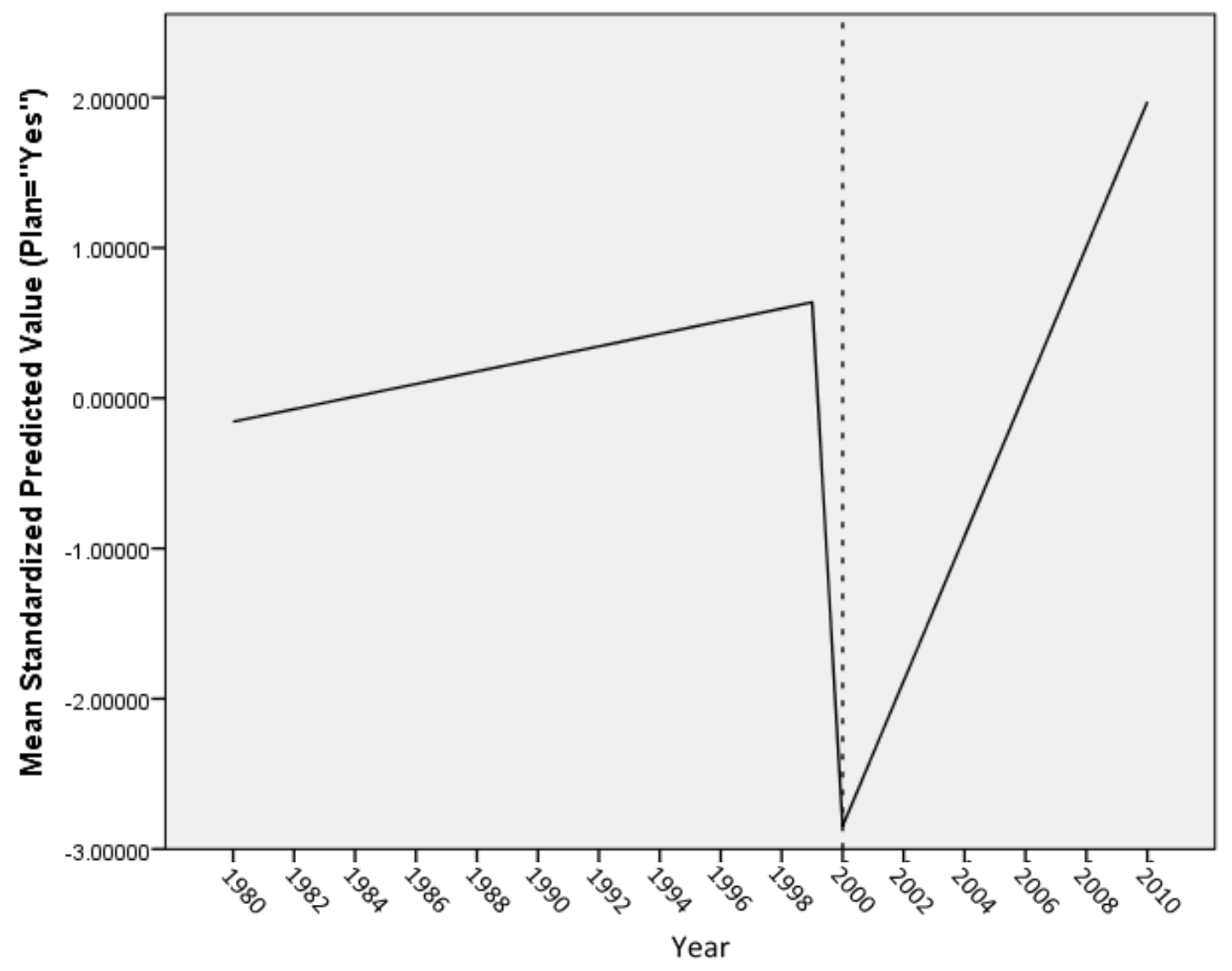


Figure 5.2

Regression Discontinuity Model Two "PLAN NO"

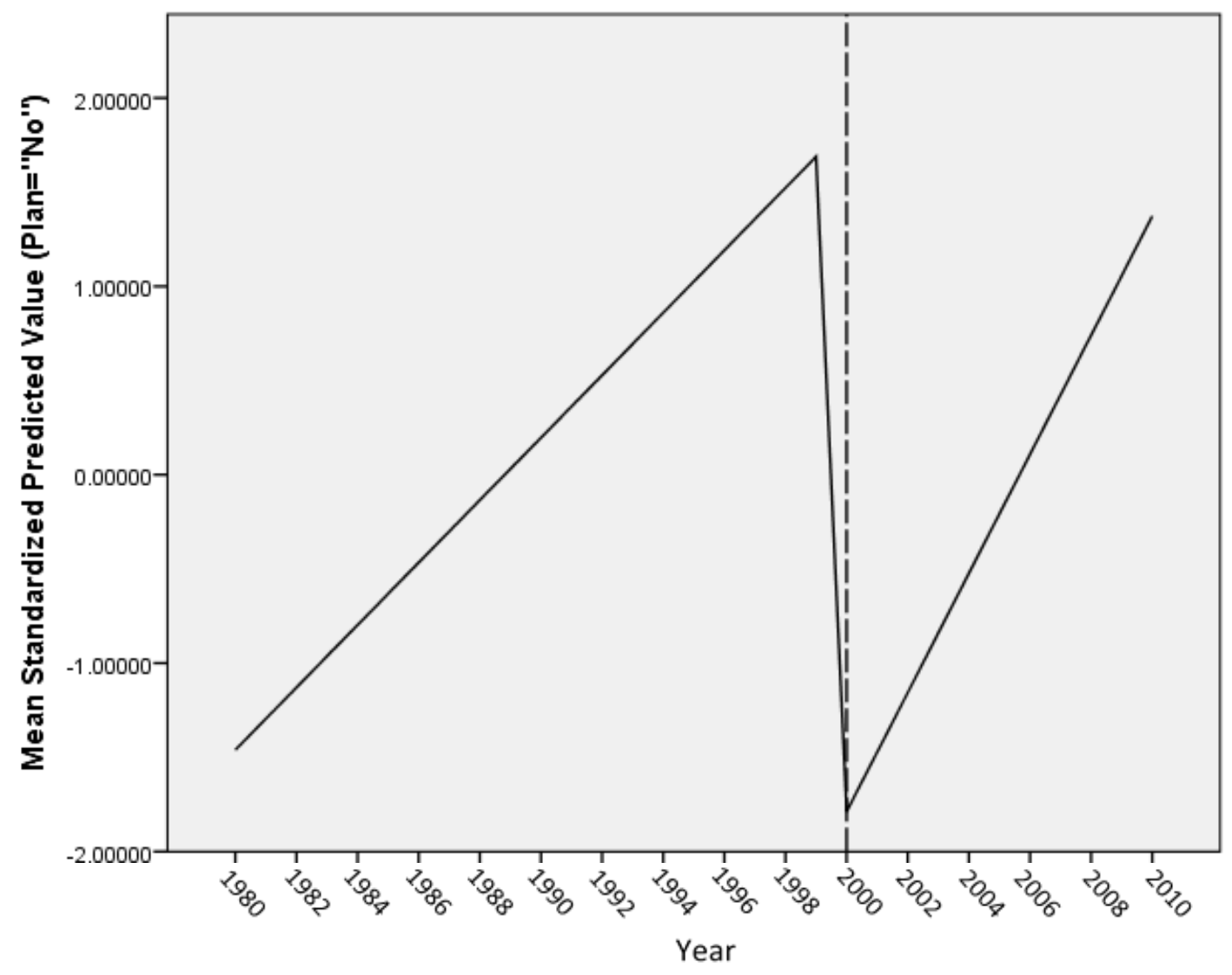


Figure 5.3

Regression Discontinuity Model Three "UPPER PLAN YES”

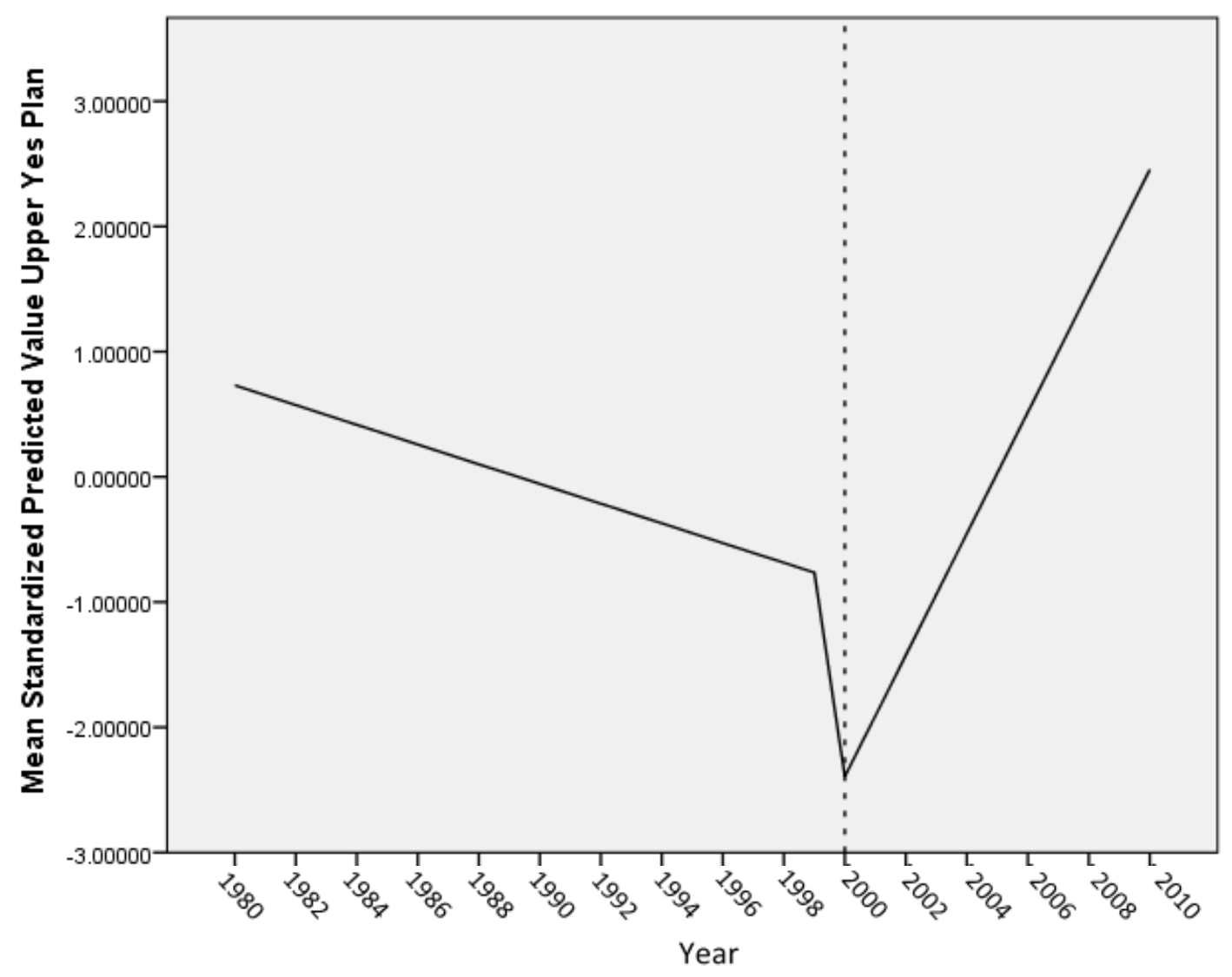


Figure 5.4

Regression Discontinuity Model Four "LOWER PLAN YES"

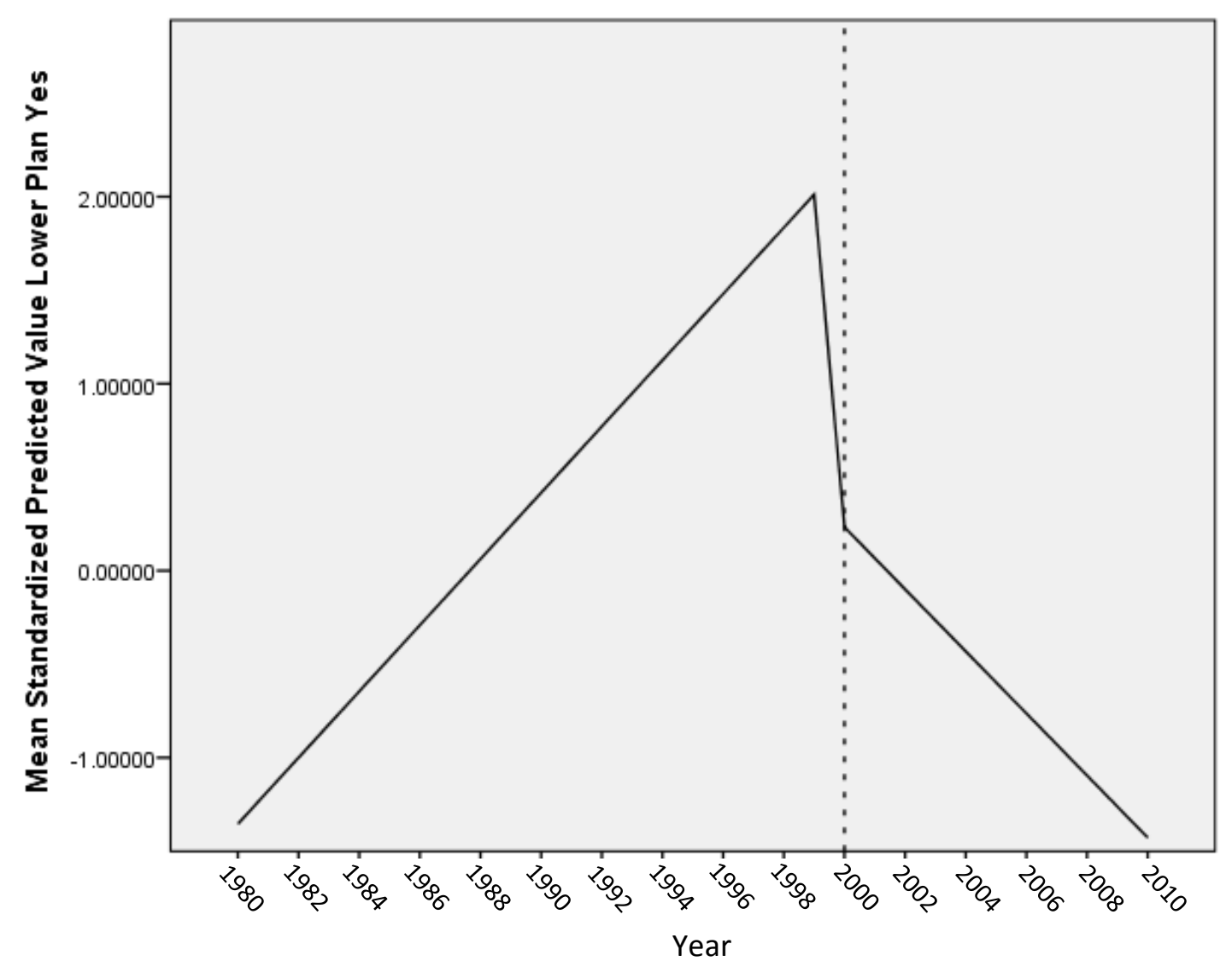




\section{Table 5.5}

Property damage costs by decade for 50 years (SHELDUS)

\begin{tabular}{|l|l|l|l|l|l|l|}
\hline State & $2000-2009$ & $1990-1999$ & $1980-1989$ & $1970-79$ & $1960-1969$ & Total \\
\hline Minnesota & $242,325,655$ & $2,477,500$ & $4,265,872$ & $10,266,667$ & $7,494,648$ & $266,830,342$ \\
\hline Wisconsin & $146,177,840$ & $8,247,024$ & 266,349 & $27,736,869$ & 505,693 & $182,933,775$ \\
\hline Iowa & $59,816,833$ & $637,964,447$ & $3,231,817$ & 500,000 & 560,606 & $702,073,703$ \\
\hline Illinois & $47,431,769$ & $210,239,965$ & $101,884,721$ & $3,432,694$ & $1,004,512$ & $363,993,661$ \\
\hline Missouri & $25,440,510$ & $18,872,279$ & $9,795,181$ & $12,056,374$ & 942 & $66,165,286$ \\
\hline & & & & & & \\
Kentucky & $2,843,976$ & $4,061,036$ & 335,659 & $2,471,881$ & $4,130,161$ & $13,842,713$ \\
\hline & & & & & & \\
Tennessee & $114,729,530$ & $7,525,261$ & $5,720,798$ & $2,504,184$ & 363,858 & $130,843,631$ \\
\hline Arkansas & $15,190,714$ & $1,772,545$ & $4,989,502$ & $1,078,788$ & 0 & $23,031,549$ \\
\hline & & & & & & \\
Mississippi & $25,903,500$ & $17,245,090$ & $85,531,169$ & $47,045,139$ & 13,929 & $175,738,827$ \\
\hline Louisiana & $14,119,000$ & $257,268,400$ & $86,573,426$ & $5,079,461$ & 730,230 & $363,770,517$ \\
\hline Total & $693,979,327$ & $1,165,673,547$ & $302,594,494$ & $112,172,057$ & $14,804,579$ & $2,289,224,004$ \\
\hline
\end{tabular}




\section{Table 5.6}

Flood disaster declarations by decade over 50 years (SHELDUS)

\begin{tabular}{|l|r|r|r|r|r|r|}
\hline State & $2000-$ & $1990-$ & $1980-$ & $1970-$ & $1960-$ & \\
\hline Minnesota & 89 & 29 & 26 & 16 & 23 & 183 \\
\hline Wisconsin & 160 & 50 & 11 & 76 & 43 & 340 \\
\hline Iowa & 153 & 349 & 138 & 1 & 6 & 647 \\
\hline Illinois & 121 & 158 & 275 & 42 & 77 & 673 \\
\hline Missouri & 115 & 123 & 71 & 131 & 19 & 459 \\
\hline Kentucky & 25 & 23 & 55 & 96 & 29 & 228 \\
\hline Tennessee & 80 & 51 & 30 & 50 & 18 & 229 \\
\hline Arkansas & 51 & 17 & 30 & 6 & 0 & 104 \\
\hline Mississippi & 125 & 78 & 60 & 85 & 8 & 356 \\
\hline Louisiana & 69 & 60 & 99 & 24 & 41 & 293 \\
\hline Total & 988 & 938 & 795 & 527 & 264 & 3512 \\
\hline
\end{tabular}




\section{Table 5.7}

State mitigation plan action items analysis

\begin{tabular}{|c|c|c|c|c|c|c|c|c|c|c|}
\hline $\begin{array}{l}\text { State Mit } \\
\text { Plan }\end{array}$ & $\begin{array}{l}\text { Total } \\
\text { Mit } \\
\text { Action }\end{array}$ & $\begin{array}{l}\text { Total } \\
\text { Flood } \\
\text { Mit } \\
\text { Actions } \\
\end{array}$ & $\begin{array}{l}\text { Percent } \\
\text { Flood } \\
\text { Actions }\end{array}$ & $\begin{array}{l}\text { Structural } \\
\text { Actions } \\
\text { Total }\end{array}$ & $\%$ & $\begin{array}{l}\text { Non- } \\
\text { Structural } \\
\text { Actions } \\
\text { Total }\end{array}$ & $\%$ & NFIP & CRS & $\begin{array}{l}\text { Rep } \\
\text { Loss }\end{array}$ \\
\hline Minnesota & 18 & 10 & 56 & 5 & 50 & 5 & 50 & Yes & Yes & Yes \\
\hline Wisconsin & 98 & 18 & 18 & 0 & 0 & 18 & 100 & Yes & Yes & $\mathrm{No}$ \\
\hline Iowa & 51 & 29 & 57 & 15 & 51 & 14 & 49 & Yes & Yes & Yes \\
\hline Illinois & 207 & 42 & 20 & 0 & 0 & 42 & 100 & Yes & No & $\mathrm{No}$ \\
\hline Missouri & 19 & 5 & 26 & 0 & 0 & 5 & 100 & Yes & Yes & Yes \\
\hline Kentucky & 66 & 24 & 36 & 2 & 8 & 22 & 92 & Yes & Yes & Yes \\
\hline Tennessee & 57 & 5 & 9 & 0 & 0 & 5 & 100 & Yes & Yes & Yes \\
\hline Arkansas & 61 & 7 & 11 & 0 & 0 & 7 & 100 & Yes & Yes & Yes \\
\hline Mississippi & 62 & 27 & 44 & 2 & 7 & 25 & 93 & Yes & Yes & $\mathrm{No}$ \\
\hline Louisiana & 18 & 0 & 0 & 0 & 0 & 0 & 0 & No & No & $\mathrm{No}$ \\
\hline
\end{tabular}


Table 5.8

State Mitigation Action Analysis: Structural Mitigation Action Items

\begin{tabular}{|c|c|c|c|c|c|c|c|c|c|c|c|}
\hline State Plans Structural Actions & WI & $\mathrm{MN}$ & IA & IL & $\mathrm{KY}$ & $\mathrm{TN}$ & MO & AR & MS & LA & Total \\
\hline Culverts & & 1 & 1 & & & & & & & & 2 \\
\hline Roads Elevate/Rpr & & & 1 & & & & & & & & 1 \\
\hline \multicolumn{12}{|l|}{ Sewers } \\
\hline Bank Stabilization & & 1 & 1 & & & & & & & & 2 \\
\hline Bridges & & 1 & 1 & & & & & & & & 2 \\
\hline Pumping Stations & & & 1 & & & & & & & & 1 \\
\hline Elevate Structures & & & & & 1 & & & & & & 1 \\
\hline Levees Dams F Wall & & 1 & 2 & & & & & & 1 & & 4 \\
\hline \multicolumn{12}{|l|}{ Retention/Reservoirs } \\
\hline Move/Rebuild/Build & & & 1 & & & & & & & & 1 \\
\hline Channel Improve & & & 1 & & & & & & & & 1 \\
\hline Otherwise Specified & & & 1 & & 1 & & & & & & 2 \\
\hline Perm Generators & & & 1 & & & & & & & & 1 \\
\hline Warning Systems & & & & & & & & & 1 & & 1 \\
\hline Reforest/Green & & 1 & 1 & & & & & & & & 2 \\
\hline Electric Grid & & & 1 & & & & & & & & 1 \\
\hline Build Shelters & & & & & & & & & & & 0 \\
\hline Flood Gates & & & & & & & & & & & 0 \\
\hline Potable Water Store & & & & & & & & & & & 0 \\
\hline Roadway Gates & & & & & & & & & & & 0 \\
\hline Totals & 0 & 5 & 13 & 0 & 2 & 0 & 0 & 0 & 2 & 0 & 22 \\
\hline
\end{tabular}




\section{Table 5.9}

State Mitigation Action Analysis: Non-structural Action Items

\begin{tabular}{|l|r|r|r|r|r|r|r|r|r|r|r|}
\hline Action Item & WI & MN & IA & IL & KY & TN & MO & AR & MS & LA & Total \\
\hline Study & & 1 & 1 & 4 & & 1 & & & 2 & \\
\hline NFIP & 1 & 1 & 1 & 4 & 3 & 1 & 1 & 2 & 6 & 9 \\
\hline Repetitive Loss & 1 & 1 & 2 & 6 & 3 & 2 & 2 & 2 & 1 & \\
\hline Maintenance & & & & & 1 & & & & & & 0 \\
\hline Policy Influence & 1 & & 1 & 2 & 4 & & & & 2 & & 10 \\
\hline Education Outreach & 5 & 1 & 1 & 2 & 3 & & 1 & & 1 & & 14 \\
\hline Purchase Equipment & & & 1 & & 1 & & & & & & 2 \\
\hline Technical Support & 4 & & & 6 & 3 & & 1 & 1 & 4 & & 19 \\
\hline Enforce Regulations & & & & 3 & & & & & 3 & & 6 \\
\hline Evac \& Sheltering & & & & & 1 & & & & & & 1 \\
\hline $\begin{array}{l}\text { Warning } \\
\text { Improvements }\end{array}$ & & & 1 & 1 & & & & & & & 2 \\
\hline $\begin{array}{l}\text { Environmental } \\
\text { Considerations }\end{array}$ & 1 & & & & & & & & & & 1 \\
\hline Other & & 1 & 1 & 1 & & 1 & 1 & 1 & 1 & & 7 \\
\hline CRS & 1 & & 1 & 4 & & & & & 3 & & 9 \\
\hline Communication & 17 & 5 & 15 & 41 & 22 & 6 & 6 & 8 & 25 & 0 & 145 \\
\hline Emergency Response & & & 2 & & 1 & & & & & & 3 \\
\hline Training & & & & & & & & & & & \\
\hline Total
\end{tabular}




\section{Table 5.10}

\section{County Mitigation Plan Flood Action Analysis: Structural Action Items}

\begin{tabular}{|c|c|c|c|c|c|c|c|c|c|c|c|}
\hline Action Item & $\mathrm{WI} / 3$ & $\mathrm{MN} / 7$ & $\mathrm{IA} / 3$ & IL/16 & $\mathrm{KY} / 4$ & $\mathrm{TN} / 2$ & $\mathrm{MO} / 14$ & $\mathrm{AR} / 0$ & $\mathrm{MS} / 7$ & $\mathrm{LA} / 6$ & Total \\
\hline $\begin{array}{l}\text { Stabilize/armour } \\
\text { banks }\end{array}$ & 4 & 0 & 1 & 22 & 1 & 0 & 1 & 0 & 0 & 4 & 33 \\
\hline Roads/elevating & 2 & 2 & 1 & 59 & 2 & 5 & 7 & 0 & 1 & 2 & 81 \\
\hline Widen culverts & 3 & 2 & 4 & 42 & 0 & 9 & 0 & 0 & 1 & 14 & 75 \\
\hline $\begin{array}{l}\text { Repair/replace } \\
\text { bridges }\end{array}$ & 2 & 1 & 0 & 23 & 0 & 4 & 0 & 0 & 0 & 2 & 32 \\
\hline Fix sewers & 3 & 0 & 7 & 23 & 0 & 1 & 0 & 0 & 1 & 10 & 45 \\
\hline Electric line issues & 1 & 1 & 0 & 0 & 0 & 0 & 0 & 0 & 0 & 4 & 6 \\
\hline Flood gates & 0 & 1 & 2 & 1 & 0 & 0 & 0 & 0 & 0 & 4 & 8 \\
\hline $\begin{array}{l}\text { Retrofit structures } \\
\text { in floodplain }\end{array}$ & 0 & 2 & 1 & 7 & 0 & 0 & 0 & 0 & 1 & 18 & 29 \\
\hline Build shelters & 1 & 0 & 0 & 2 & 0 & 1 & 0 & 0 & 0 & 2 & 6 \\
\hline $\begin{array}{l}\text { Build floodwall } \\
\text { levees }\end{array}$ & 1 & 3 & 5 & 12 & 0 & 2 & 1 & 0 & 0 & 6 & 30 \\
\hline Warning systems & 0 & 2 & 2 & 2 & 0 & 0 & 0 & 0 & 0 & 4 & 10 \\
\hline Install generators & 0 & 0 & 3 & 7 & 0 & 0 & 0 & 0 & 0 & 1 & 11 \\
\hline Build pump stations & 0 & 0 & 2 & 2 & 0 & 1 & 0 & 0 & 0 & 25 & 30 \\
\hline $\begin{array}{l}\text { Retention ponds } \\
\text { reservoirs }\end{array}$ & 0 & 0 & 1 & 7 & 1 & 18 & 0 & 0 & 0 & 1 & 28 \\
\hline $\begin{array}{l}\text { Buildings out of } \\
\text { floodplain }\end{array}$ & 1 & 0 & 4 & 10 & 4 & 0 & 0 & 0 & 3 & 4 & 26 \\
\hline Channel improve & 0 & 1 & 0 & 7 & 0 & 8 & 0 & 0 & 0 & 10 & 26 \\
\hline $\begin{array}{l}\text { Reforestation } \\
\text { /greenway }\end{array}$ & 0 & 0 & 0 & 2 & 0 & 0 & 4 & 0 & 0 & 5 & 11 \\
\hline $\begin{array}{l}\text { Other } \\
\text { improvements }\end{array}$ & 0 & 1 & 4 & 8 & 4 & 0 & 0 & 0 & 0 & 5 & 22 \\
\hline Totals & 18 & 16 & 37 & 236 & 12 & 49 & 13 & 0 & 7 & 121 & 509 \\
\hline
\end{tabular}




\section{Table 5.11}

County Mitigation Action Analysis: Non-Structural Mitigation Action Items

\begin{tabular}{|l|r|r|r|r|r|r|r|r|r|r|r|}
\hline Action Item & WI & MN & IA & IL & KY & TN & MO & AR & MS & LA & Total \\
\hline Study & 1 & 10 & 4 & 52 & 1 & 5 & 9 & 0 & 1 & 9 & 92 \\
\hline NFIP & 3 & 4 & 5 & 12 & 11 & 3 & 12 & 0 & 4 & 5 & 59 \\
\hline Repetitive Loss & 2 & 9 & 6 & 12 & 2 & 0 & 8 & 0 & 2 & 9 & 50 \\
\hline Maintenance & 3 & 2 & 5 & 16 & 4 & 1 & 13 & 0 & 3 & 3 & 50 \\
\hline Policy Influence & 2 & 3 & 10 & 4 & 0 & 0 & 16 & 0 & 1 & 12 & 48 \\
\hline $\begin{array}{l}\text { Education } \\
\text { Outreach }\end{array}$ & 1 & 2 & 2 & 15 & 5 & 0 & 8 & 0 & 0 & 12 & 45 \\
\hline $\begin{array}{l}\text { Purchase } \\
\text { Equipment }\end{array}$ & 0 & 5 & 5 & 24 & 0 & 0 & 4 & 0 & 0 & 1 & 39 \\
\hline $\begin{array}{l}\text { Technical } \\
\text { Support }\end{array}$ & 1 & 8 & 0 & 4 & 0 & 2 & 9 & 0 & 3 & 9 & 36 \\
\hline $\begin{array}{l}\text { Enforce } \\
\text { Regulations }\end{array}$ & 0 & 0 & 6 & 8 & 0 & 0 & 16 & 0 & 0 & 2 & 32 \\
\hline $\begin{array}{l}\text { Evacuation \& } \\
\text { Sheltering }\end{array}$ & 1 & 0 & 4 & 10 & 0 & 0 & 4 & 0 & 0 & 0 & 19 \\
\hline $\begin{array}{l}\text { Warning } \\
\text { Improvements }\end{array}$ & 1 & 0 & 0 & 12 & 0 & 0 & 4 & 0 & 1 & 0 & 18 \\
\hline $\begin{array}{l}\text { Environmental } \\
\text { Considerations }\end{array}$ & 0 & 0 & 0 & 3 & 2 & 0 & 10 & 0 & 0 & 0 & 15 \\
\hline Other & 0 & 0 & 3 & 6 & 0 & 0 & 1 & 0 & 0 & 3 & 13 \\
\hline CRS & 0 & 0 & 0 & 3 & 0 & 0 & 1 & 0 & 0 & 8 & 12 \\
\hline Communication & 0 & 0 & 2 & 3 & 0 & 0 & 4 & 0 & 0 & 1 & 10 \\
\hline $\begin{array}{l}\text { Emergency } \\
\text { Response }\end{array}$ & 1 & 0 & 0 & 1 & 0 & 0 & 4 & 0 & 0 & 0 & 6 \\
\hline Training & 0 & 1 & 0 & 2 & 0 & 0 & 0 & 0 & 0 & 2 & 5 \\
\hline $\begin{array}{l}|r| \\
\text { Total }\end{array}$ & 16 & 52 & 187 & 25 & 11 & 123 & 0 & 15 & 76 & 549 \\
\hline
\end{tabular}




\section{Table 5.12}

\section{Minnesota Flood Property Damage 50 Year (SHELDUS)}

\begin{tabular}{|l|r|r|r|r|r|r|}
\hline $\begin{array}{l}\text { Minnesota } \\
\text { Counties }\end{array}$ & $\begin{array}{l}\text { Total Property } \\
\text { Damage 50 } \\
\text { yrs }\end{array}$ & $\begin{array}{l}\text { Total PD } \\
2000\end{array}$ & $\begin{array}{l}\text { Total PD } \\
1990\end{array}$ & $\begin{array}{l}\text { Total PD } \\
1980\end{array}$ & $\begin{array}{l}\text { Total PD } \\
1970\end{array}$ & $\begin{array}{l}\text { Total PD } \\
1960\end{array}$ \\
\hline Anoka & $6,084,150$ & $4,883,049$ & 0 & 1,389 & 625,000 & 574,713 \\
\hline Benton & $9,537,484$ & $8,478,049$ & 0 & 18,056 & 466,667 & 574,713 \\
\hline Dakota & $26,928,713$ & $24,878,049$ & 0 & 847,619 & 625,000 & 574,713 \\
\hline Goodhue & $11,525,197$ & $7,679,715$ & $1,653,125$ & 114,286 & $1,500,000$ & 578,071 \\
\hline Hennepin & $7,427,483$ & $4,893,049$ & 0 & 835,722 & $1,125,000$ & 574,713 \\
\hline Houston & $56,167,123$ & $54,088,333$ & 69,792 & 180,952 & $1,250,000$ & 578,046 \\
\hline Ramsey & $9,314,483$ & $7,280,049$ & 0 & 834,722 & 625,000 & 574,713 \\
\hline Sherburne & $7,495,817$ & $6,903,049$ & 0 & 18,056 & 0 & 574,713 \\
\hline Stearns & $12,872,817$ & $12,280,049$ & 0 & 18,056 & 0 & 574,713 \\
\hline Wabasha & $27,656,815$ & $25,121,333$ & 174,792 & 280,952 & $1,500,000$ & 579,738 \\
\hline Washington & $6,915,817$ & $4,878,049$ & 0 & 834,722 & 625,000 & 578,046 \\
\hline Winona & $51,625,290$ & $48,884,833$ & 579,792 & 280,952 & $1,300,000$ & 579,713 \\
\hline Wright & $33,279,150$ & $32,078,049$ & 0 & 1,389 & 625,000 & 574,713 \\
\hline Total & $249,325,655$ & $242,325,655$ & $2,477,500$ & $4,265,872$ & $10,266,667$ & $7,494,648$ \\
\hline
\end{tabular}




\section{Table 5.13}

Minnesota Flood Disaster Declarations 50 Year (SHELDUS)

\begin{tabular}{|l|r|r|r|r|r|r|}
\hline $\begin{array}{l}\text { Minnesota } \\
\text { Counties }\end{array}$ & Total Disasters & 1960 & 1970 & 1980 & 1990 & 2000 \\
\hline Anoka & 6 & 1 & 1 & 1 & 1 & 2 \\
\hline Benton & 9 & 1 & 2 & 2 & 0 & 4 \\
\hline Dakota & 8 & 2 & 1 & 2 & 1 & 2 \\
\hline Goodhue & 20 & 3 & 2 & 2 & 5 & 8 \\
\hline Hennepin & 8 & 1 & 2 & 2 & 1 & 2 \\
\hline Houston & 31 & 2 & 1 & 2 & 5 & 21 \\
\hline Ramsey & 9 & 1 & 1 & 2 & 2 & 3 \\
\hline Sherburne & 6 & 1 & 0 & 2 & 0 & 3 \\
\hline Stearns & 10 & 1 & 0 & 2 & 0 & 7 \\
\hline Wabasha & 30 & 4 & 2 & 3 & 5 & 16 \\
\hline Washington & 7 & 2 & 1 & 2 & 1 & 1 \\
\hline Winona & 33 & 3 & 2 & 3 & 8 & 17 \\
\hline Wright & 6 & 1 & 1 & 1 & 0 & 3 \\
\hline Total & 183 & 23 & 16 & 26 & 29 & 89 \\
\hline
\end{tabular}




\section{Table 5.14}

\section{Minnesota Mitigation Actions: State to County Comparison}

\begin{tabular}{|c|c|c|c|c|c|}
\hline \multicolumn{6}{|c|}{ Minnesota: State to County Ranked Comparison of Top Mitigation Needs } \\
\hline $\begin{array}{c}\text { Structural } \\
\text { Mitigation } \\
\text { Ranked: }\end{array}$ & 1 & 2 & 3 & 4 & 5 \\
\hline State & Culverts & $\begin{array}{c}\text { Bank } \\
\text { Stabilization }\end{array}$ & Bridges & $\begin{array}{c}\text { Levees } \\
\text { Dams } \\
\text { Floodwalls }\end{array}$ & $\begin{array}{c}\text { Reforest/ } \\
\text { Green }\end{array}$ \\
\hline Counties & $\begin{array}{c}\text { Levees, Dams, } \\
\text { Floodwalls }\end{array}$ & $\begin{array}{l}\text { Warning } \\
\text { Systems }\end{array}$ & $\begin{array}{c}\text { Elevate } \\
\text { Structures }\end{array}$ & Culverts & $\begin{array}{l}\text { Flood } \\
\text { Gates }\end{array}$ \\
\hline $\begin{array}{c}\text { Nonstructura } \\
\text { Mitigation } \\
\text { Ranked: }\end{array}$ & 1 & 2 & 3 & 4 & 5 \\
\hline State & Studies & NFIP & $\begin{array}{l}\text { Rep Loss } \\
\text { Funding }\end{array}$ & $\begin{array}{c}\text { Education } \\
\text { Outreach }\end{array}$ & CRS \\
\hline Counties & Studies & $\begin{array}{l}\text { Rep Loss } \\
\text { Funding }\end{array}$ & Tech Support & $\begin{array}{l}\text { Equipment } \\
\text { Funding }\end{array}$ & NFIP \\
\hline
\end{tabular}




\section{Table 5.15}

Wisconsin Flood Property Damage 50 years (SHELDUS)

\begin{tabular}{|l|l|r|r|r|r|r|}
\hline $\begin{array}{l}\text { Wisconsin } \\
\text { Counties }\end{array}$ & $\begin{array}{l}\text { Total Property } \\
\text { Damage 50 yrs }\end{array}$ & Total PD 2000 & $\begin{array}{l}\text { Total PD } \\
1990\end{array}$ & $\begin{array}{l}\text { Total PD } \\
1980\end{array}$ & $\begin{array}{l}\text { Total PD } \\
1970\end{array}$ & \multicolumn{1}{l|}{$\begin{array}{l}\text { Total PD } \\
1960\end{array}$} \\
\hline Buffalo & $10,171,784$ & $6,136,067$ & 448,000 & 7,500 & $3,536,440$ & 46,778 \\
\hline Crawford & $40,108,276$ & $35,541,667$ & $1,034,286$ & 238,810 & $3,414,950$ & 93,564 \\
\hline Grant & $23,176,364$ & $18,356,267$ & $1,282,952$ & 238,810 & $3,419,771$ & 93,564 \\
\hline La Crosse & $21,561,360$ & $17,740,667$ & 320,000 & 48,810 & $3,408,106$ & 43,778 \\
\hline Pepin & $7,376,884$ & $3,725,000$ & 100,000 & 0 & $3,503,106$ & 48,788 \\
\hline Pierce & $6,269,681$ & $2,600,000$ & 50,000 & 55,556 & $3,503,106$ & 61,019 \\
\hline Trempealeau & $15,106,350$ & $8,569,207$ & $2,915,000$ & 58,056 & $3,536,440$ & 27,649 \\
\hline Vernon & $59,163,076$ & $53,508,967$ & $2,096,786$ & 48,810 & $3,414,950$ & 93,564 \\
\hline Total & $182,993,775$ & $146,177,840$ & $8,247,024$ & 266,349 & $27,736,869$ & 505,693 \\
\hline
\end{tabular}




\section{Table 5.16}

Wisconsin Flood Disaster Declarations 50 Years (SHELDUS)

\begin{tabular}{|l|l|l|l|l|l|l|}
\hline $\begin{array}{l}\text { Wisconsin } \\
\text { Counties }\end{array}$ & $\begin{array}{l}\text { Total } \\
\text { Disasters }\end{array}$ & 1960 & 1970 & 1980 & 1990 & 2000 \\
\hline Buffalo & 41 & 4 & 10 & 2 & 8 & 17 \\
\hline Crawford & 57 & 7 & 10 & 1 & 7 & 32 \\
\hline Grant & 67 & 7 & 12 & 1 & 7 & 40 \\
\hline La Crosse & 35 & 4 & 8 & 2 & 5 & 16 \\
\hline Pepin & 19 & 5 & 8 & 0 & 2 & 4 \\
\hline Pierce & 17 & 5 & 8 & 1 & 1 & 2 \\
\hline Trempealeau & 40 & 3 & 10 & 2 & 10 & 15 \\
\hline Vernon & 64 & 8 & 10 & 2 & 10 & 8 \\
\hline Total & 340 & 43 & 76 & 11 & 50 & 134 \\
\hline
\end{tabular}




\section{Table 5.17}

Wisconsin Mitigation Actions: State to County Comparison

\begin{tabular}{|c|c|c|c|c|c|}
\hline \multicolumn{6}{|c|}{ Wisconsin: State to County Ranked Comparison of Top Mitigation Needs } \\
\hline $\begin{array}{l}\text { Structural } \\
\text { Mitigation } \\
\text { Ranked: }\end{array}$ & 1 & 2 & 3 & 4 & 5 \\
\hline State & none & none & none & none & none \\
\hline Counties & Culverts & Sewers & $\begin{array}{c}\text { Bank } \\
\text { Stabilization }\end{array}$ & $\begin{array}{l}\text { Roads } \\
\text { Elevated }\end{array}$ & Bridges \\
\hline $\begin{array}{l}\text { Nonstructural } \\
\text { Mitigation } \\
\text { Ranked: }\end{array}$ & 1 & 2 & 3 & 4 & 5 \\
\hline State & $\begin{array}{c}\text { Education } \\
\text { Outreach }\end{array}$ & $\begin{array}{c}\text { Technical } \\
\text { Support }\end{array}$ & Training & NFIP & $\begin{array}{l}\text { Rep Loss } \\
\text { Funding }\end{array}$ \\
\hline Counties & NFIP & $\begin{array}{c}\text { Maintenance } \\
\text { Check/Clean } \\
\text { Drainage }\end{array}$ & $\begin{array}{l}\text { Rep Loss } \\
\text { Funding }\end{array}$ & $\begin{array}{c}\text { Policy } \\
\text { Influence }\end{array}$ & $\begin{array}{l}\text { Education } \\
\text { Outreach }\end{array}$ \\
\hline
\end{tabular}




\section{Table 5.18}

\section{Iowa Flood Property Damage 50 Years (SHELDUS)}

\begin{tabular}{|l|c|l|r|r|r|r|}
\hline $\begin{array}{l}\text { Iowa } \\
\text { Counties }\end{array}$ & $\begin{array}{l}\text { Total Property } \\
\text { Damage 50 yrs }\end{array}$ & $\begin{array}{l}\text { Total PD } \\
2000\end{array}$ & $\begin{array}{l}\text { Total PD } \\
1990\end{array}$ & $\begin{array}{l}\text { Total PD } \\
1980\end{array}$ & $\begin{array}{l}\text { Total PD } \\
1970\end{array}$ & \multicolumn{1}{l}{$\begin{array}{l}\text { Total PD } \\
1960\end{array}$} \\
\hline Allamakee & $90,996,322$ & $12,951,000$ & $77,932,828$ & 97,342 & 0 & 15,151 \\
\hline Clayton & $107,060,963$ & $16,652,833$ & $90,295,636$ & 97,342 & 0 & 15,151 \\
\hline Clinton & $10,710,416$ & $3,366,000$ & $7,318,352$ & 26,064 & 0 & 0 \\
\hline Des Moines & $93,992,726$ & $7,235,000$ & $85,626,156$ & $1,131,570$ & 0 & 0 \\
\hline Dubuque & $108,507,520$ & $2,060,000$ & $106,415,253$ & 17,116 & 0 & 15,151 \\
\hline Jackson & $86,879,454$ & $2,080,000$ & $84,770,322$ & 13,981 & 0 & 15,151 \\
\hline Lee & $92,720,430$ & $6,164,000$ & $84,877,360$ & $1,179,070$ & 500,000 & 0 \\
\hline Louisa & $88,466,968$ & $3,175,000$ & $84,913,979$ & 377,989 & 0 & 0 \\
\hline Muscatine & $10,253,631$ & $2,180,000$ & $7,358,352$ & 215,279 & 0 & 500,000 \\
\hline Scott & $12,485,274$ & $3,953,000$ & $8,456,209$ & 76,064 & 0 & 0 \\
\hline & $702,073,703$ & $59,816,833$ & $637,964,447$ & $3,231,817$ & 500,000 & 560,167 \\
\hline
\end{tabular}




\section{Table 5.19}

Iowa Flood Disaster Declarations 50 Year (SHELDUS)

\begin{tabular}{|l|l|l|l|l|l|l|}
\hline $\begin{array}{l}\text { Iowa } \\
\text { Counties }\end{array}$ & $\begin{array}{l}\text { Total } \\
\text { Disasters }\end{array}$ & 1960 & 1970 & 1980 & 1990 & 2000 \\
\hline Allamakee & 63 & 1 & 0 & 12 & 30 & 20 \\
\hline Clayton & 80 & 1 & 0 & 12 & 38 & 28 \\
\hline Clinton & 55 & 0 & 0 & 13 & 26 & 16 \\
\hline $\begin{array}{l}\text { Des } \\
\text { Moines }\end{array}$ & 72 & 0 & 0 & 17 & 43 & 12 \\
\hline Dubuque & 61 & 1 & 0 & 13 & 41 & 6 \\
\hline Jackson & 52 & 1 & 0 & 12 & 34 & 5 \\
\hline Lee & 89 & 1 & 1 & 17 & 44 & 26 \\
\hline Louisa & 64 & 0 & 0 & 14 & 38 & 12 \\
\hline Muscatine & 50 & 1 & 0 & 14 & 26 & 9 \\
\hline Scott & 62 & 0 & 0 & 14 & 28 & 20 \\
\hline Total & 648 & 6 & 1 & 138 & 348 & 154 \\
\hline
\end{tabular}


Table 5.20

Iowa Mitigation Actions: State to County Comparison

\begin{tabular}{|c|c|c|c|c|c|}
\hline \multicolumn{7}{|c|}{ Iowa: State to County Ranked Comparison of Top Mitigation Needs } \\
\hline $\begin{array}{c}\text { Structural } \\
\text { Mitigation }\end{array}$ & 1 & 2 & 3 & 4 & 5 \\
\hline State & $\begin{array}{c}\text { Levees Dams } \\
\text { Floodwalls }\end{array}$ & Culverts & $\begin{array}{c}\text { Roads } \\
\text { Elevate/Repair }\end{array}$ & $\begin{array}{c}\text { Bank } \\
\text { Stabilization }\end{array}$ & Bridges \\
\hline Counties & Sewers & $\begin{array}{c}\text { Levees Dams } \\
\text { Floodwalls }\end{array}$ & Culverts & $\begin{array}{c}\text { Move/Build } \\
\text { Rebuild out of } \\
\text { Floodplain }\end{array}$ & $\begin{array}{c}\text { Otherwise } \\
\text { specified } \\
\text { need }\end{array}$ \\
\hline $\begin{array}{c}\text { Nonstructural } \\
\text { Mitigation }\end{array}$ & 1 & 2 & 3 & 4 & 5 \\
\hline State & Training & $\begin{array}{c}\text { Rep Loss } \\
\text { Funding }\end{array}$ & $\begin{array}{c}\text { Emergency } \\
\text { Response }\end{array}$ & Study & NFIP \\
\hline Counties & $\begin{array}{c}\text { Policy } \\
\text { Influence }\end{array}$ & $\begin{array}{c}\text { Enforce } \\
\text { Regulations }\end{array}$ & $\begin{array}{c}\text { Rep Loss } \\
\text { Funding }\end{array}$ & NFIP & Maintenance \\
\hline
\end{tabular}




\section{Table 5.21}

\section{Illinois Flood Property Damage 50 Year (SHELDUS)}

\begin{tabular}{|l|r|r|r|r|r|r|}
\hline $\begin{array}{l}\text { Illinois } \\
\text { Counties }\end{array}$ & $\begin{array}{l}\text { Total } \\
\text { Property } \\
\text { Damage 50 } \\
\text { yrs }\end{array}$ & $\begin{array}{l}\text { Total PD } \\
2000\end{array}$ & $\begin{array}{l}\text { Total PD } \\
1990\end{array}$ & $\begin{array}{l}\text { Total PD } \\
1980\end{array}$ & \multicolumn{1}{l}{$\begin{array}{l}\text { Total PD } \\
1970\end{array}$} & \multicolumn{1}{l}{$\begin{array}{l}\text { Total PD } \\
1960\end{array}$} \\
\hline Adams & $23,784,240$ & 610,000 & $17,386,480$ & $5,652,322$ & 51,292 & 84,146 \\
\hline Alexander & $24,759,778$ & $1,840,115$ & $17,187,452$ & $5,614,208$ & 49,019 & 68,983 \\
\hline Calhoun & $23,215,405$ & 0 & $17,432,645$ & $5,647,321$ & 51,292 & 84,146 \\
\hline Carroll & $17,272,767$ & $11,015,500$ & 66,342 & $5,823,624$ & 363,971 & 3,331 \\
\hline Hancock & $24,370,476$ & $2,835,000$ & $15,744,119$ & $5,658,191$ & 49,020 & 84,146 \\
\hline Henderson & $7,732,443$ & $1,875,250$ & 63,564 & $5,658,191$ & 51,292 & 84,146 \\
\hline Jackson & $25,010,094$ & $2,410,949$ & $16,938,119$ & $5,542,779$ & 49,247 & 69,000 \\
\hline Jersey & $23,270,653$ & 46,000 & $17,441,666$ & $5,647,322$ & 51,520 & 84,146 \\
\hline Jo Daviess & $8,556,377$ & $2,641,000$ & 68,342 & $5,773,624$ & 70,080 & 3,331 \\
\hline Madison & $25,143,667$ & 51,000 & $19,447,566$ & $5,524,808$ & 51,292 & 69,000 \\
\hline Mercer & $22,717,623$ & $16,433,000$ & 116,341 & $5,798,706$ & 366,244 & 3,331 \\
\hline Monroe & $23,055,546$ & & $17,394,748$ & $5,542,779$ & 49,020 & 69,000 \\
\hline Pike & $23,138,176$ & 20,000 & $17,335,417$ & $5,647,322$ & 51,292 & 84,146 \\
\hline Randolph & $21,519,013$ & 10,000 & $15,848,214$ & $5,542,779$ & 49,020 & 69,000 \\
\hline $\begin{array}{l}\text { Rock } \\
\text { Island }\end{array}$ & $10,702,293$ & $3,217,670$ & $1,316,342$ & $5,798,706$ & 366,244 & 3,331 \\
\hline St. Clair & $24,931,225$ & 221,000 & $19,048,814$ & $5,592,411$ & 49,623 & 69,000 \\
\hline Union & $23,983,295$ & $1,838,615$ & $16,412,452$ & $5,614,208$ & 49,020 & 69,000 \\
\hline Whiteside & $10,830,593$ & $2,966,670$ & 391,342 & $5,855,052$ & $1,614,198$ & 3,331 \\
\hline Total & $363,993,661$ & $47,431,769$ & $210,239,965$ & $101,884,721$ & $3,432,694$ & $1,004,512$ \\
\hline
\end{tabular}




\section{Table 5.22}

Illinois Flood Disaster Declarations 50 Year (SHELDUS)

\begin{tabular}{|l|r|r|r|r|r|r|}
\hline $\begin{array}{l}\text { Illinois } \\
\text { Counties }\end{array}$ & \multicolumn{1}{|l|}{$\begin{array}{l}\text { Total } \\
\text { Disasters }\end{array}$} & 1960 & 1970 & 1980 & 1990 & 2000 \\
\hline Adams & 34 & 7 & 2 & 13 & 9 & 3 \\
\hline Alexander & 52 & 3 & 1 & 15 & 13 & 21 \\
\hline Calhoun & 31 & 7 & 2 & 12 & 10 & 0 \\
\hline Carroll & 38 & 3 & 3 & 20 & 4 & 7 \\
\hline Hancock & 40 & 7 & 1 & 12 & 5 & 14 \\
\hline Henderson & 29 & 7 & 2 & 12 & 2 & 5 \\
\hline Jackson & 53 & 3 & 2 & 14 & 12 & 14 \\
\hline Jersey & 36 & 7 & 3 & 12 & 11 & 3 \\
\hline Jo Daviess & 38 & 3 & 3 & 19 & 5 & 8 \\
\hline Madison & 31 & 3 & 2 & 12 & 12 & 2 \\
\hline Mercer & 40 & 3 & 4 & 20 & 5 & 8 \\
\hline Monroe & 29 & 3 & 1 & 14 & 11 & 0 \\
\hline Pike & 30 & 7 & 2 & 12 & 7 & 2 \\
\hline Randolph & 26 & 3 & 1 & 14 & 7 & 1 \\
\hline Rock & 56 & 3 & 4 & 21 & 13 & 15 \\
Island & & & & & & \\
\hline St. Clair & 32 & 3 & 3 & 14 & 9 & 3 \\
\hline Union & 35 & 3 & 1 & 15 & 9 & 7 \\
\hline Whiteside & 44 & 3 & 5 & 22 & 7 & 7 \\
\hline Total & 674 & 78 & 42 & 273 & 151 & 120 \\
\hline
\end{tabular}




\section{Table 5.23}

Illinois Mitigation Actions: State to County Comparisons

\begin{tabular}{|c|c|c|c|c|c|}
\hline \multicolumn{7}{|c|}{ Illinois: State to County Ranked Comparison of Top Mitigation Needs } \\
\hline $\begin{array}{c}\text { Structural } \\
\text { Mitigation }\end{array}$ & 1 & 2 & 3 & 4 & 5 \\
\hline State & no action & no action & no action & no action & no action \\
\hline Counties & Sewers & $\begin{array}{c}\text { Levees Dams } \\
\text { Floodwalls }\end{array}$ & Culverts & $\begin{array}{c}\text { Mebuild out of } \\
\text { Floodplain }\end{array}$ & $\begin{array}{c}\text { Otherwise } \\
\text { specified } \\
\text { need }\end{array}$ \\
\hline \multicolumn{7}{|c|}{$\begin{array}{l}\text { Nonstructural } \\
\text { Mitigation }\end{array}$} & 1 & 2 & 3 & 4 & 5 \\
\hline State & Training & $\begin{array}{c}\text { Rep Loss } \\
\text { Funding }\end{array}$ & $\begin{array}{c}\text { Technical } \\
\text { Support }\end{array}$ & Studies & NFIP \\
\hline \multicolumn{7}{|c|}{$\begin{array}{c}\text { Maintenance } \\
\text { Check/Clean } \\
\text { Debris }\end{array}$} & $\begin{array}{c}\text { Education } \\
\text { Outreach }\end{array}$ & $\begin{array}{c}\text { Rep Loss } \\
\text { Funding }\end{array}$ \\
\hline
\end{tabular}


Table 5.24

Missouri Flood Property Damage 50 Year (SHELDUS)

\begin{tabular}{|l|l|r|r|r|r|r|}
\hline $\begin{array}{l}\text { Missouri } \\
\text { Counties }\end{array}$ & $\begin{array}{l}\text { Total } \\
\text { Property } \\
\text { Damage } \\
50 \text { yrs }\end{array}$ & $\begin{array}{l}\text { Total PD } \\
2000\end{array}$ & $\begin{array}{l}\text { Total PD } \\
1990\end{array}$ & $\begin{array}{l}\text { Total PD } \\
1980\end{array}$ & $\begin{array}{l}\text { Total PD } \\
1970\end{array}$ & \multicolumn{1}{l}{$\begin{array}{l}\text { Total } \\
\text { PD } \\
1960\end{array}$} \\
\hline $\begin{array}{l}\text { Cape } \\
\text { Girardeau }\end{array}$ & $7,879,492$ & $3,596,000$ & 160,833 & $3,218,425$ & 904,190 & 4348 \\
\hline Clark & $6,684,761$ & $4,425,000$ & $1,412,502$ & 251,020 & 596,195 & 4348 \\
\hline Jefferson & $2,857,776$ & 600,000 & $1,465,048$ & 163,369 & 629,316 & 4348 \\
\hline Lewis & $3,215,461$ & 956,000 & $1,412,202$ & 251,020 & 596,195 & 4348 \\
\hline Lincoln & $5,350,186$ & $2,675,000$ & $1,731,348$ & 346,202 & 597,511 & 4348 \\
\hline Marion & $9,666,357$ & $7,300,000$ & $1,519,048$ & 251,070 & 596,195 & 4348 \\
\hline Mississippi & $2,821,946$ & $1,121,000$ & 102,434 & 736,944 & 861,525 & 4348 \\
\hline $\begin{array}{l}\text { New } \\
\text { Madrid }\end{array}$ & $2,235,390$ & $1,122,000$ & 70,434 & 181,388 & 861,525 & 4348 \\
\hline Pemiscot & $1,125,400$ & 47,010 & 35,434 & 181,388 & 861,525 & 4348 \\
\hline Perry & $2,907,889$ & 230,000 & $1,608,286$ & 162,869 & 906,690 & 4348 \\
\hline Pike & $2,797,970$ & 385,000 & $1,470,448$ & 346,202 & 596,195 & 4348 \\
\hline Ralls & $2,666,489$ & 255,000 & $1,469,048$ & 346,202 & 596,195 & 4348 \\
\hline Scott & $4,410,593$ & 763,500 & 82,767 & $2,681,388$ & 882,894 & 4348 \\
\hline St. Charles & $5,316,923$ & $1,852,000$ & $2,519,948$ & 346,202 & 598,647 & 4348 \\
\hline St. Louis & $3,782,615$ & 103,000 & $2,411,548$ & 168,619 & 129,652 & 4348 \\
\hline $\begin{array}{l}\text { St. } \\
\text { Genevieve }\end{array}$ & $2,446,038$ & 10,000 & $1,400,952$ & 162,869 & 872,173 & 4348 \\
\hline Total & $66,165,286$ & $25,440,510$ & $18,872,279$ & $9,795,181$ & $12,056,374$ & 94,200 \\
\hline
\end{tabular}




\section{Table 5.25}

Missouri Flood Disaster Declarations 50 Year (SHELDUS)

\begin{tabular}{|l|r|r|r|r|r|r|}
\hline $\begin{array}{l}\text { Missouri } \\
\text { Counties }\end{array}$ & $\begin{array}{l}\text { Total } \\
\text { Disasters }\end{array}$ & 1960 & 1970 & 1980 & 1990 & 2000 \\
\hline Cape & 59 & 1 & 13 & 6 & 11 & 28 \\
Girardeau & 37 & 1 & 3 & 2 & 4 & 28 \\
\hline Clark & 25 & 1 & 8 & 5 & 8 & 3 \\
\hline Jefferson & 12 & 1 & 3 & 2 & 3 & 3 \\
\hline Lewis & 25 & 2 & 4 & 4 & 11 & 4 \\
\hline Lincoln & 14 & 1 & 3 & 3 & 5 & 2 \\
\hline Marion & 35 & 1 & 14 & 6 & 6 & 8 \\
\hline Mississippi & & & & & & \\
\hline New & 31 & 1 & 13 & 5 & 6 & 7 \\
Madrid & 29 & 1 & 13 & 5 & 5 & 5 \\
\hline Pemiscot & 37 & 1 & 14 & 4 & 12 & 6 \\
\hline Perry & 17 & 2 & 3 & 4 & 6 & 3 \\
\hline Pike & 14 & 1 & 3 & 4 & 4 & 2 \\
\hline Ralls & 35 & 1 & 14 & 6 & 6 & 8 \\
\hline Scott & 33 & 2 & 5 & 4 & 18 & 4 \\
\hline St. Charles & 35 & 1 & 7 & 7 & 16 & 4 \\
\hline St. Louis & 21 & 1 & 12 & 4 & 3 & 1 \\
\hline St. & 459 & 19 & 132 & 71 & 124 & 116 \\
\hline Genevieve & & & & & \\
\hline Total & & & & & & \\
\hline
\end{tabular}


Table 5.26

Missouri Mitigation Actions: State to County Comparisons

\begin{tabular}{|c|c|c|c|c|c|}
\hline \multicolumn{6}{|c|}{ Missouri: State to County Ranked Comparison of Top Mitigation Needs } \\
\hline $\begin{array}{r}\text { Structural } \\
\text { Mitigation }\end{array}$ & 1 & 2 & 3 & 4 & 5 \\
\hline State & none & none & none & none & none \\
\hline Counties & $\begin{array}{c}\text { Roads } \\
\text { Elevate/Repair }\end{array}$ & $\begin{array}{l}\text { Reforest } \\
\text { Green }\end{array}$ & $\begin{array}{c}\text { Bank } \\
\text { Stabilization }\end{array}$ & $\begin{array}{c}\text { Levees } \\
\text { Dams } \\
\text { Floodwalls }\end{array}$ & none \\
\hline $\begin{array}{c}\text { Nonstructural } \\
\text { Mitigation }\end{array}$ & 1 & 2 & 3 & 4 & 5 \\
\hline State & $\begin{array}{l}\text { Rep Loss } \\
\text { Funding }\end{array}$ & NFIP & $\begin{array}{l}\text { Education } \\
\text { Outreach }\end{array}$ & $\begin{array}{c}\text { Technical } \\
\text { Support }\end{array}$ & CRS \\
\hline Counties & Policy Influence & $\begin{array}{c}\text { Regulation } \\
\text { Enforcement }\end{array}$ & $\begin{array}{c}\text { Maintenance } \\
\text { Check/Clean } \\
\text { Debris } \\
\end{array}$ & NFIP & $\begin{array}{l}\text { Environmental } \\
\text { Considerations }\end{array}$ \\
\hline
\end{tabular}




\section{Table 5.27}

\section{Kentucky Flood Property Damage 50 Year (SHELDUS)}

\begin{tabular}{|l|l|l|l|l|l|l|}
\hline $\begin{array}{l}\text { Kentucky } \\
\text { Counties }\end{array}$ & $\begin{array}{l}\text { Total } \\
\text { Property } \\
\text { Damage 50 } \\
\text { yrs }\end{array}$ & $\begin{array}{l}\text { Total PD } \\
2000\end{array}$ & $\begin{array}{l}\text { Total PD } \\
1990\end{array}$ & $\begin{array}{l}\text { Total PD } \\
1980\end{array}$ & $\begin{array}{l}\text { Total PD } \\
1970\end{array}$ & $\begin{array}{l}\text { Total PD } \\
1960\end{array}$ \\
\hline Ballard & $6,355,738$ & 962,143 & $3,625,036$ & 137,665 & 608,355 & $1,032,540$ \\
\hline Carlisle & $2,338,060$ & 610,000 & 17,000 & 70,165 & 608,355 & $1,032,540$ \\
\hline Fulton & $3,0746,88$ & 928,417 & 393,000 & 73,915 & 646,817 & $1,032,540$ \\
\hline Hickman & $2,074,227$ & 343,417 & 26,000 & 63,915 & 608,355 & $1,032,540$ \\
\hline Total & $13,842,713$ & $2,843,976$ & $4,061,036$ & 335,659 & $2,471,881$ & $4,130,161$ \\
\hline
\end{tabular}




\section{Table 5.28}

Kentucky Flood Disaster Declarations 50 Year (SHELDUS)

\begin{tabular}{|l|l|l|l|l|l|l|}
\hline $\begin{array}{l}\text { Kentucky } \\
\text { Counties }\end{array}$ & $\begin{array}{l}\text { Total } \\
\text { Disasters }\end{array}$ & 1960 & 1970 & 1980 & 1990 & 2000 \\
\hline Ballard & 62 & 7 & 25 & 15 & 10 & 5 \\
\hline Carlisle & 57 & 7 & 25 & 16 & 3 & 8 \\
\hline Fulton & 55 & 7 & 21 & 14 & 7 & 6 \\
\hline Hickman & 54 & 8 & 25 & 12 & 3 & 6 \\
\hline Total & 228 & 29 & 96 & 57 & 23 & 25 \\
\hline
\end{tabular}




\section{Table 5.29}

\section{Kentucky Mitigation Actions: State to County Comparisons}

\begin{tabular}{|c|c|c|c|c|c|}
\hline \multicolumn{6}{|c|}{ Kentucky: State to County Ranked Comparison of Top Mitigation Needs } \\
\hline $\begin{array}{c}\text { Structural } \\
\text { Mitigation }\end{array}$ & 1 & 2 & 3 & 4 & 5 \\
\hline State & $\begin{array}{c}\text { Elevate } \\
\text { Structures }\end{array}$ & $\begin{array}{c}\text { Otherwise } \\
\text { Specified } \\
\text { Need }\end{array}$ & none & none & none \\
\hline Counties & $\begin{array}{l}\text { Move/Rebuild } \\
\text { Build out of } \\
\text { Floodplain }\end{array}$ & $\begin{array}{c}\text { Otherwise } \\
\text { Specified } \\
\text { Need } \\
\end{array}$ & $\begin{array}{c}\text { Road } \\
\text { Elevate/Repair }\end{array}$ & $\begin{array}{c}\text { Bank } \\
\text { Stabilization }\end{array}$ & $\begin{array}{c}\text { Retention Ponds } \\
\text { Reservoirs }\end{array}$ \\
\hline $\begin{array}{c}\text { Nonstructural } \\
\text { Mitigation }\end{array}$ & 1 & 2 & 3 & 4 & 5 \\
\hline State & $\begin{array}{c}\text { Policy } \\
\text { Influence }\end{array}$ & $\begin{array}{l}\text { Education } \\
\text { Outreach }\end{array}$ & NFIP & $\begin{array}{l}\text { Rep Loss } \\
\text { Funding }\end{array}$ & $\begin{array}{l}\text { Technical } \\
\text { Support }\end{array}$ \\
\hline Counties & NFIP & $\begin{array}{l}\text { Education } \\
\text { Outreach }\end{array}$ & $\begin{array}{l}\text { Maintenance } \\
\text { Check/Clean } \\
\text { Debris }\end{array}$ & $\begin{array}{l}\text { Rep Loss } \\
\text { Funding }\end{array}$ & $\begin{array}{l}\text { Environmental } \\
\text { Considerations }\end{array}$ \\
\hline
\end{tabular}




\section{Table 5.30}

Tennessee Flood Property Damage 50 Year (SHELDUS)

\begin{tabular}{|l|r|r|r|r|r|r|}
\hline $\begin{array}{c}\text { Tennessee } \\
\text { Counties }\end{array}$ & $\begin{array}{r}\text { Total Property } \\
\text { Damage 50 yrs }\end{array}$ & $\begin{array}{r}\text { Total PD } \\
2000\end{array}$ & $\begin{array}{r}\text { Total PD } \\
1990\end{array}$ & $\begin{array}{r}\text { Total PD } \\
1980\end{array}$ & $\begin{array}{r}\text { Total PD } \\
1970\end{array}$ & $\begin{array}{r}\text { Total PD } \\
1960\end{array}$ \\
\hline Dyer & $12,066,650$ & $9,865,667$ & $1,523,452$ & 194,160 & 468,100 & 15,273 \\
\hline Lake & $2,151,660$ & 54,677 & $1,471,952$ & 144,160 & 463,100 & 17,772 \\
\hline Lauderdale & $5,945,150$ & $3,719,668$ & $1,557,952$ & 144,160 & 518,100 & 5,272 \\
\hline Shelby & $83,174,345$ & $80,437,020$ & $1,515,452$ & 94,160 & 807,442 & 320,272 \\
\hline Tipton & $27,505,825$ & $20,652,500$ & $1,456,452$ & $5,144,160$ & 247,442 & 5,278 \\
\hline Total & $130,843,630$ & $114,729,530$ & $7,525,261$ & $5,720,798$ & $2,504,184$ & 363,858 \\
\hline
\end{tabular}




\section{Table 5.31}

Tennessee Flood Disaster Declarations 50 Year (SHELDUS)

\begin{tabular}{|l|l|r|r|r|r|r|}
\hline $\begin{array}{l}\text { Tennessee } \\
\text { Counties }\end{array}$ & $\begin{array}{l}\text { Total } \\
\text { Disasters }\end{array}$ & 1960 & 1970 & 1980 & 1990 & 2000 \\
\hline Dyer & 41 & 3 & 10 & 8 & 12 & 8 \\
\hline Lake & 35 & 4 & 9 & 5 & 10 & 7 \\
\hline Lauderdale & 37 & 2 & 11 & 6 & 11 & 7 \\
\hline Shelby & 76 & 7 & 12 & 5 & 11 & 41 \\
\hline Tipton & 40 & 2 & 8 & 6 & 7 & 17 \\
\hline Total & 41 & 3 & 10 & 8 & 12 & 8 \\
\hline
\end{tabular}




\section{Table 5.32}

Tennessee Mitigation Actions: State to County Comparisons

\begin{tabular}{|c|c|c|c|c|c|}
\hline \multicolumn{6}{|c|}{ Tennessee: State to County Ranked Comparison of Top Mitigation Needs } \\
\hline $\begin{array}{c}\text { Structural } \\
\text { Mitigation }\end{array}$ & 1 & 2 & 3 & 4 & 5 \\
\hline State & none & none & none & none & none \\
\hline Counties & $\begin{array}{c}\text { Retention Ponds } \\
\text { Reservoirs }\end{array}$ & Channel Repairs & Culverts & $\begin{array}{c}\text { Roads } \\
\text { Elevate/ } \\
\text { Repair }\end{array}$ & Bridges \\
\hline $\begin{array}{c}\text { Nonstructural } \\
\text { Mitigation }\end{array}$ & 1 & 2 & 3 & 4 & 5 \\
\hline State & $\begin{array}{c}\text { Rep Loss } \\
\text { Funding }\end{array}$ & Studies & NFIP & CRS & Training \\
\hline Counties & Studies & NFIP & $\begin{array}{c}\text { Technical } \\
\text { Support }\end{array}$ & Maintenance & none \\
\hline
\end{tabular}




\section{Table 5.33}

Arkansas Flood Property Damage 50 Year (SHELDUS)

\begin{tabular}{|l|l|l|r|r|r|r|}
\hline $\begin{array}{l}\text { Arkansas } \\
\text { Counties }\end{array}$ & $\begin{array}{l}\text { Total } \\
\text { Property } \\
\text { Damage } \\
50 \mathrm{yrs}\end{array}$ & $\begin{array}{l}\text { Total PD } \\
2000\end{array}$ & $\begin{array}{l}\text { Total PD } \\
1990\end{array}$ & $\begin{array}{l}\text { Total PD } \\
1980\end{array}$ & $\begin{array}{l}\text { Total PD } \\
1970\end{array}$ & $\begin{array}{l}\text { Total } \\
\text { PD } \\
1960\end{array}$ \\
\hline Chicot & $4,151,940$ & $2,924,000$ & 200,000 & 800,667 & 0 & 0 \\
\hline Crittenden & $8,502,528$ & $7,589,750$ & 51,000 & 850,667 & 11,111 & 0 \\
\hline Desha & $4,389,440$ & $2,751,000$ & 837,273 & 801,167 & 0 & 0 \\
\hline Lee & 831,778 & 10,000 & 0 & 810,667 & 11,111 & 0 \\
\hline Mississippi & $2,102,947$ & 789,714 & 456,000 & 800,667 & 56,566 & 0 \\
\hline Phillips & $3,052,917$ & $1,126,250$ & 51,000 & 875,667 & $1,000,000$ & 0 \\
\hline Total & $23,031,546$ & $15,190,714$ & $1,772,545$ & $4,989,502$ & $1,078,788$ & 0 \\
\hline
\end{tabular}




\section{Table 5.34}

Arkansas Flood Disaster Declarations 50 Year (SHELDUS)

\begin{tabular}{|l|r|r|r|r|r|r|}
\hline $\begin{array}{l}\text { Arkansas } \\
\text { Counties }\end{array}$ & $\begin{array}{l}\text { Total } \\
\text { Disasters }\end{array}$ & 1960 & 1970 & 1980 & 1990 & \multicolumn{2}{l|}{2000} \\
\hline Chicot & 25 & 0 & 0 & 4 & 3 & 18 \\
\hline Crittenden & 20 & 0 & 1 & 5 & 2 & 12 \\
\hline Desha & 13 & 0 & 0 & 5 & 4 & 4 \\
\hline Lee & 8 & 0 & 1 & 6 & 0 & 1 \\
\hline Mississippi & 22 & 0 & 2 & 4 & 7 & 9 \\
\hline Phillips & 16 & 0 & 2 & 6 & 1 & 7 \\
\hline & 104 & 0 & 6 & 30 & 17 & 51 \\
\hline
\end{tabular}




\section{Table 5.35}

Arkansas Mitigation Actions: State to County Comparisons

\begin{tabular}{|c|c|c|c|c|c|}
\hline \multicolumn{6}{|c|}{ Arkansas: State to County Ranked Comparison of Top Mitigation Needs } \\
\hline $\begin{array}{l}\text { Structural } \\
\text { Mitigation } \\
\end{array}$ & 1 & 2 & 3 & 4 & 5 \\
\hline State & none & none & none & none & none \\
\hline Counties & no data & no data & no data & no data & $\begin{array}{c}\text { no } \\
\text { data }\end{array}$ \\
\hline $\begin{array}{l}\text { Nonstructural } \\
\text { Mitigation }\end{array}$ & 1 & 2 & 3 & 4 & 5 \\
\hline State & NFIP & $\begin{array}{c}\text { Rep Loss } \\
\text { Funding }\end{array}$ & $\begin{array}{c}\text { Education } \\
\text { Outreach }\end{array}$ & $\begin{array}{l}\text { Technical } \\
\text { Support }\end{array}$ & CRS \\
\hline Counties & no data & no data & no data & no data & $\begin{array}{c}\text { no } \\
\text { data }\end{array}$ \\
\hline
\end{tabular}




\section{Table 3.36}

\section{Mississippi Flood Property Damage 50 Year (SHELDUS)}

\begin{tabular}{|l|r|r|r|r|r|r|}
\hline $\begin{array}{l}\text { Mississippi } \\
\text { Counties }\end{array}$ & $\begin{array}{l}\text { Total } \begin{array}{l}\text { Total PD } \\
\text { Property } \\
\text { Damage 50 } \\
\text { yrs }\end{array} \\
\text { 2000 }\end{array}$ & $\begin{array}{l}\text { Total PD } \\
1990\end{array}$ & Total PD 1980 & $\begin{array}{l}\text { Total PD } \\
1970\end{array}$ & \multicolumn{1}{l|}{$\begin{array}{l}\text { Total } \\
\text { PD } \\
1960\end{array}$} \\
\hline Adams & $12,073,837$ & $1,348,000$ & $2,023,020$ & $8,560,285$ & 142,533 & 0 \\
\hline Bolivar & $10,030,641$ & $1,425,500$ & $2,095,327$ & $6,371,951$ & 137,624 & 2,381 \\
\hline Claiborne & $30,537,342$ & 322,000 & $1,903,020$ & $6,421,951$ & $21,890,371$ & 0 \\
\hline Coahoma & $8,309,838$ & 277,500 & 920,137 & $6,795,187$ & 136,776 & 2,381 \\
\hline DeSoto & $12,531,030$ & $5,337,500$ & 681,329 & $6,375,187$ & 136,776 & 2,381 \\
\hline Issaquena & $9,902,571$ & 604,000 & $1,769,686$ & $6,381,951$ & $1,146,696$ & 2,381 \\
\hline Jefferson & $11,530,087$ & $1,073,000$ & $1,853,020$ & $8,455,285$ & 142,533 & 6,250 \\
\hline Tunica & $7,490,530$ & 300,500 & 677,829 & $6,375,187$ & 136,776 & 2,381 \\
\hline Warren & $53,899,592$ & $13,741,000$ & $2,589,565$ & $14,676,951$ & $22,885,826$ & 6,250 \\
\hline Washington & $10,033,712$ & $1,349,500$ & $2,055,327$ & $6,481,951$ & 146,696 & 2,381 \\
\hline Wilkinson & $9,399,646$ & 125,000 & 676,829 & $8,455,285$ & 142,533 & 0 \\
\hline Total & $175,738,827$ & $25,903,500$ & $17,245,090$ & $85,531,169$ & $47,045,139$ & 13,939 \\
\hline
\end{tabular}




\section{Table 5.37}

Mississippi Flood Disaster Declarations 50 Year (SHELDUS)

\begin{tabular}{|l|l|l|l|l|l|l|}
\hline $\begin{array}{l}\text { Mississippi } \\
\text { Counties }\end{array}$ & $\begin{array}{l}\text { Total } \\
\text { Disasters }\end{array}$ & 1960 & 1970 & 1980 & 1990 & 2000 \\
\hline Adams & 38 & 0 & 7 & 9 & 10 & 12 \\
\hline Bolivar & 46 & 1 & 9 & 4 & 8 & 24 \\
\hline Claiborne & 28 & 0 & 10 & 4 & 7 & 7 \\
\hline Coahoma & 31 & 1 & 6 & 7 & 6 & 11 \\
\hline DeSoto & 42 & 1 & 6 & 6 & 7 & 21 \\
\hline Issaquena & 25 & 1 & 9 & 4 & 5 & 6 \\
\hline Jefferson & 23 & 1 & 7 & 4 & 5 & 5 \\
\hline Tunica & 19 & 1 & 6 & 5 & 4 & 3 \\
\hline Warren & 49 & 1 & 10 & 7 & 14 & 17 \\
\hline Washington & 38 & 1 & 9 & 6 & 8 & 16 \\
\hline Wilkinson & 16 & 0 & 7 & 4 & 3 & 2 \\
\hline Total & 356 & 8 & 85 & 60 & 78 & 125 \\
\hline
\end{tabular}




\section{Table 5.38}

\section{Mississippi Mitigation Actions: State to County Comparisons}

\begin{tabular}{|c|c|c|c|c|c|}
\hline \multicolumn{6}{|c|}{ Mississippi: State to County Ranked Comparison of Top Mitigation Needs } \\
\hline $\begin{array}{c}\text { Structural } \\
\text { Mitigation }\end{array}$ & 1 & 2 & 3 & 4 & 5 \\
\hline State & $\begin{array}{l}\text { Levees Dams } \\
\text { Floodwalls }\end{array}$ & $\begin{array}{l}\text { Warning } \\
\text { Systems }\end{array}$ & none & none & none \\
\hline Counties & $\begin{array}{l}\text { Move/Build } \\
\text { Rebuild out of } \\
\text { Floodplain }\end{array}$ & Culverts & $\begin{array}{c}\text { Road } \\
\text { Elevation/Repair }\end{array}$ & Sewers & $\begin{array}{c}\text { Elevate } \\
\text { Structures }\end{array}$ \\
\hline $\begin{array}{l}\text { Nonstructural } \\
\text { Mitigation }\end{array}$ & 1 & 2 & 3 & 4 & 5 \\
\hline State & NFIP & $\begin{array}{l}\text { Technical } \\
\text { Support }\end{array}$ & $\begin{array}{c}\text { Enforce } \\
\text { Regulations }\end{array}$ & Communicate & Studies \\
\hline Counties & NFIP & $\begin{array}{l}\text { Maintenance } \\
\text { Check/Clean } \\
\text { Debris }\end{array}$ & Technical Support & $\begin{array}{l}\text { Rep Loss } \\
\text { Funding }\end{array}$ & Studies \\
\hline
\end{tabular}




\section{Table 5.39}

\section{Louisiana Flood Property Damage 50 Year (SHELDUS)}

\begin{tabular}{|l|r|r|r|r|r|r|}
\hline $\begin{array}{l}\text { Louisiana } \\
\text { Counties }\end{array}$ & $\begin{array}{l}\text { Total Property } \\
\text { Damage 50 } \\
\text { yrs }\end{array}$ & \multicolumn{1}{l|}{\begin{tabular}{l} 
Total PD \\
\multicolumn{1}{l|}{$\begin{array}{l}\text { Total PD } \\
1990\end{array}$}
\end{tabular}} & $\begin{array}{l}\text { Total PD } \\
1980\end{array}$ & $\begin{array}{l}\text { Total PD } \\
1970\end{array}$ & \multicolumn{1}{l}{$\begin{array}{l}\text { Total } \\
\text { PD } \\
1960\end{array}$} \\
\hline Ascension & $51,460,119$ & $2,600,000$ & $41,833,711$ & $6,519,897$ & 505,747 & 0 \\
\hline Concordia & $1,774,790$ & 608,000 & 50,000 & 781,250 & 343,391 & 301,149 \\
\hline $\begin{array}{l}\text { East Baton } \\
\text { Rouge }\end{array}$ & $51,6764,66$ & $2,452,000$ & $42,073,711$ & $6,639,879$ & 505,747 & 5,129 \\
\hline East Carroll & $3,837,755$ & $1,748,000$ & 270,000 & $1,289,583$ & 501,613 & 28,559 \\
\hline Iberville & $50,701,133$ & $2,400,000$ & $41,983,711$ & $5,806,546$ & 505,747 & 5,129 \\
\hline Jefferson & $13,131,675$ & 345,000 & 350,000 & $12,431,546$ & 0 & 5,129 \\
\hline Madison & $5,316,755$ & $1,272,000$ & 850,000 & $2,664,583$ & 501,613 & 28,559 \\
\hline Orleans & $8,397,327$ & 365,000 & 550,000 & $7,481,546$ & 0 & 78,125 \\
\hline Plaquemines & $5,900,008$ & 130,000 & 500,000 & $5,264,879$ & 0 & 5,129 \\
\hline $\begin{array}{l}\text { Pointe } \\
\text { Coupee }\end{array}$ & $45,750,119$ & 590,000 & $41,763,711$ & $2,889,879$ & 505,747 & 78,125 \\
\hline St. Bernard & $8,376,675$ & 330,000 & 610,000 & $7,431,546$ & 0 & 5,129 \\
\hline St. Charles & $7,828,719$ & 500,000 & $1,092,044$ & $6,231,546$ & 0 & 5,129 \\
\hline St. James & $5,679,467$ & 85,000 & 152,044 & $5,264,879$ & 172,414 & 5,129 \\
\hline $\begin{array}{l}\text { St. John the } \\
\text { Baptist }\end{array}$ & $6,572,386$ & 327,000 & 642,044 & $5,264,879$ & 33,333 & 5,129 \\
\hline Tensas & $3,495,873$ & 332,000 & 300,000 & $2,039,583$ & 501,613 & 322,677 \\
\hline $\begin{array}{l}\text { West Baton } \\
\text { Rouge }\end{array}$ & $47,669,466$ & 25,000 & $41,743,711$ & $5,389,879$ & 505,747 & 5,129 \\
\hline $\begin{array}{l}\text { West } \\
\text { Feliciana }\end{array}$ & $46,201,785$ & 10,000 & $42,503,711$ & $3,181,546$ & 505,747 & 78,125 \\
\hline Total & $363,770,517$ & $14,119,000$ & $257,268,400$ & $86,573,426$ & $5,079,461$ & 730,230 \\
\hline
\end{tabular}




\section{Table 5.40}

Louisiana Flood Disaster Declarations 50 Year (SHELDUS)

\begin{tabular}{|l|r|r|r|r|r|r|}
\hline $\begin{array}{l}\text { Louisiana } \\
\text { Counties }\end{array}$ & $\begin{array}{l}\text { Total } \\
\text { Disasters }\end{array}$ & 1960 & 1970 & 1980 & 1990 & 2000 \\
\hline Ascension & 18 & 1 & 2 & 8 & 4 & 3 \\
\hline Concordia & 18 & 3 & 3 & 1 & 1 & 10 \\
\hline $\begin{array}{l}\text { East Baton } \\
\text { Rouge }\end{array}$ & 28 & 3 & 2 & 8 & 10 & 5 \\
\hline East Carroll & 15 & 2 & 3 & 3 & 2 & 5 \\
\hline Iberville & 21 & 3 & 2 & 7 & 6 & 3 \\
\hline Jefferson & 26 & 3 & 0 & 9 & 4 & 10 \\
\hline Madison & 16 & 2 & 2 & 4 & 3 & 6 \\
\hline Orleans & 18 & 1 & 0 & 9 & 3 & 5 \\
\hline Plaquemines & 10 & 3 & 0 & 5 & 1 & 1 \\
\hline $\begin{array}{l}\text { Pointe } \\
\text { Coupee }\end{array}$ & 14 & 1 & 2 & 5 & 3 & 3 \\
\hline St. Bernard & 16 & 3 & 0 & 8 & 3 & 2 \\
\hline St. Charles & 19 & 3 & 0 & 8 & 4 & 4 \\
\hline St. James & 17 & 3 & 1 & 5 & 4 & 4 \\
\hline $\begin{array}{l}\text { St. John the } \\
\text { Baptist }\end{array}$ & 16 & 3 & 1 & 5 & 4 & 4 \\
\hline Tensas & 22 & 3 & 2 & 3 & 2 & 12 \\
\hline $\begin{array}{l}\text { West Baton } \\
\text { Rouge }\end{array}$ & 14 & 3 & 2 & 6 & 2 & 1 \\
\hline $\begin{array}{l}\text { West } \\
\text { Feliciana }\end{array}$ & 13 & 1 & 2 & 5 & 4 & 1 \\
\hline Total & 239 & 41 & 24 & 99 & 60 & 69 \\
\hline
\end{tabular}




\section{Table 5.41}

\section{Louisiana Mitigation Actions: State to County Comparisons}

\begin{tabular}{|c|c|c|c|c|c|}
\hline \multicolumn{6}{|c|}{ Louisiana: State to County Ranked Comparison of Top Mitigation Needs } \\
\hline $\begin{array}{l}\text { Structural } \\
\text { Mitigation }\end{array}$ & 1 & 2 & 3 & 4 & 5 \\
\hline State & none & none & none & none & none \\
\hline Counties & $\begin{array}{l}\text { Pumping } \\
\text { Stations }\end{array}$ & $\begin{array}{c}\text { Elevate } \\
\text { Structures } \\
\end{array}$ & Culverts & Sewers & $\begin{array}{c}\text { Channel } \\
\text { Improvements }\end{array}$ \\
\hline $\begin{array}{c}\text { Nonstructural } \\
\text { Mitigation }\end{array}$ & 1 & 2 & 3 & 4 & 5 \\
\hline State & none & none & none & none & none \\
\hline Counties & Policy Influence & $\begin{array}{c}\text { Education } \\
\text { Outreach }\end{array}$ & Studies & $\begin{array}{l}\text { Rep Loss } \\
\text { Funding }\end{array}$ & $\begin{array}{c}\text { Technical } \\
\text { Support }\end{array}$ \\
\hline
\end{tabular}




\section{Table 5.42}

Census Tract Population/Households in/near Floodplain and High Poverty Percentage

\begin{tabular}{|l|l|l|l|l|l|}
\hline & $\begin{array}{l}\text { Census } \\
\text { Tract Total } \\
\text { Population }\end{array}$ & Percent & $\begin{array}{l}\text { Census } \\
\text { Tract Total } \\
\text { Households }\end{array}$ & Percent & $\begin{array}{l}\text { Highest } \\
\text { Poverty } \\
\text { Level } \\
\text { Percent }\end{array}$ \\
\hline Minnesota & 437,001 & 14 & 167,229 & 13 & 56 \\
\hline Wisconsin & 121,223 & 40 & 50,624 & 47 & 31 \\
\hline Iowa & 440,858 & 90 & 177,101 & 89 & 49 \\
\hline Missouri & 189,894 & 10 & 72,483 & 10 & 64 \\
\hline Illinois & 177,454 & 16 & 87,431 & 16 & 65 \\
\hline Kentucky & 17,764 & 71 & 7,311 & 71 & 30 \\
\hline Tennessee & 30,565 & 3 & 10,557 & 3 & 44 \\
\hline Arkansas & 43,000 & 28 & 15,000 & 27 & 59 \\
\hline Mississippi & 103,404 & 27 & 38,629 & 27 & 66 \\
\hline Louisiana & 703,672 & 43 & 264,442 & 43 & 45 \\
\hline
\end{tabular}




\section{Figure 5.5}

Upper Mississippi River Region: Overall Poverty

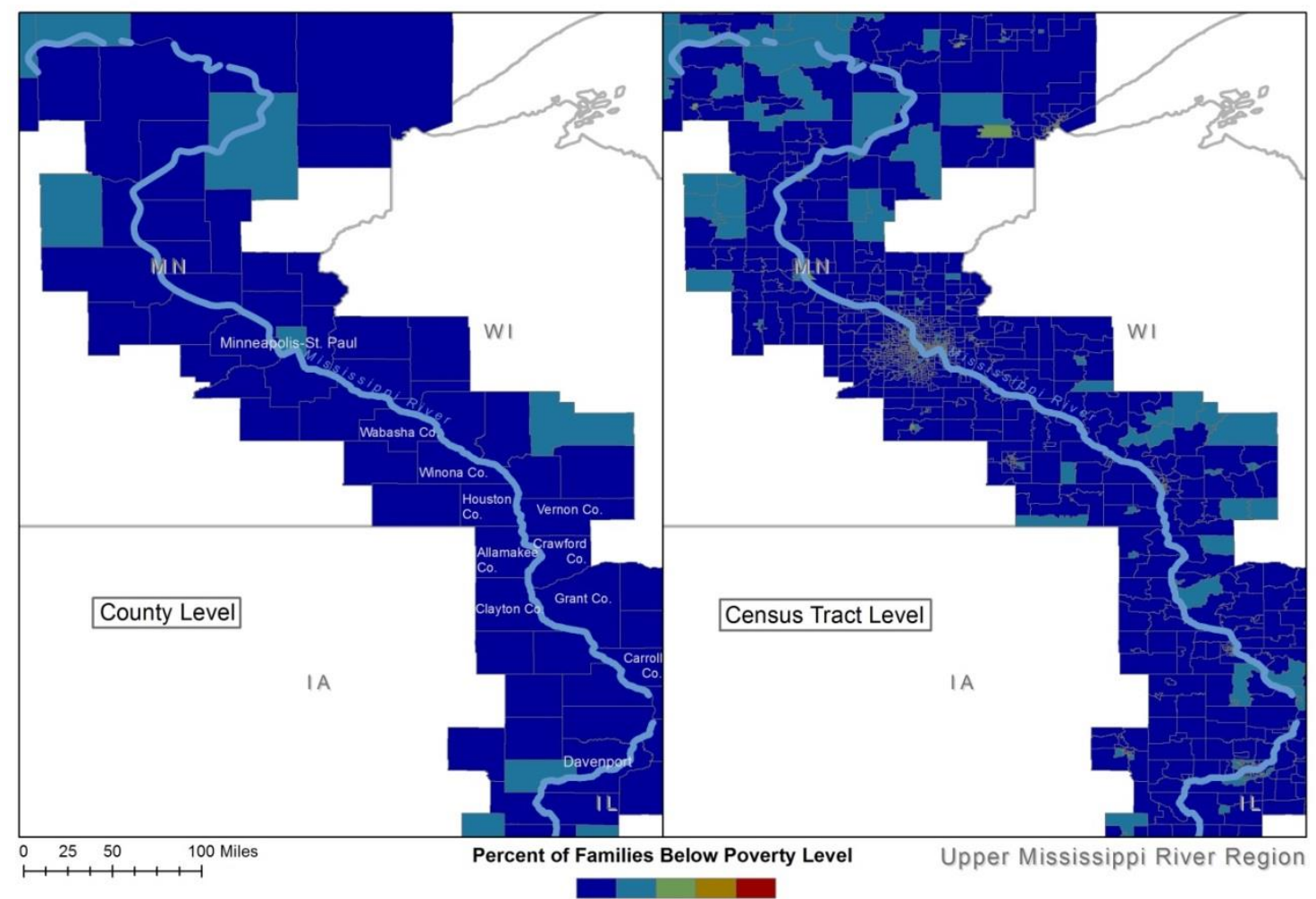

American Community Survey 2012 (5 year estimates) county and census tract data was mapped using ArcGIS ${ }^{\circledR}$ software by Esri. ArcGIS ${ }^{\circledR}$ and ArcMap ${ }^{\mathrm{TM}}$ are the intellectual property of Esri and are used herein under license. 


\section{Figure 5.6}

Upper Middle Mississippi River Region: Overall Poverty

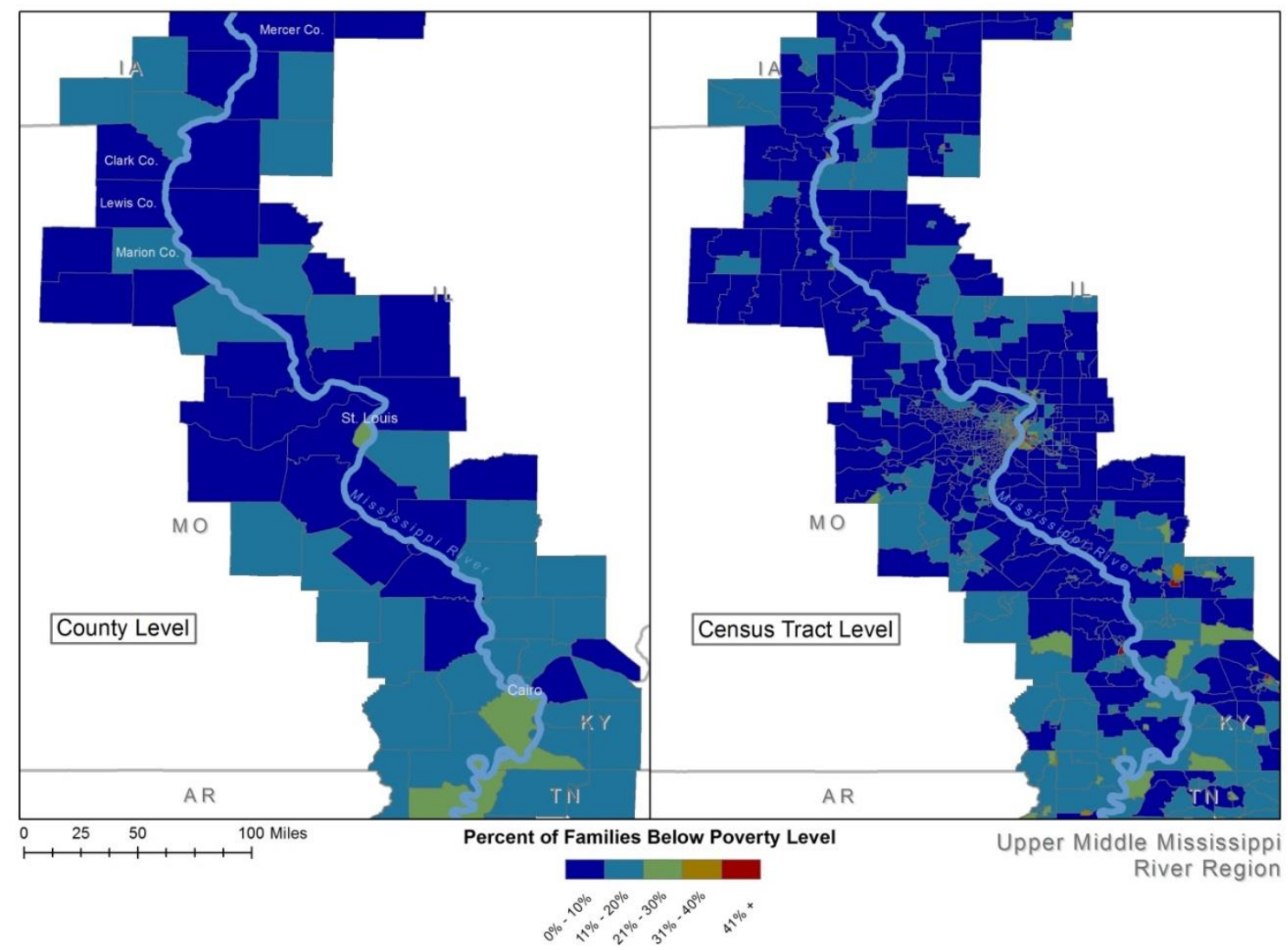

American Community Survey 2012 (5 year estimates) county and census tract data mapped using ArcGIS ${ }^{\circledR}$ software by Esri. ArcGIS ${ }^{\circledR}$ and ArcMap ${ }^{\mathrm{TM}}$ are the intellectual property of Esri and are used herein under license. 


\section{Figure 5.7}

Lower Mississippi River Region: Overall Poverty

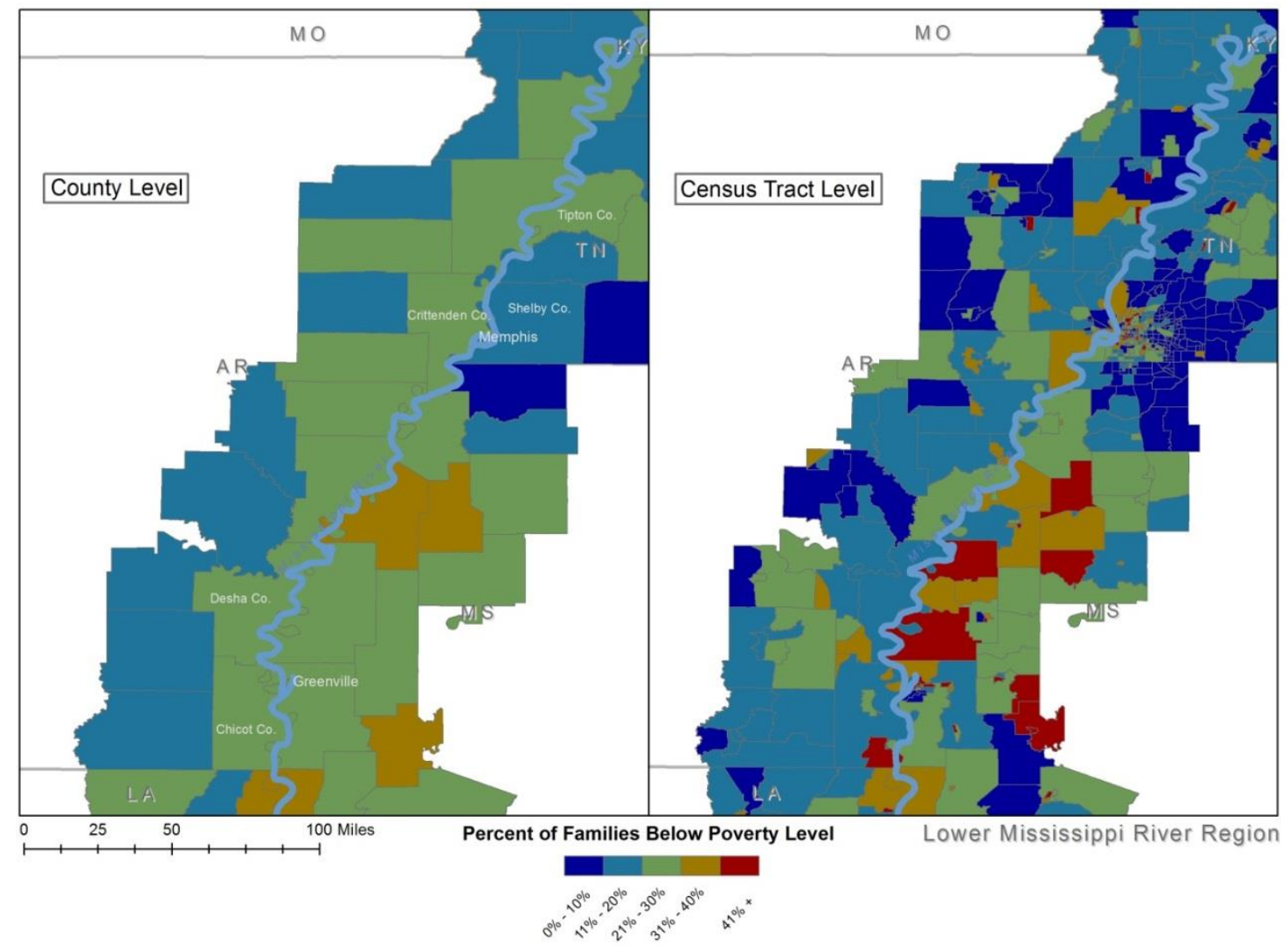

American Community Survey 2012 (5 year estimates) county and census tract data mapped using ArcGIS ${ }^{\circledR}$ software by Esri. ArcGIS ${ }^{\circledR}$ and ArcMap ${ }^{\mathrm{TM}}$ are the intellectual property of Esri and are used herein under license. 


\section{Figure 5.8}

Louisiana Region: Overall Poverty

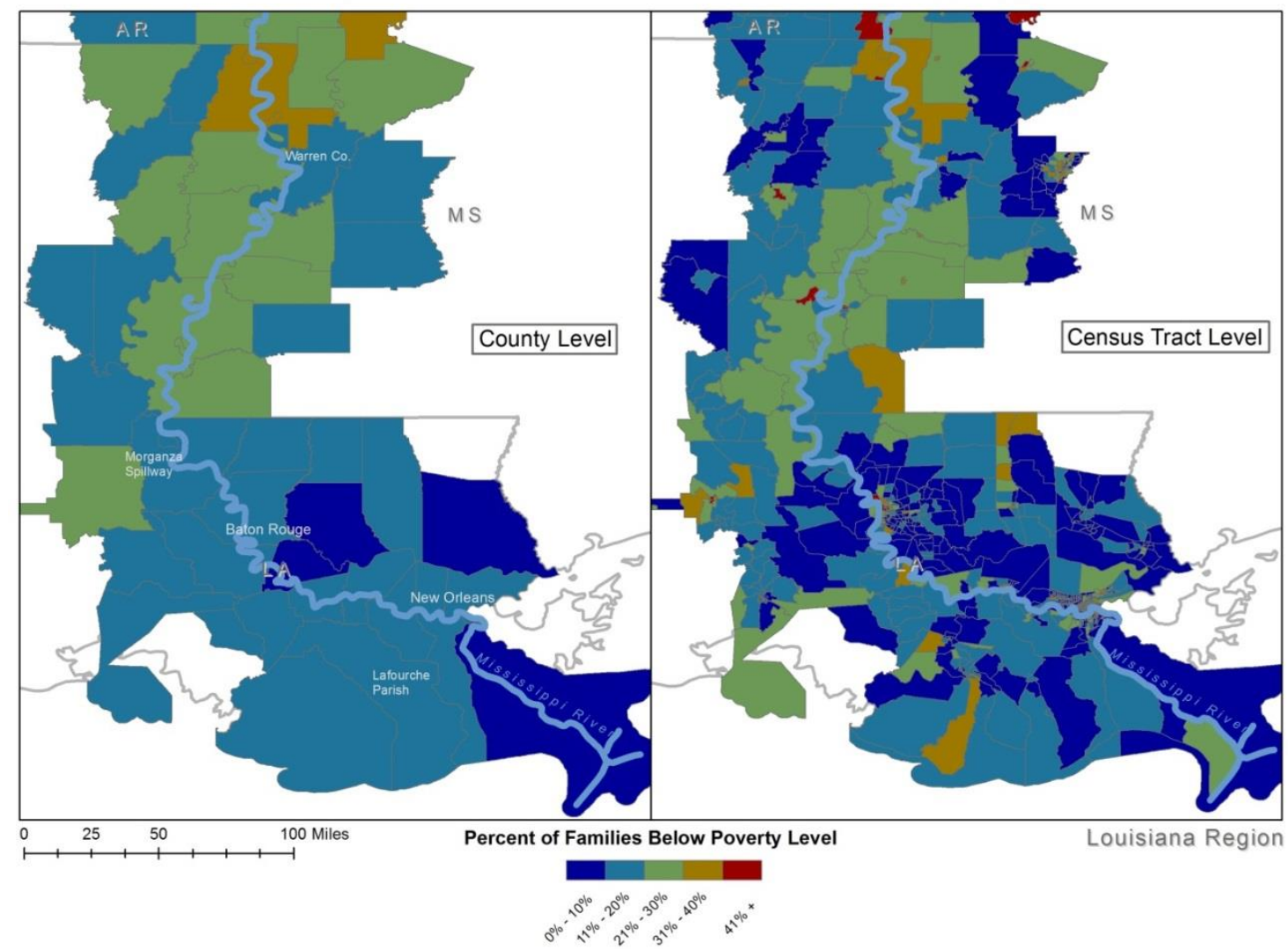

American Community Survey 2012 (5 year estimates) county and census tract data mapped using ArcGIS ${ }^{\circledR}$ software by Esri. ArcGIS ${ }^{\circledR}$ and $\operatorname{ArcMap}^{\mathrm{TM}}$ are the intellectual property of Esri and are used herein under license. 


\section{Figure 5.9}

Minneapolis/St. Paul, MN: Overall Poverty - Census Tract Level

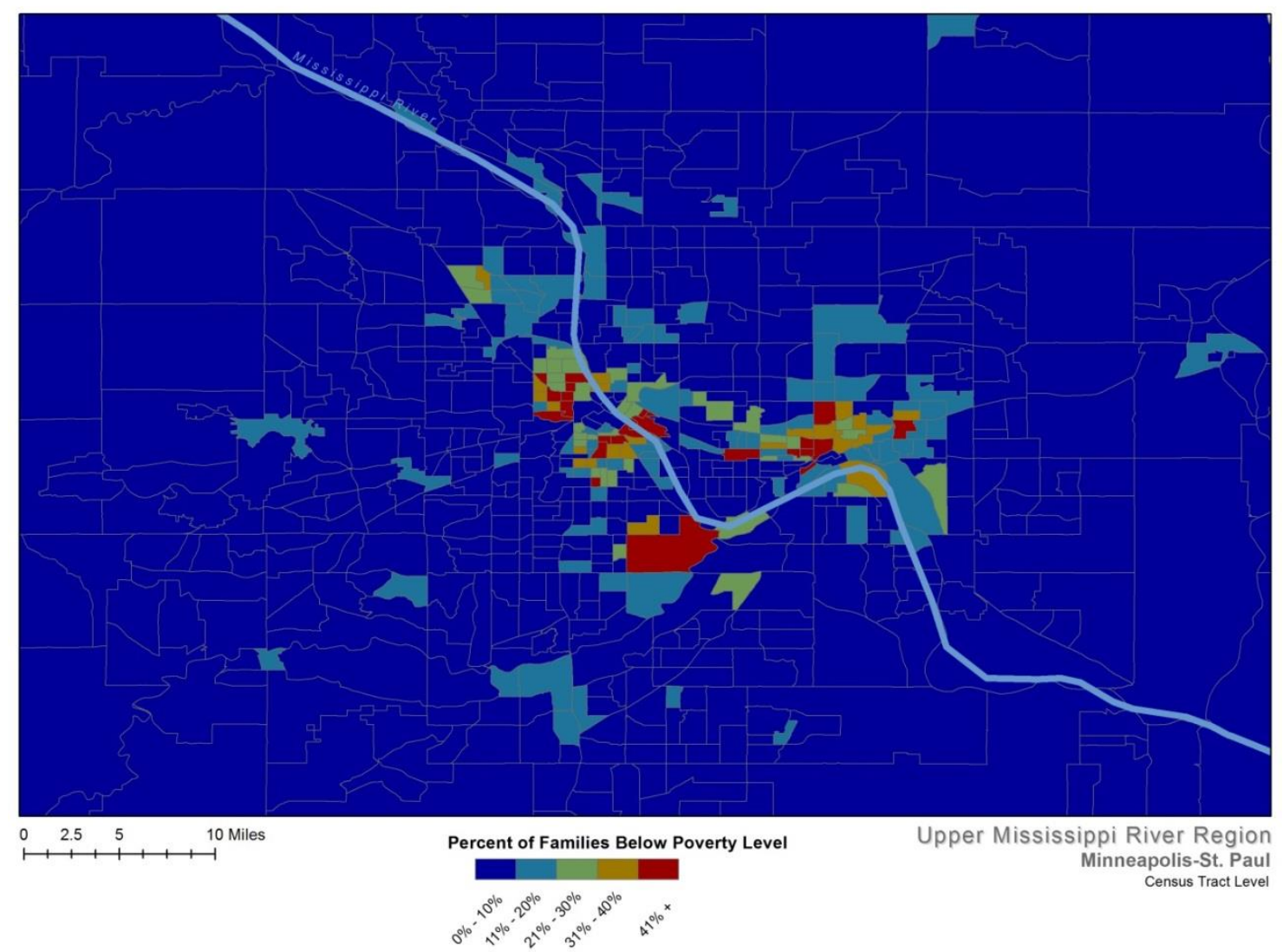

American Community Survey 2012 (5 year estimates) county and census tract data mapped using ArcGIS ${ }^{\circledR}$ software by Esri. ArcGIS ${ }^{\circledR}$ and ArcMap ${ }^{\mathrm{TM}}$ are the intellectual property of Esri and are used herein under license. 


\section{Figure 5.10}

Quad Cities (Side View): Overall Poverty - Census Tract Level

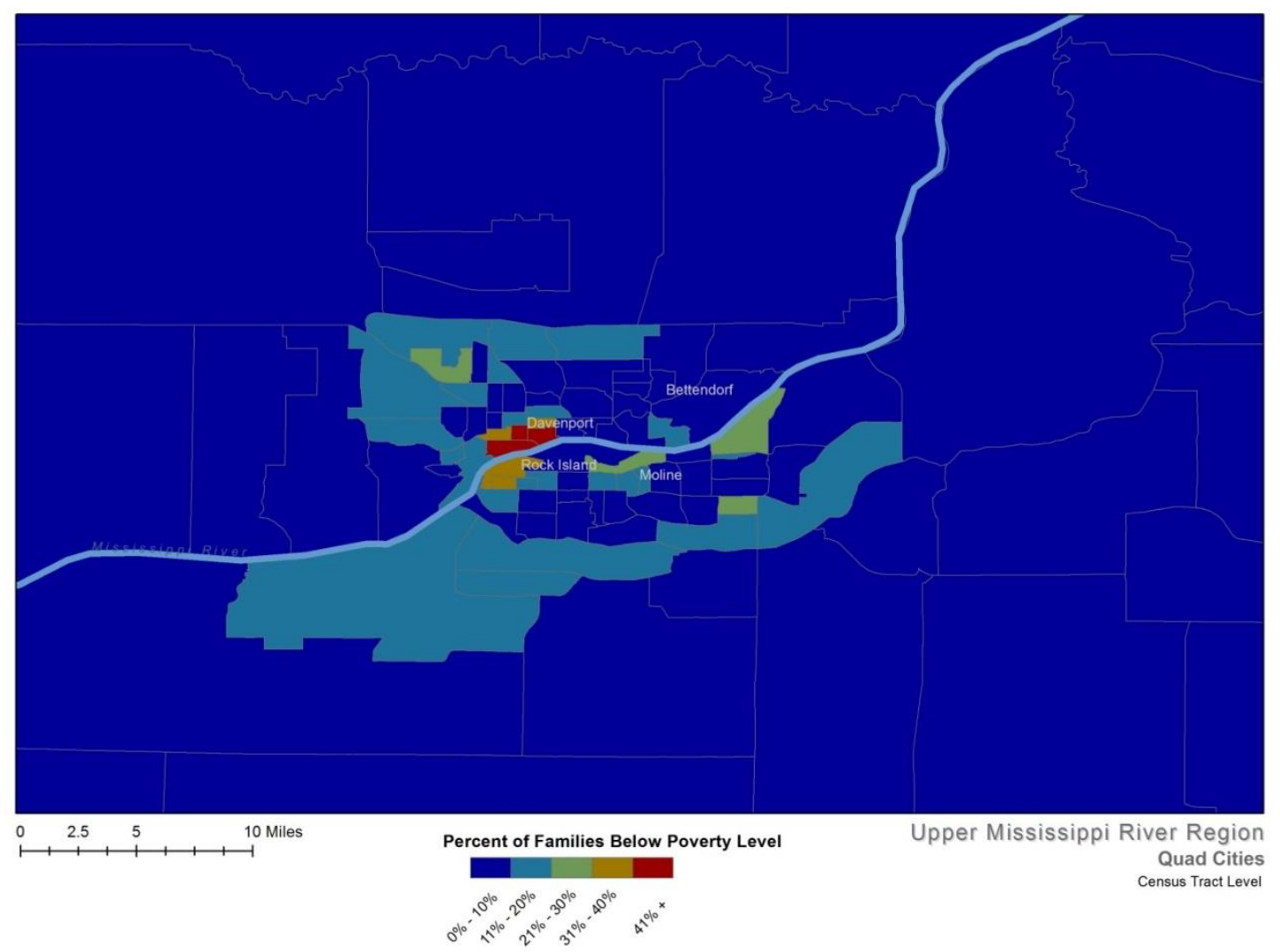

American Community Survey 2012 (5 year estimates) county and census tract data mapped using ArcGIS ${ }^{\circledR}$ software by Esri. ArcGIS ${ }^{\circledR}$ and $\operatorname{ArcMap}^{\mathrm{TM}}$ are the intellectual property of Esri and are used herein under license. 


\section{Table 5.11}

St. Louis: Overall Poverty - Census Tract Level

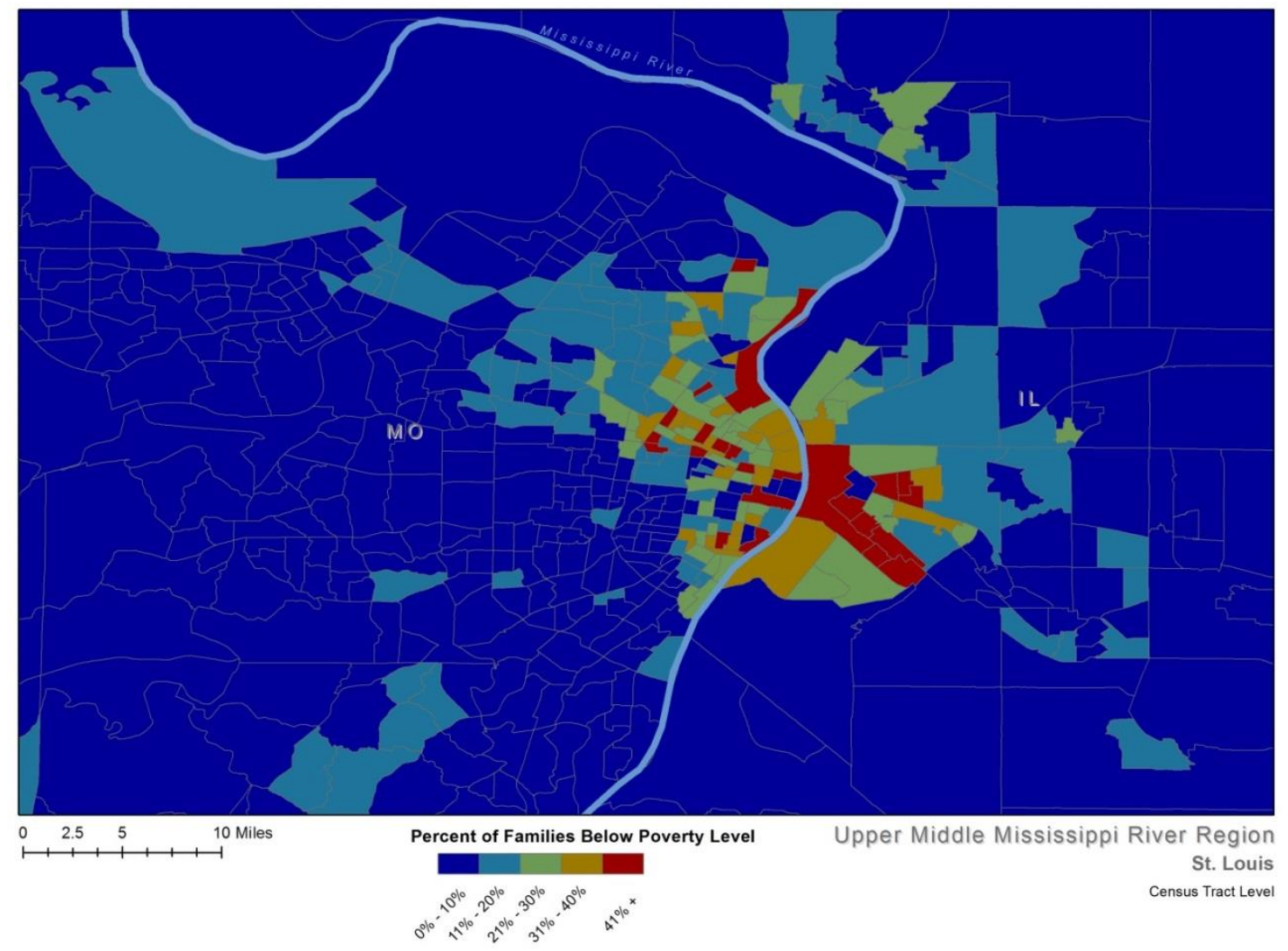

American Community Survey 2012 (5 year estimates) county and census tract data mapped using ArcGIS ${ }^{\circledR}$ software by Esri. ArcGIS ${ }^{\circledR}$ and $\operatorname{ArcMap}^{\mathrm{TM}}$ are the intellectual property of Esri and are used herein under license. 
Figure 5.12

Memphis, TN Overall Poverty - Census Tract Level

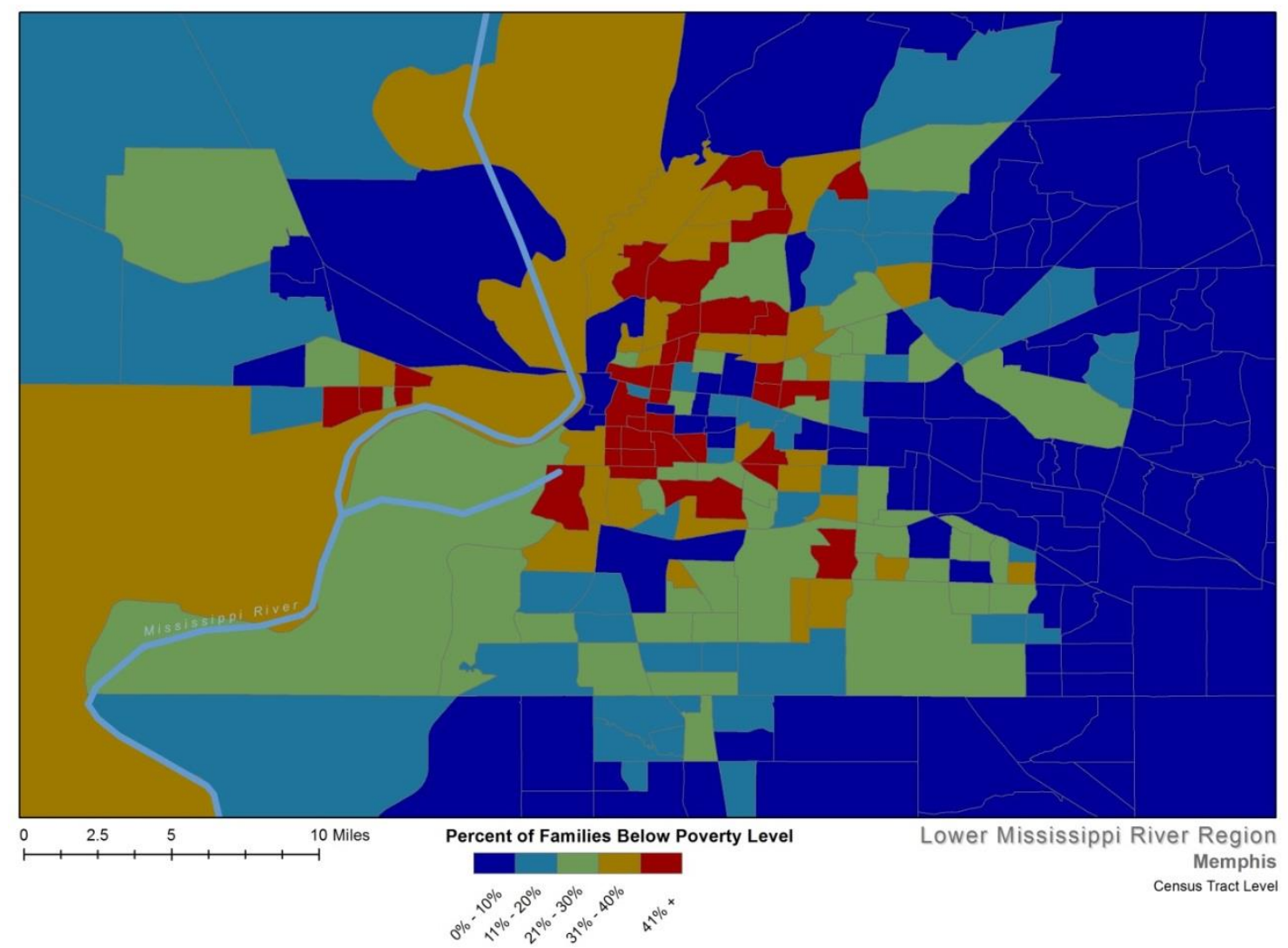

American Community Survey 2012 (5 year estimates) county and census tract data mapped using ArcGIS ${ }^{\circledR}$ software by Esri. ArcGIS ${ }^{\circledR}$ and ArcMap ${ }^{\mathrm{TM}}$ are the intellectual property of Esri and are used herein under license. 


\section{Figure 5.13}

Baton Rouge, LA: Overall Poverty - Census Tract Level

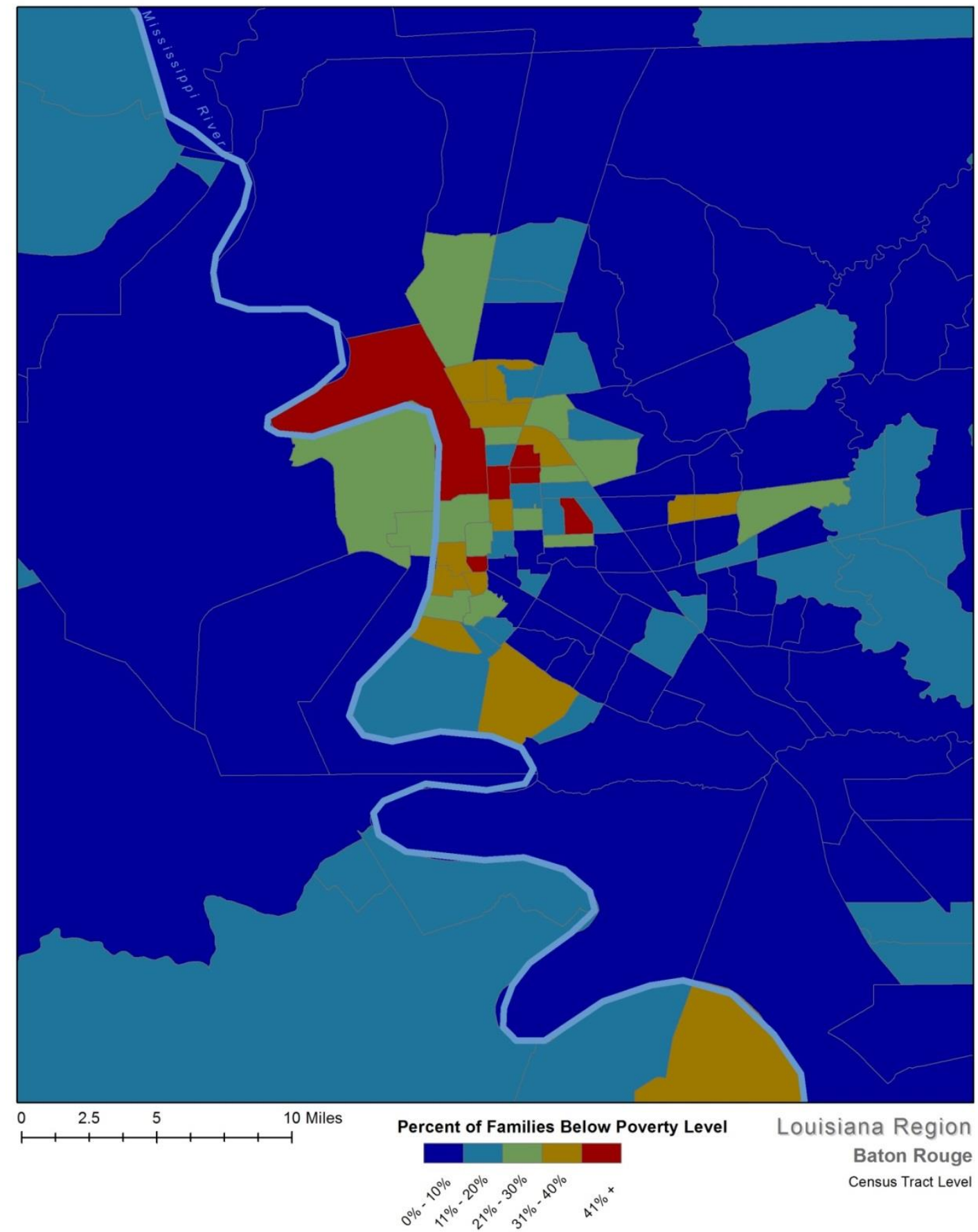

American Community Survey 2012 (5 year estimates) county and census tract data mapped using ArcGIS ${ }^{\circledR}$ software by Esri. ArcGIS ${ }^{\circledR}$ and ArcMap ${ }^{\mathrm{TM}}$ are the intellectual property of Esri and are used herein under license. 


\section{Figure 5.14}

New Orleans, LA: Overall Poverty - Census Tract Level

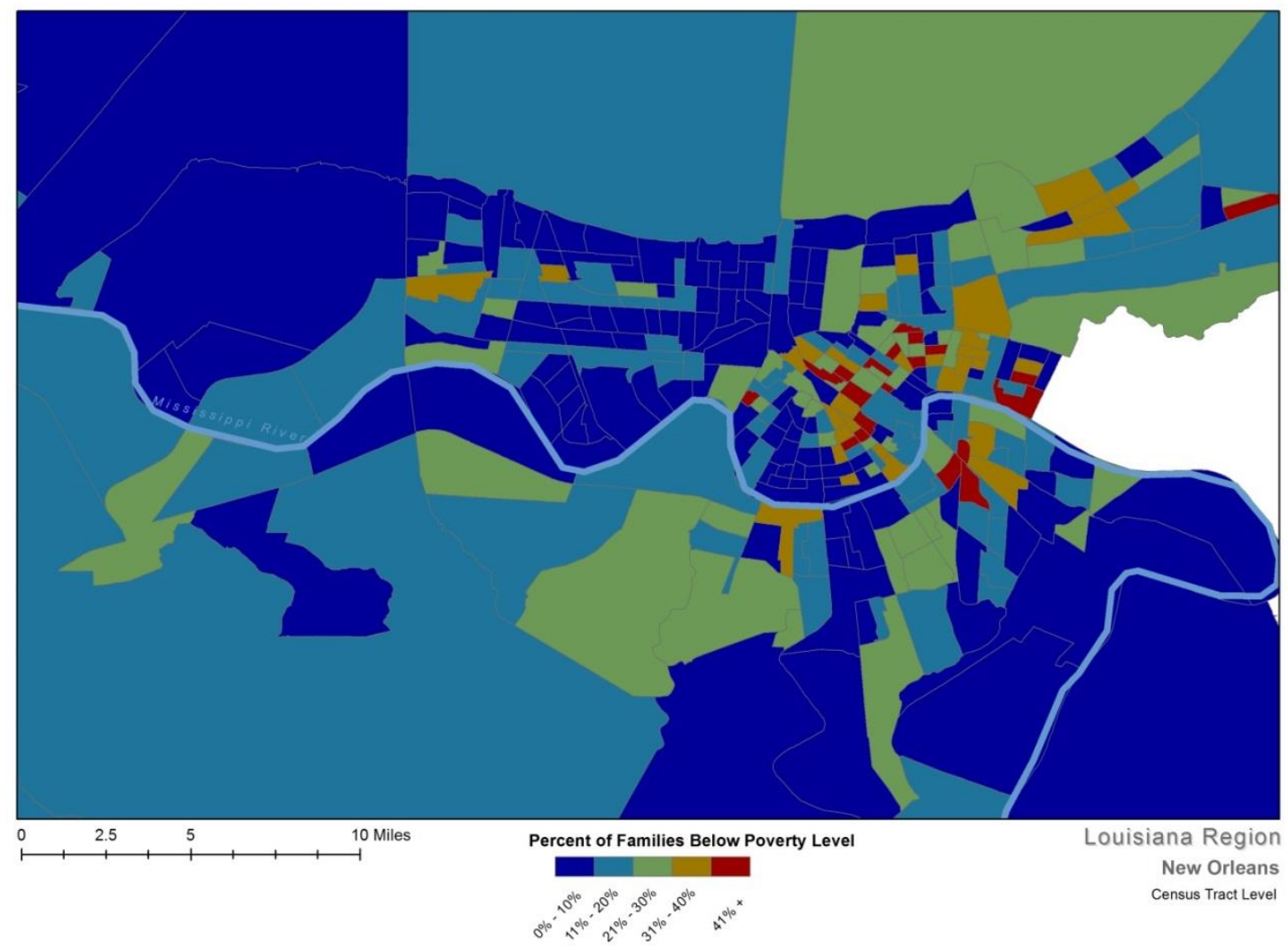

American Community Survey 2012 (5 year estimates) county and census tract data mapped using ArcGIS ${ }^{\circledR}$ software by Esri. ArcGIS ${ }^{\circledR}$ and ArcMap ${ }^{\mathrm{TM}}$ are the intellectual property of Esri and are used herein under license. 


\section{Figure 5.15}

Upper Mississippi River Region: White Poverty

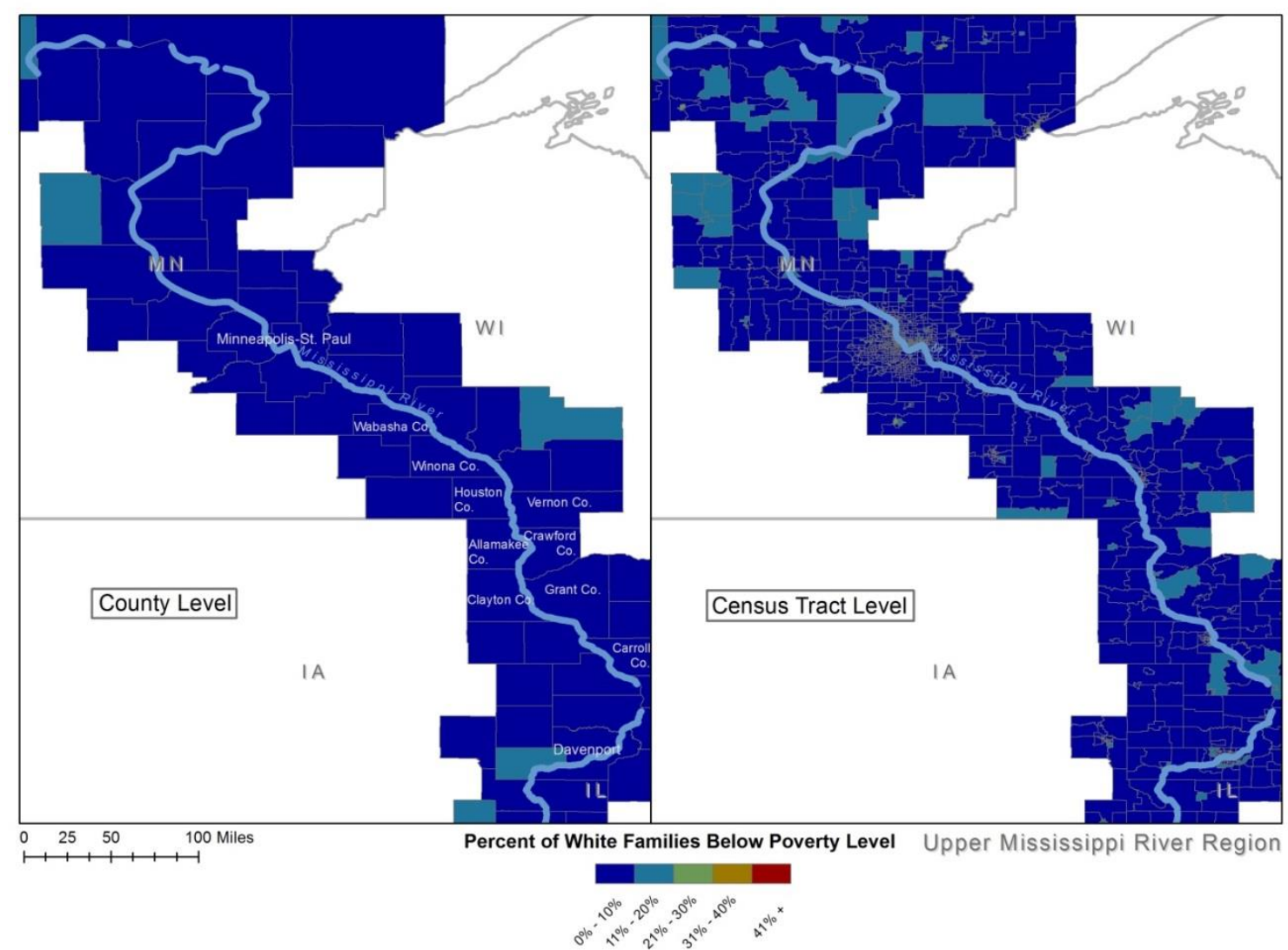

American Community Survey 2012 (5 year estimates) county and census tract data mapped using ArcGIS ${ }^{\circledR}$ software by Esri. ArcGIS ${ }^{\circledR}$ and ArcMap ${ }^{\mathrm{TM}}$ are the intellectual property of Esri and are used herein under license. 
Figure 5.16

Upper Middle Mississippi River Region: White Poverty

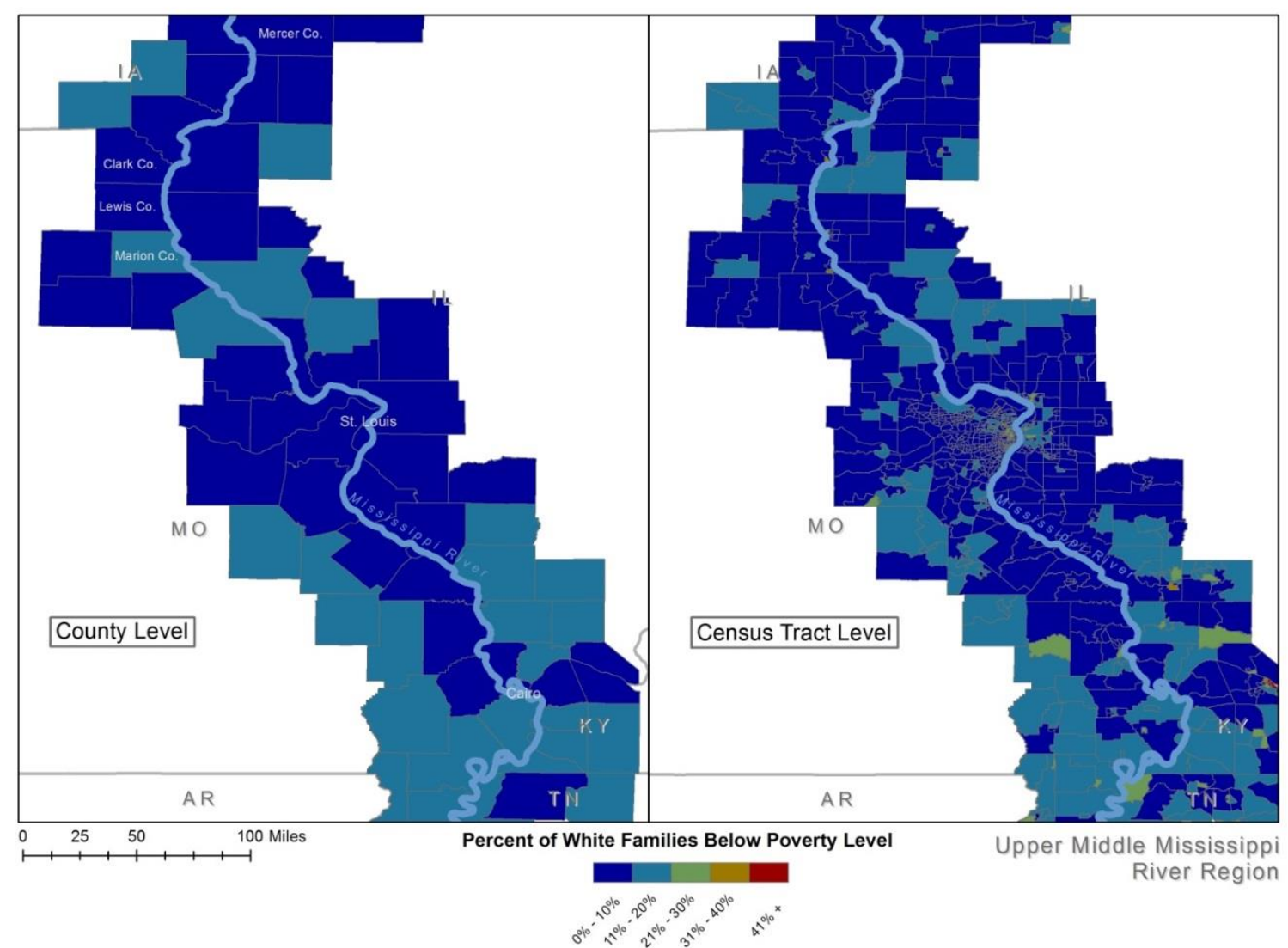

American Community Survey 2012 (5 year estimates) county and census tract data mapped using ArcGIS ${ }^{\circledR}$ software by Esri. ArcGIS ${ }^{\circledR}$ and ArcMap ${ }^{\mathrm{TM}}$ are the intellectual property of Esri and are used herein under license. 


\section{Figure 5.17}

Lower Mississippi River Region: White Poverty

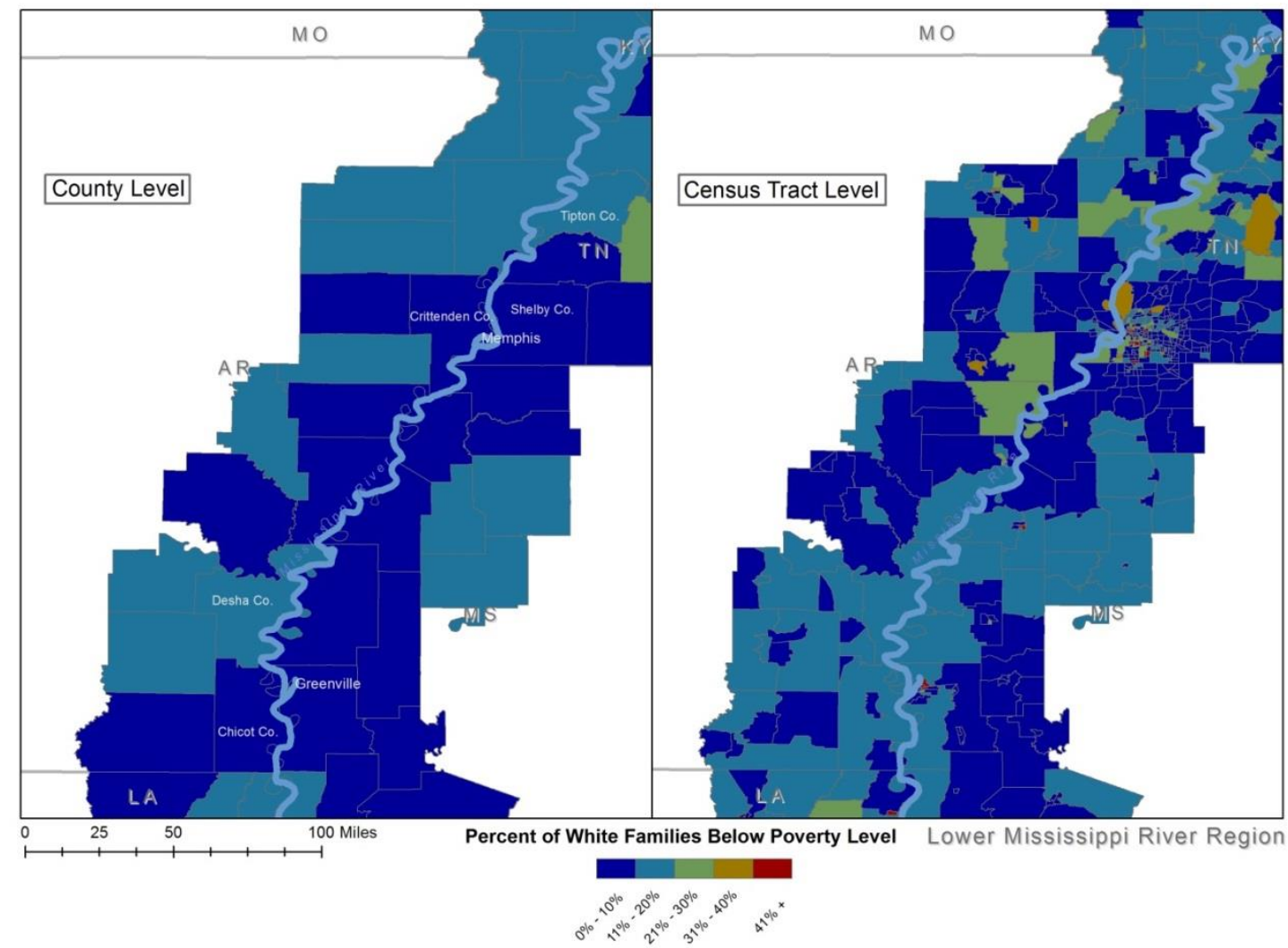

American Community Survey 2012 (5 year estimates) county and census tract data mapped using ArcGIS ${ }^{\circledR}$ software by Esri. ArcGIS ${ }^{\circledR}$ and ArcMap ${ }^{\mathrm{TM}}$ are the intellectual property of Esri and are used herein under license. 
Figure 5.18

Lower Mississippi River Region: White Poverty

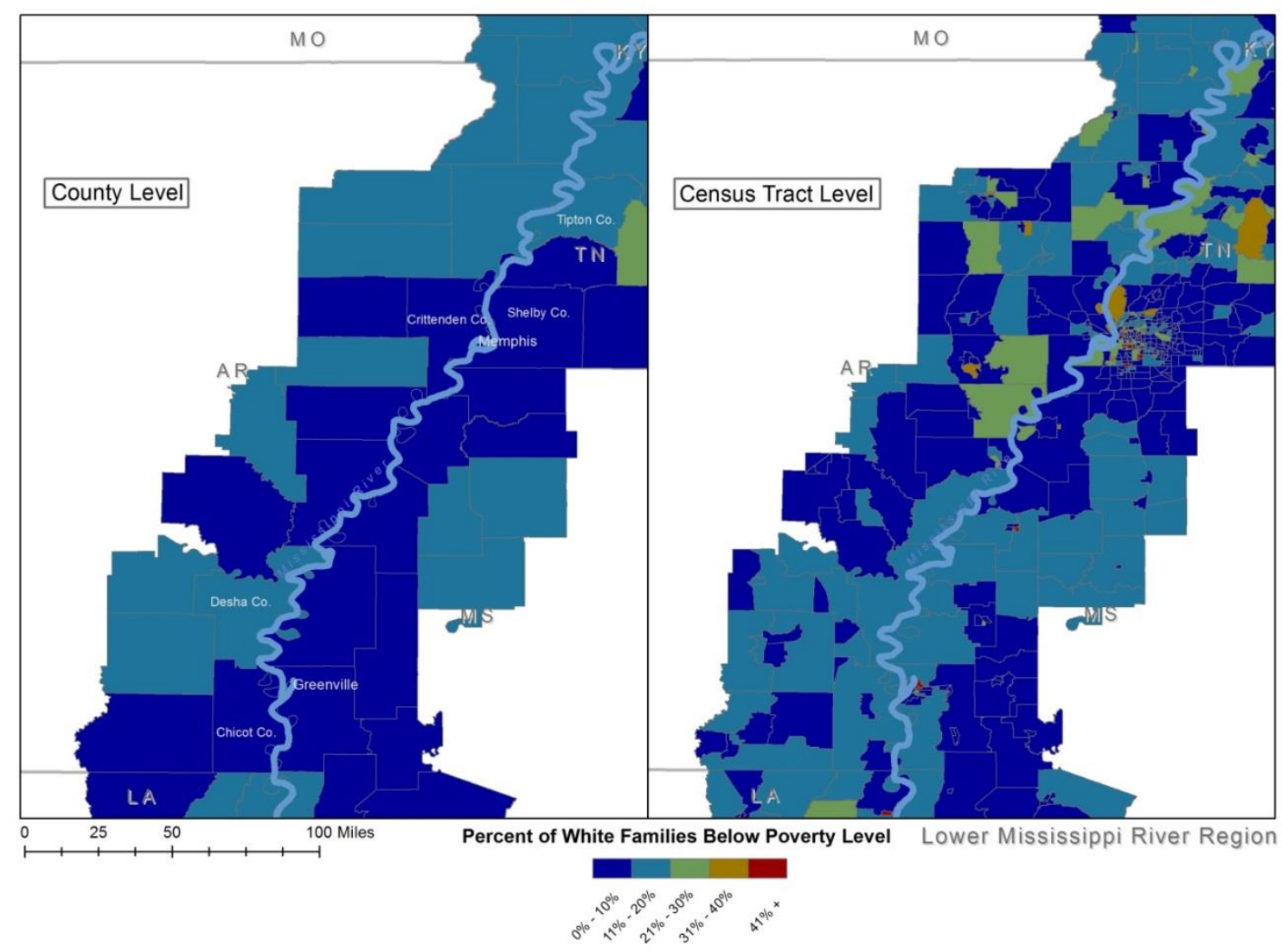

American Community Survey 2012 (5 year estimates) county and census tract data mapped using ArcGIS ${ }^{\circledR}$ software by Esri. ArcGIS $\AA$ and ArcMap ${ }^{\mathrm{TM}}$ are the intellectual property of Esri and are used herein under license. 
Figure 5.19

Louisiana Region: White Poverty

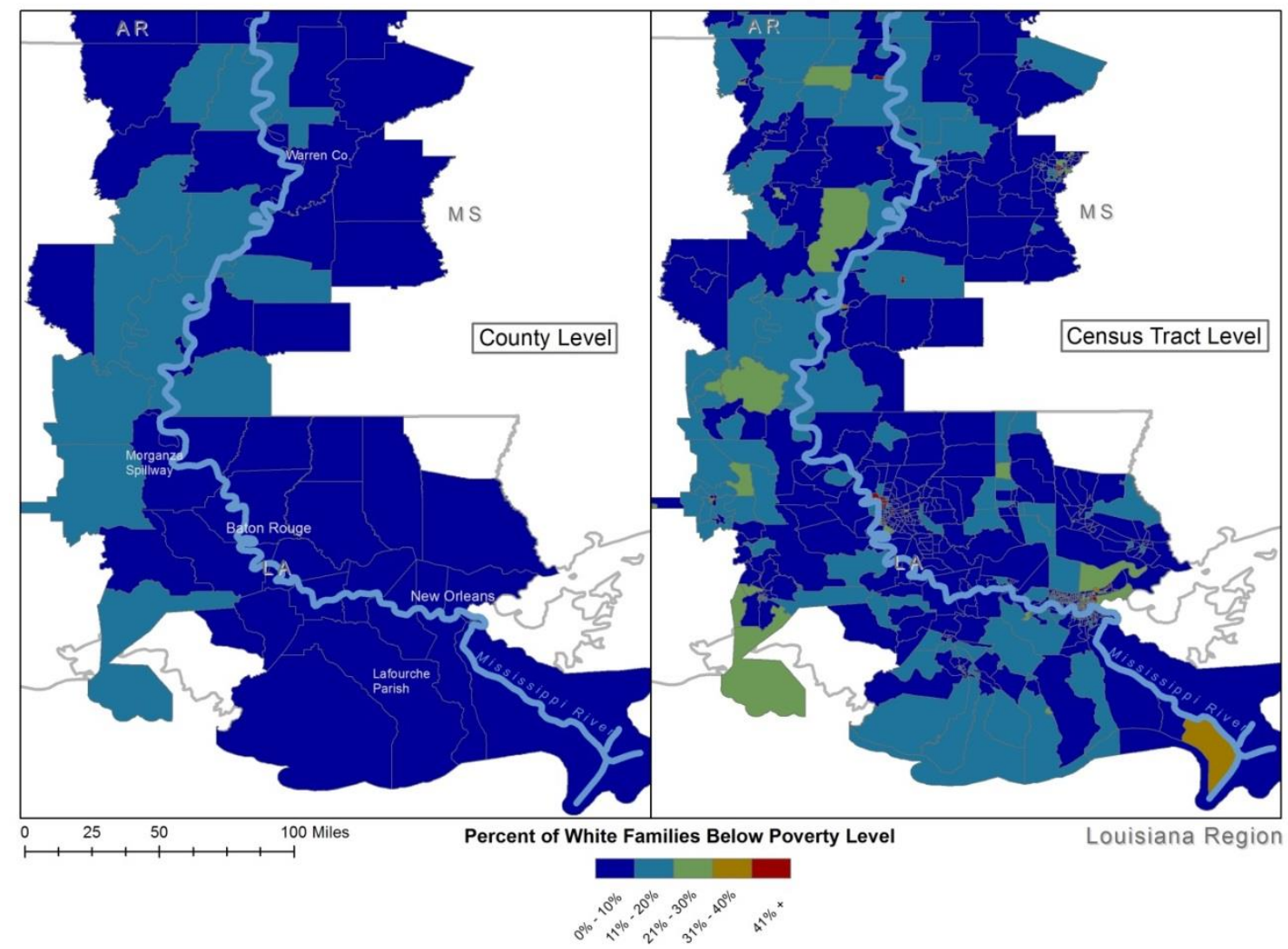

American Community Survey 2012 (5 year estimates) county and census tract data mapped using ArcGIS ${ }^{\circledR}$ software by Esri. ArcGIS ${ }^{\circledR}$ and ArcMap ${ }^{\mathrm{TM}}$ are the intellectual property of Esri and are used herein under license. 


\section{Figure 5.20}

Minneapolis/St. Paul, MN: White Poverty - Census Tract Level

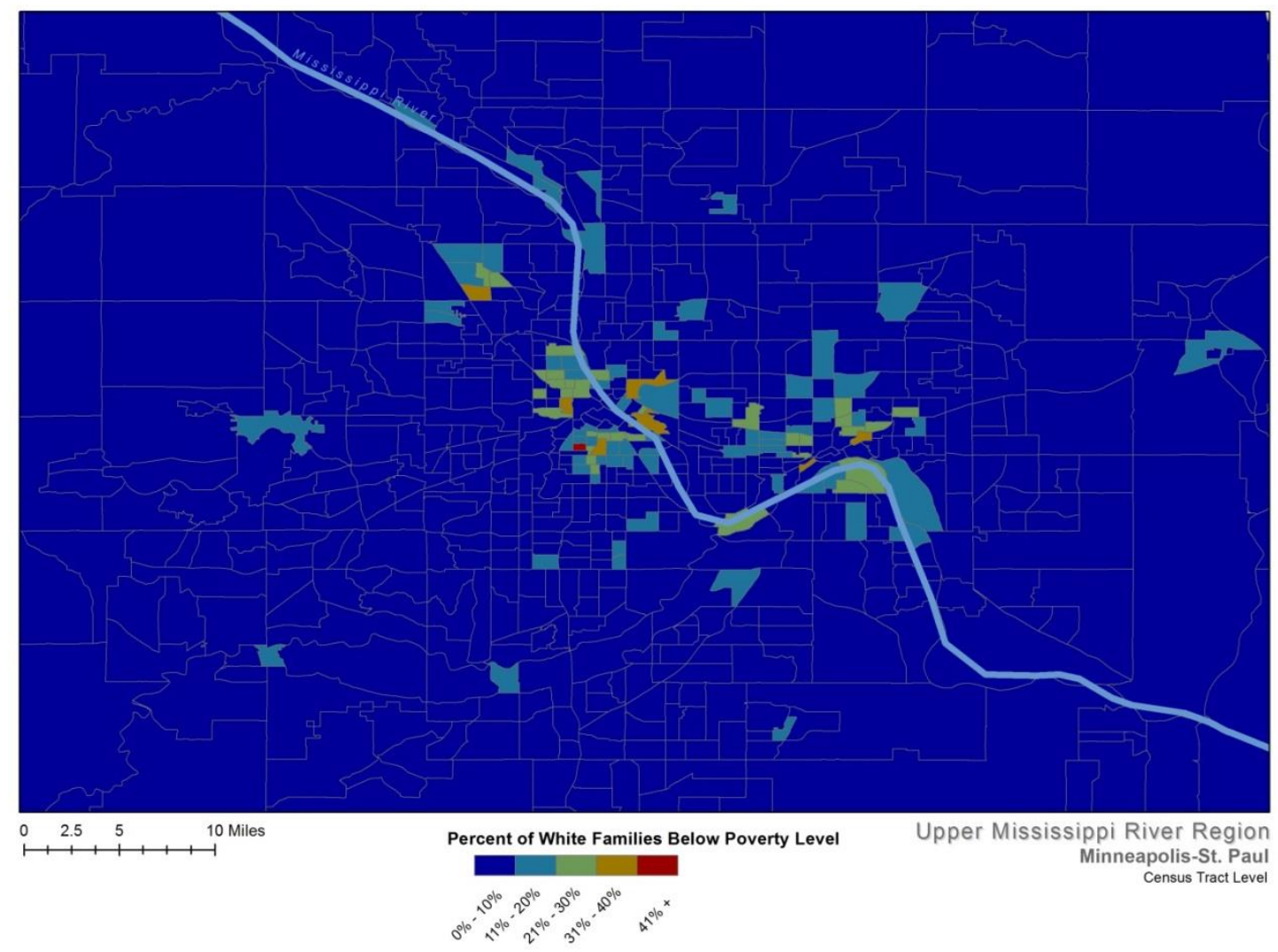

American Community Survey 2012 (5 year estimates) county and census tract data mapped using ArcGIS ${ }^{\circledR}$ software by Esri. ArcGIS ${ }^{\circledR}$ and ArcMap ${ }^{\mathrm{TM}}$ are the intellectual property of Esri and are used herein under license. 


\section{Figure 5.21}

Quad Cities (side view): White Poverty - Census Tract Level

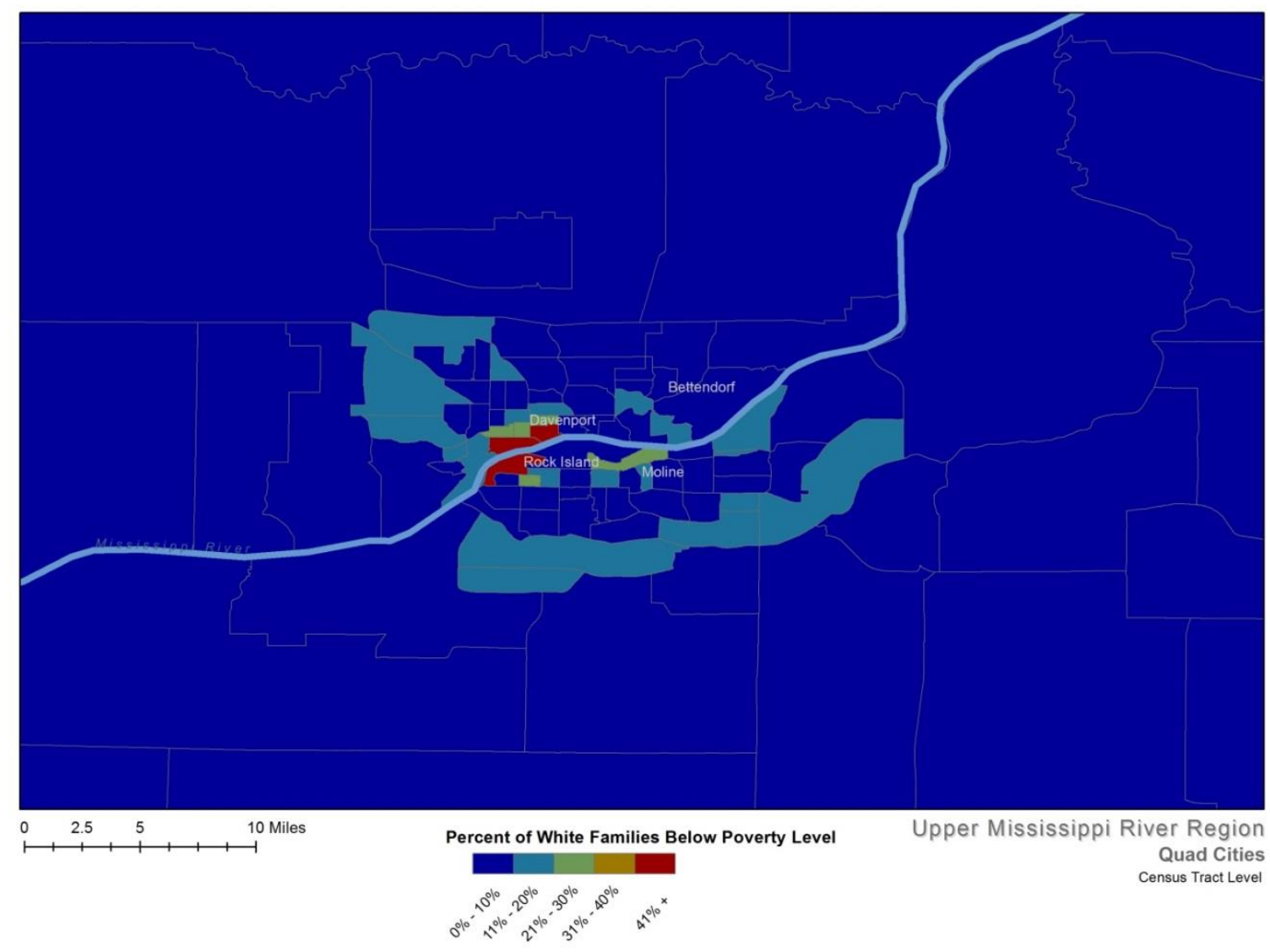

American Community Survey 2012 (5 year estimates) county and census tract data mapped using ArcGIS ${ }^{\circledR}$ software by Esri. ArcGIS ${ }^{\circledR}$ and ArcMap ${ }^{\mathrm{TM}}$ are the intellectual property of Esri and are used herein under license. 


\section{Figure 5.22}

St. Louis, MO: White Poverty - Census Tract Level

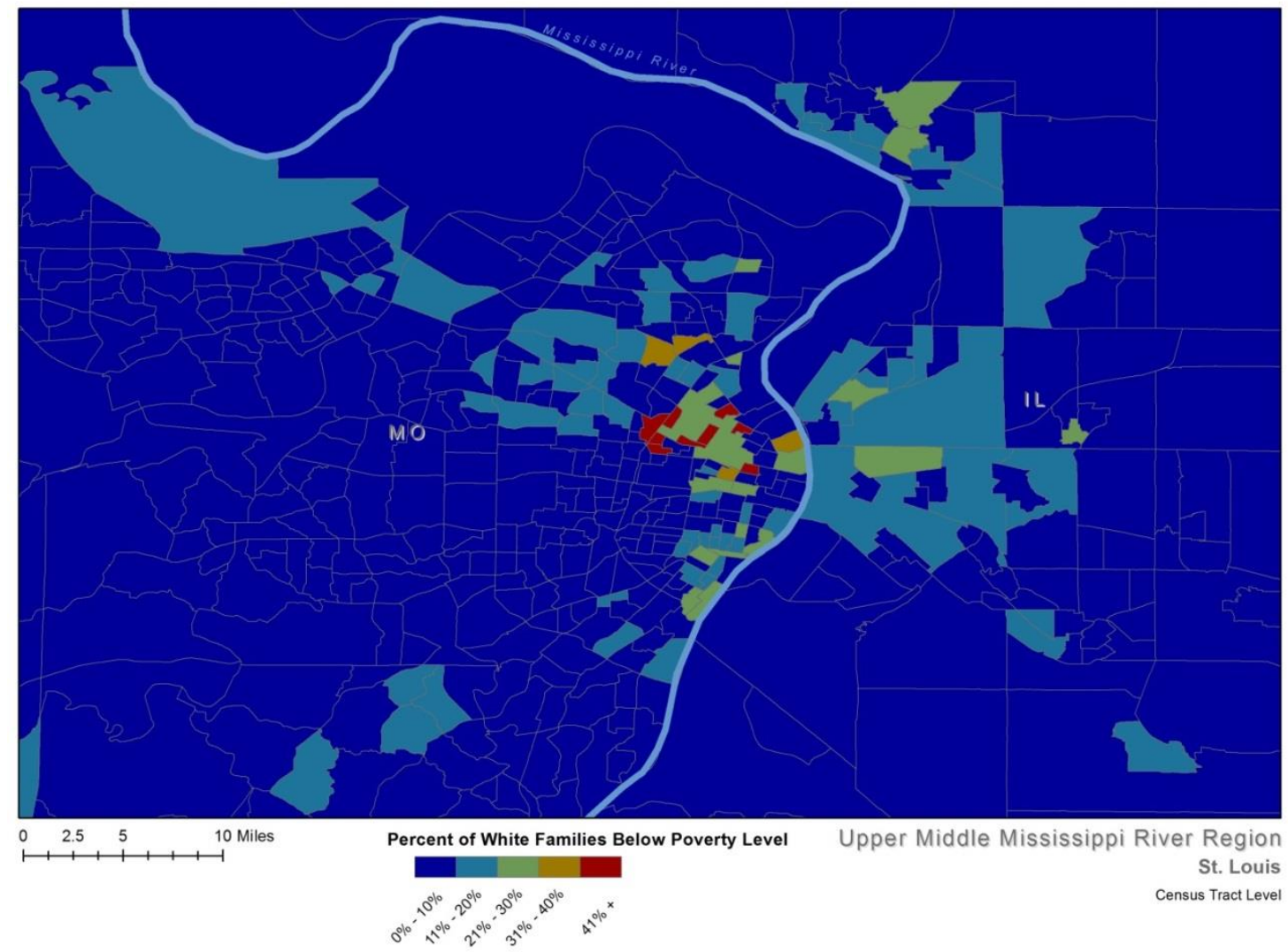

American Community Survey 2012 (5 year estimates) county and census tract data mapped using ArcGIS ${ }^{\circledR}$ software by Esri. ArcGIS ${ }^{\circledR}$ and $\operatorname{ArcMap}^{\mathrm{TM}}$ are the intellectual property of Esri and are used herein under license. 
Figure 2.23

Memphis, TN: White Poverty - Census Tract Level

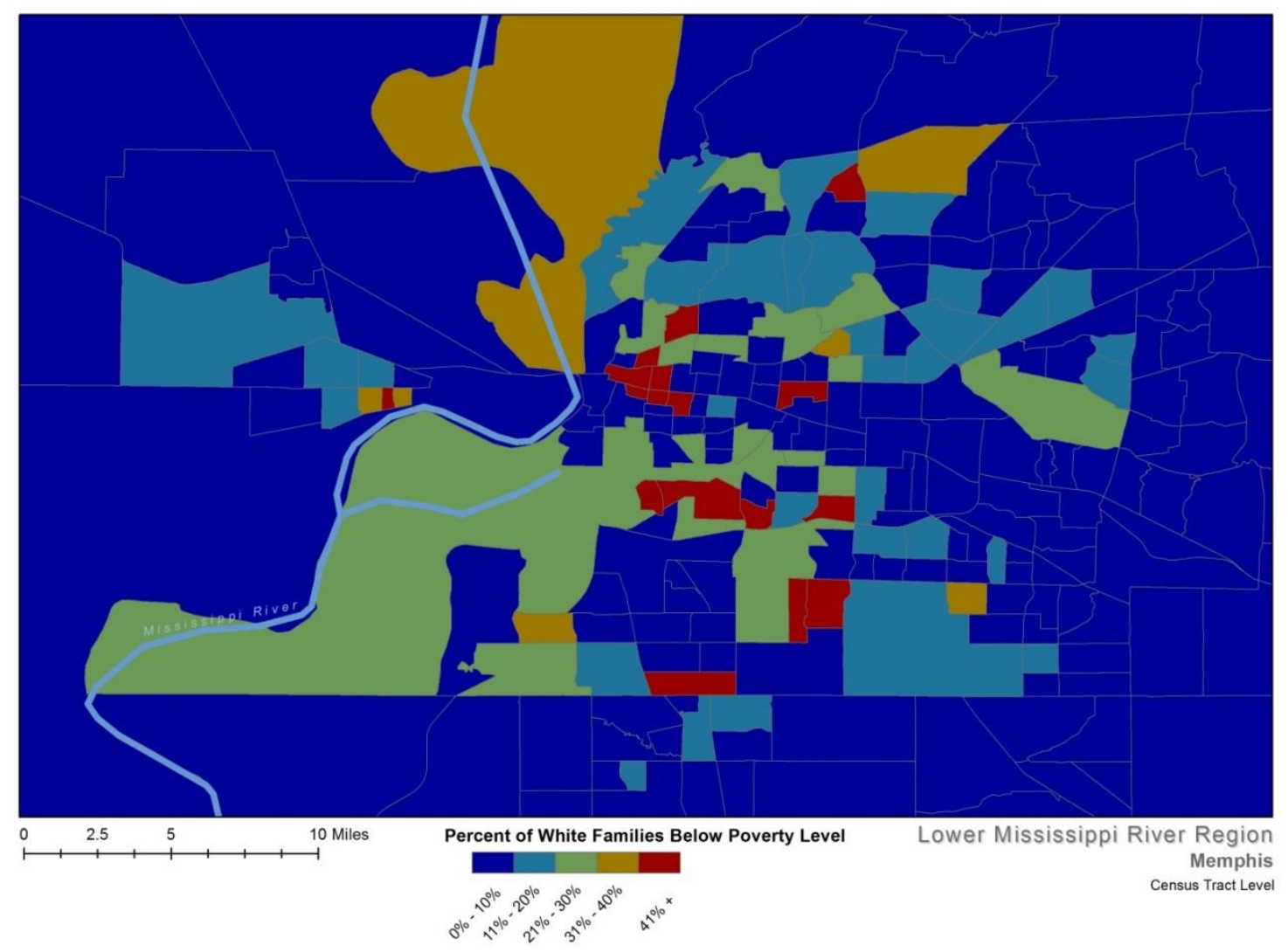

American Community Survey 2012 (5 year estimates) county and census tract data mapped using ArcGIS ${ }^{\circledR}$ software by Esri. ArcGIS ${ }^{\circledR}$ and ArcMap ${ }^{\mathrm{TM}}$ are the intellectual property of Esri and are used herein under license. 


\section{Figure 5.24}

Baton Rouge, LA: White Poverty - Census Tract Level

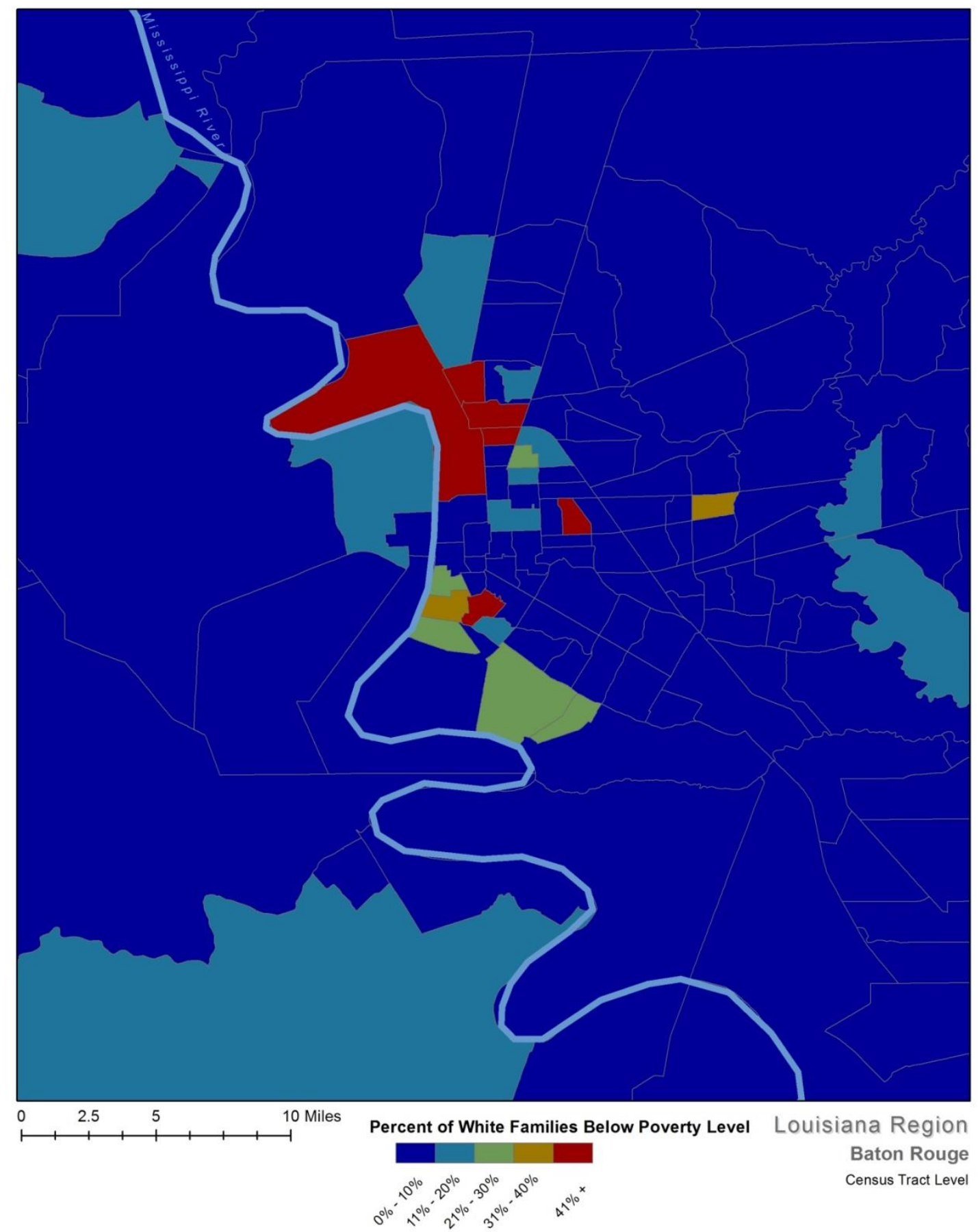

American Community Survey 2012 (5 year estimates) county and census tract data mapped using ArcGIS ${ }^{\circledR}$ software by Esri. ArcGIS ${ }^{\circledR}$ and ArcMap $^{\mathrm{TM}}$ are the intellectual property of Esri and are used herein under license. 


\section{Figure 5.25}

New Orleans, LA: White Poverty - Census Tract Level

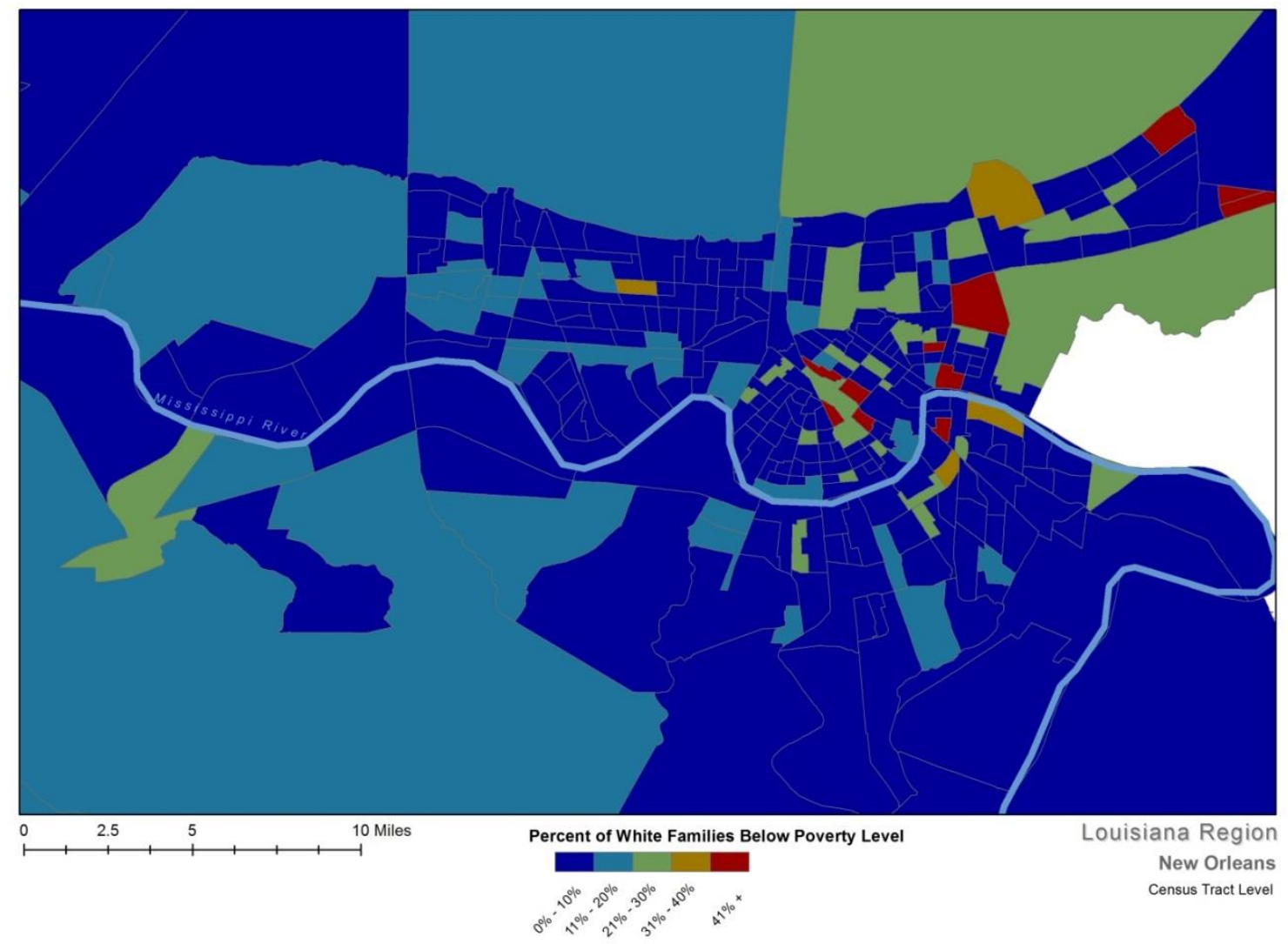

American Community Survey 2012 (5 year estimates) county and census tract data mapped using ArcGIS ${ }^{\circledR}$ software by Esri. ArcGIS ${ }^{\circledR}$ and ArcMap $^{\mathrm{TM}}$ are the intellectual property of Esri and are used herein under license. 


\section{Figure 5.26}

Upper Mississippi River Region: Black Poverty

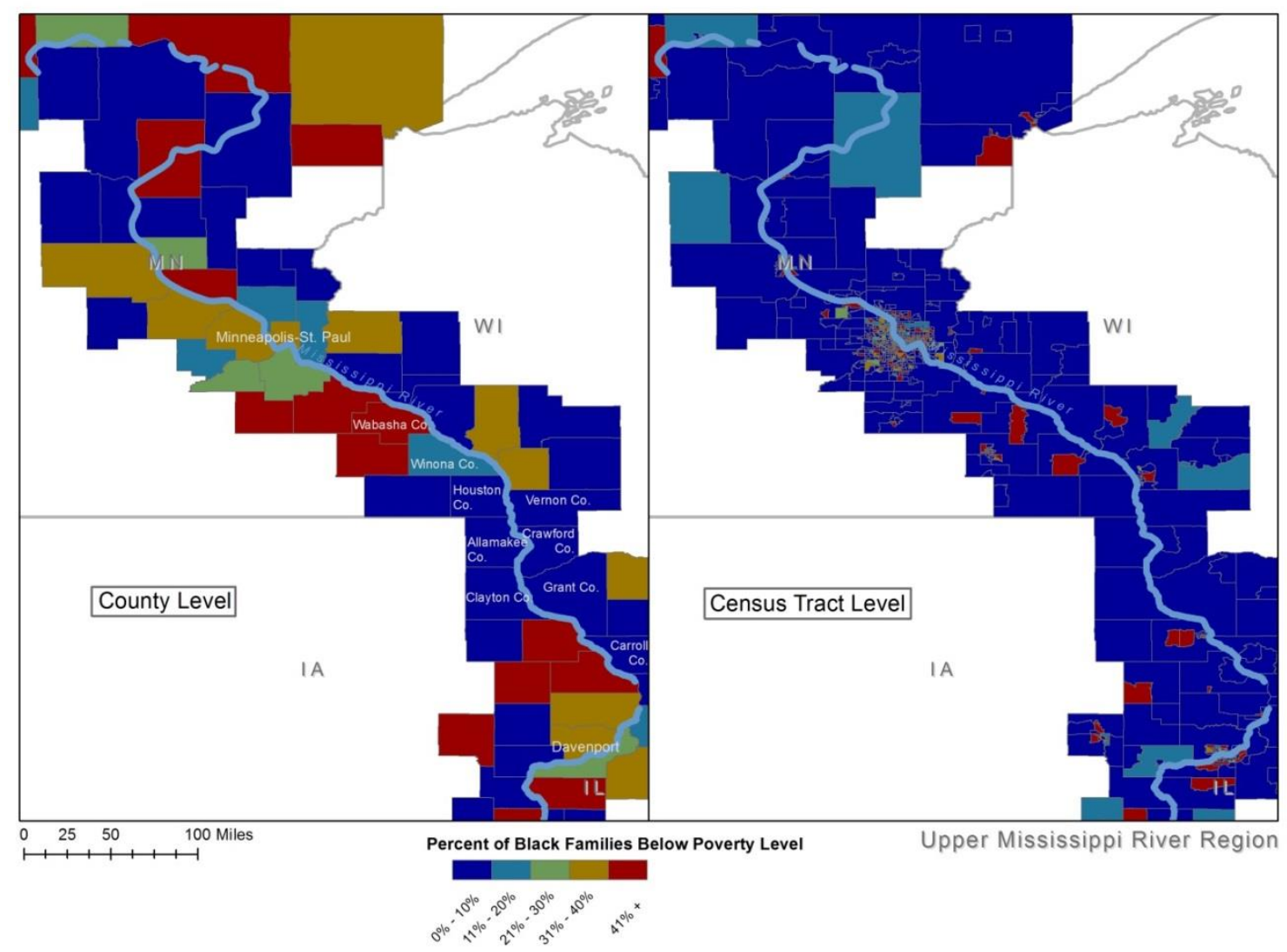

American Community Survey 2012 (5 year estimates) county and census tract data mapped using ArcGIS ${ }^{\circledR}$ software by Esri. ArcGIS ${ }^{\circledR}$ and ArcMap ${ }^{\mathrm{TM}}$ are the intellectual property of Esri and are used herein under license. 


\section{Figure 5.27}

Upper Middle Mississippi River Region: Black Poverty

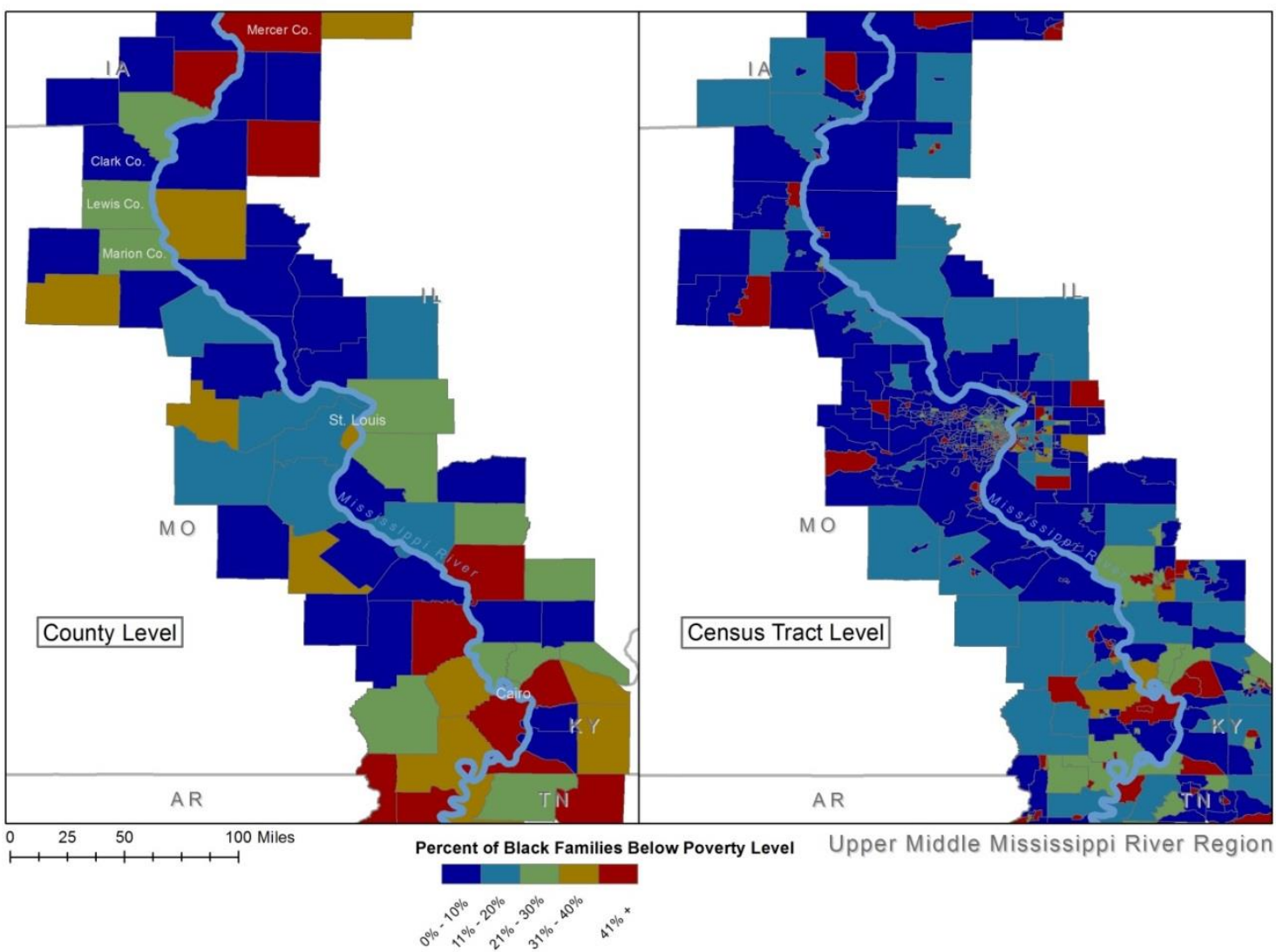

American Community Survey 2012 (5 year estimates) county and census tract data mapped using ArcGIS ${ }^{\circledR}$ software by Esri. ArcGIS ${ }^{\circledR}$ and ArcMap ${ }^{\mathrm{TM}}$ are the intellectual property of Esri and are used herein under license. 


\section{Figure 5.28}

Lower Mississippi River Region: Black Poverty

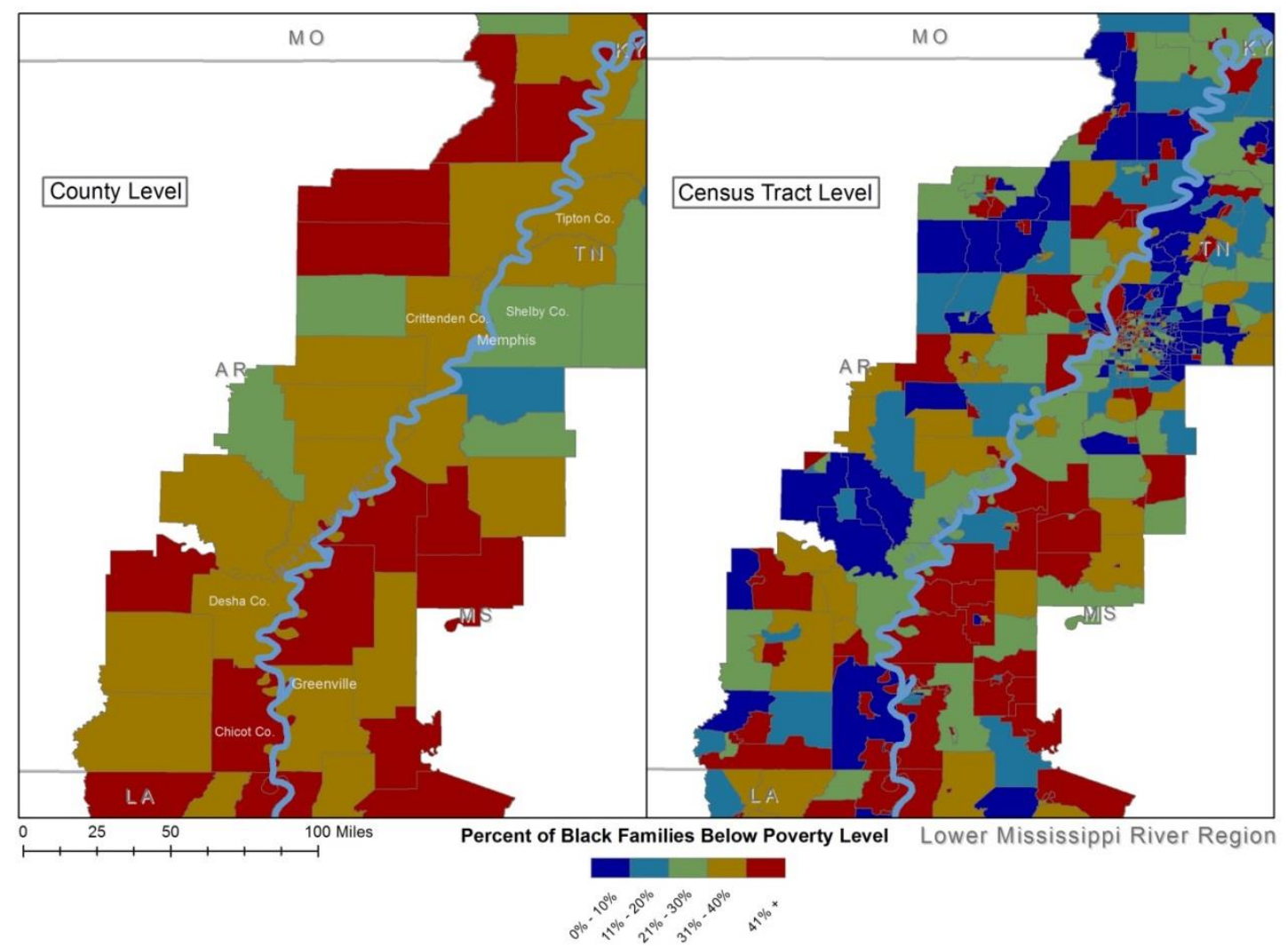

American Community Survey 2012 (5 year estimates) county and census tract data mapped using ArcGIS ${ }^{\circledR}$ software by Esri. ArcGIS ${ }^{\circledR}$ and $\operatorname{ArcMap}^{\mathrm{TM}}$ are the intellectual property of Esri and are used herein under license. 
Figure 5.29

Louisiana Region: Black Poverty

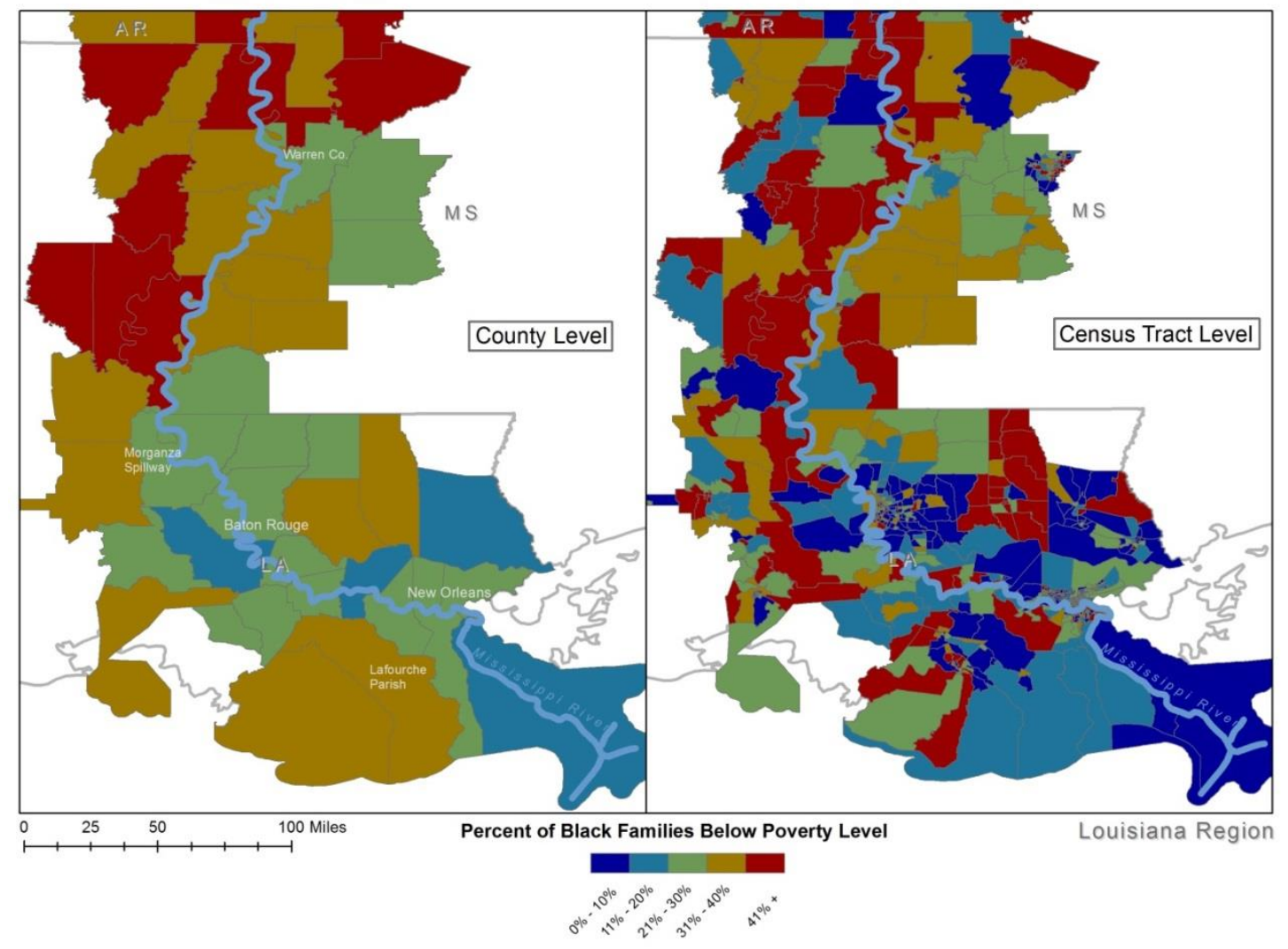

American Community Survey 2012 (5 year estimates) county and census tract data mapped using ArcGIS ${ }^{\circledR}$ software by Esri. ArcGIS ${ }^{\circledR}$ and ArcMap ${ }^{\mathrm{TM}}$ are the intellectual property of Esri and are used herein under license. 


\section{Figure 5.30}

Minneapolis, MN: Black Poverty - Census Tract Level

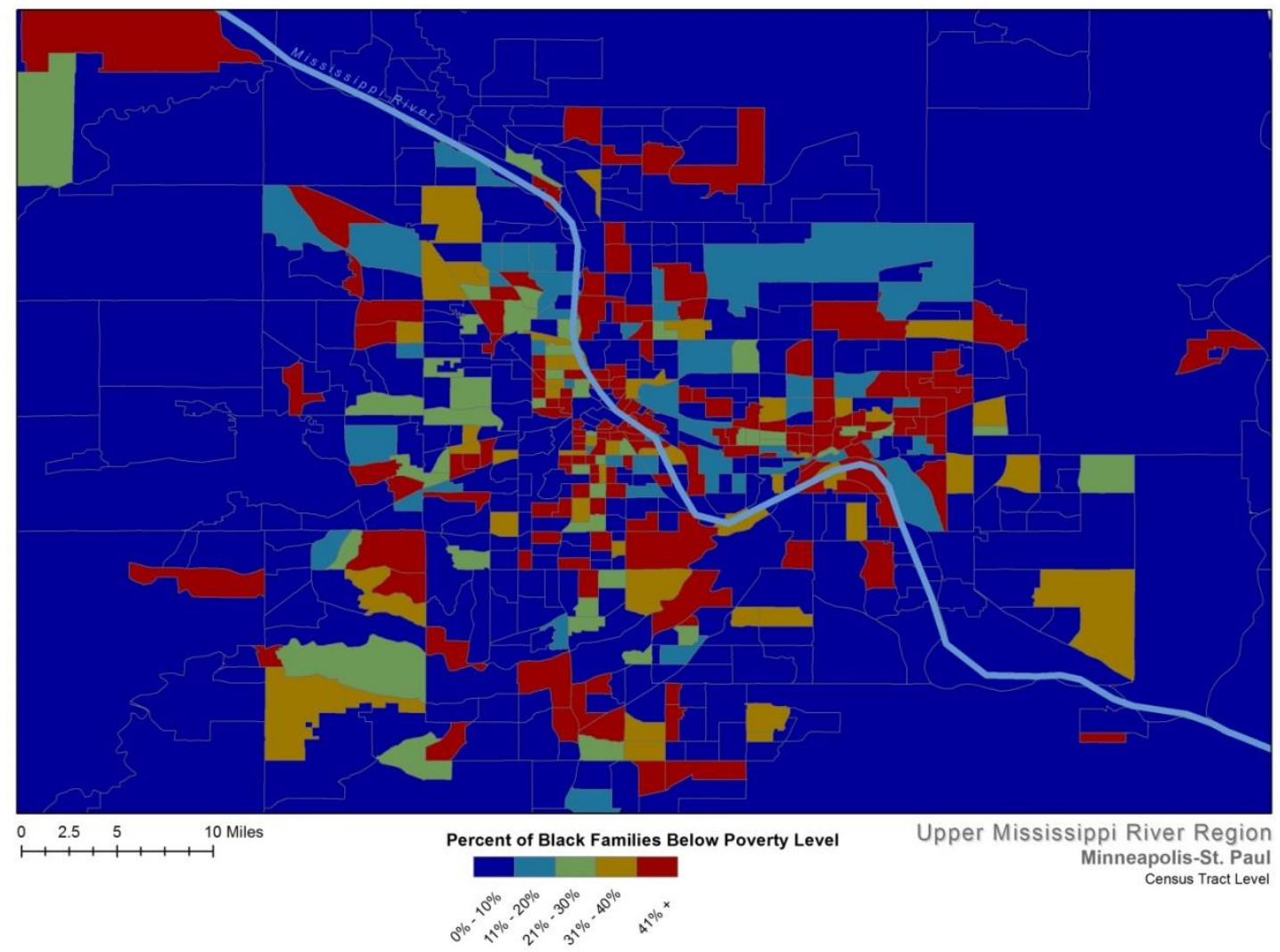

American Community Survey 2012 (5 year estimates) county and census tract data mapped using ArcGIS ${ }^{\circledR}$ software by Esri. ArcGIS ${ }^{\circledR}$ and $\operatorname{ArcMap}^{\mathrm{TM}}$ are the intellectual property of Esri and are used herein under license. 


\section{Figure 5.31}

Quad Cities (side view): Black Poverty - Census Tract Level

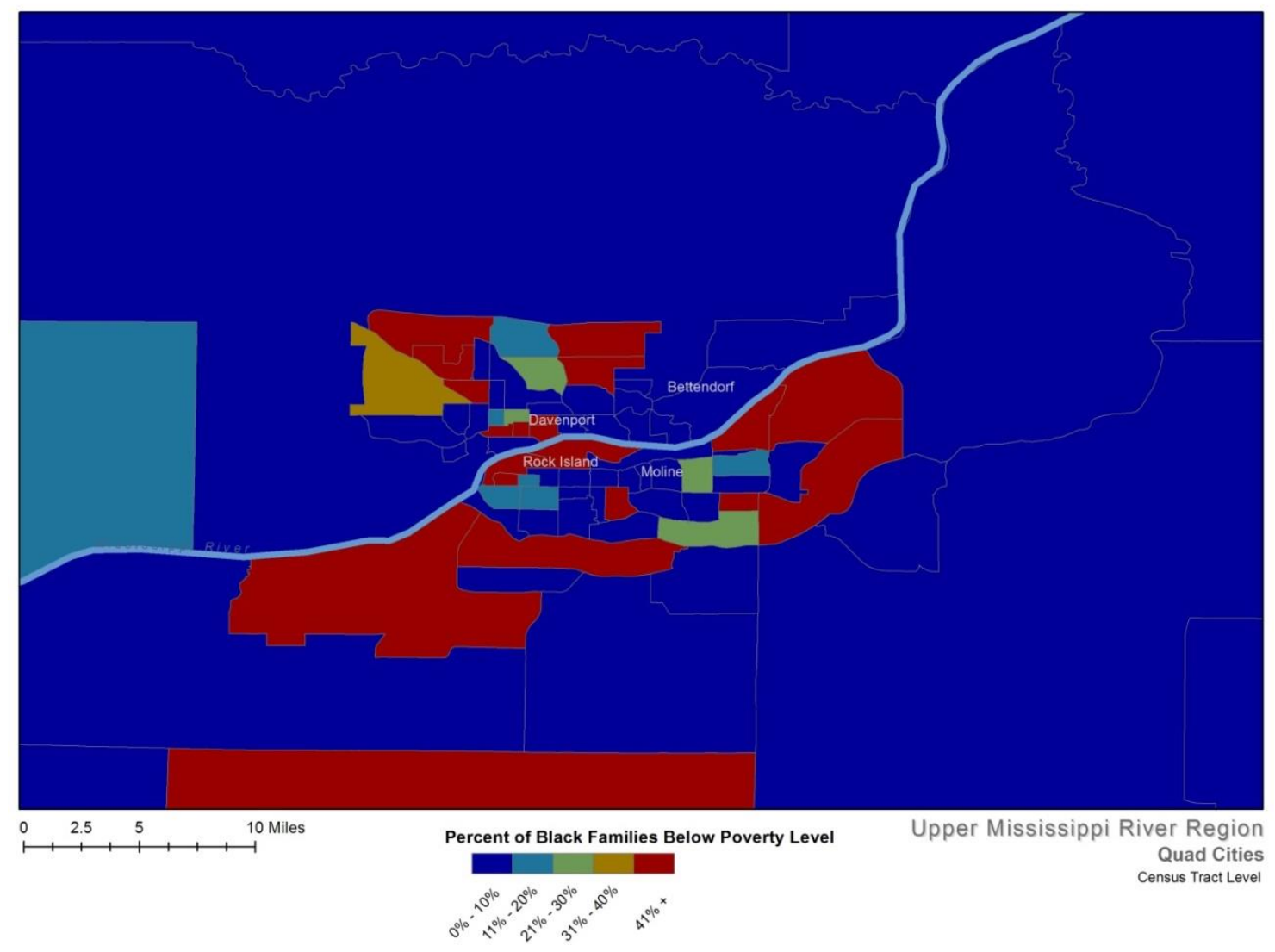

American Community Survey 2012 (5 year estimates) county and census tract data mapped using ArcGIS ${ }^{\circledR}$ software by Esri. ArcGIS ${ }^{\circledR}$ and ArcMap ${ }^{\mathrm{TM}}$ are the intellectual property of Esri and are used herein under license. 


\section{Figure 5.32}

St. Louis, MO: Black Poverty - Census Tract Level

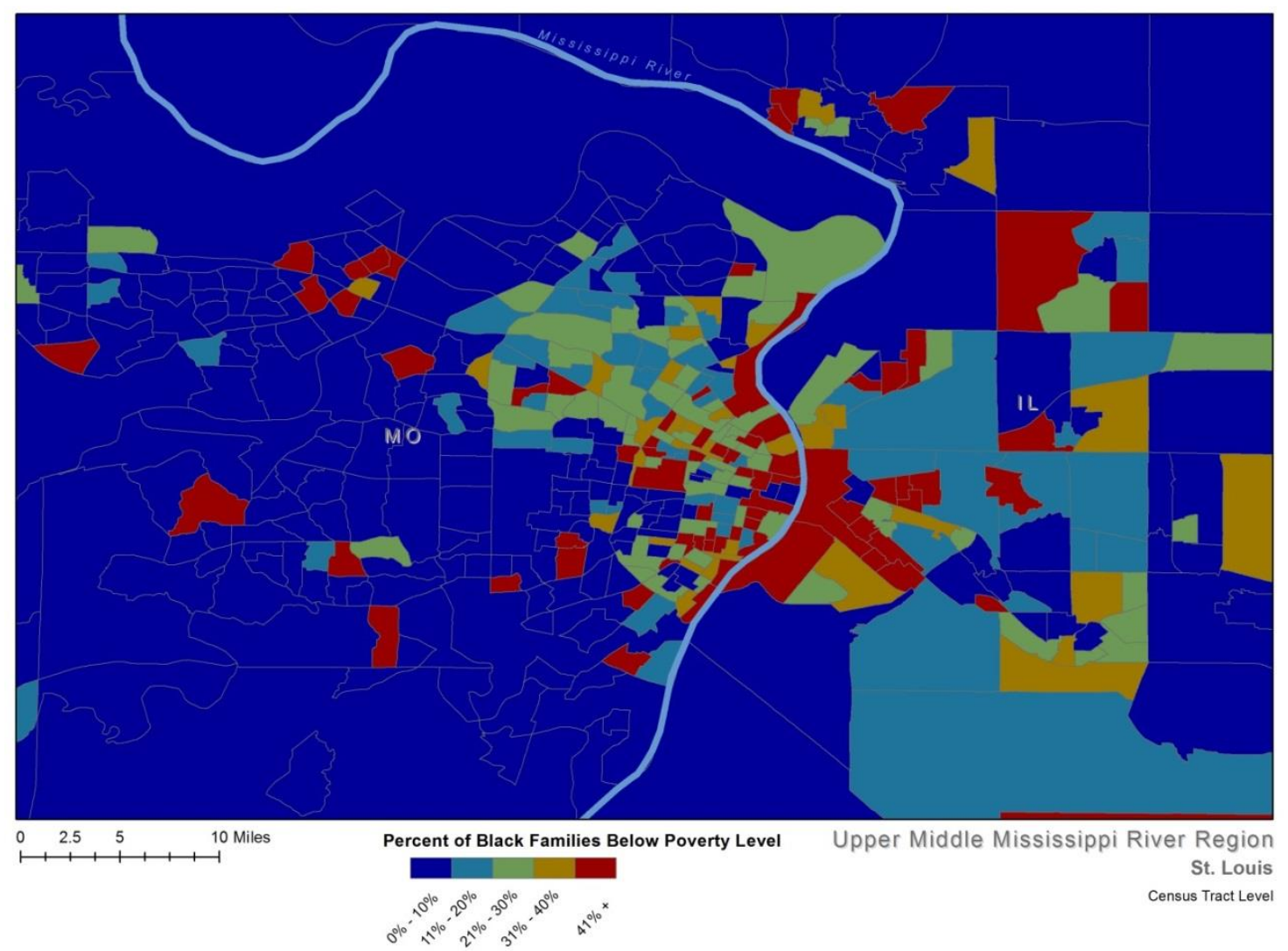

American Community Survey 2012 (5 year estimates) county and census tract data mapped using ArcGIS ${ }^{\circledR}$ software by Esri. ArcGIS ${ }^{\circledR}$ and ArcMap ${ }^{\mathrm{TM}}$ are the intellectual property of Esri and are used herein under license. 


\section{Figure 5.33}

Memphis, TN: Black Poverty - Census Tract Level

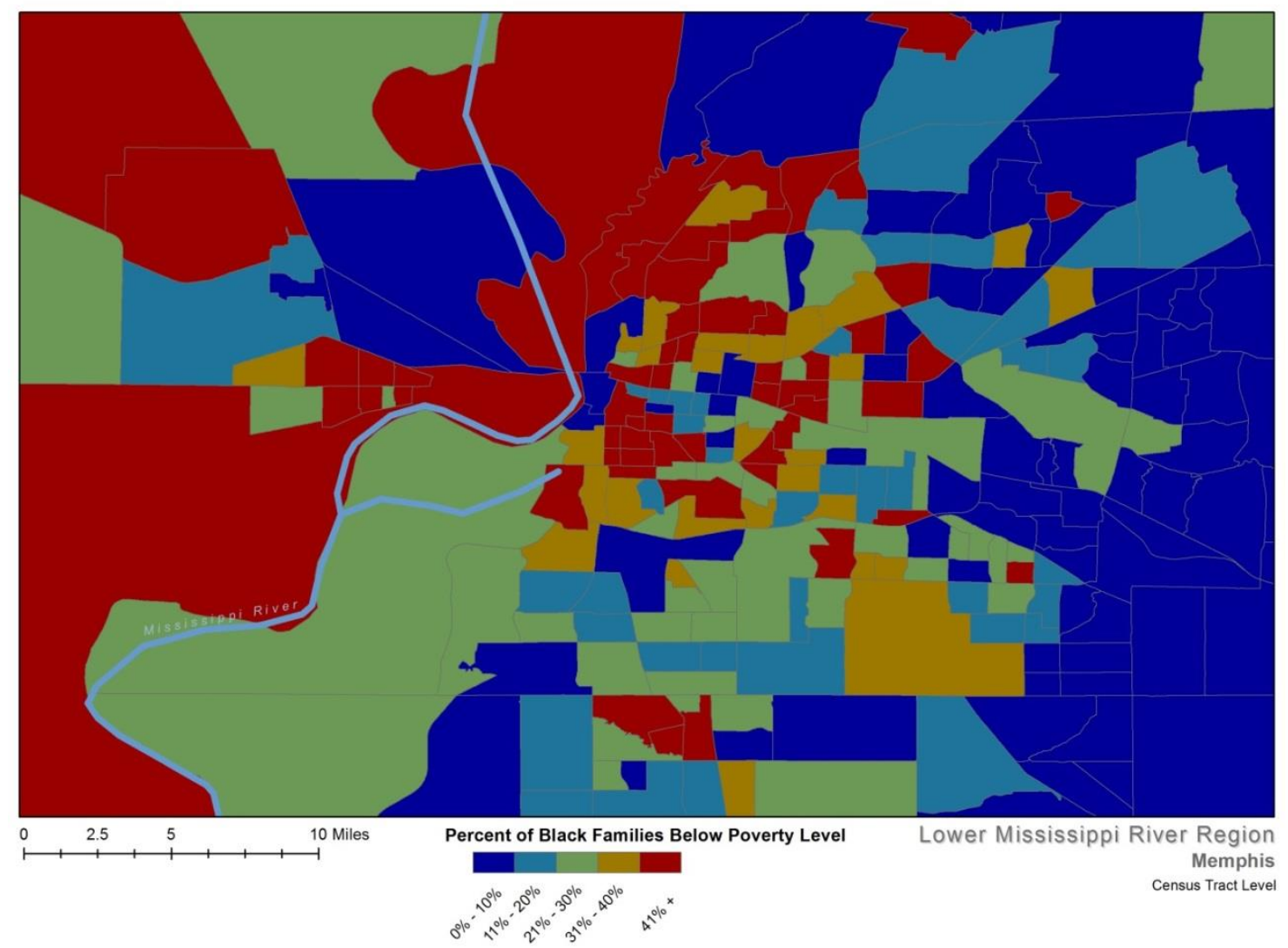

American Community Survey 2012 (5 year estimates) county and census tract data mapped using ArcGIS ${ }^{\circledR}$ software by Esri. ArcGIS ${ }^{\circledR}$ and ArcMap ${ }^{\mathrm{TM}}$ are the intellectual property of Esri and are used herein under license. 


\section{Figure 5.34}

Baton Rouge, LA: Black Poverty - Census Tract Level

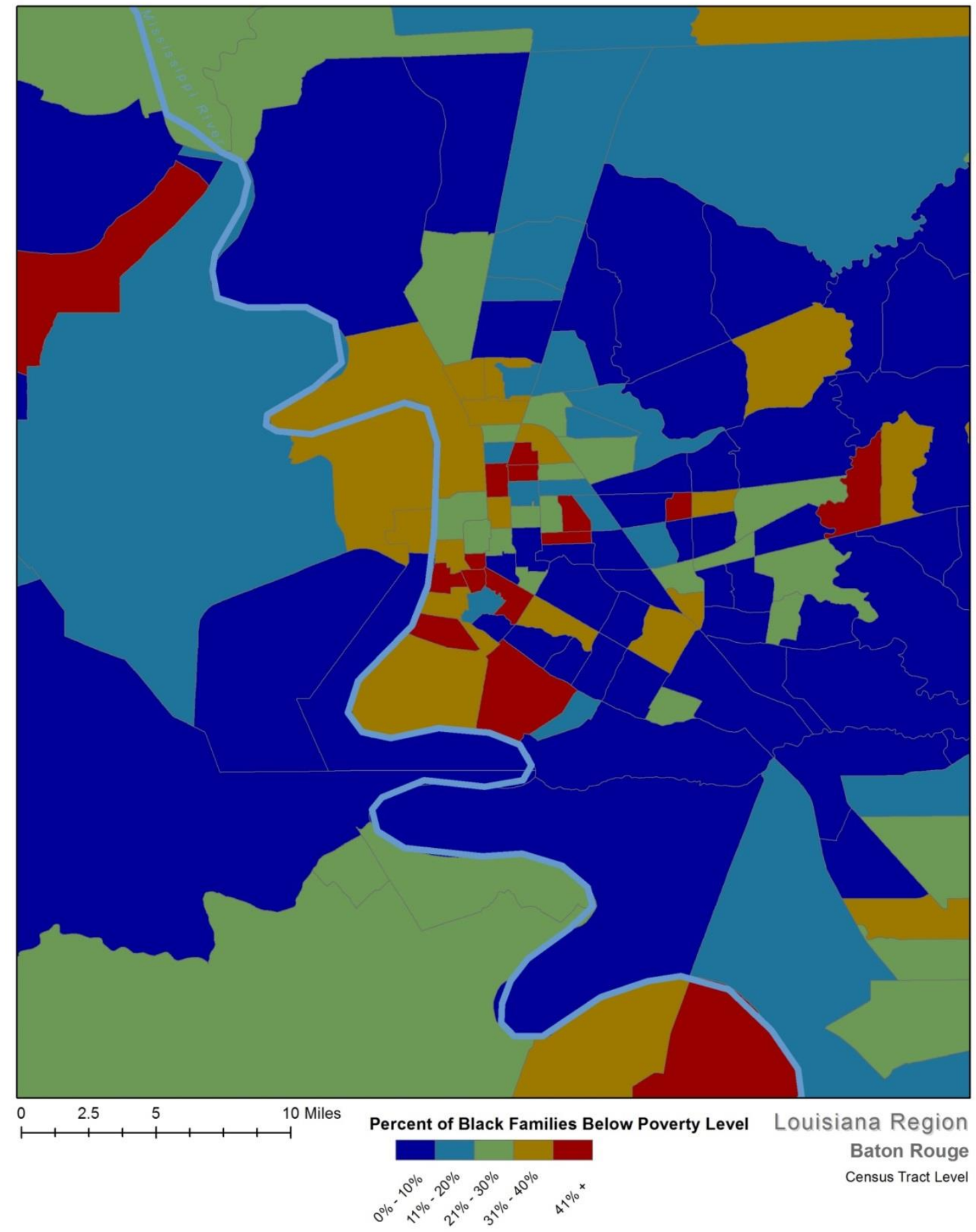

American Community Survey 2012 (5 year estimates) county and census tract data mapped using ArcGIS ${ }^{\circledR}$ software by Esri. ArcGIS ${ }^{\circledR}$ and ArcMap ${ }^{\mathrm{TM}}$ are the intellectual property of Esri and are used herein under license. 


\section{Figure 5.35}

New Orleans, LA: Black Poverty - Census Tract Level

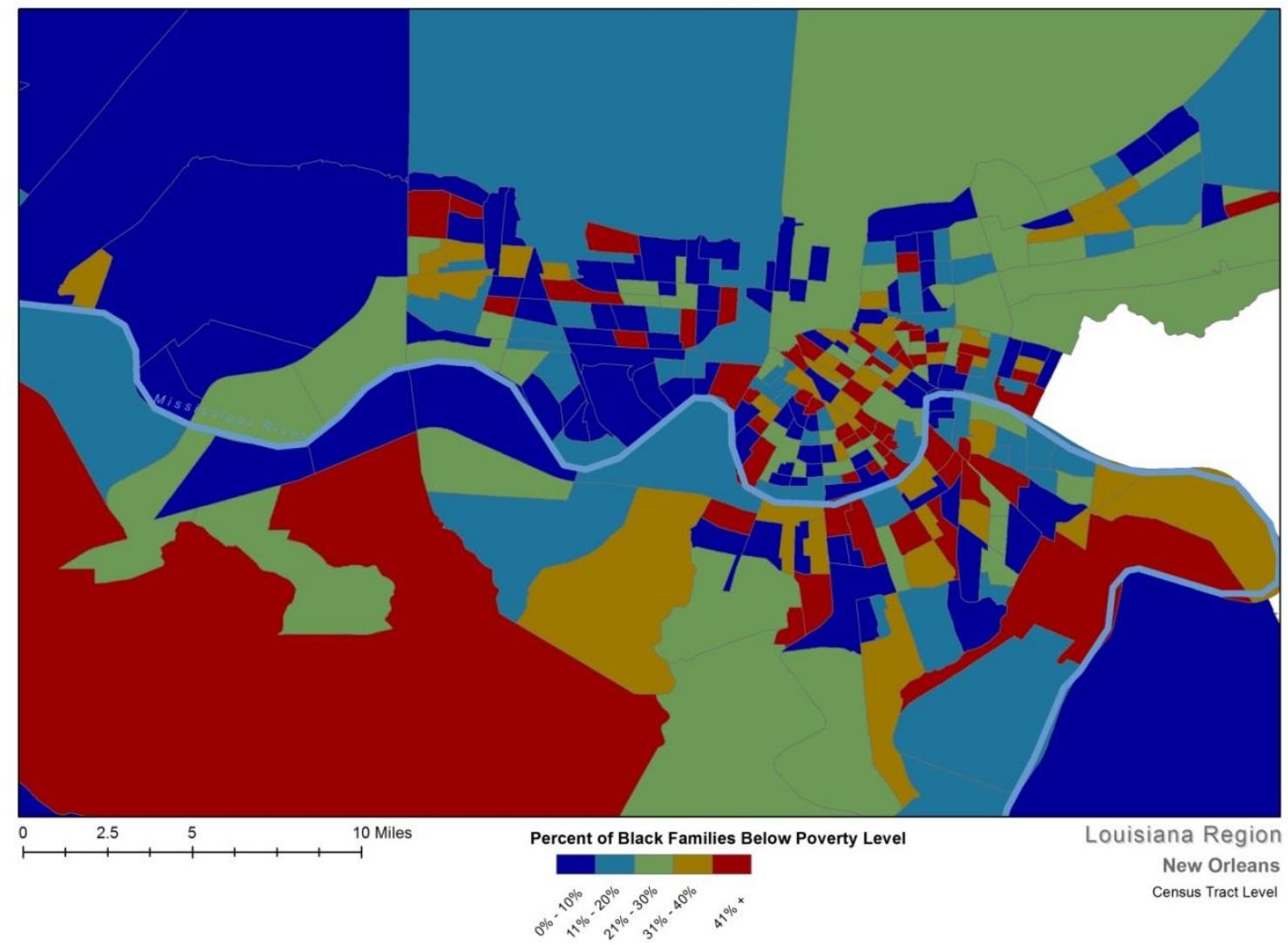

American Community Survey 2012 (5 year estimates) county and census tract data mapped using ArcGIS ${ }^{\circledR}$ software by Esri. ArcGIS ${ }^{\circledR}$ and ArcMap ${ }^{\mathrm{TM}}$ are the intellectual property of Esri and are used herein under license. 


\section{Figure 5.36}

Upper Mississippi River Region: Elderly Poverty

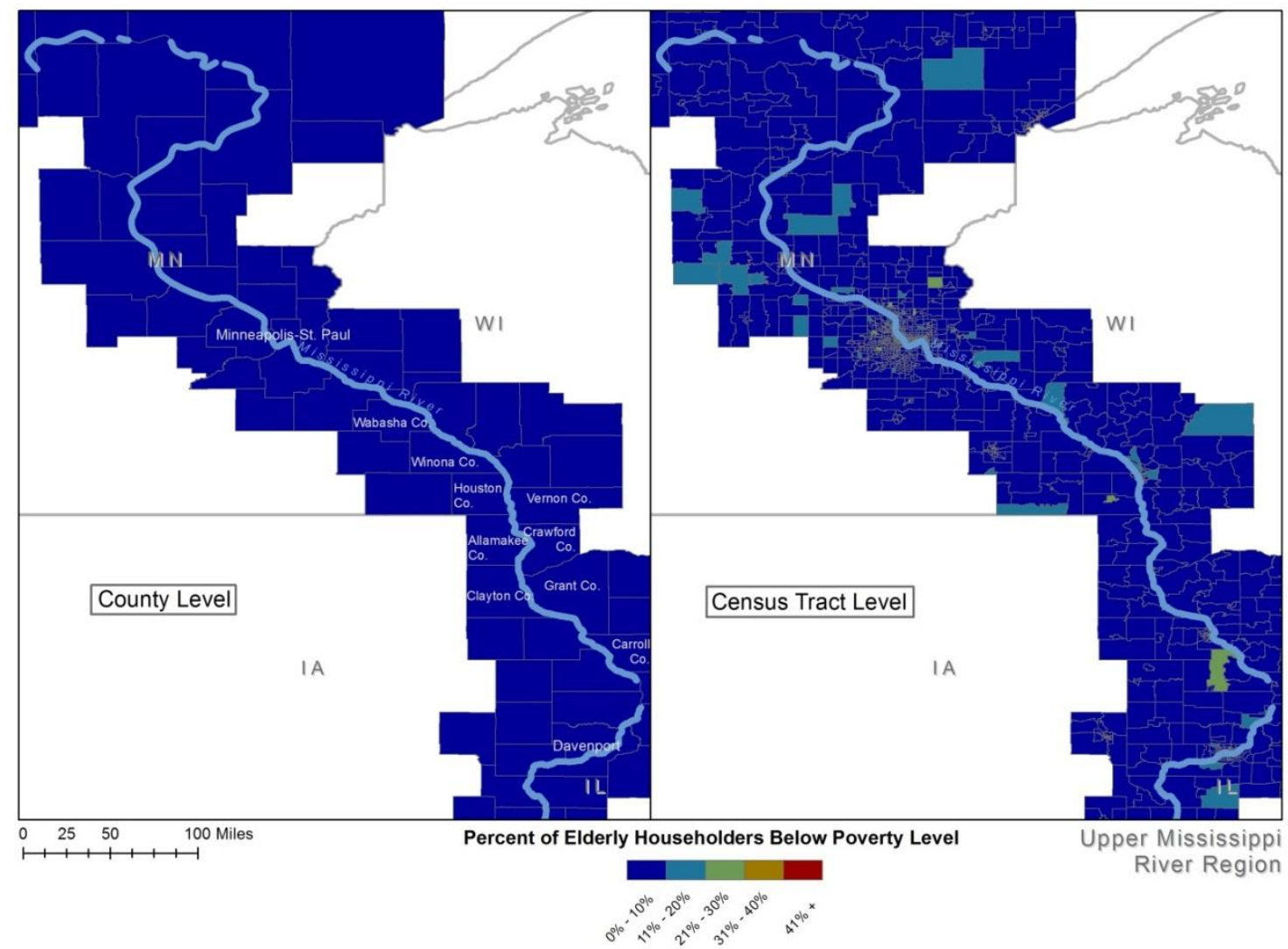

American Community Survey 2012 (5 year estimates) county and census tract data mapped using ArcGIS ${ }^{\circledR}$ software by Esri. ArcGIS ${ }^{\circledR}$ and ArcMap ${ }^{\mathrm{TM}}$ are the intellectual property of Esri and are used herein under license. 


\section{Figure 5.37}

Upper Middle Mississippi River Region: Elderly Poverty

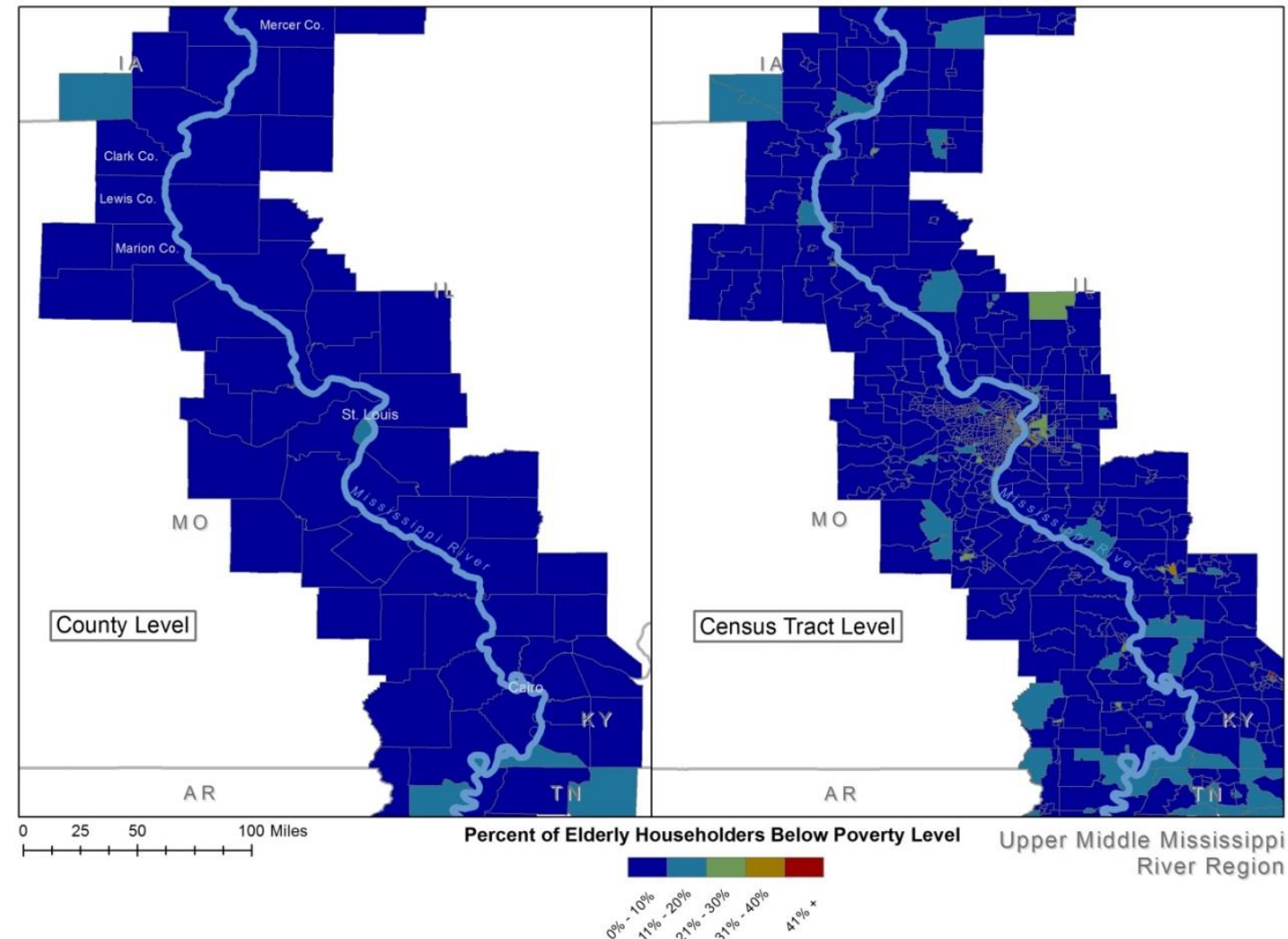

American Community Survey 2012 (5 year estimates) county and census tract data mapped using ArcGIS ${ }^{\circledR}$ software by Esri. ArcGIS ${ }^{\circledR}$ and ArcMap $^{\mathrm{TM}}$ are the intellectual property of Esri and are used herein under license. 


\section{Figure 5.38}

Lower Mississippi River Region: Elderly Poverty

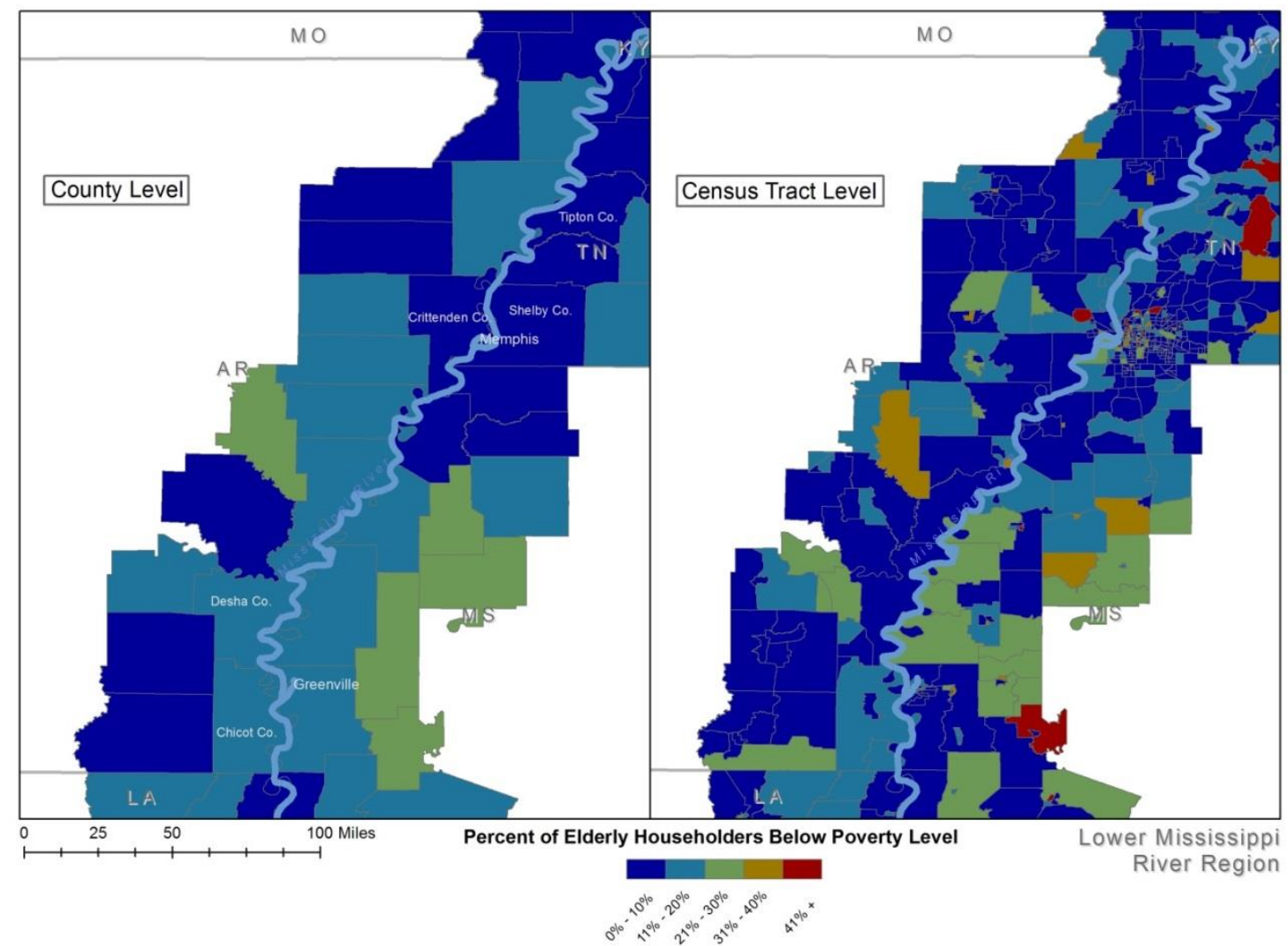

American Community Survey 2012 (5 year estimates) county and census tract data mapped using ArcGIS ${ }^{\circledR}$ software by Esri. ArcGIS ${ }^{\circledR}$ and ArcMap $^{\mathrm{TM}}$ are the intellectual property of Esri and are used herein under license. 
Figure 5.39

Louisiana Region: Elderly Poverty

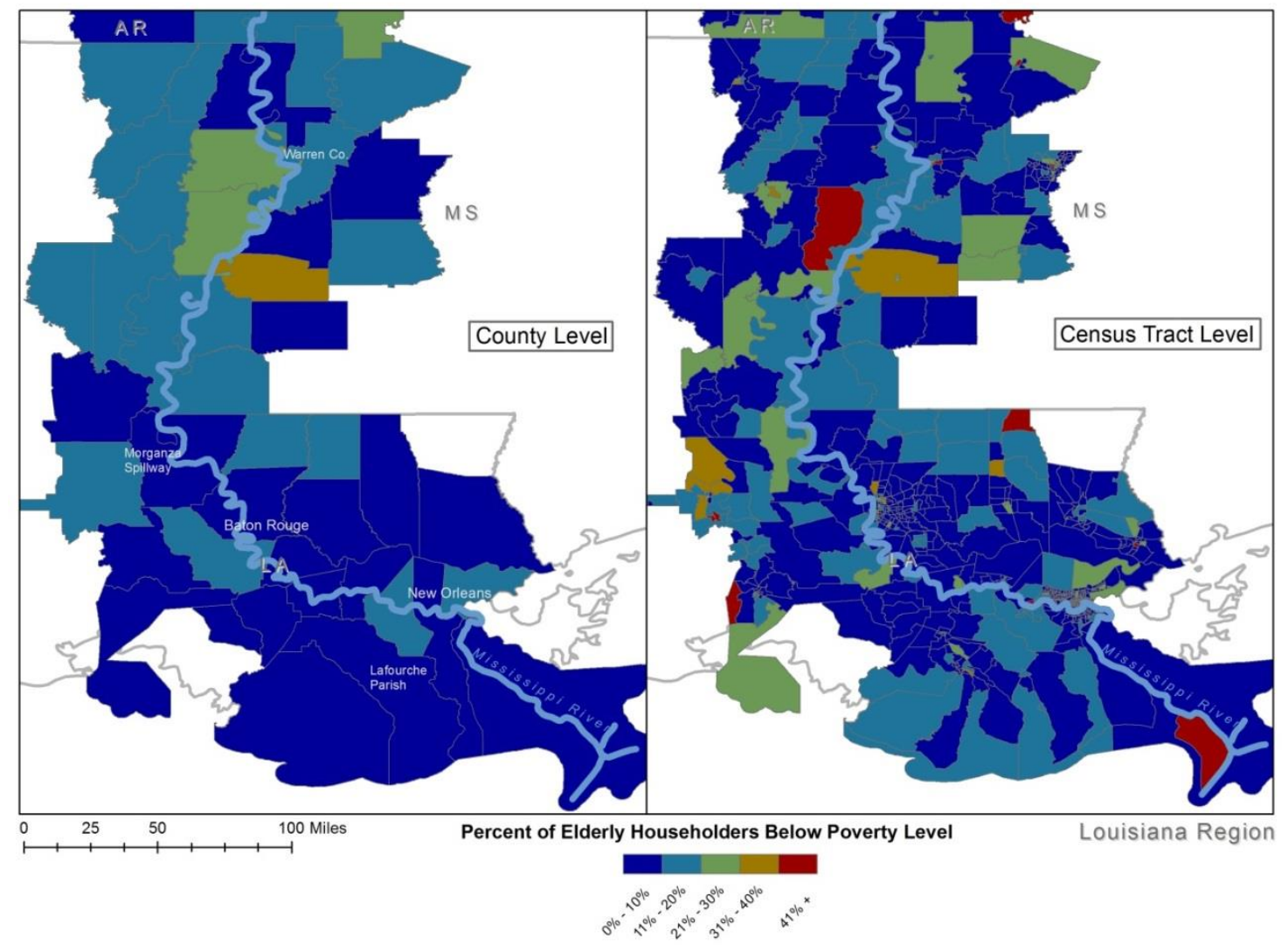

American Community Survey 2012 (5 year estimates) county and census tract data mapped using ArcGIS ${ }^{\circledR}$ software by Esri. ArcGIS $\AA$ and ArcMap ${ }^{\mathrm{TM}}$ are the intellectual property of Esri and are used herein under license. 


\section{Figure 5.40}

Minneapolis/St. Paul, MN: Elderly Poverty - Census Tract Level

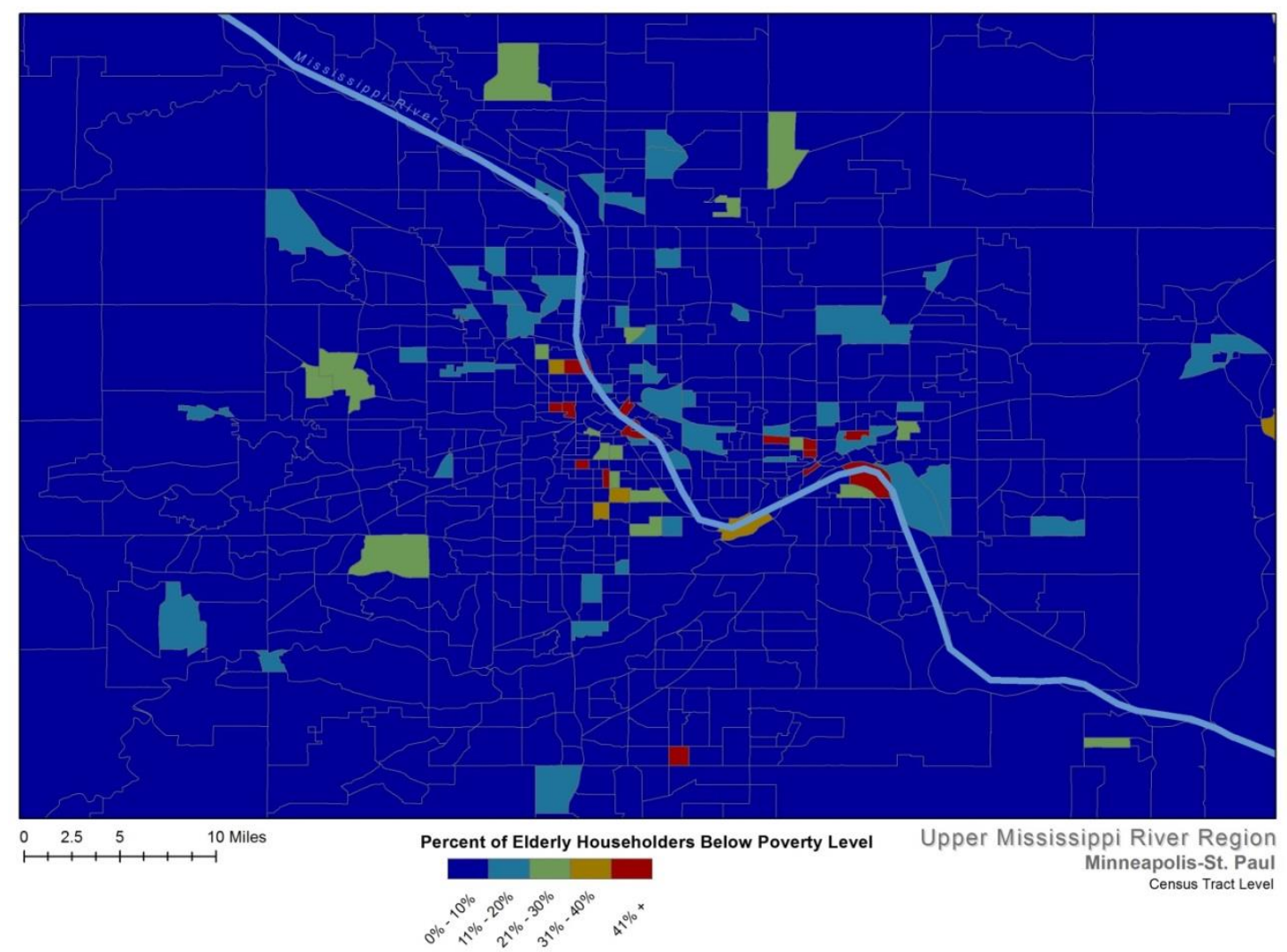

American Community Survey 2012 (5 year estimates) county and census tract data mapped using ArcGIS ${ }^{\circledR}$ software by Esri. ArcGIS ${ }^{\circledR}$ and ArcMap ${ }^{\mathrm{TM}}$ are the intellectual property of Esri and are used herein under license. 


\section{Figure 5.41}

Quad Cities (side view): Elderly Poverty - Census Tract Level

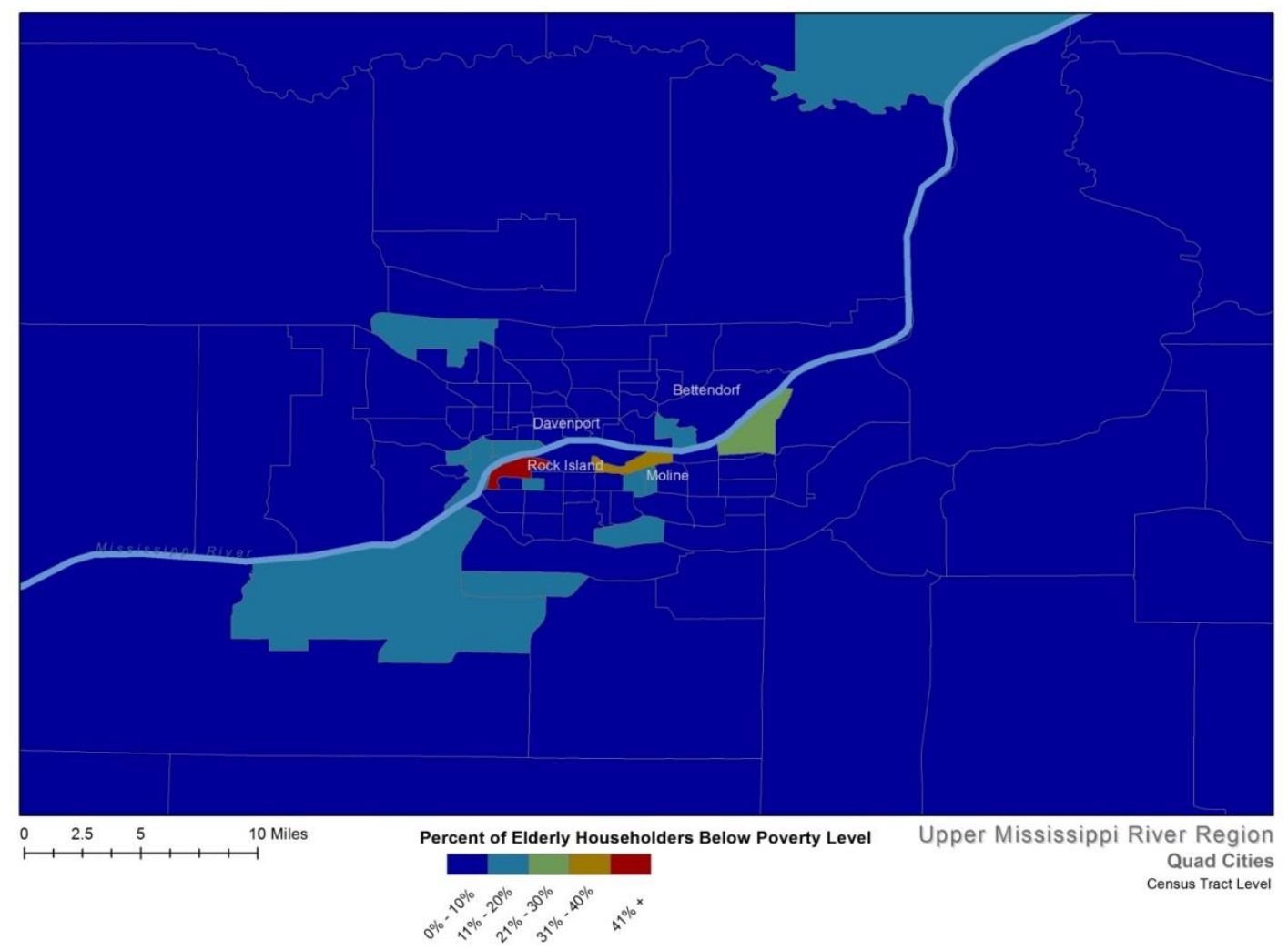

American Community Survey 2012 (5 year estimates) county and census tract data mapped using ArcGIS ${ }^{\circledR}$ software by Esri. ArcGIS ${ }^{\circledR}$ and ArcMap ${ }^{\mathrm{TM}}$ are the intellectual property of Esri and are used herein under license. 


\section{Figure 5.42}

St. Louis, MO: Elderly Poverty - Census Tract Level

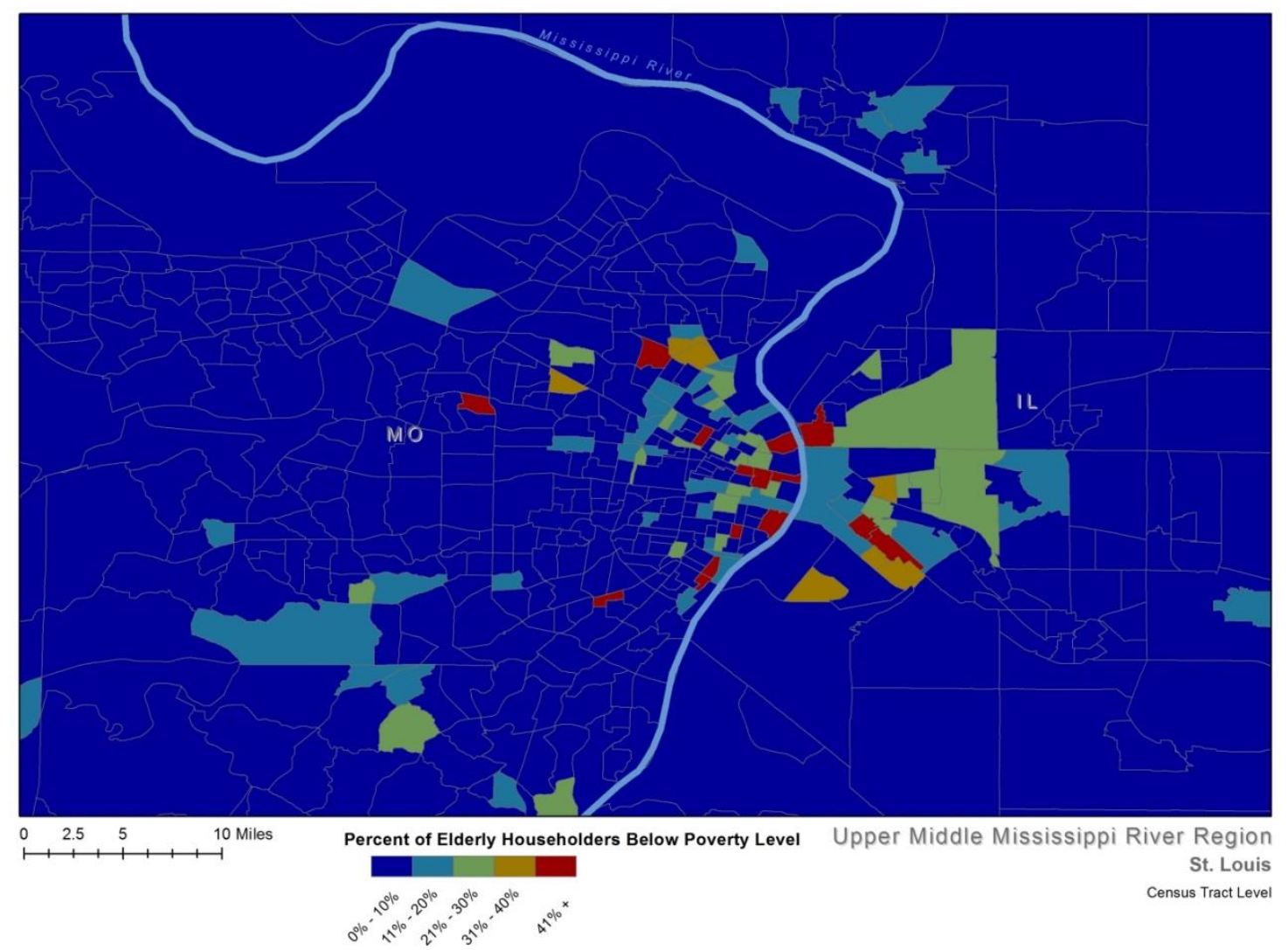

American Community Survey 2012 (5 year estimates) county and census tract data mapped using ArcGIS ${ }^{\circledR}$ software by Esri. ArcGIS ${ }^{\circledR}$ and ArcMap ${ }^{\mathrm{TM}}$ are the intellectual property of Esri and are used herein under license. 


\section{Figure 5.43}

Memphis, TN: Elderly Poverty - Census Tract Level

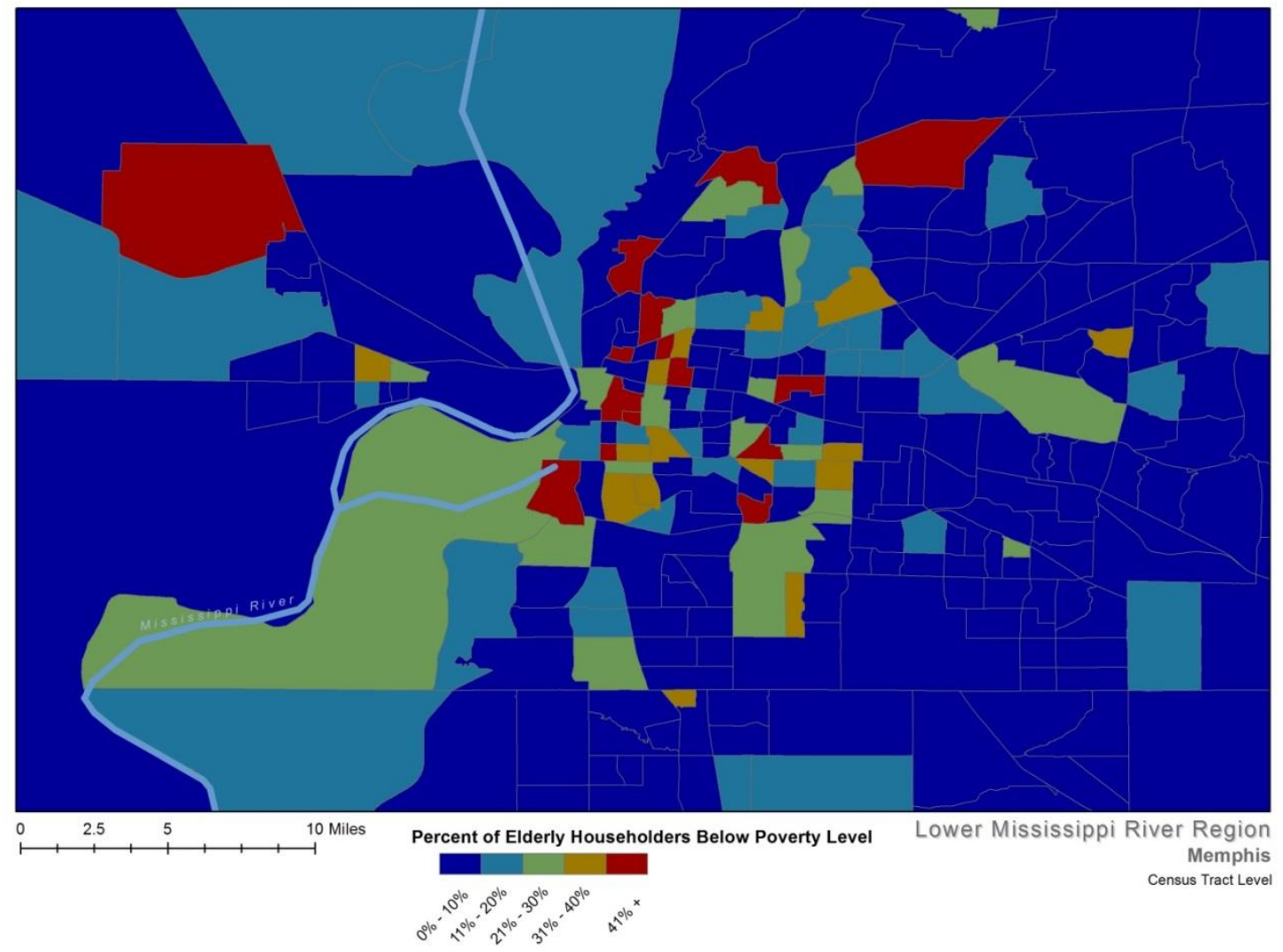

American Community Survey 2012 (5 year estimates) county and census tract data mapped using ArcGIS ${ }^{\circledR}$ software by Esri. ArcGIS ${ }^{\circledR}$ and ArcMap ${ }^{\mathrm{TM}}$ are the intellectual property of Esri and are used herein under license. 


\section{Figure 5.44}

Baton Rouge, LA: Elderly Poverty - Census Tract Level

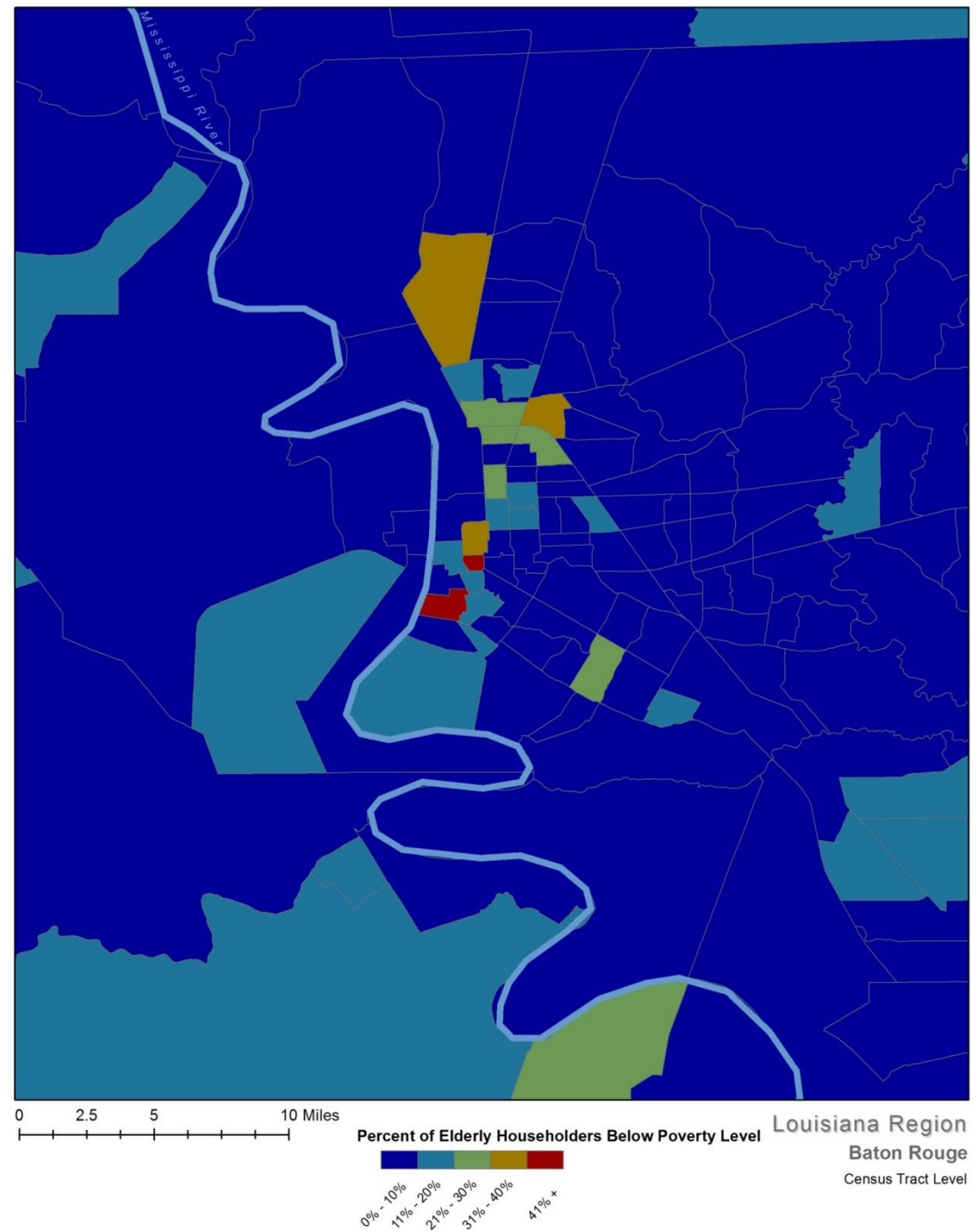

American Community Survey 2012 (5 year estimates) county and census tract data mapped using ArcGIS ${ }^{\circledR}$ software by Esri. ArcGIS ${ }^{\circledR}$ and ArcMap ${ }^{\mathrm{TM}}$ are the intellectual property of Esri and are used herein under license. 


\section{Figure 5.45}

New Orleans, LA: Elderly Poverty - Census Tract Level

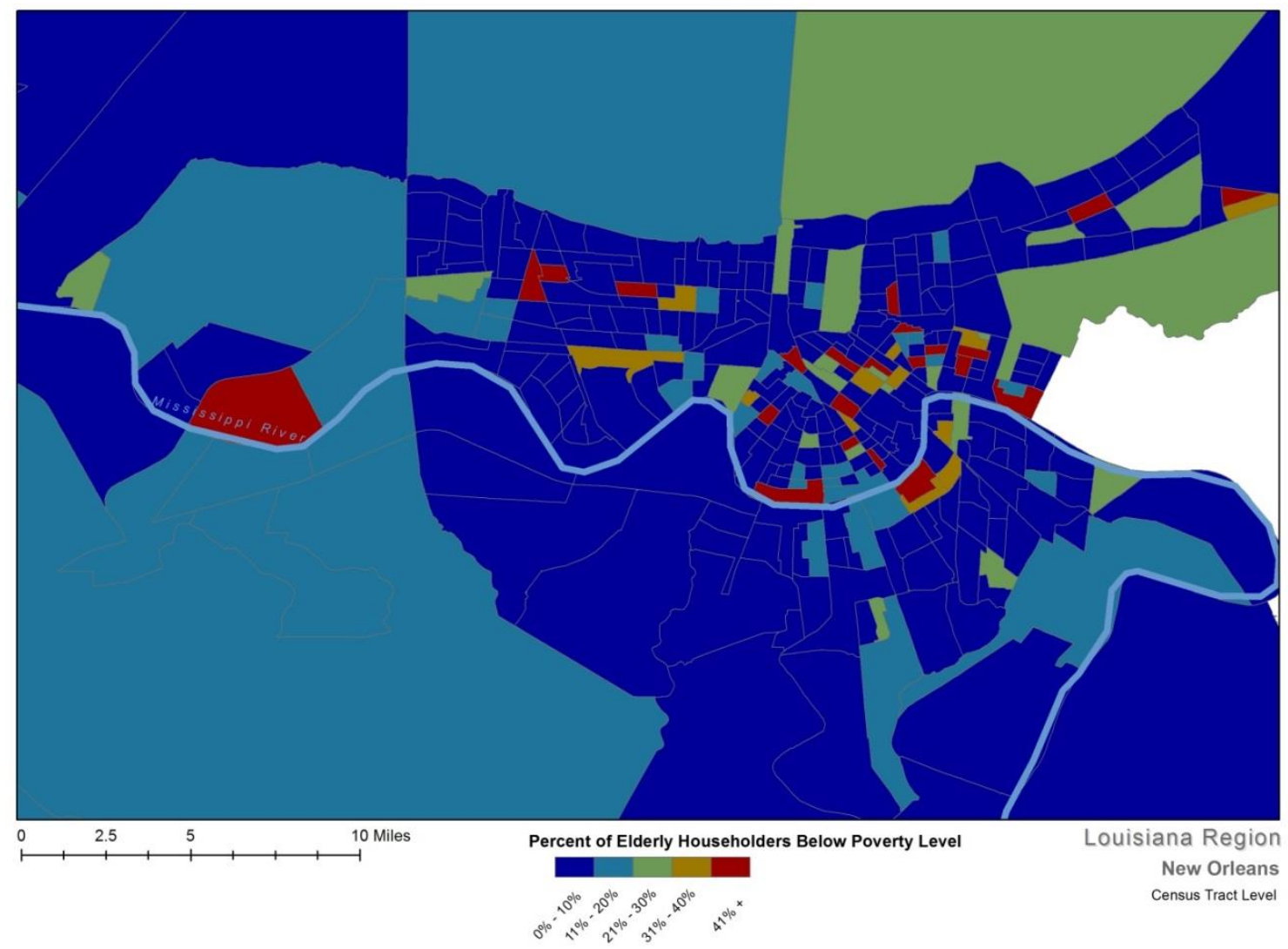

American Community Survey 2012 (5 year estimates) county and census tract data mapped using ArcGIS ${ }^{\circledR}$ software by Esri. ArcGIS ${ }^{\circledR}$ and ArcMap ${ }^{\mathrm{TM}}$ are the intellectual property of Esri and are used herein under license. 


\section{Figure 5.46}

Upper Mississippi River Region: Elderly Households

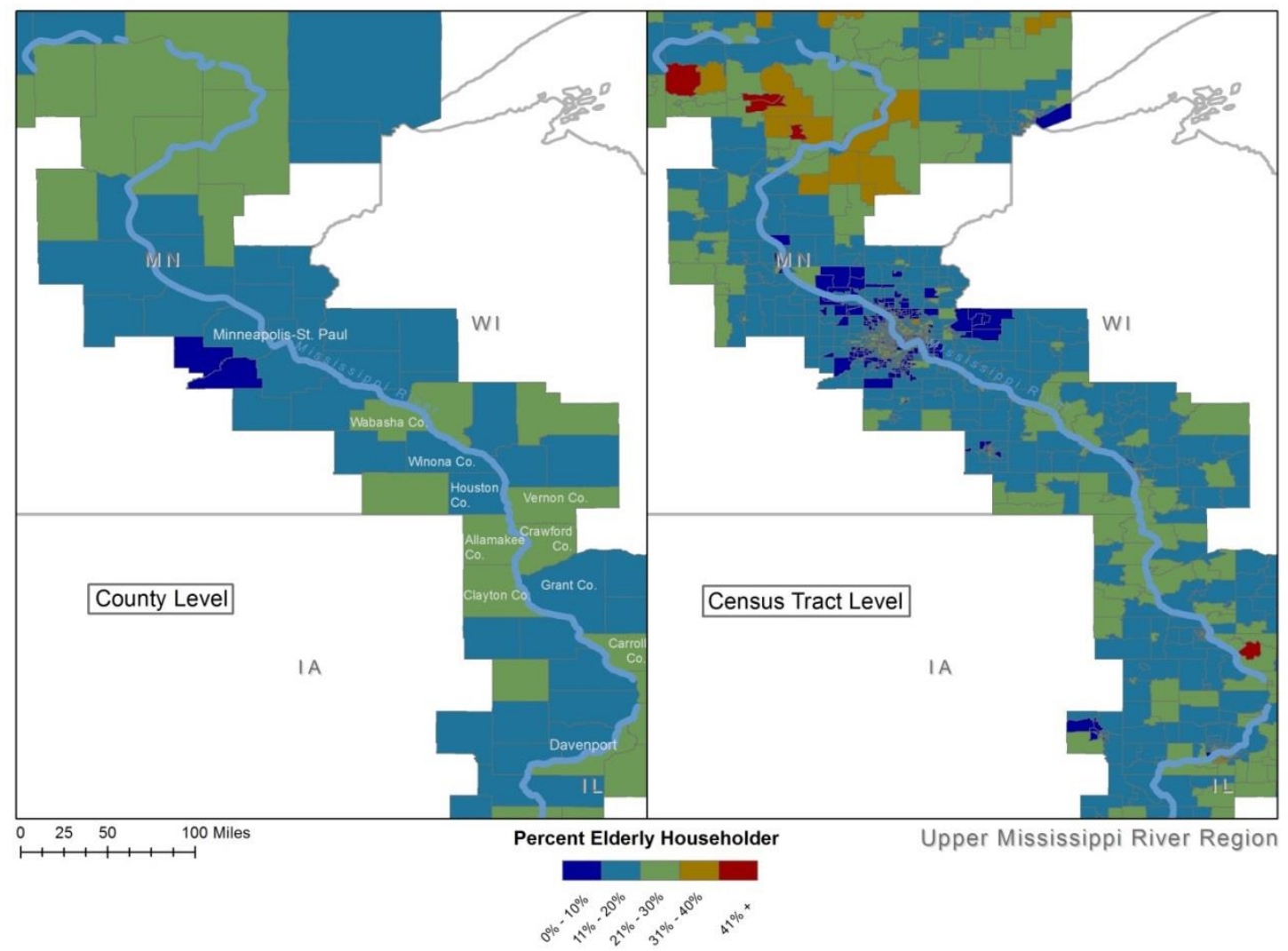

American Community Survey 2012 (5 year estimates) county and census tract data mapped using ArcGIS ${ }^{\circledR}$ software by Esri. ArcGIS ${ }^{\circledR}$ and $\operatorname{ArcMap}^{\mathrm{TM}}$ are the intellectual property of Esri and are used herein under license. 
Figure 5.47

Upper Middle Mississippi River Region: Elderly Households

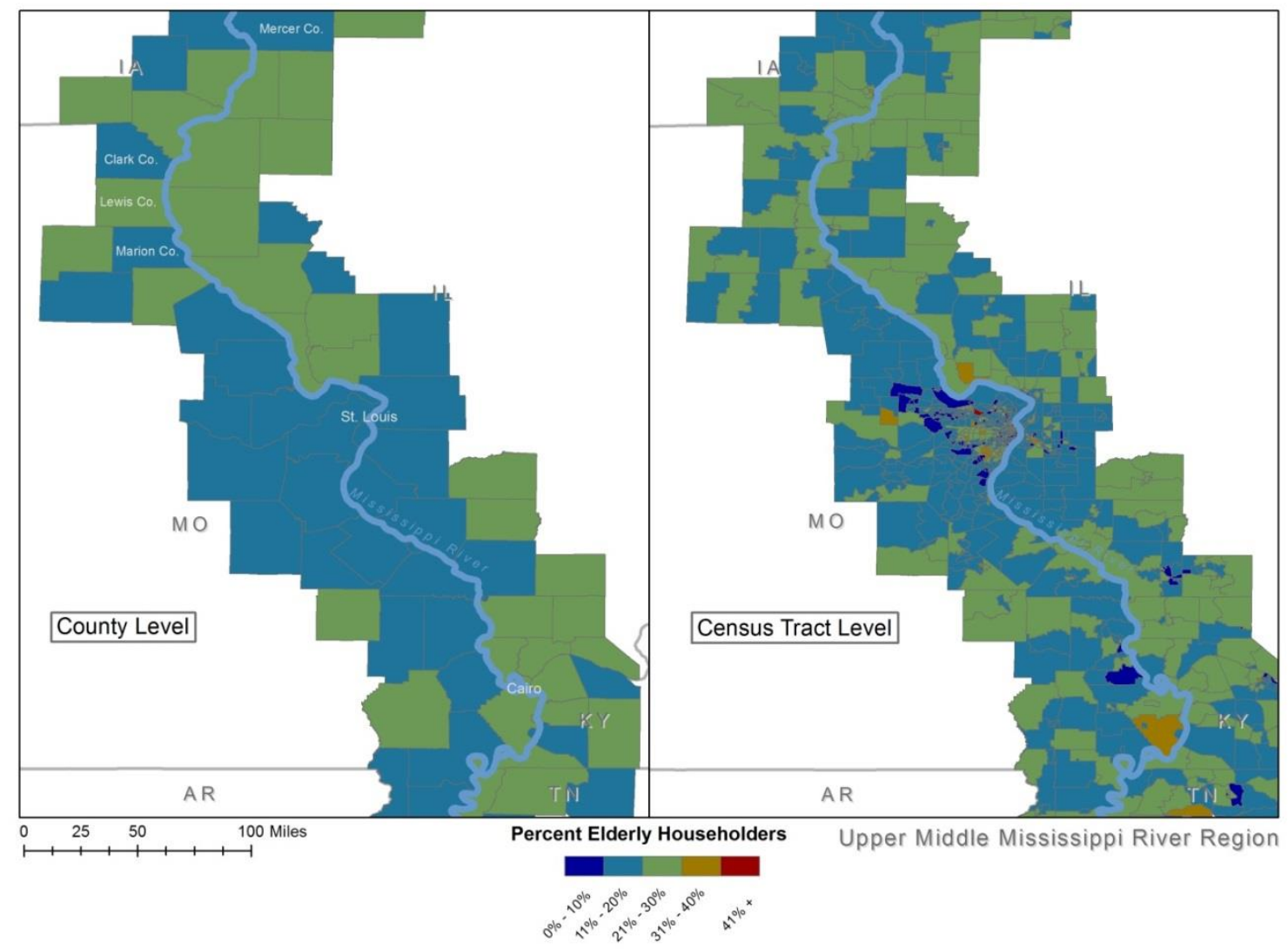

American Community Survey 2012 (5 year estimates) county and census tract data mapped using ArcGIS ${ }^{\circledR}$ software by Esri. ArcGIS ${ }^{\circledR}$ and ArcMap ${ }^{\mathrm{TM}}$ are the intellectual property of Esri and are used herein under license. 


\section{Figure 5.48}

Lower Mississippi River Region: Elderly Households

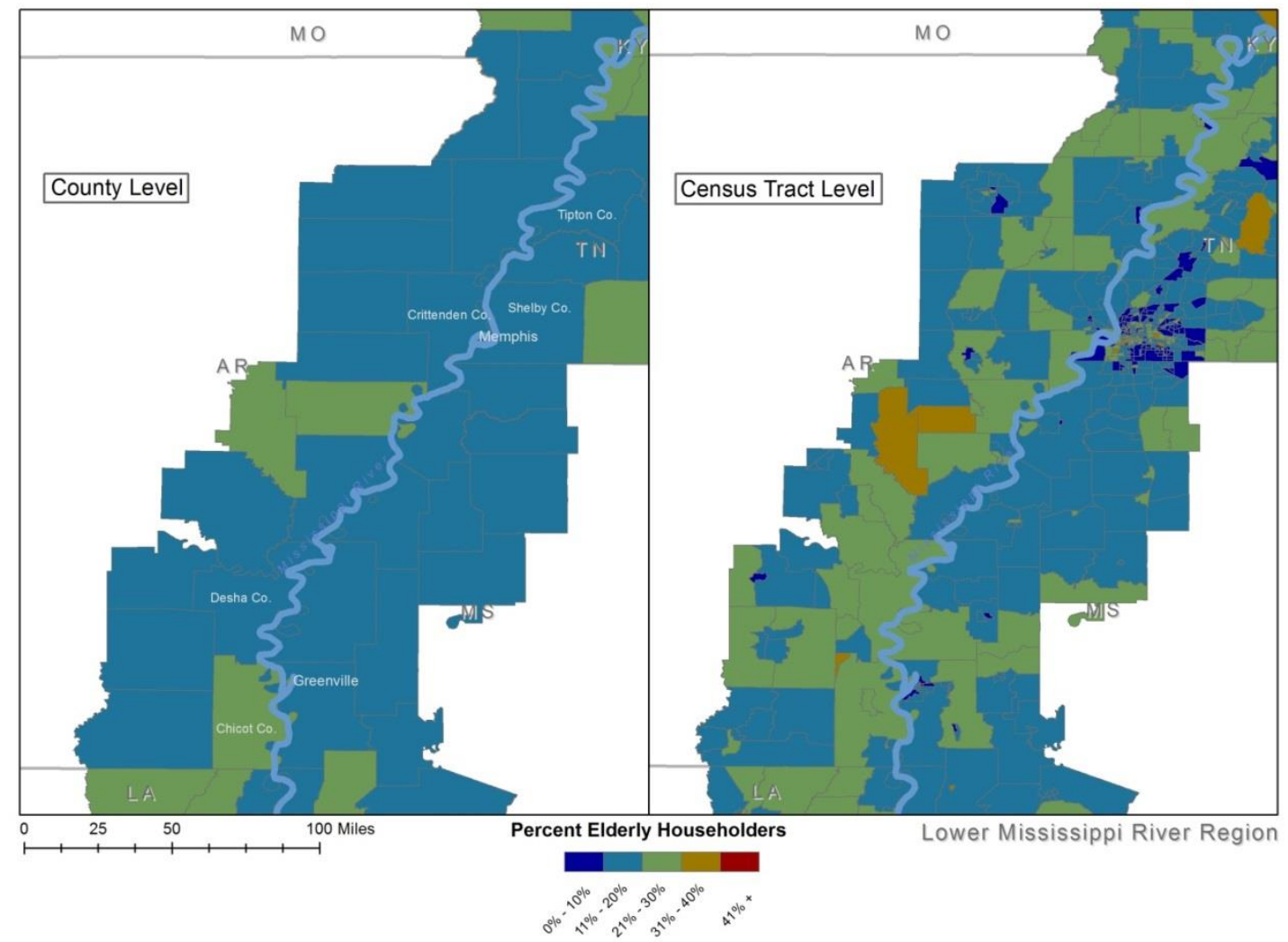

American Community Survey 2012 (5 year estimates) county and census tract data mapped using ArcGIS ${ }^{\circledR}$ software by Esri. ArcGIS ${ }^{\circledR}$ and ArcMap $^{\mathrm{TM}}$ are the intellectual property of Esri and are used herein under license. 
Figure 5.49

Louisiana Region: Elderly Households

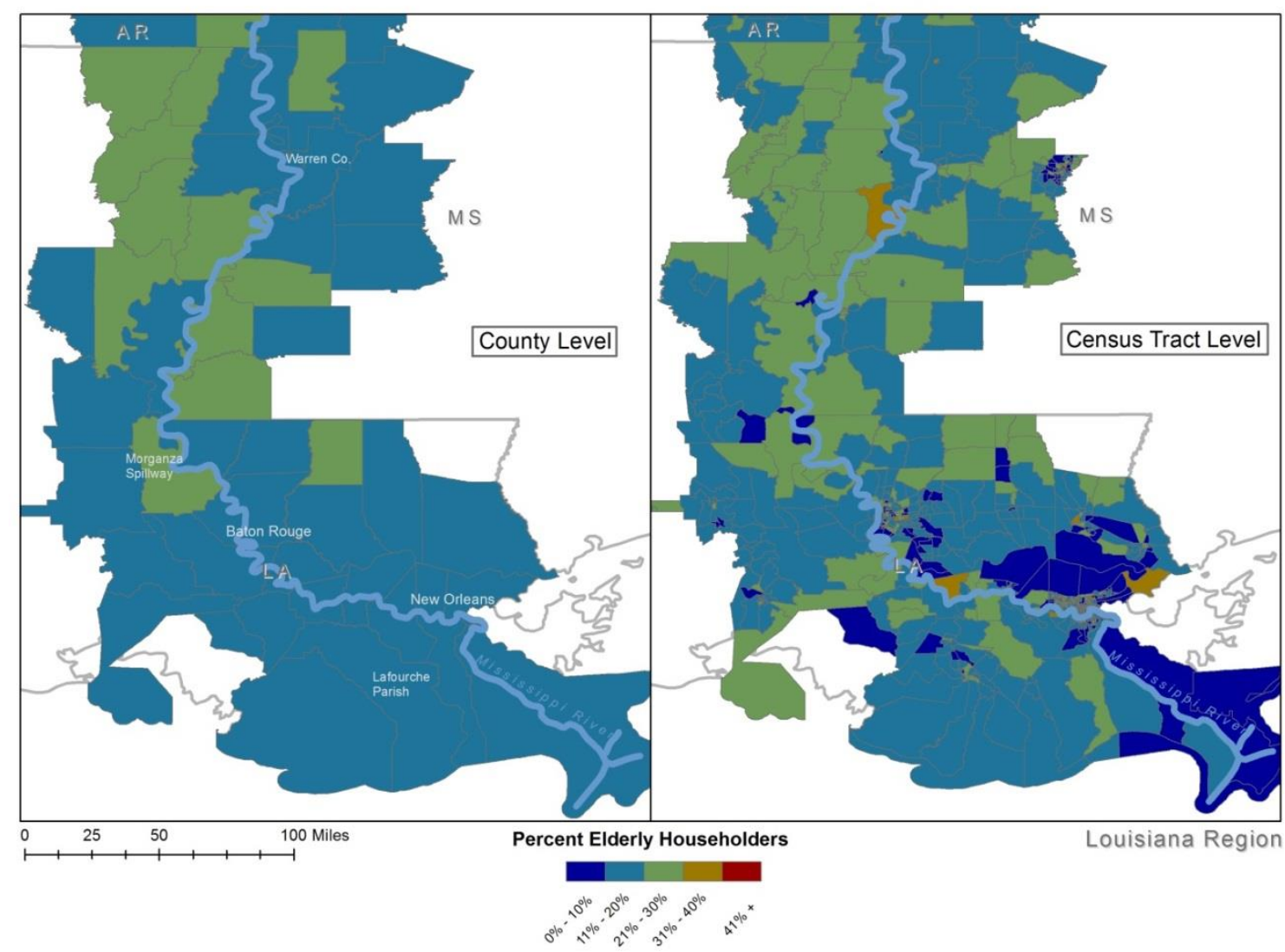

American Community Survey 2012 (5 year estimates) county and census tract data mapped using ArcGIS ${ }^{\circledR}$ software by Esri. ArcGIS ${ }^{\circledR}$ and ArcMap ${ }^{\mathrm{TM}}$ are the intellectual property of Esri and are used herein under license. 


\section{Figure 5.50}

Minneapolis/St. Paul, MN: Elderly Households

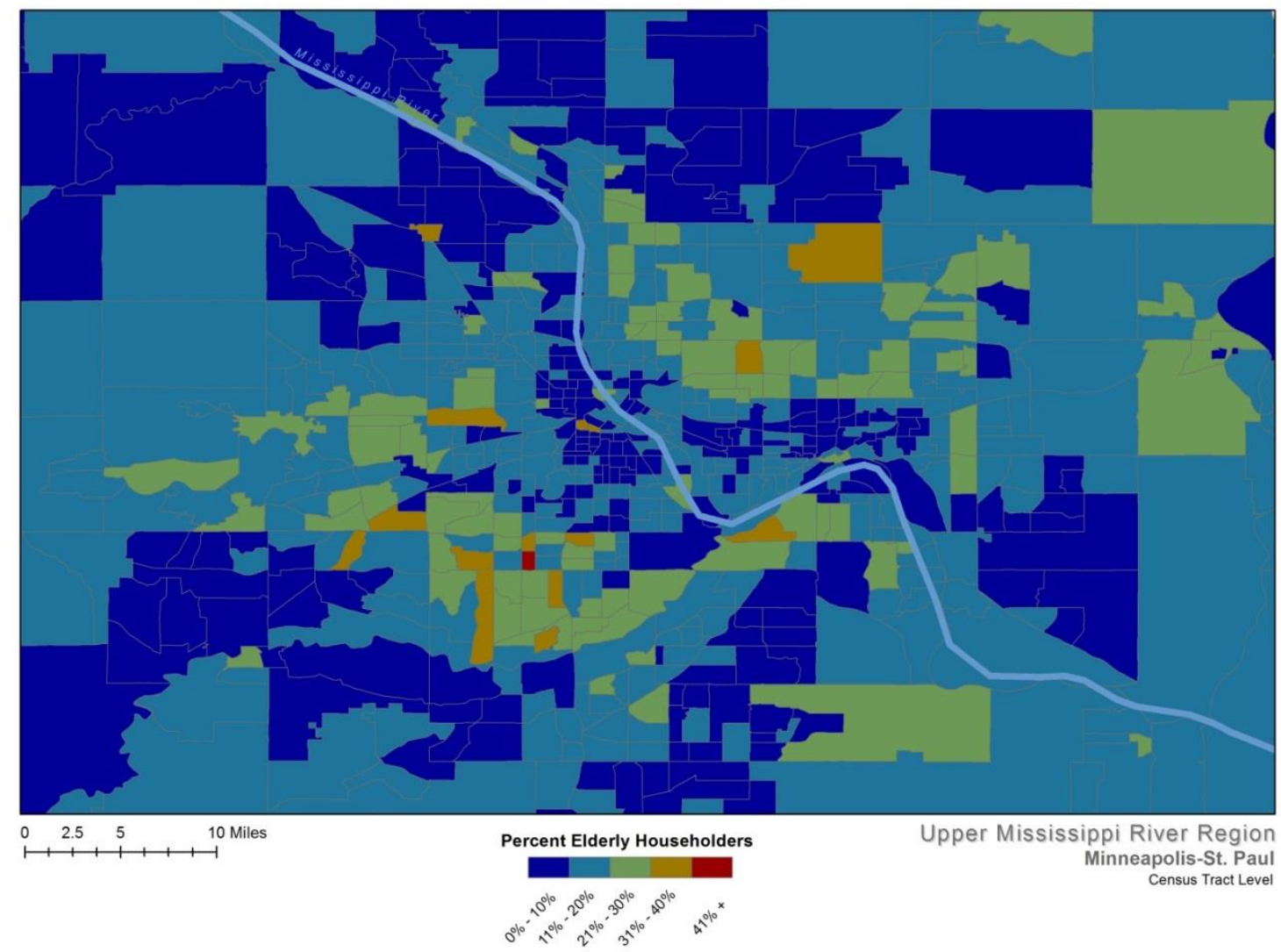

American Community Survey 2012 (5 year estimates) county and census tract data mapped using ArcGIS ${ }^{\circledR}$ software by Esri. ArcGIS ${ }^{\circledR}$ and ArcMap ${ }^{\mathrm{TM}}$ are the intellectual property of Esri and are used herein under license. 


\section{Figure 5.51}

Quad Cities (side view): Elderly Households

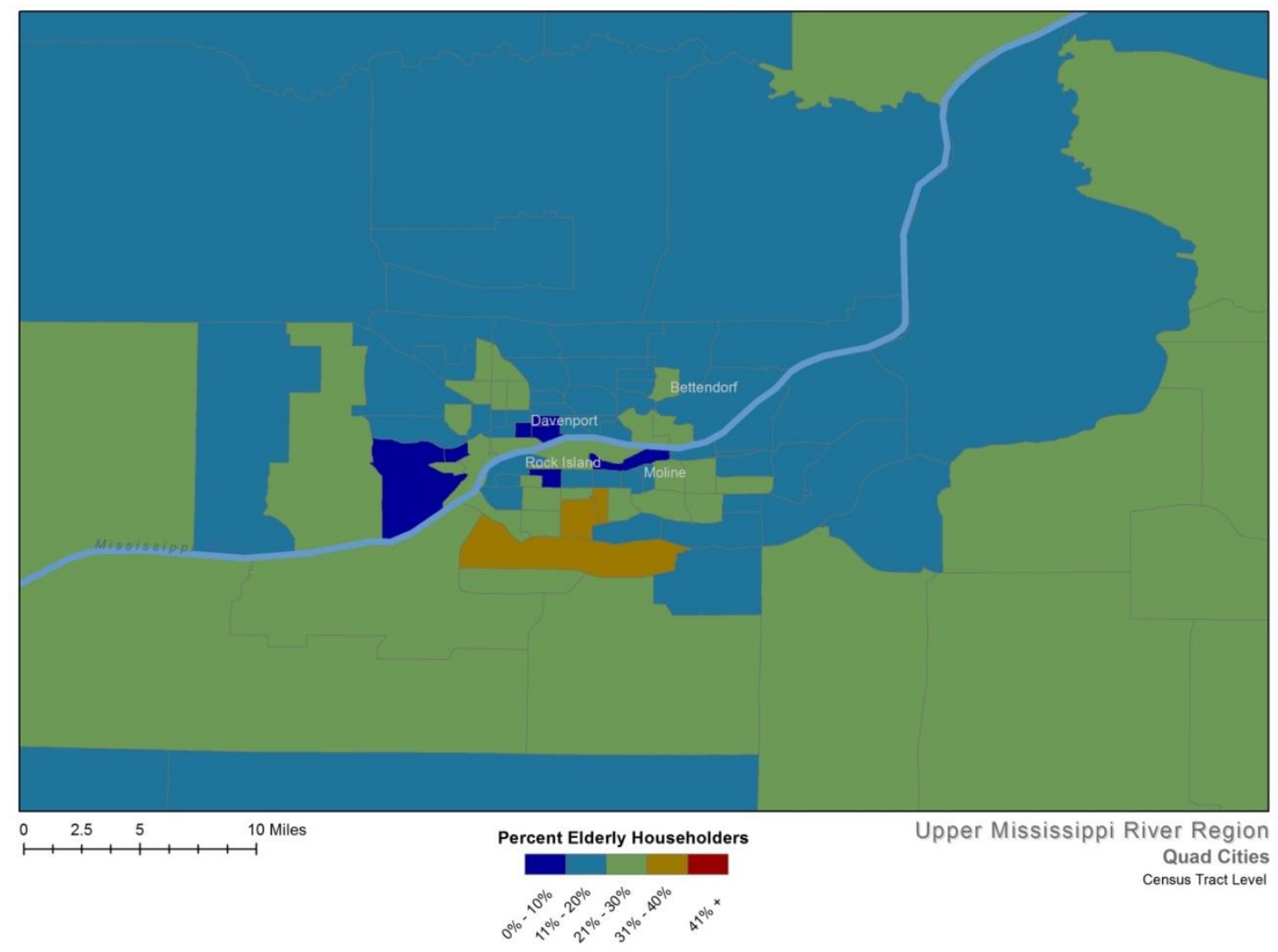

American Community Survey 2012 (5 year estimates) county and census tract data mapped using ArcGIS ${ }^{\circledR}$ software by Esri. ArcGIS ${ }^{\circledR}$ and ArcMap ${ }^{\mathrm{TM}}$ are the intellectual property of Esri and are used herein under license. 


\section{Figure 5.52}

St. Louis, MO: Elderly Households

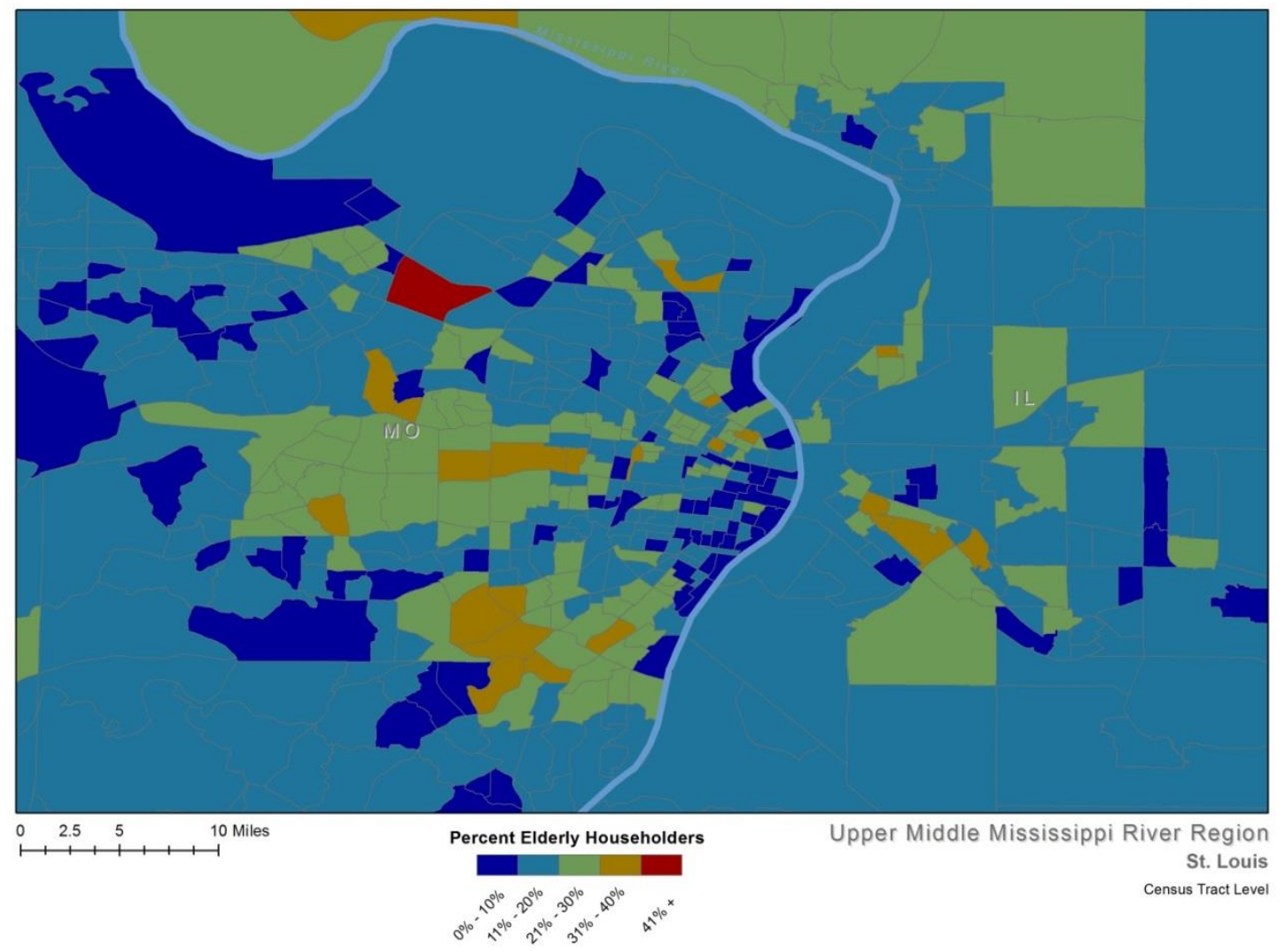

American Community Survey 2012 (5 year estimates) county and census tract data mapped using ArcGIS ${ }^{\circledR}$ software by Esri. ArcGIS ${ }^{\circledR}$ and ArcMap ${ }^{\mathrm{TM}}$ are the intellectual property of Esri and are used herein under license. 


\section{Figure 5.53}

Memphis, TN: Elderly Households

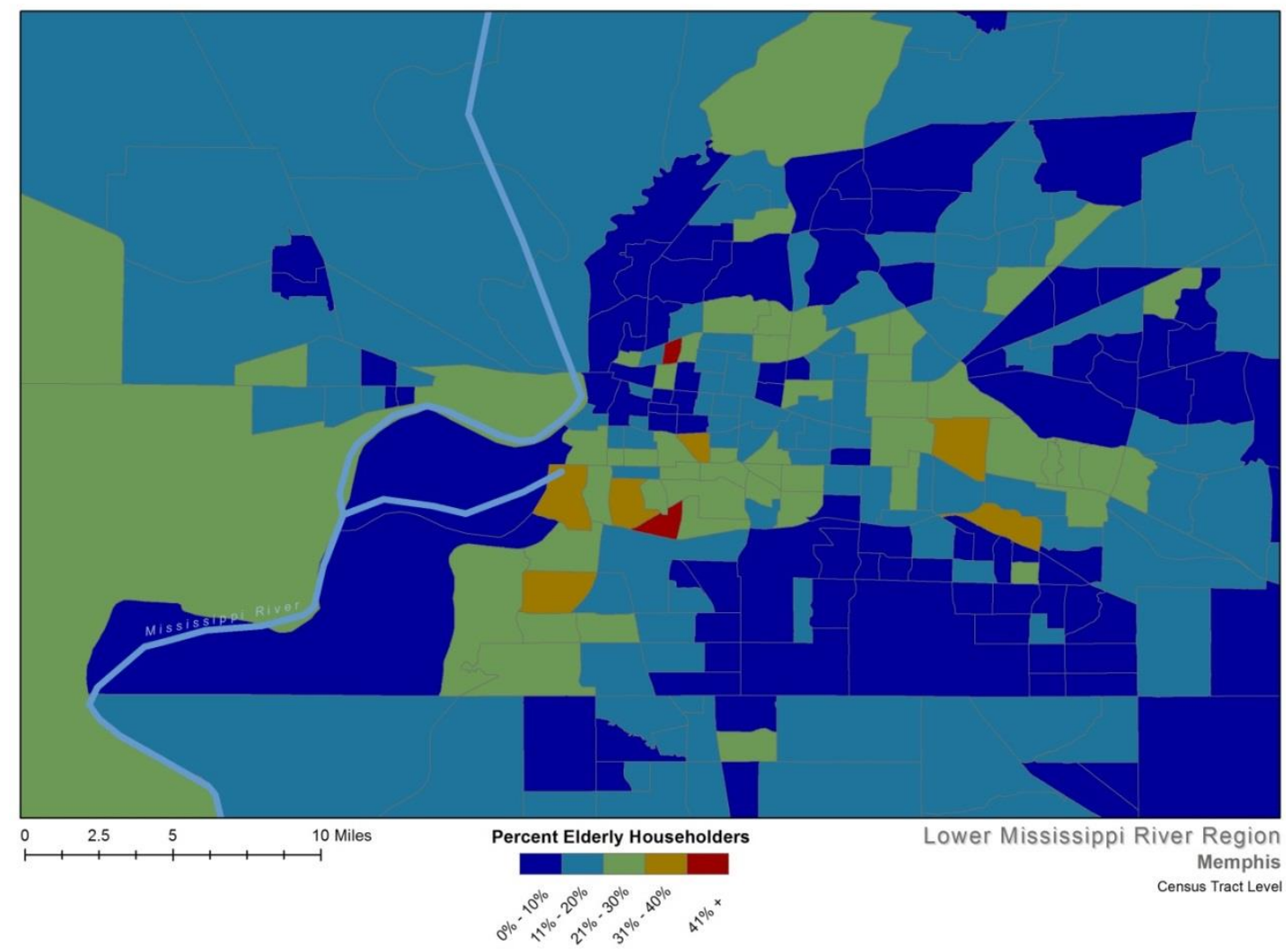

American Community Survey 2012 (5 year estimates) county and census tract data mapped using ArcGIS ${ }^{\circledR}$ software by Esri. ArcGIS $\AA$ and ArcMap ${ }^{\mathrm{TM}}$ are the intellectual property of Esri and are used herein under license. 


\section{Figure 5.54}

Baton Rouge, LA: Elderly Households

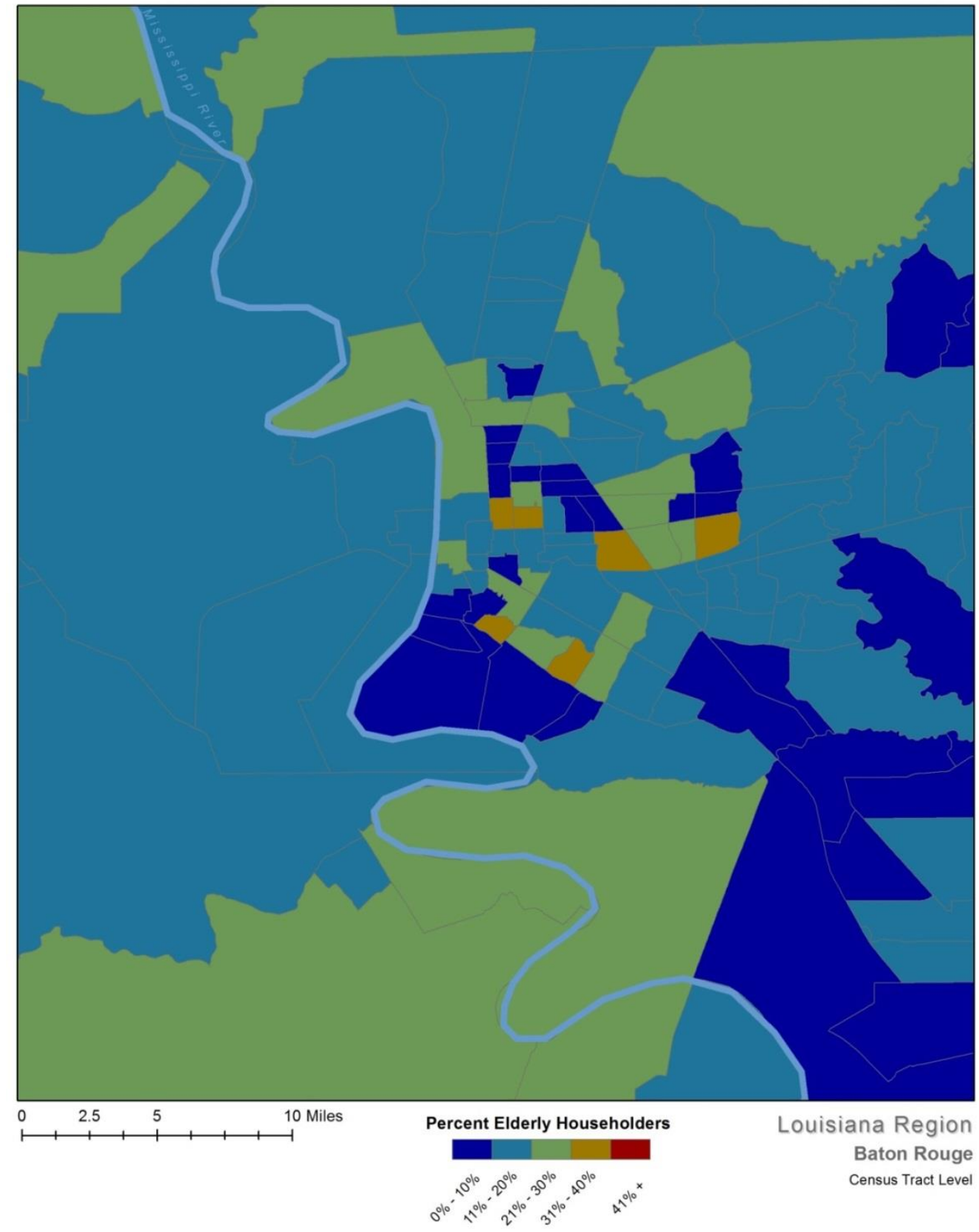

American Community Survey 2012 (5 year estimates) county and census tract data mapped using ArcGIS ${ }^{\circledR}$ software by Esri. ArcGIS ${ }^{\circledR}$ and ArcMap ${ }^{\mathrm{TM}}$ are the intellectual property of Esri and are used herein under license. 


\section{Figure 5.55}

New Orleans, LA: Elderly Households

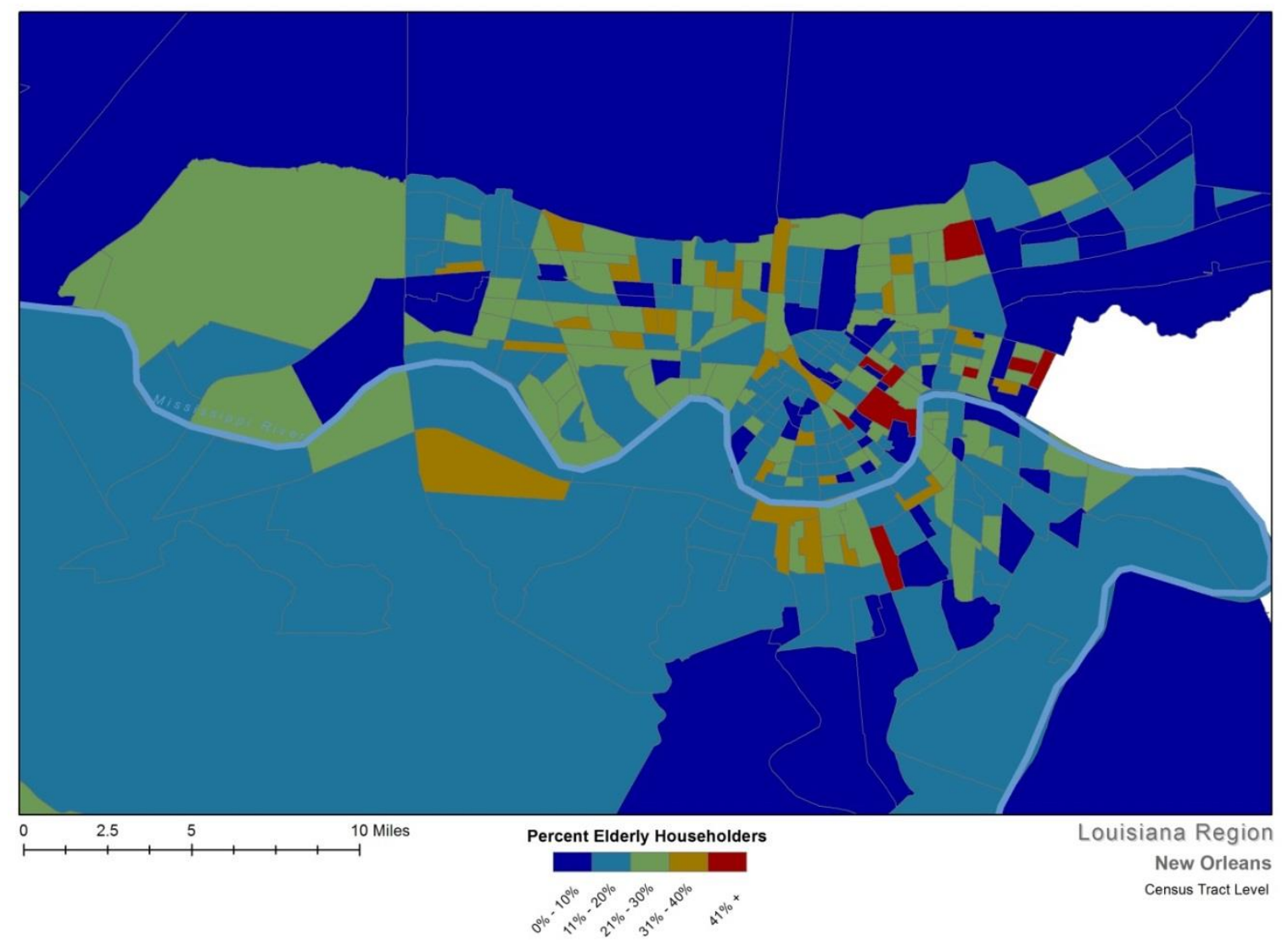

American Community Survey 2012 (5 year estimates) county and census tract data mapped using ArcGIS ${ }^{\circledR}$ software by Esri. ArcGIS ${ }^{\circledR}$ and ArcMap ${ }^{\mathrm{TM}}$ are the intellectual property of Esri and are used herein under license. 


\section{Figure 5.56}

Upper Mississippi River Region: Median Household Income

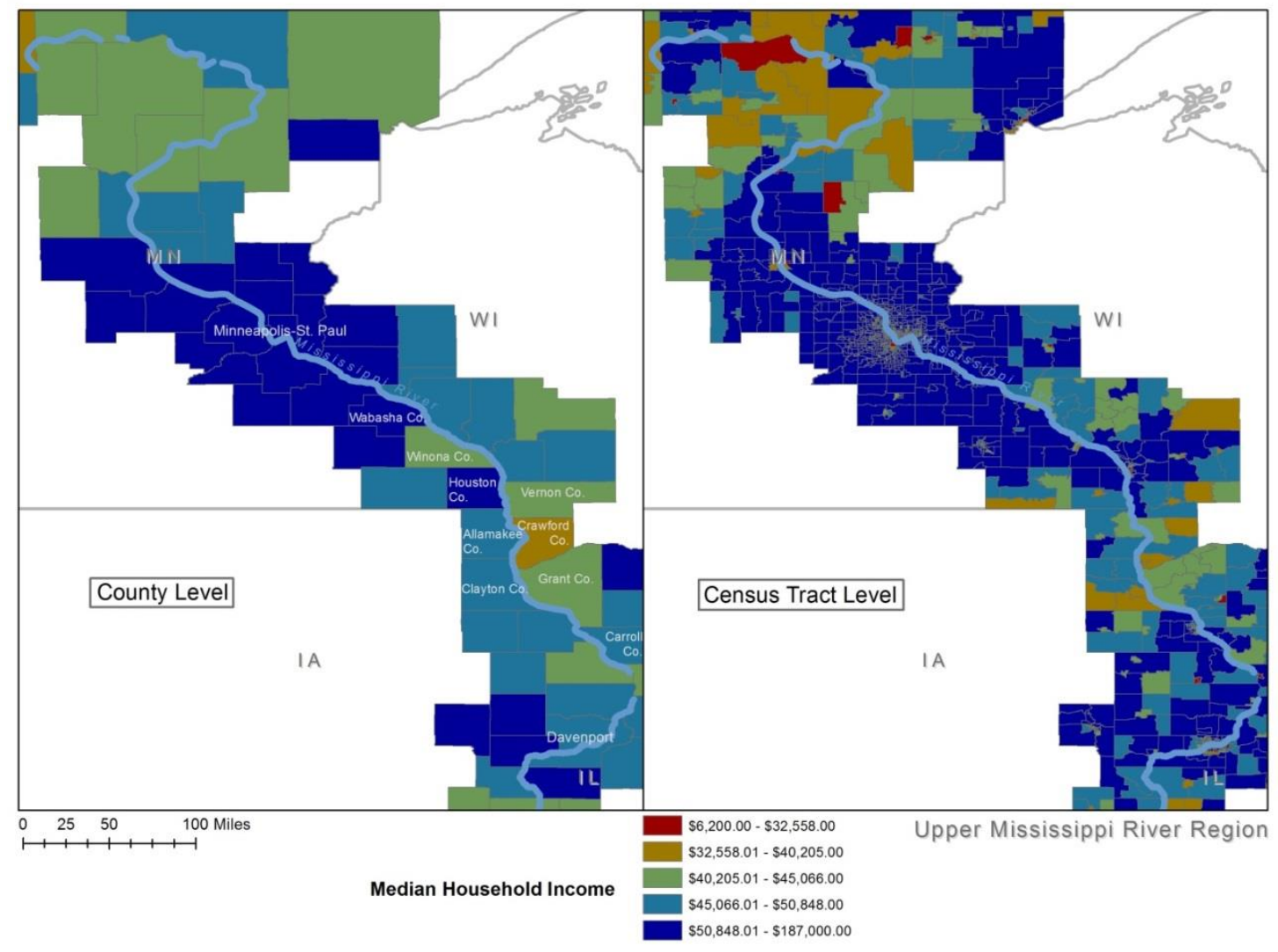

American Community Survey 2012 (5 year estimates) county and census tract data mapped using ArcGIS ${ }^{\circledR}$ software by Esri. ArcGIS ${ }^{\circledR}$ and ArcMap ${ }^{\mathrm{TM}}$ are the intellectual property of Esri and are used herein under license. 


\section{Figure 5.57}

Upper Middle Mississippi River Region: Median Household Income

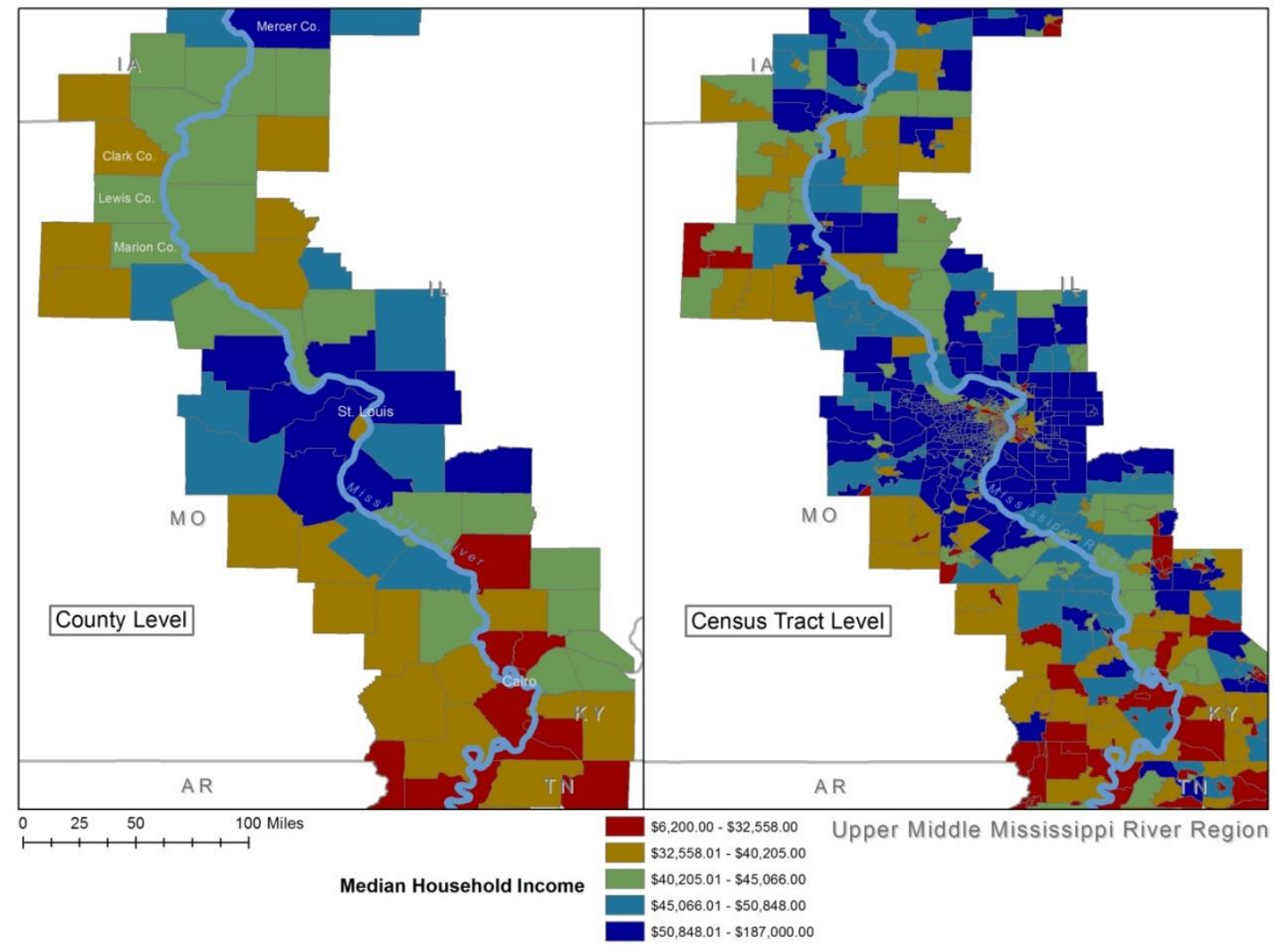

American Community Survey 2012 (5 year estimates) county and census tract data mapped using ArcGIS ${ }^{\circledR}$ software by Esri. ArcGIS ${ }^{\circledR}$ and ArcMap ${ }^{\mathrm{TM}}$ are the intellectual property of Esri and are used herein under license. 


\section{Figure 5.58}

Lower Mississippi River Region: Median Household Income

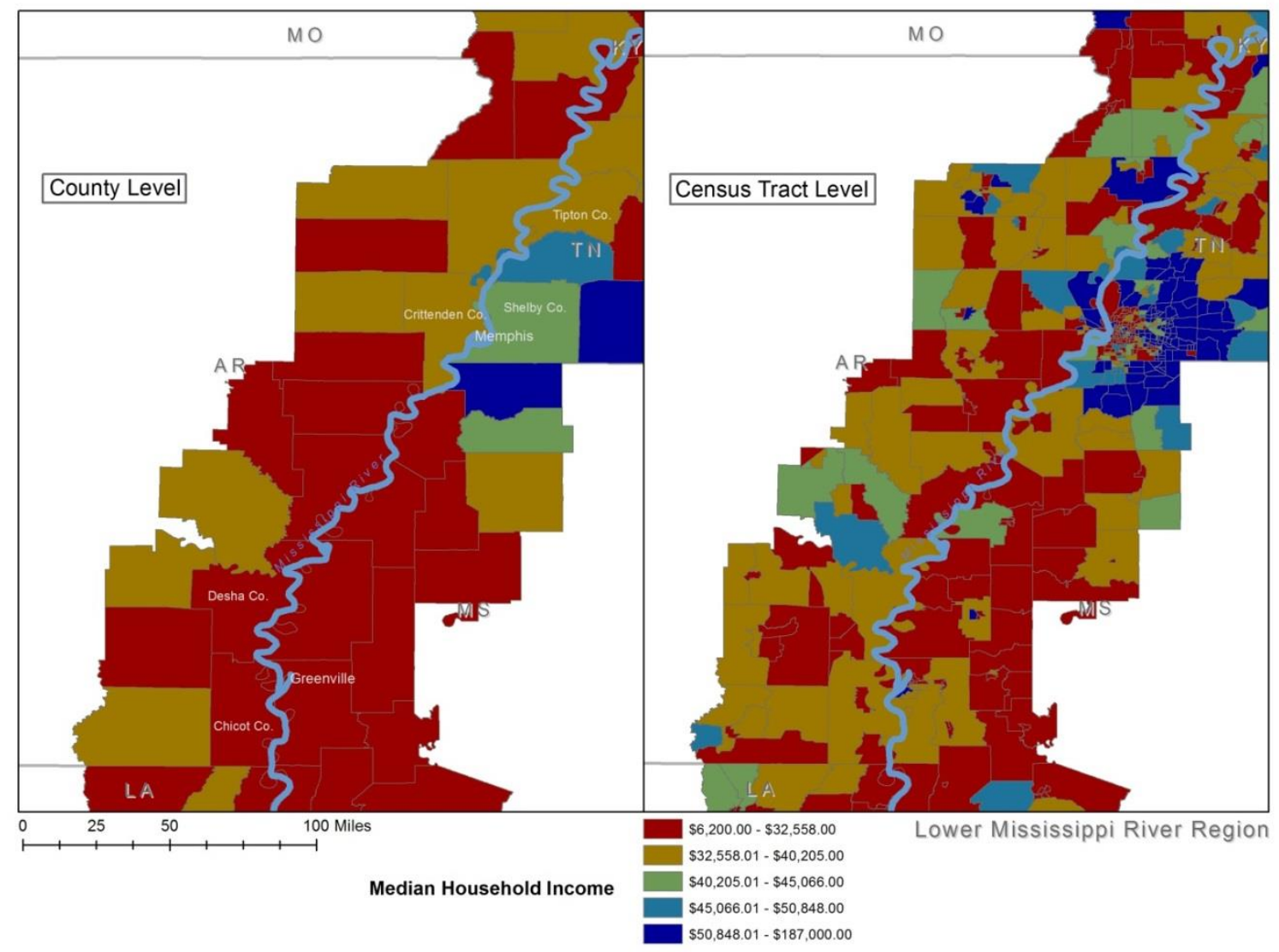

American Community Survey 2012 (5 year estimates) county and census tract data mapped using ArcGIS ${ }^{\circledR}$ software by Esri. ArcGIS ${ }^{\circledR}$ and ArcMap $^{\mathrm{TM}}$ are the intellectual property of Esri and are used herein under license. 


\section{Figure 5.59}

Louisiana Region: Median Household Income

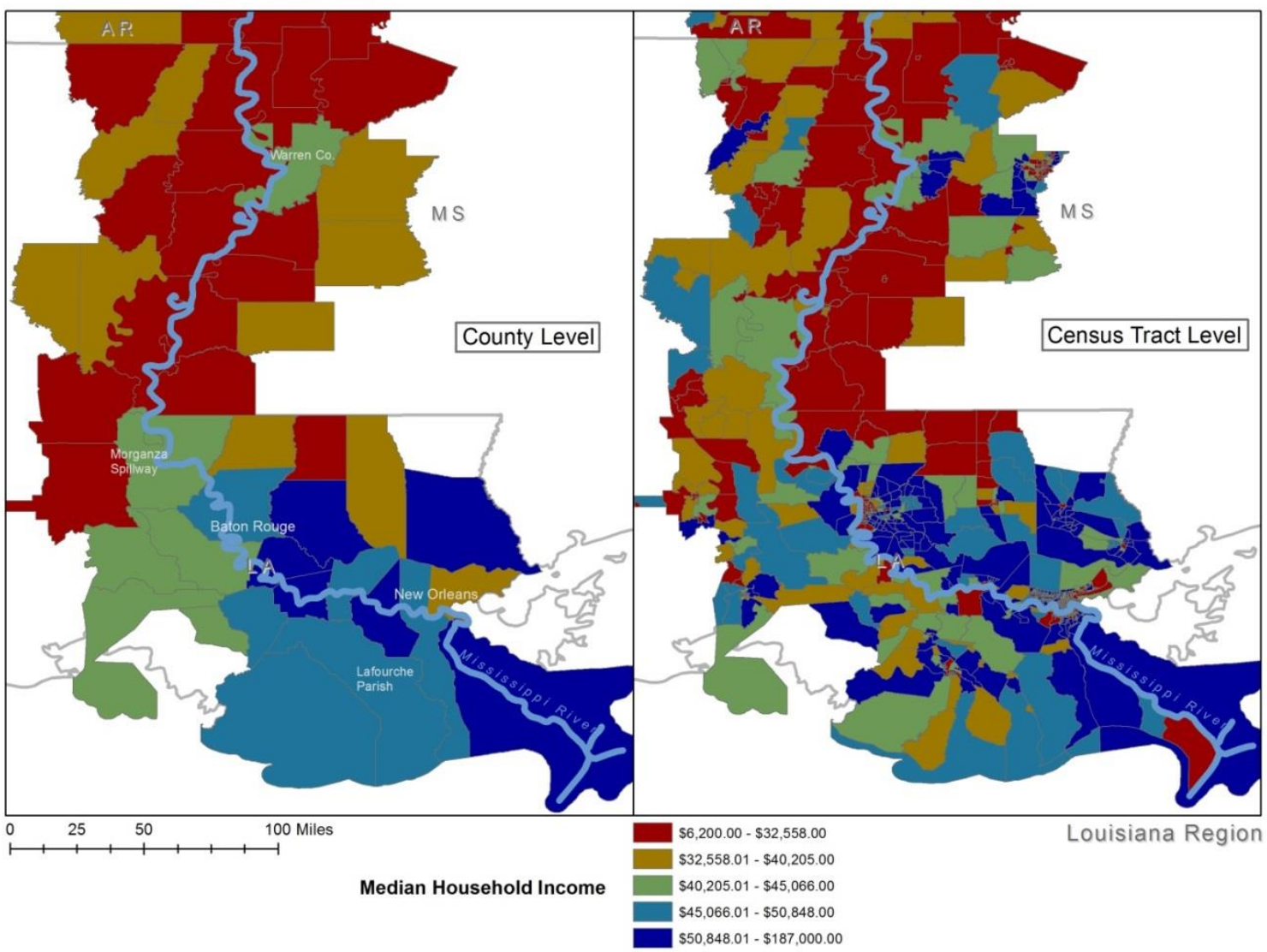

American Community Survey 2012 (5 year estimates) county and census tract data mapped using ArcGIS ${ }^{\circledR}$ software by Esri. ArcGIS ${ }^{\circledR}$ and ArcMap ${ }^{\mathrm{TM}}$ are the intellectual property of Esri and are used herein under license. 


\section{Figure 5.60}

Minneapolis/St. Paul, MN: Median Household Income

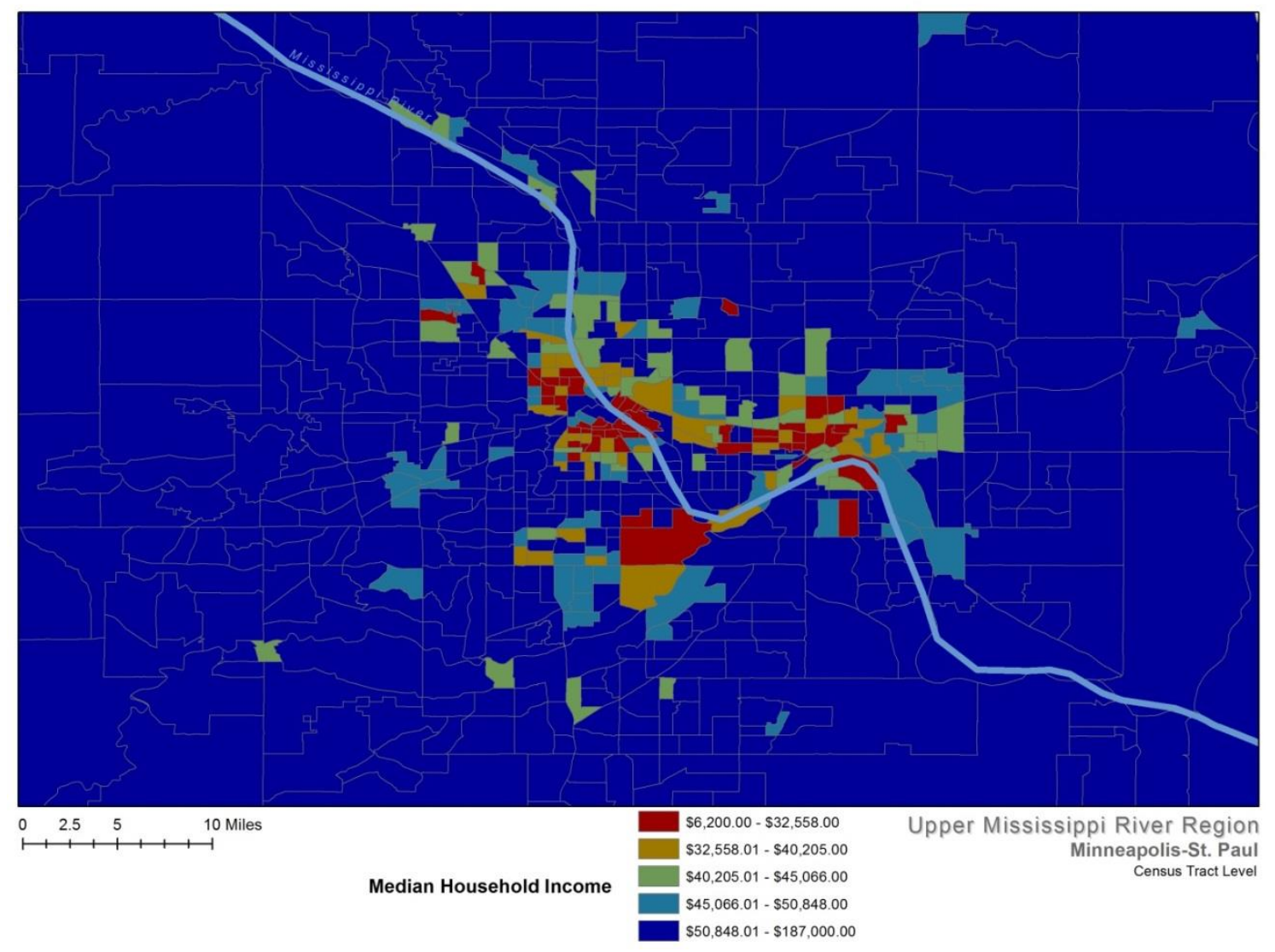

American Community Survey 2012 (5 year estimates) county and census tract data mapped using ArcGIS ${ }^{\circledR}$ software by Esri. ArcGIS ${ }^{\circledR}$ and $\operatorname{ArcMap}^{\mathrm{TM}}$ are the intellectual property of Esri and are used herein under license. 


\section{Figure 5.61}

Quad Cities (side view): Median Household Income

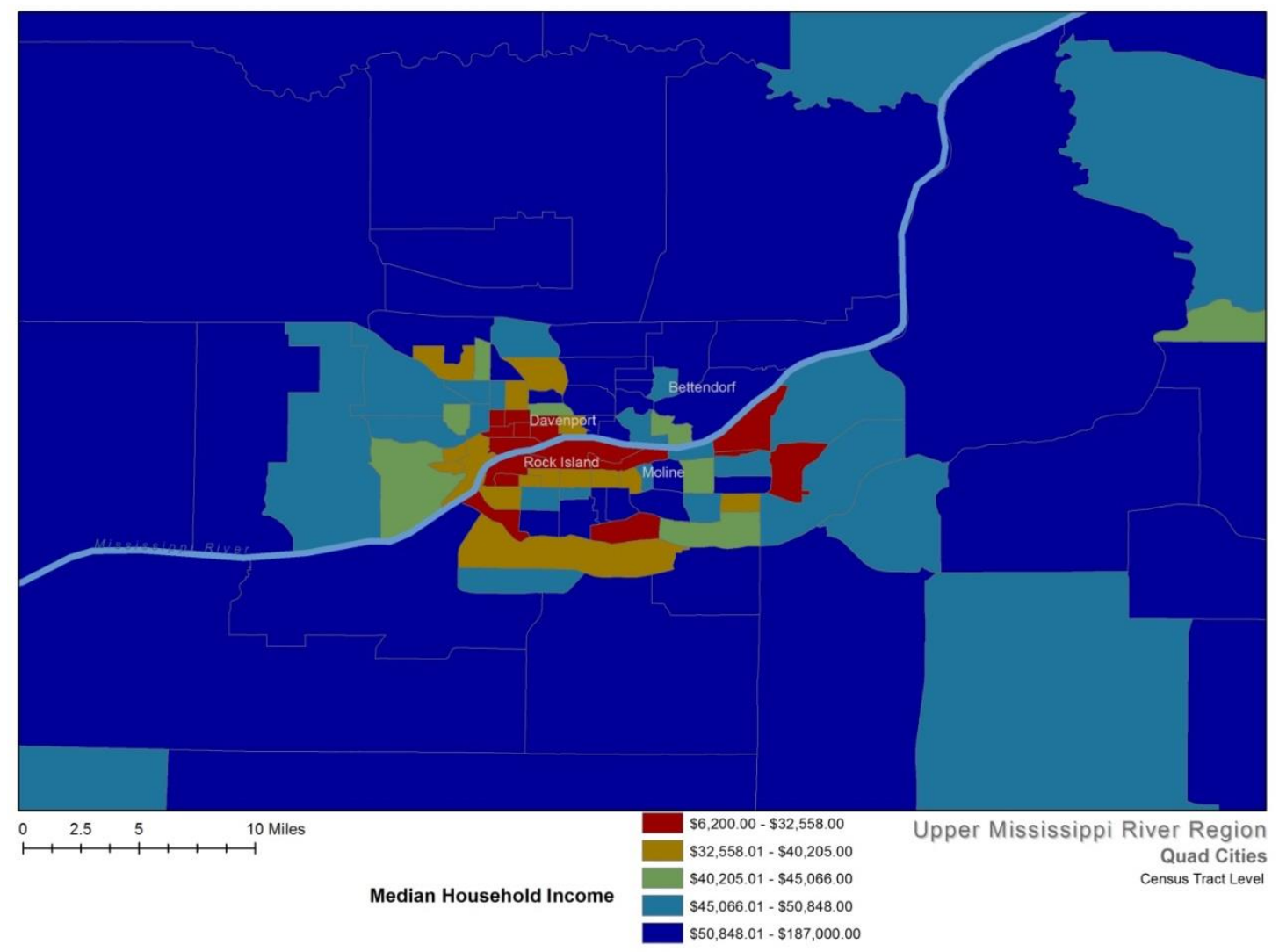

American Community Survey 2012 (5 year estimates) county and census tract data mapped using ArcGIS ${ }^{\circledR}$ software by Esri. ArcGIS ${ }^{\circledR}$ and ArcMap ${ }^{\mathrm{TM}}$ are the intellectual property of Esri and are used herein under license. 


\section{Figure 5.62}

St. Louis, MO: Median Household Income

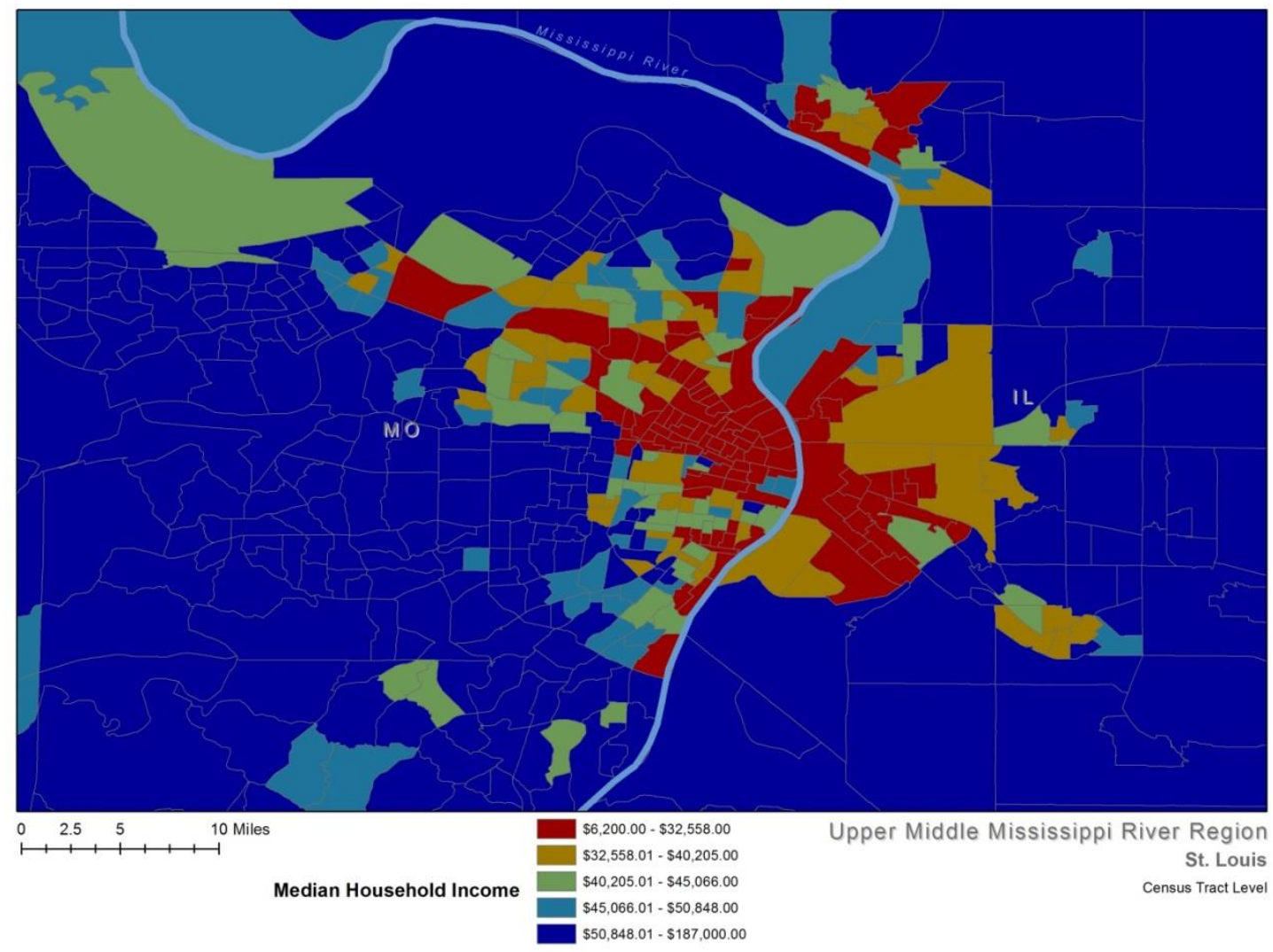

American Community Survey 2012 (5 year estimates) county and census tract data mapped using ArcGIS ${ }^{\circledR}$ software by Esri. ArcGIS ${ }^{\circledR}$ and ArcMap $^{\mathrm{TM}}$ are the intellectual property of Esri and are used herein under license. 


\section{Figure 5.63}

Memphis, TN: Median Household Income

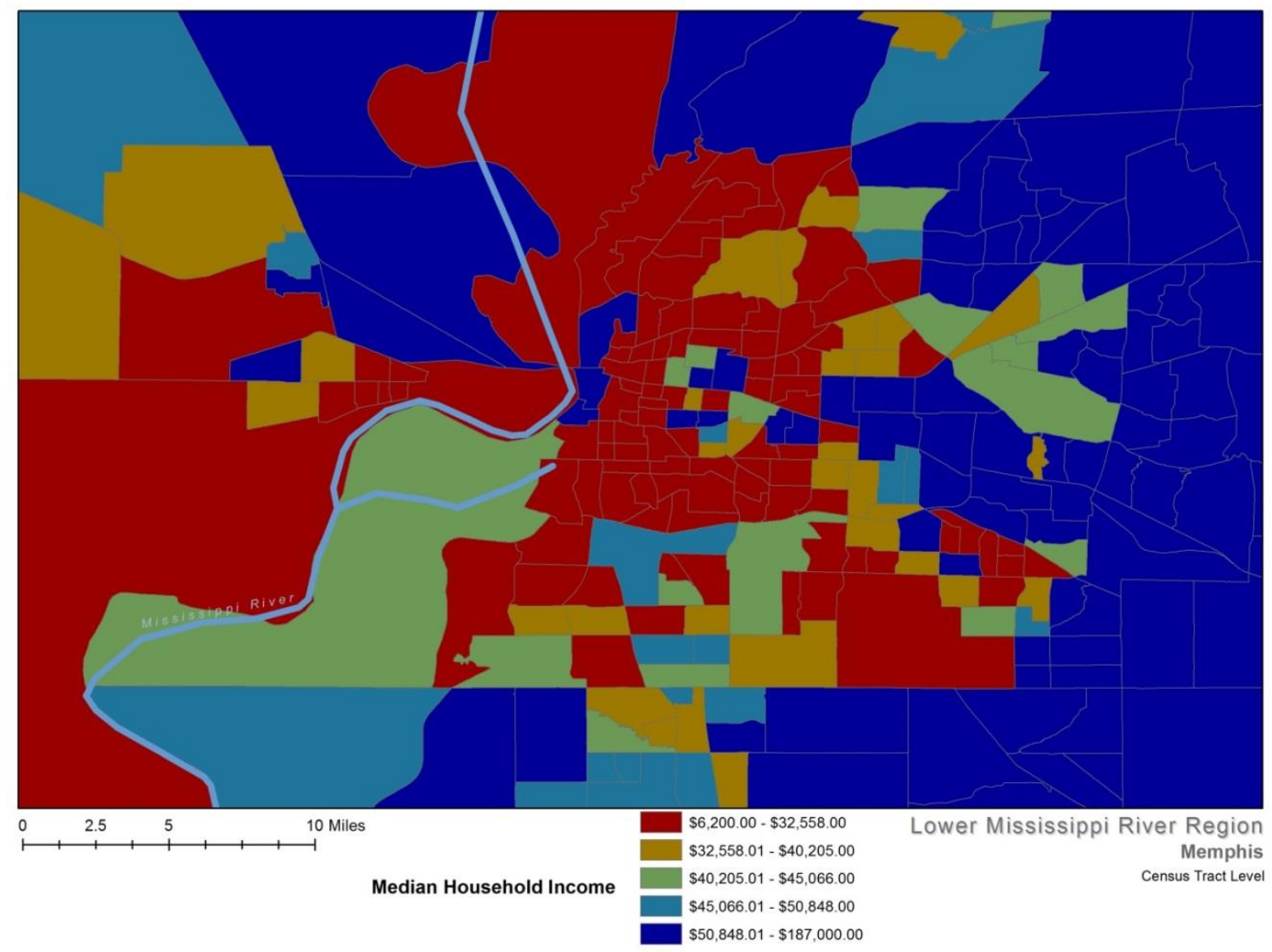

American Community Survey 2012 (5 year estimates) county and census tract data mapped using ArcGIS ${ }^{\circledR}$ software by Esri. ArcGIS ${ }^{\circledR}$ and $\operatorname{ArcMap}^{\mathrm{TM}}$ are the intellectual property of Esri and are used herein under license. 


\section{Figure 5.64}

Baton Rouge, LA: Median Household Income

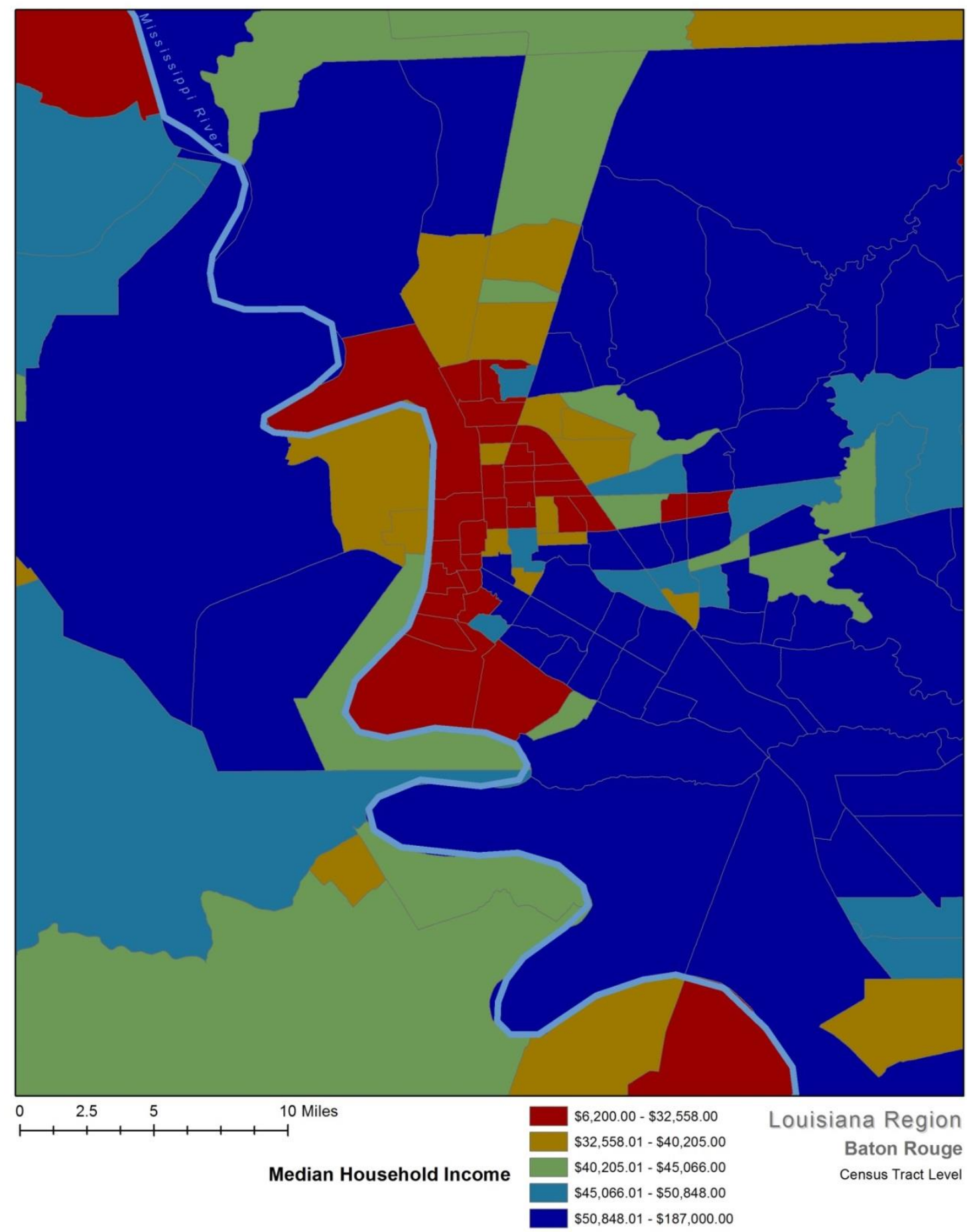

American Community Survey 2012 (5 year estimates) county and census tract data mapped using ArcGIS ${ }^{\circledR}$ software by Esri. ArcGIS ${ }^{\circledR}$ and ArcMap ${ }^{\mathrm{TM}}$ are the intellectual property of Esri and are used herein under license. 


\section{Figure 5.65}

New Orleans, LA: Median Household Income

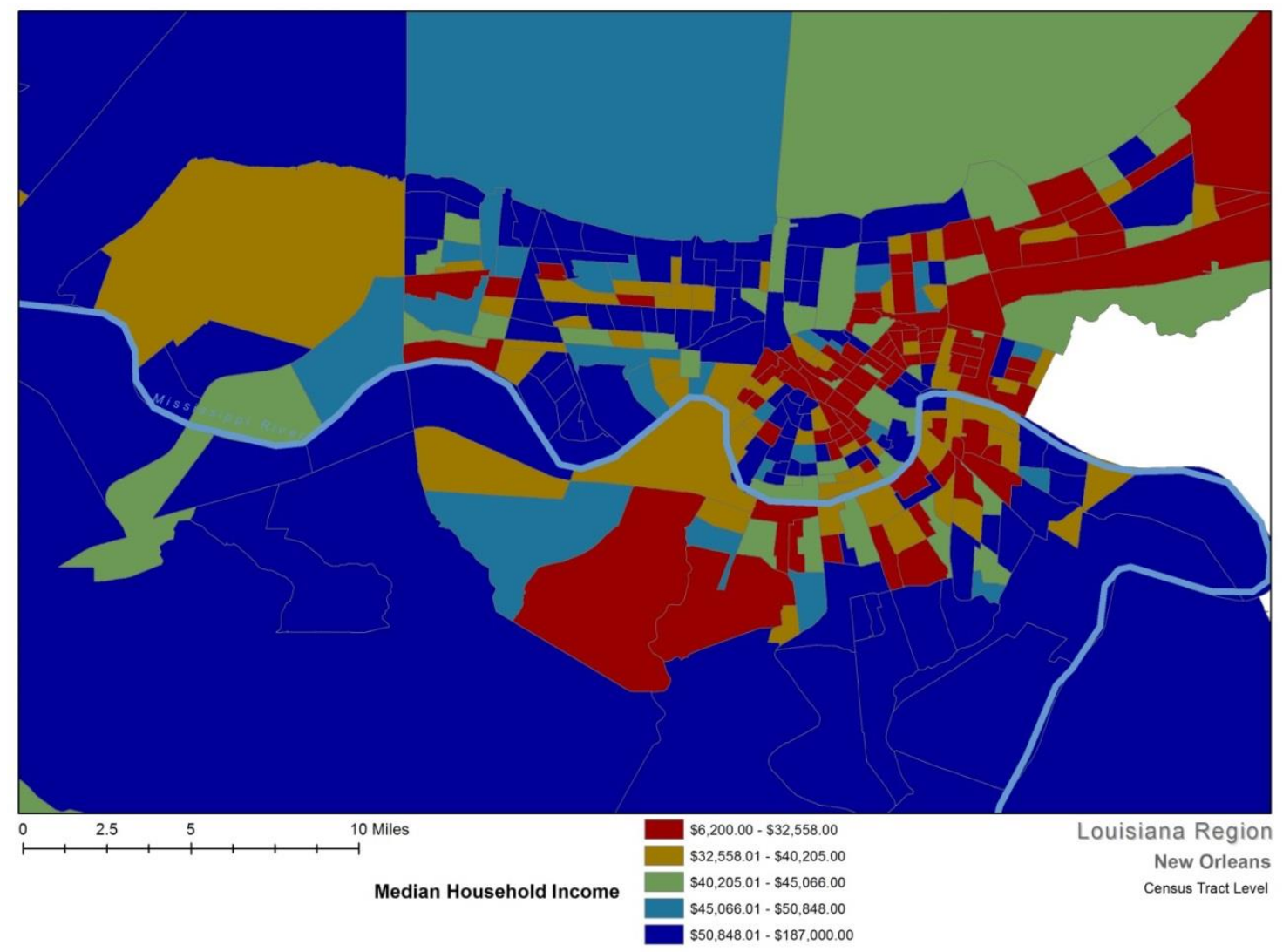

American Community Survey 2012 (5 year estimates) county and census tract data mapped using ArcGIS ${ }^{\circledR}$ software by Esri. ArcGIS ${ }^{\circledR}$ and ArcMap ${ }^{\mathrm{TM}}$ are the intellectual property of Esri and are used herein under license. 


\section{Figure 5.66}

Upper Mississippi River Region: Renter Occupied Housing

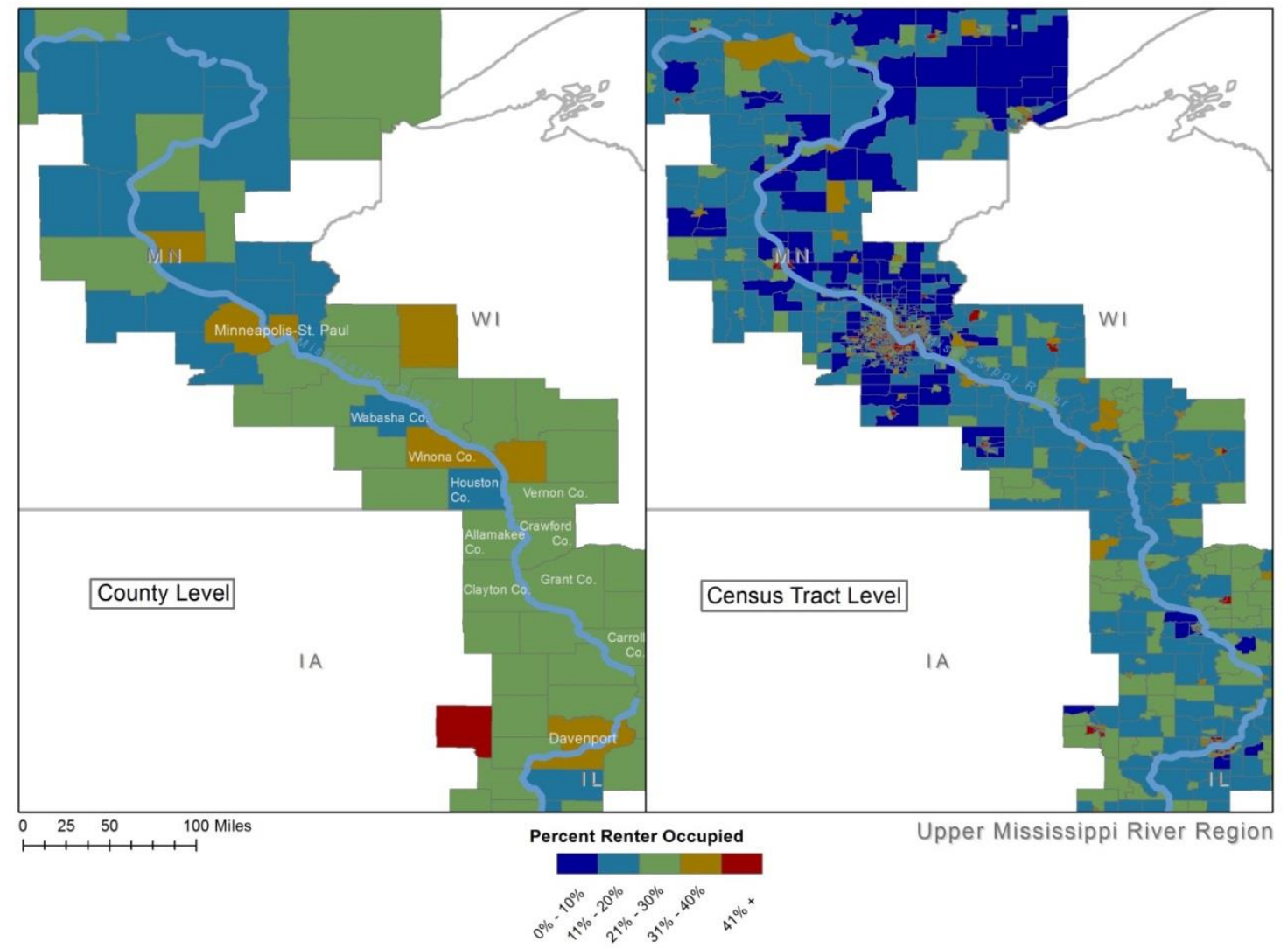

American Community Survey 2012 (5 year estimates) county and census tract data mapped using ArcGIS ${ }^{\circledR}$ software by Esri. ArcGIS ${ }^{\circledR}$ and ArcMap ${ }^{\mathrm{TM}}$ are the intellectual property of Esri and are used herein under license. 


\section{Figure 5.67}

Upper Middle Mississippi River Region: Renter Occupied Housing

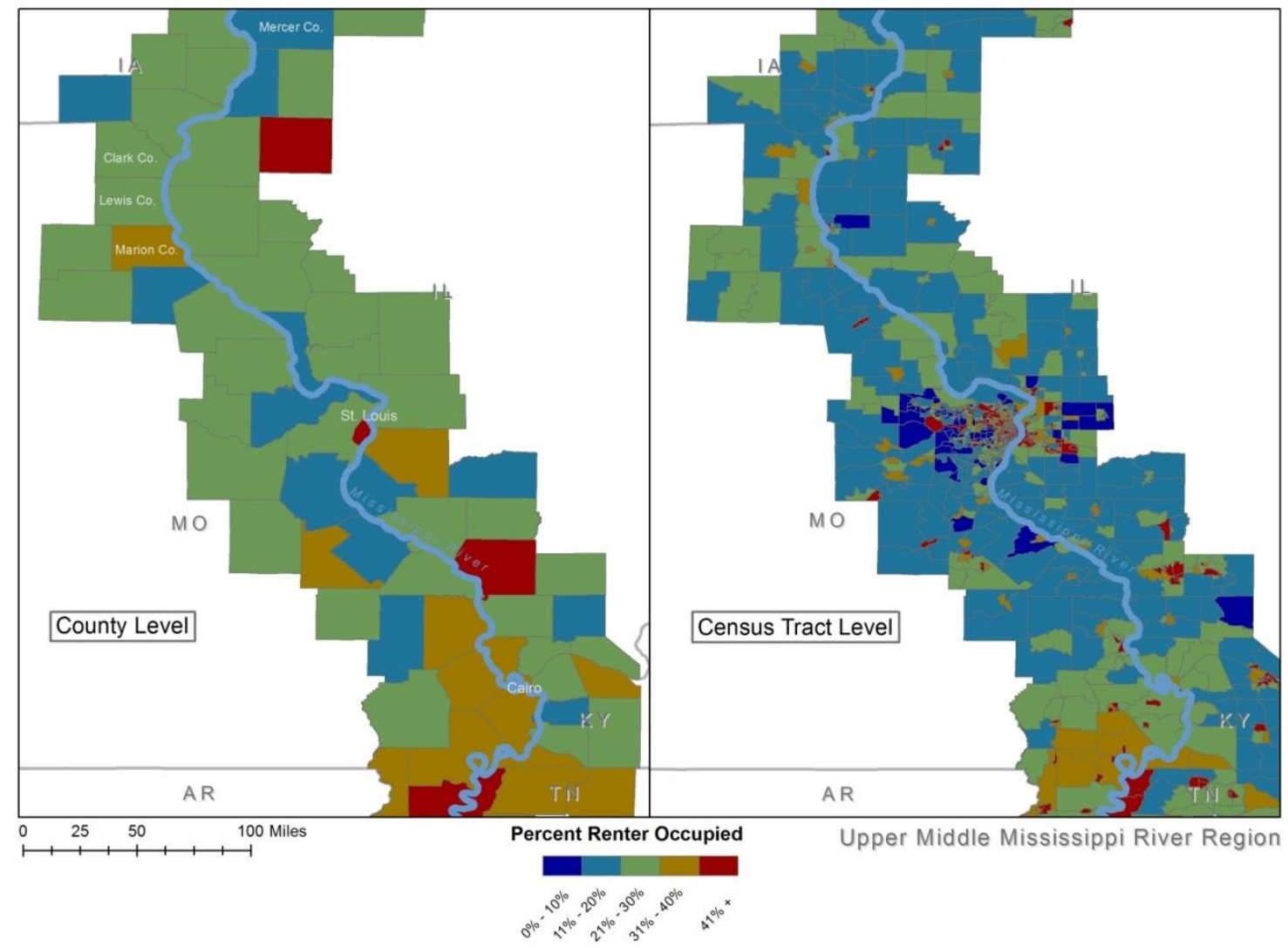

American Community Survey 2012 (5 year estimates) county and census tract data mapped using ArcGIS ${ }^{\circledR}$ software by Esri. ArcGIS ${ }^{\circledR}$ and $\operatorname{ArcMap}^{\mathrm{TM}}$ are the intellectual property of Esri and are used herein under license. 


\section{Figure 5.68}

Lower Mississippi River Region: Renter Occupied Housing

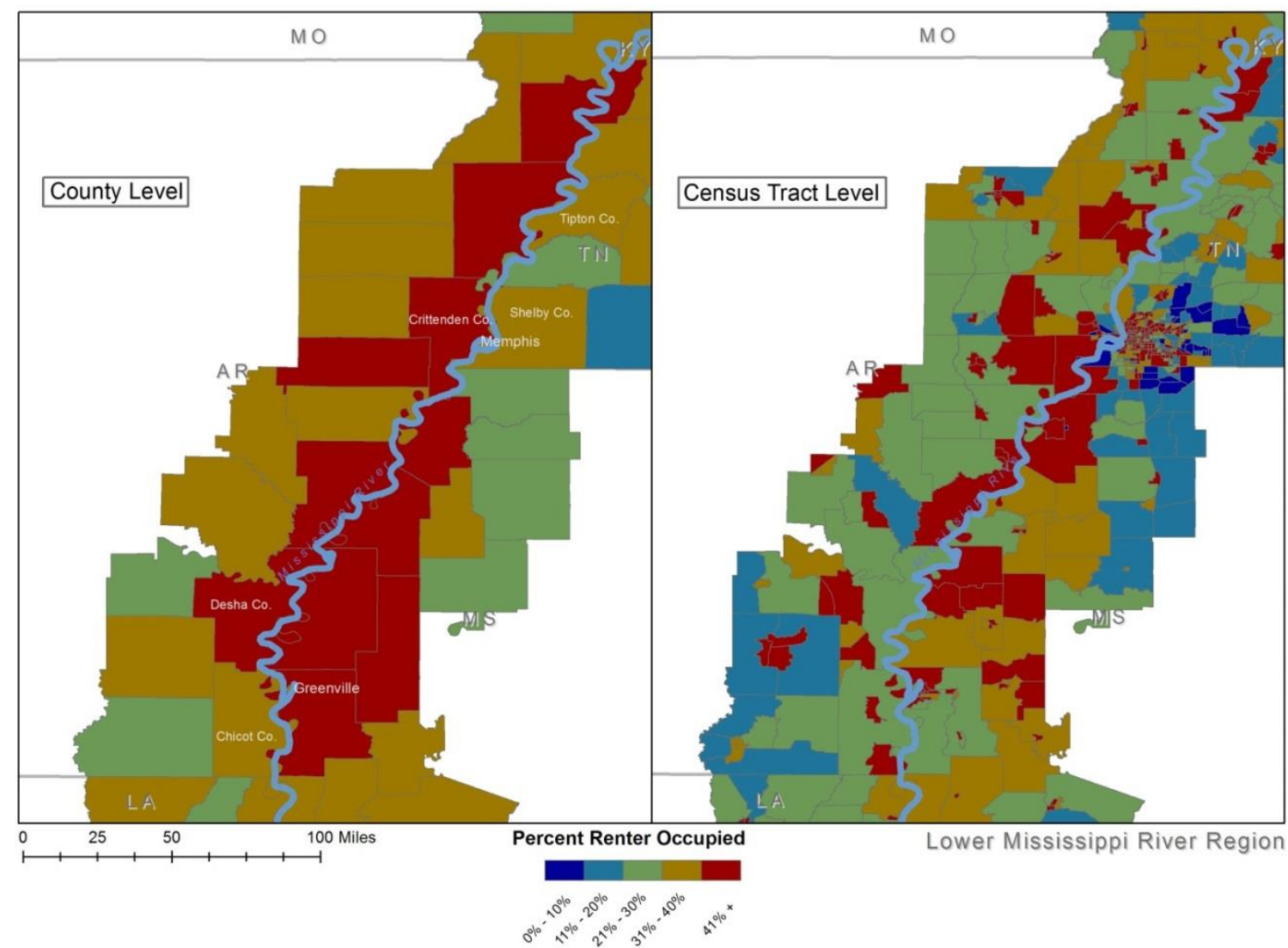

American Community Survey 2012 (5 year estimates) county and census tract data mapped using ArcGIS ${ }^{\circledR}$ software by Esri. ArcGIS ${ }^{\circledR}$ and ArcMap ${ }^{\mathrm{TM}}$ are the intellectual property of Esri and are used herein under license. 
Figure 5.69

Louisiana Region: Renter Occupied Housing

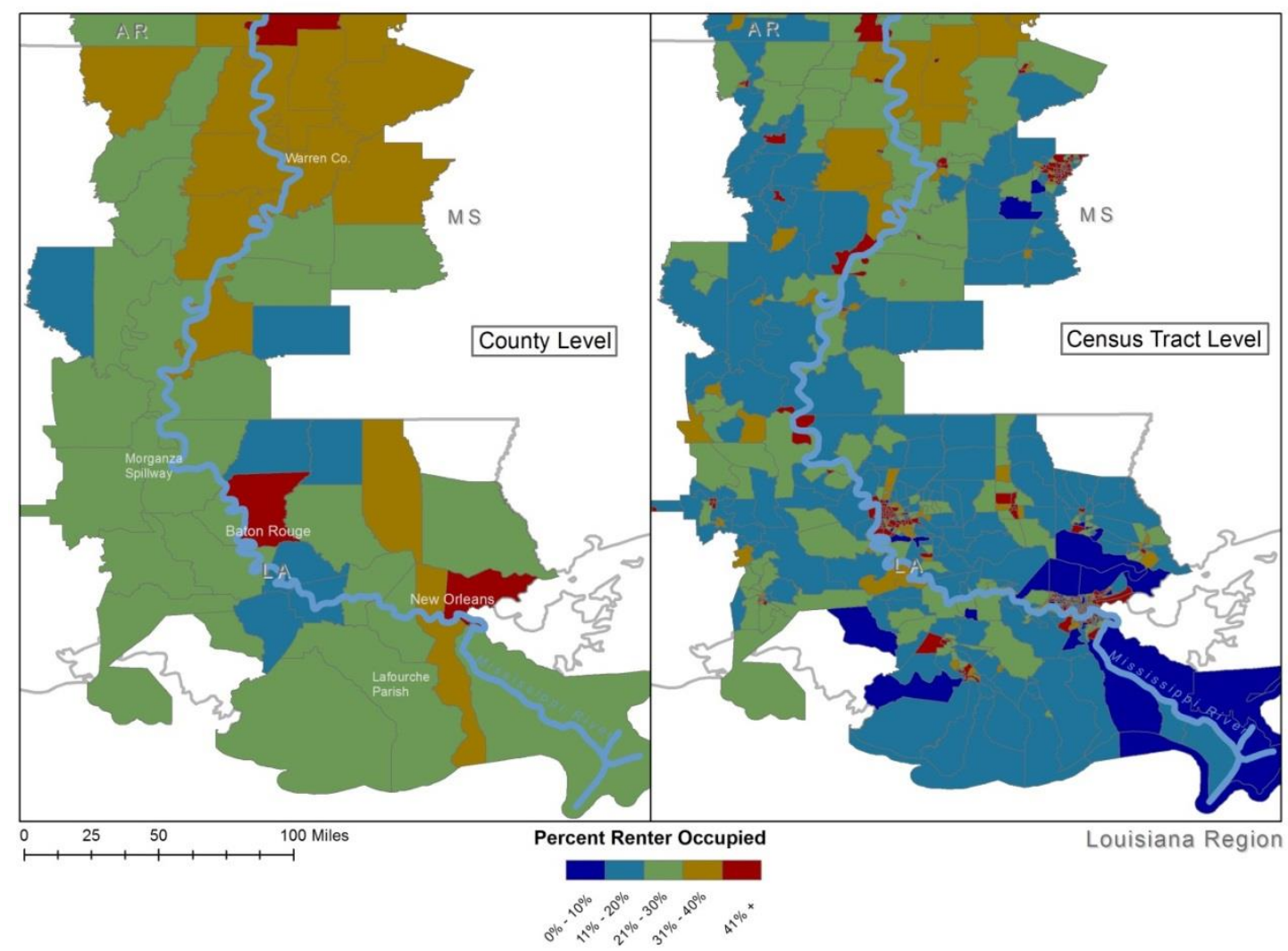

American Community Survey 2012 (5 year estimates) county and census tract data mapped using ArcGIS ${ }^{\circledR}$ software by Esri. ArcGIS ${ }^{\circledR}$ and ArcMap ${ }^{\mathrm{TM}}$ are the intellectual property of Esri and are used herein under license. 


\section{Figure 5.70}

Minneapolis/St. Paul, MN: Renter Occupied Housing

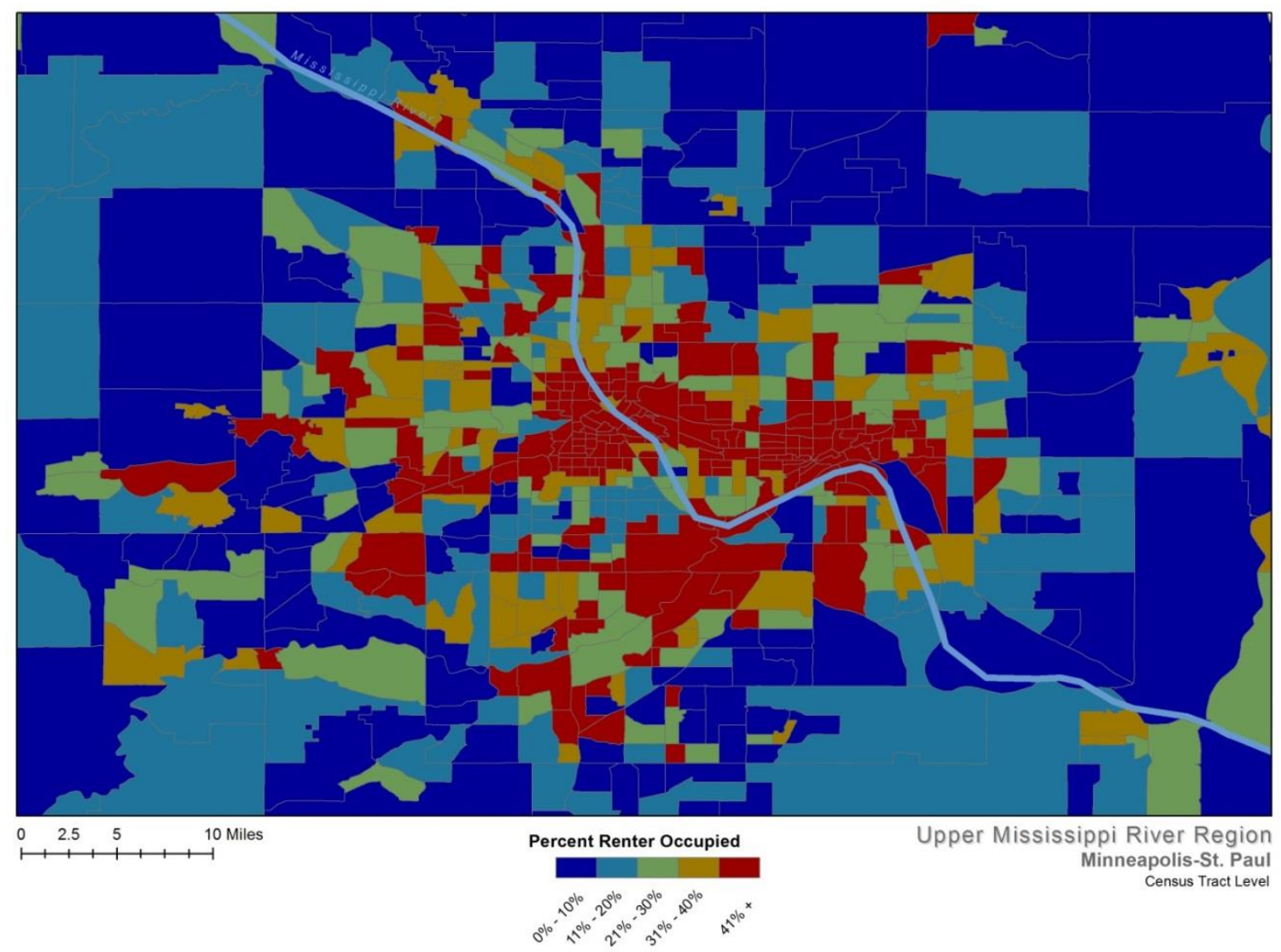

American Community Survey 2012 (5 year estimates) county and census tract data mapped using ArcGIS ${ }^{\circledR}$ software by Esri. ArcGIS ${ }^{\circledR}$ and ArcMap ${ }^{\mathrm{TM}}$ are the intellectual property of Esri and are used herein under license. 


\section{Figure 5.71}

Quad Cities (side view): Renter Occupied Housing

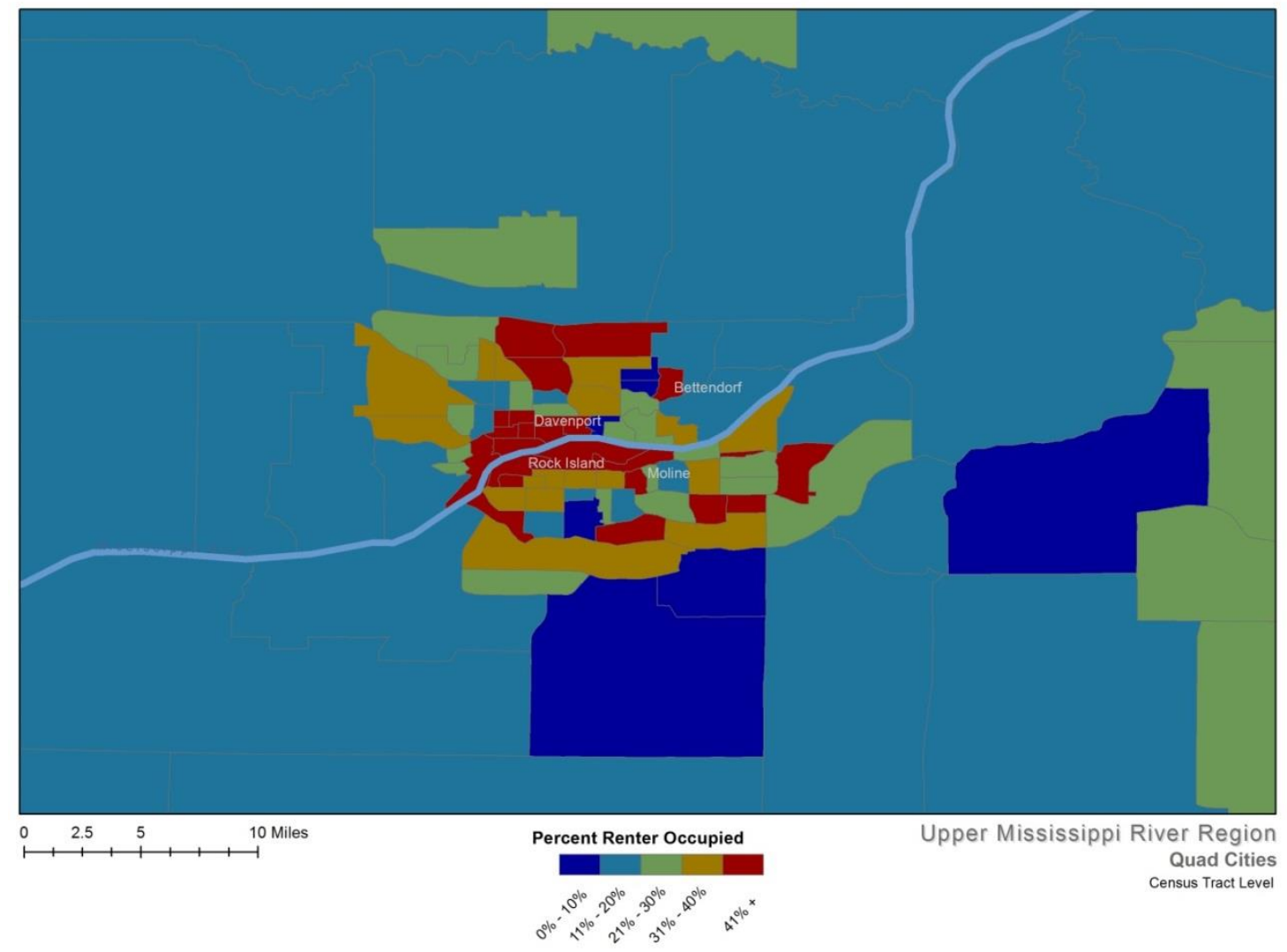

American Community Survey 2012 (5 year estimates) county and census tract data mapped using ArcGIS ${ }^{\circledR}$ software by Esri. ArcGIS ${ }^{\circledR}$ and ArcMap ${ }^{\mathrm{TM}}$ are the intellectual property of Esri and are used herein under license. 


\section{Figure 5.72}

St. Louis, MO: Renter Occupied Housing

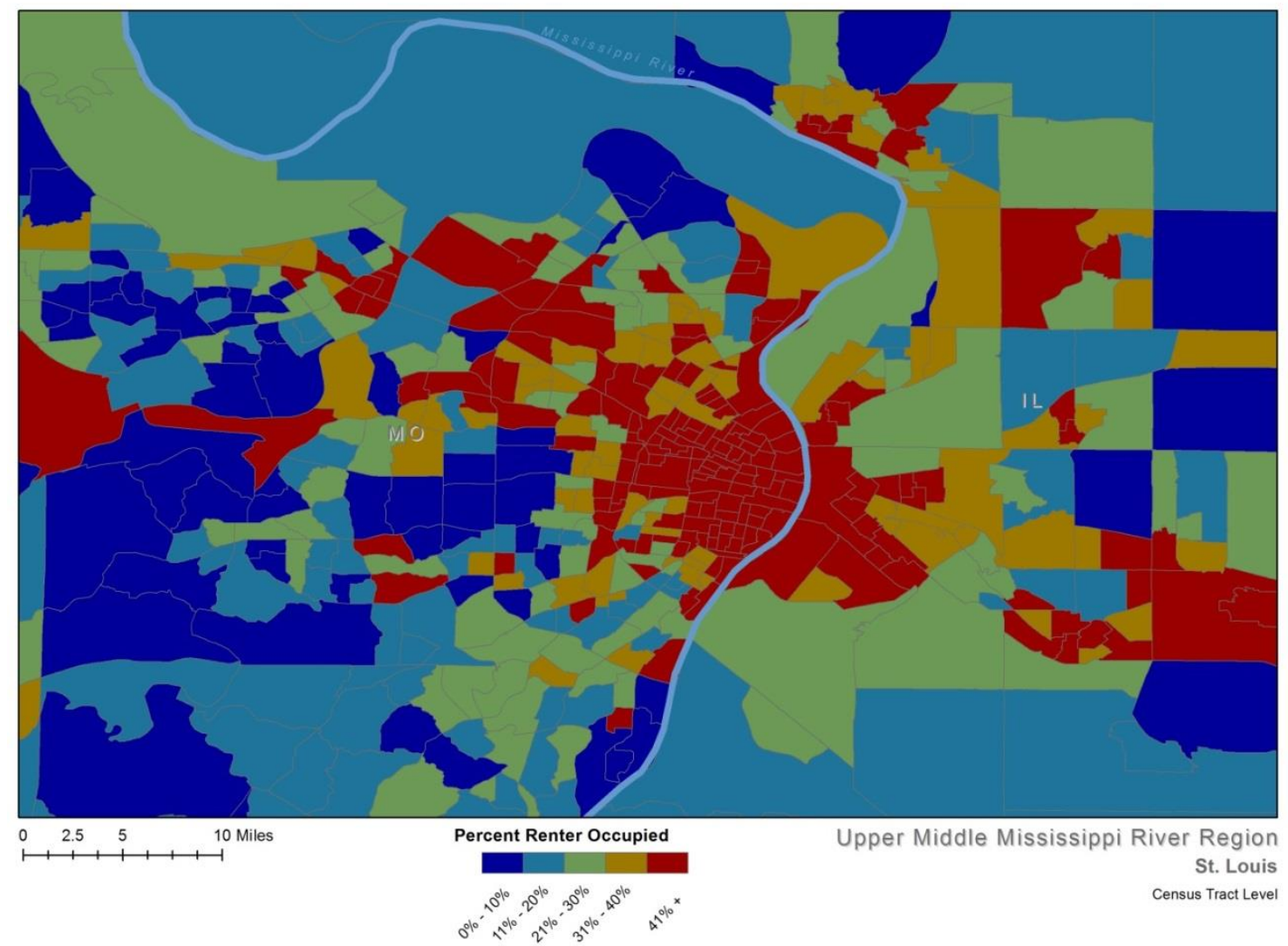

American Community Survey 2012 (5 year estimates) county and census tract data mapped using ArcGIS ${ }^{\circledR}$ software by Esri. ArcGIS ${ }^{\circledR}$ and $\operatorname{ArcMap}^{\mathrm{TM}}$ are the intellectual property of Esri and are used herein under license. 


\section{Figure 5.73}

Memphis, TN: Renter Occupied Housing

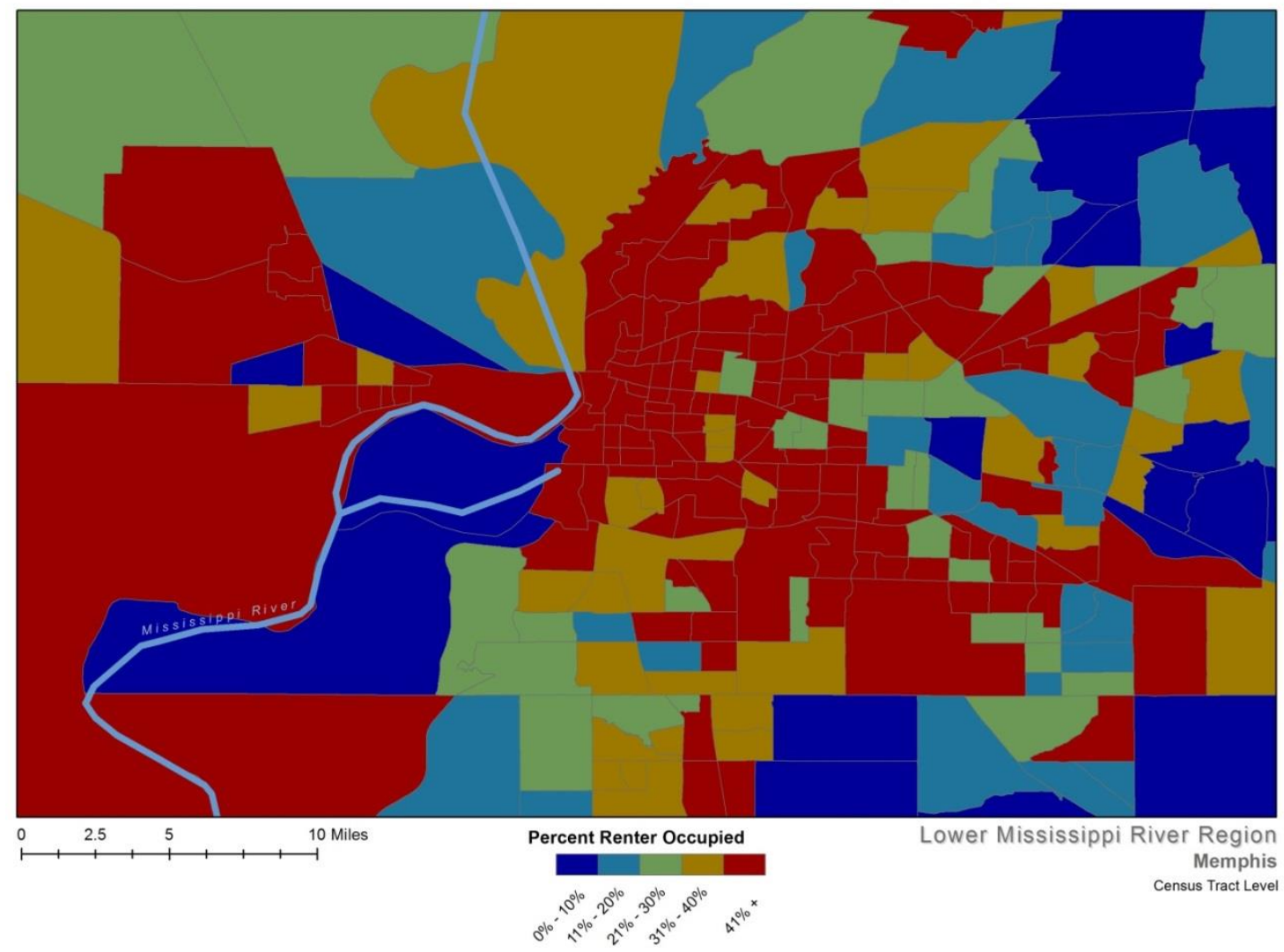

American Community Survey 2012 (5 year estimates) county and census tract data mapped using ArcGIS ${ }^{\circledR}$ software by Esri. ArcGIS ${ }^{\circledR}$ and $\operatorname{ArcMap}^{\mathrm{TM}}$ are the intellectual property of Esri and are used herein under license. 


\section{Figure 5.74}

Baton Rouge, LA: Renter Occupied Housing

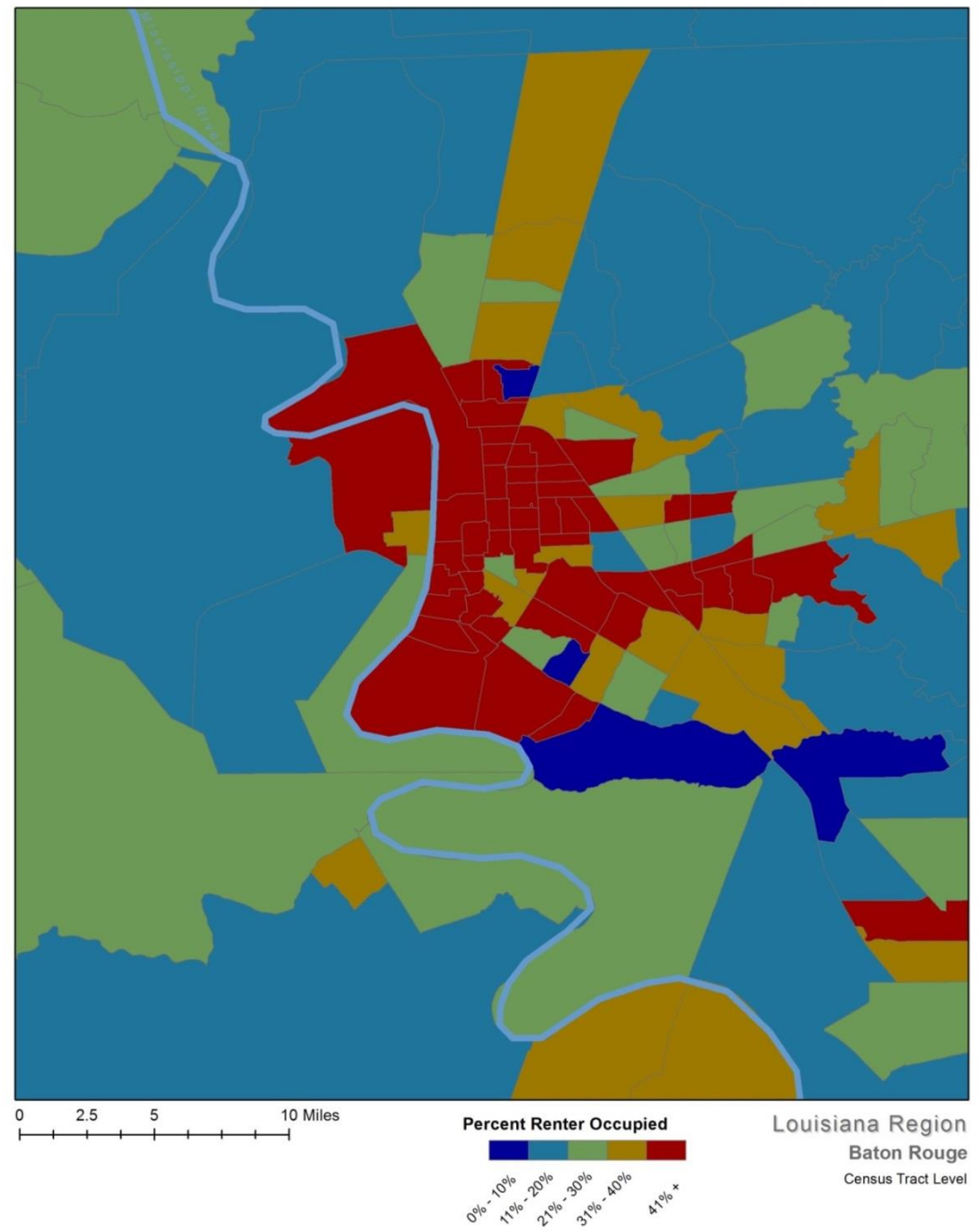

American Community Survey 2012 (5 year estimates) county and census tract data mapped using ArcGIS ${ }^{\circledR}$ software by Esri. ArcGIS ${ }^{\circledR}$ and ArcMap ${ }^{\mathrm{TM}}$ are the intellectual property of Esri and are used herein under license. 


\section{Figure 5.75}

New Orleans, LA: Renter Occupied Housing

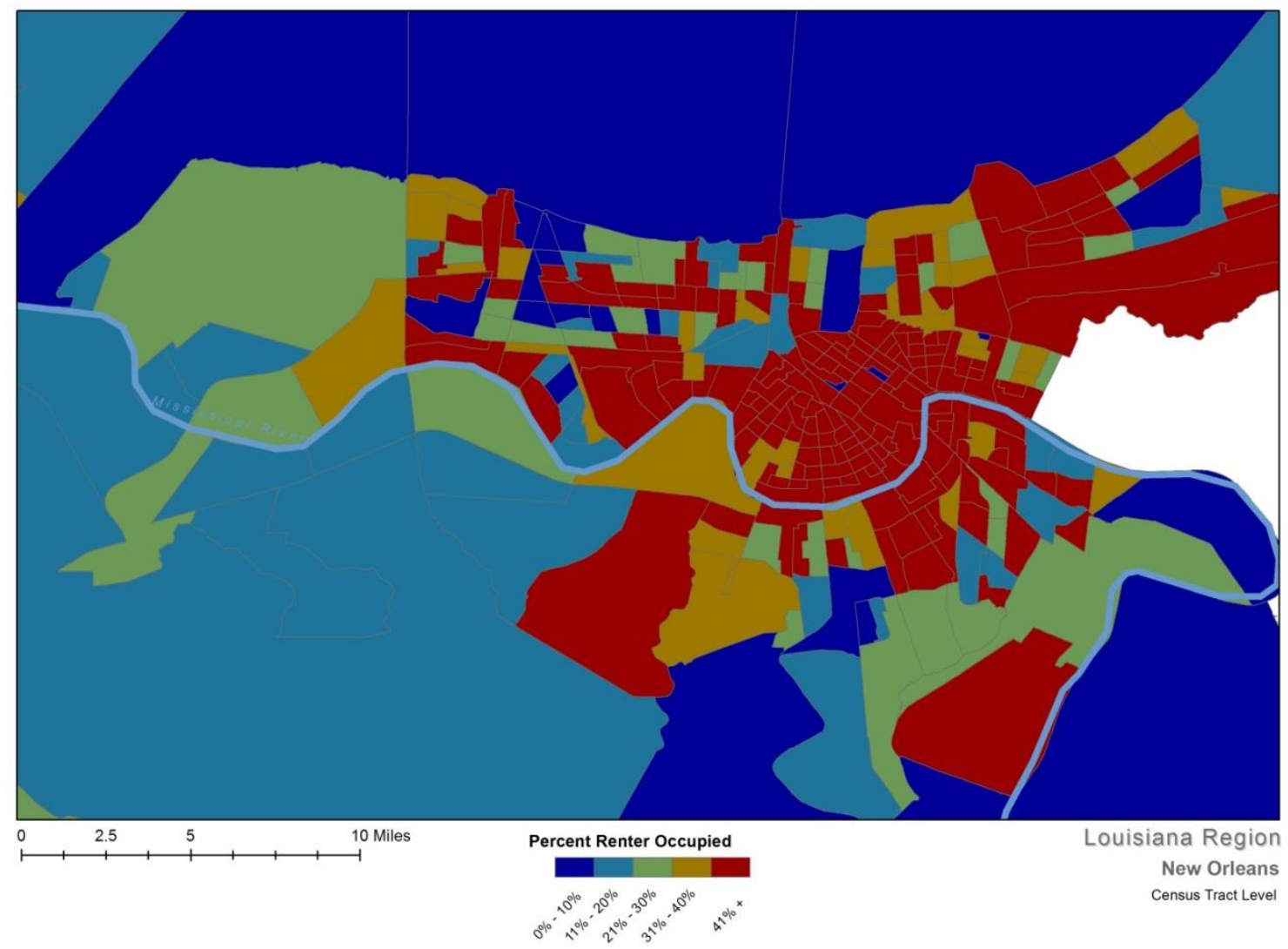

American Community Survey 2012 (5 year estimates) county and census tract data mapped using ArcGIS ${ }^{\circledR}$ software by Esri. ArcGIS ${ }^{\circledR}$ and ArcMap ${ }^{\mathrm{TM}}$ are the intellectual property of Esri and are used herein under license. 


\section{Figure 5.76}

Upper Mississippi River Region: Housing Built Prior to 1969

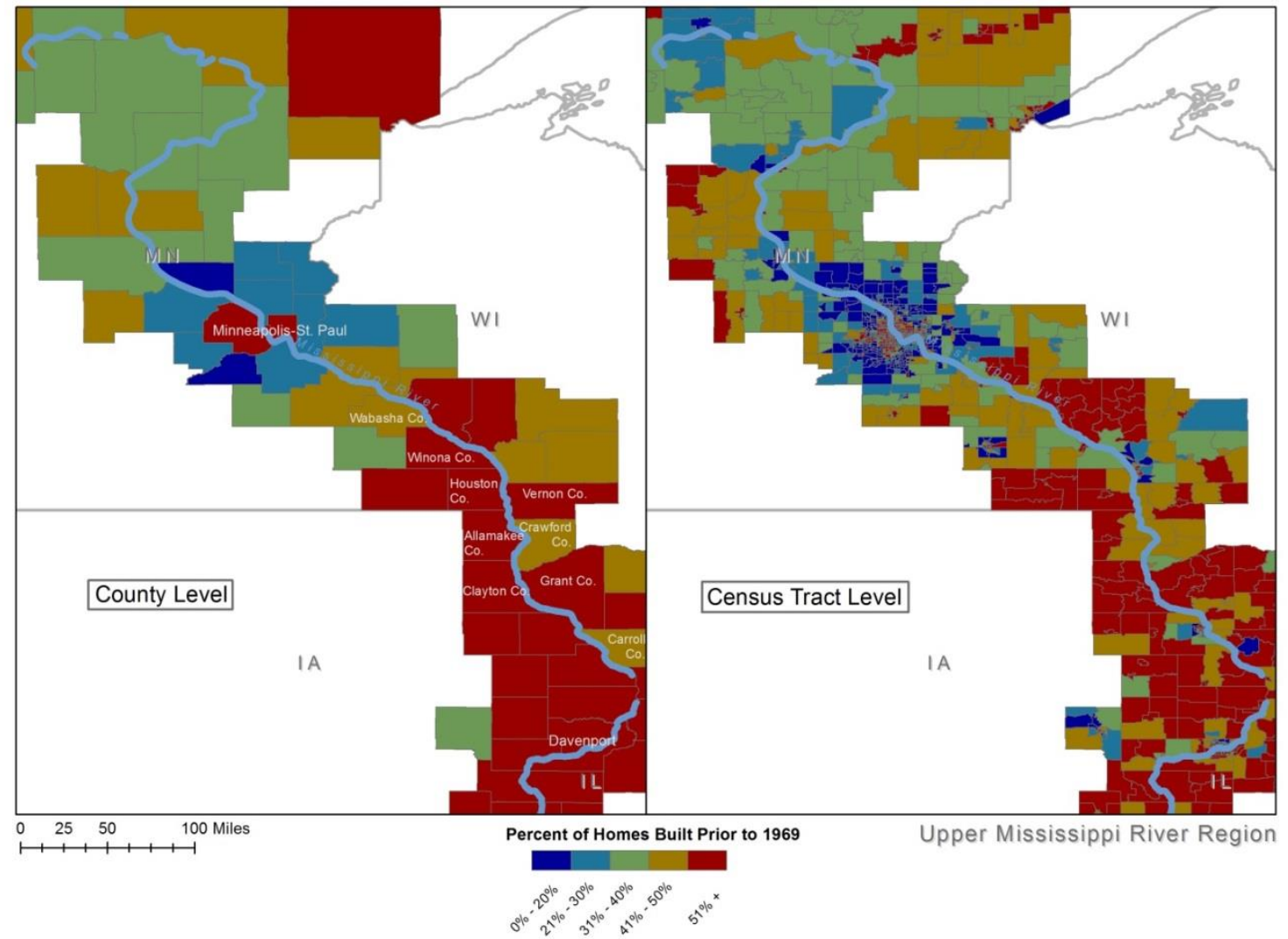

American Community Survey 2012 (5 year estimates) county and census tract data mapped using ArcGIS ${ }^{\circledR}$ software by Esri. ArcGIS ${ }^{\circledR}$ and ArcMap ${ }^{\mathrm{TM}}$ are the intellectual property of Esri and are used herein under license. 


\section{Figure 5.77}

Upper Middle Mississippi River Region: Housing Built Prior to 1969

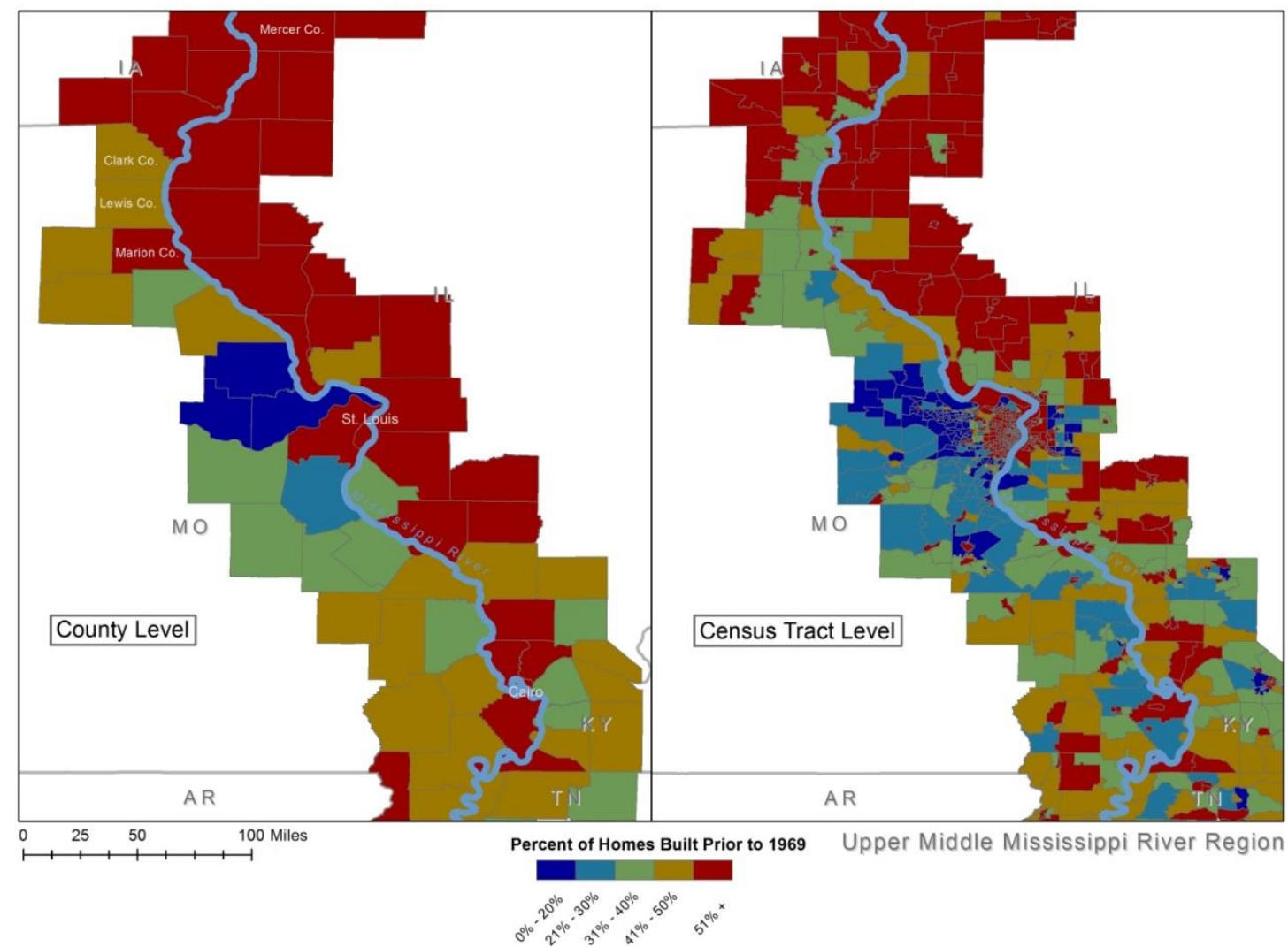

American Community Survey 2012 (5 year estimates) county and census tract data mapped using ArcGIS ${ }^{\circledR}$ software by Esri. ArcGIS ${ }^{\circledR}$ and $\operatorname{ArcMap}^{\mathrm{TM}}$ are the intellectual property of Esri and are used herein under license. 


\section{Figure 5.78}

Lower Mississippi River Region: Housing Built Prior to 1969

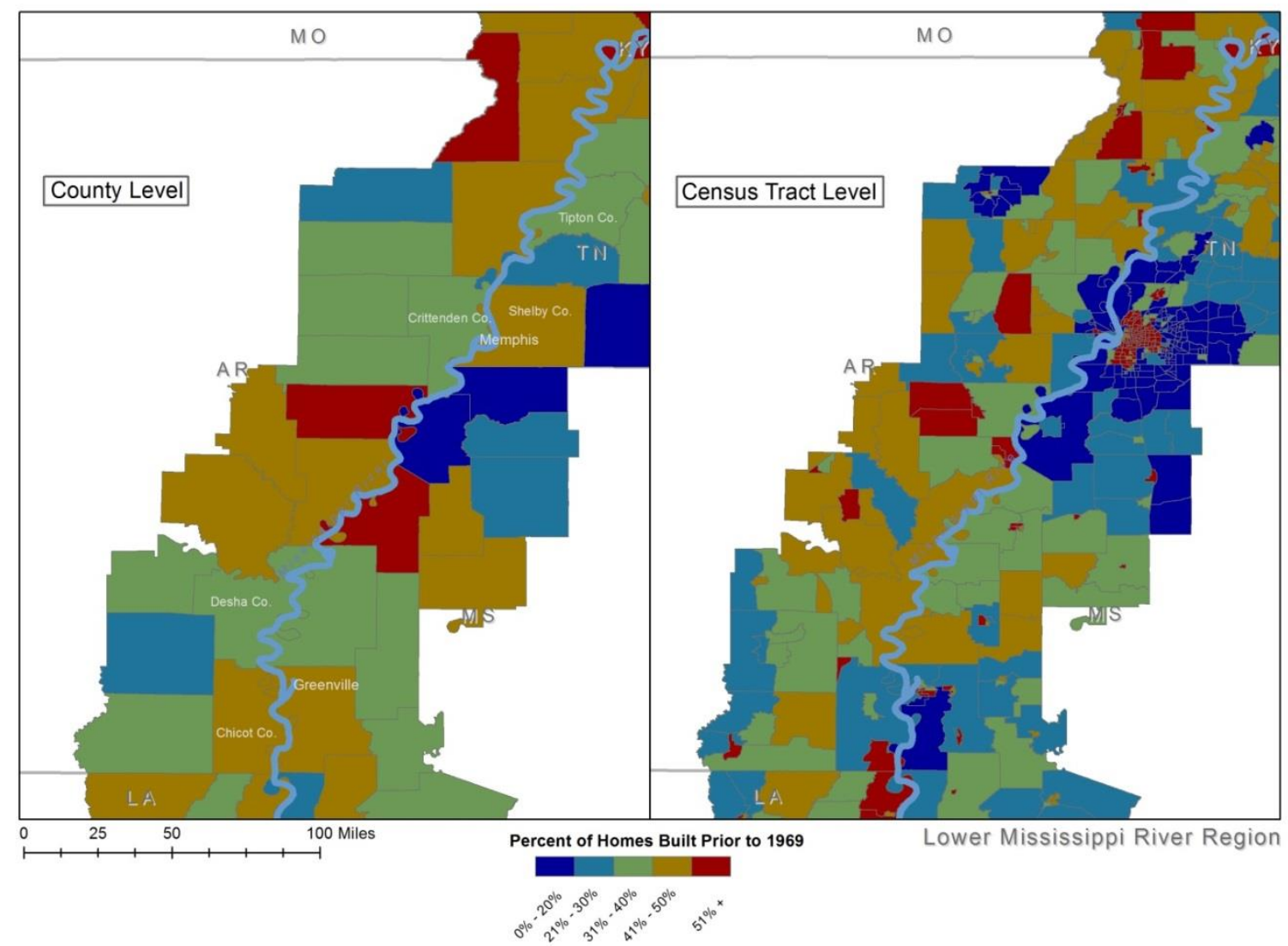

American Community Survey 2012 (5 year estimates) county and census tract data mapped using ArcGIS ${ }^{\circledR}$ software by Esri. ArcGIS ${ }^{\circledR}$ and ArcMap $^{\mathrm{TM}}$ are the intellectual property of Esri and are used herein under license. 


\section{Figure 5.79}

Louisiana Region: Housing Built Prior to 1969

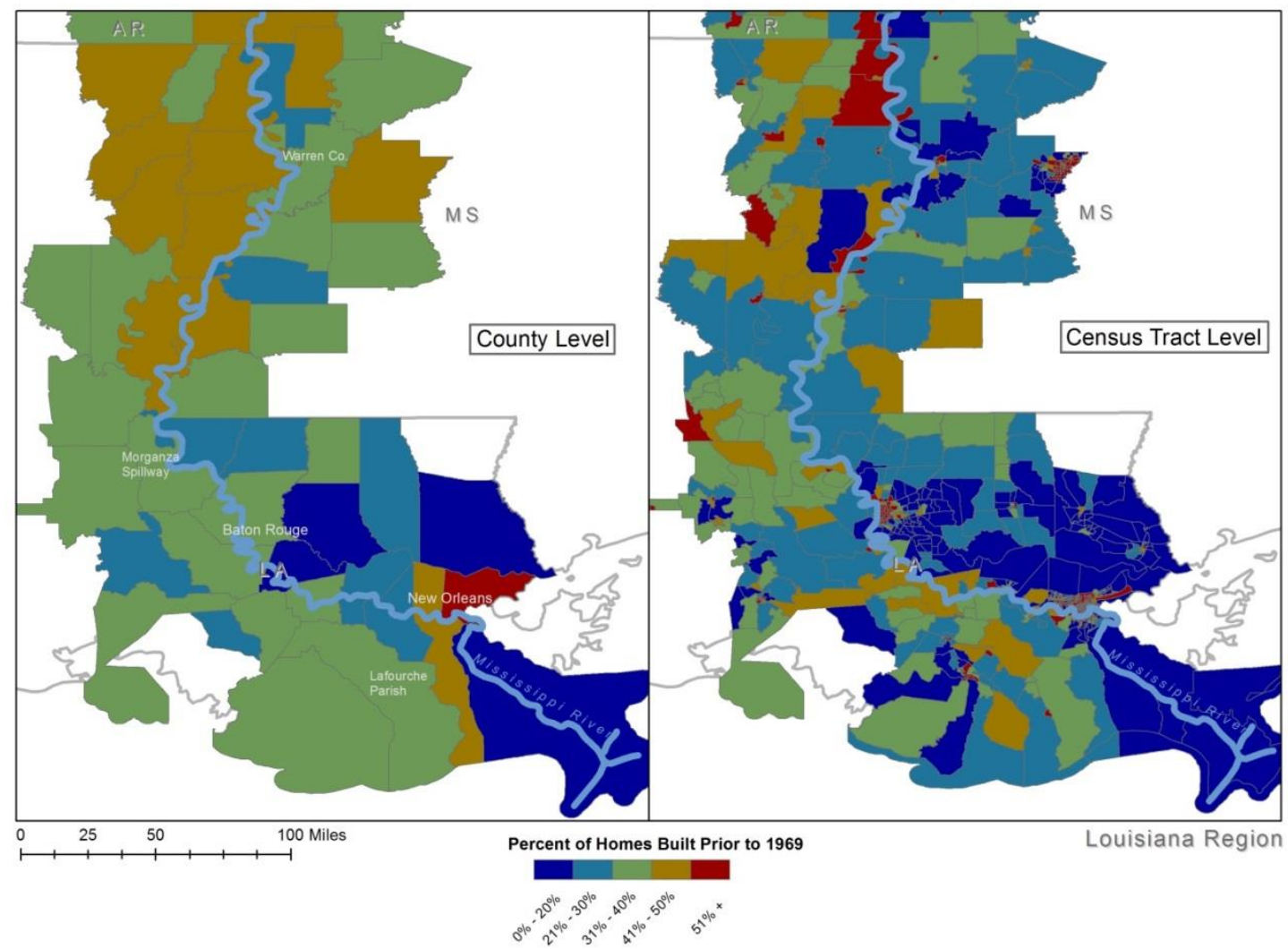

American Community Survey 2012 (5 year estimates) county and census tract data mapped using ArcGIS ${ }^{\circledR}$ software by Esri. ArcGIS ${ }^{\circledR}$ and ArcMap ${ }^{\mathrm{TM}}$ are the intellectual property of Esri and are used herein under license. 


\section{Figure 5.80}

Minneapolis/St. Paul, MN: Housing Built Prior to 1969

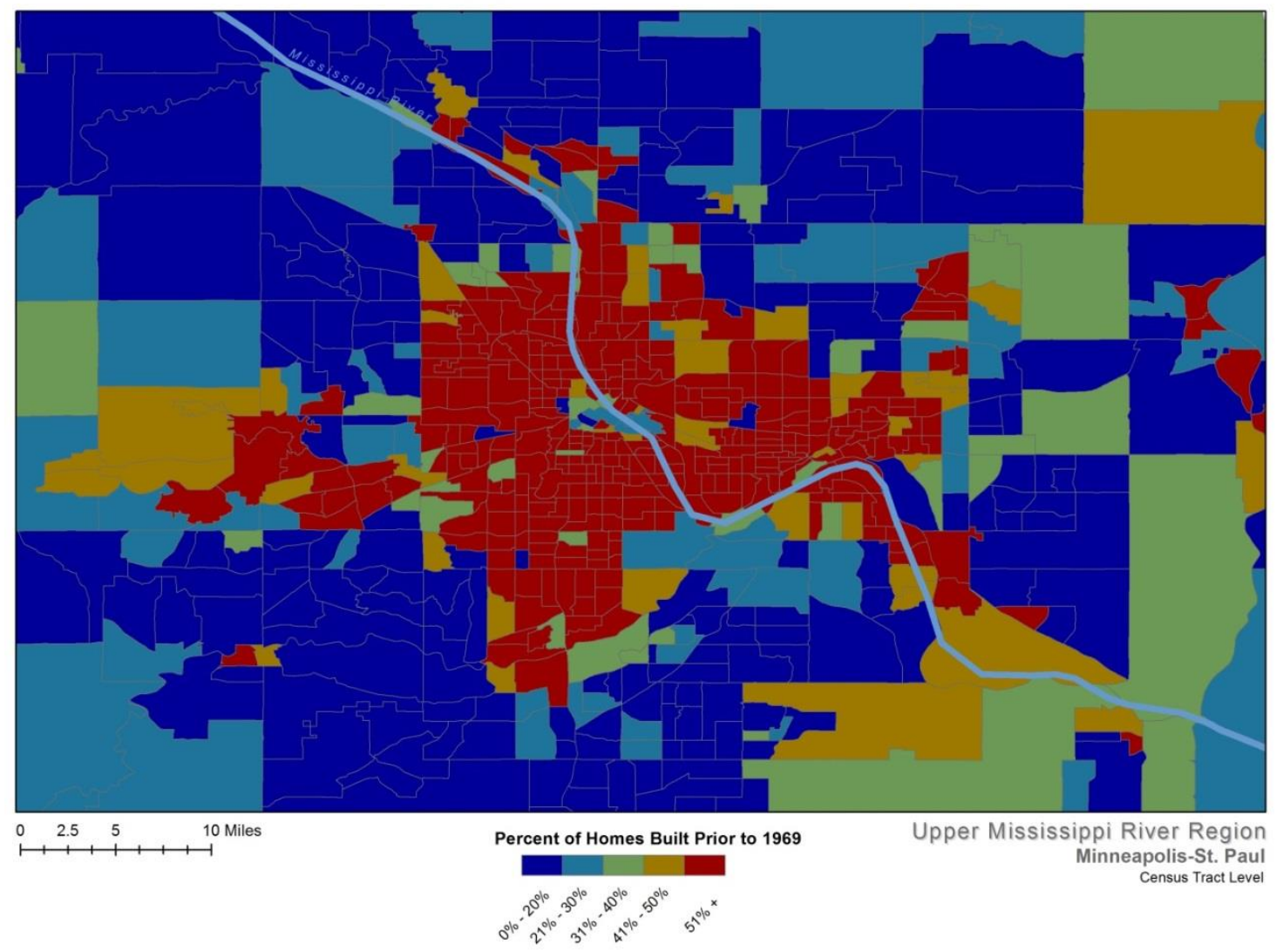

American Community Survey 2012 (5 year estimates) county and census tract data mapped using ArcGIS ${ }^{\circledR}$ software by Esri. ArcGIS ${ }^{\circledR}$ and $\operatorname{ArcMap}^{\mathrm{TM}}$ are the intellectual property of Esri and are used herein under license. 


\section{Figure 5.81}

Quad Cities (side view): Housing Built Prior to 1969

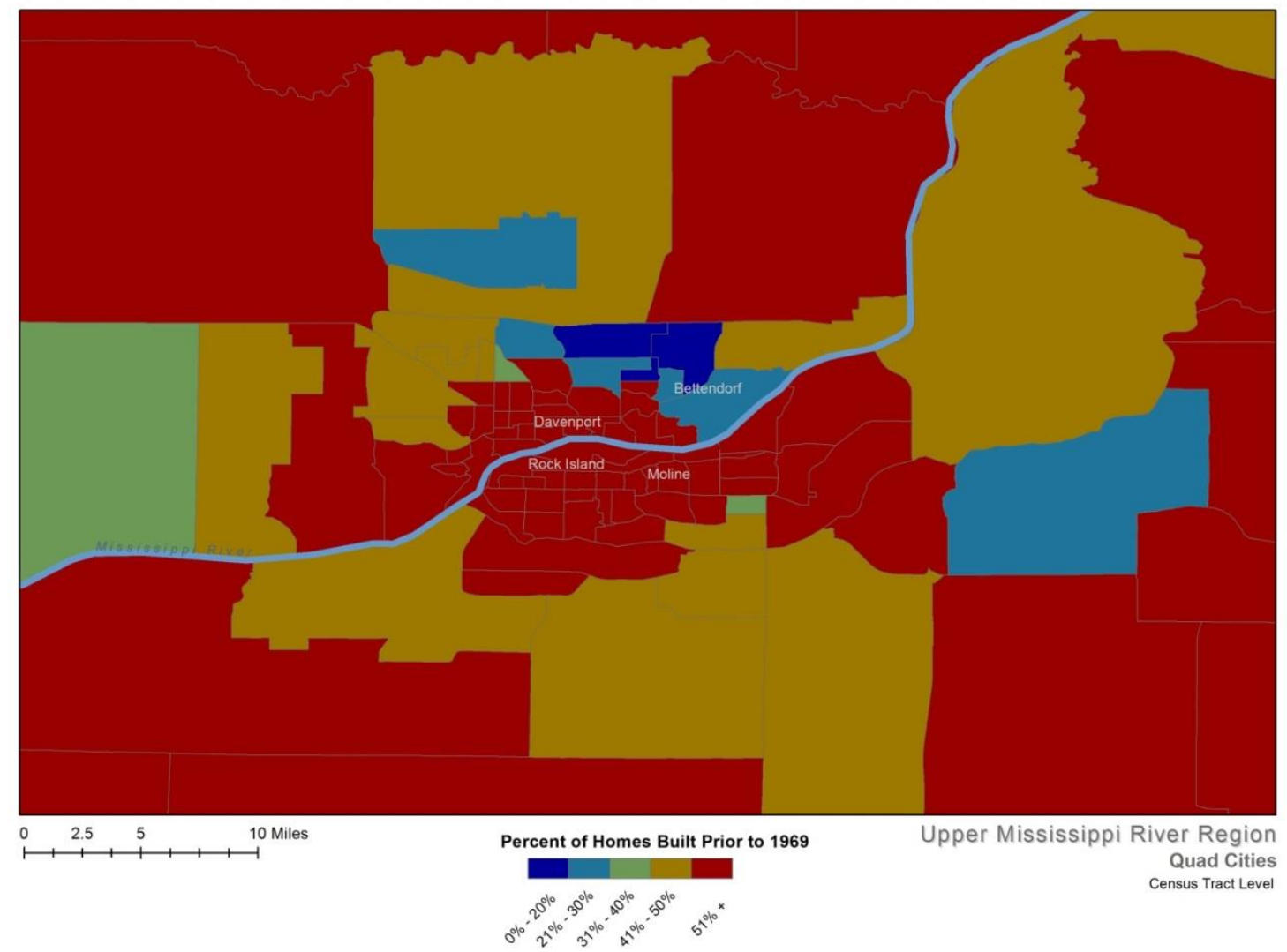

American Community Survey 2012 (5 year estimates) county and census tract data mapped using ArcGIS ${ }^{\circledR}$ software by Esri. ArcGIS ${ }^{\circledR}$ and ArcMap ${ }^{\mathrm{TM}}$ are the intellectual property of Esri and are used herein under license. 


\section{Figure 5.82}

St. Louis, MO: Housing Built Prior to 1969

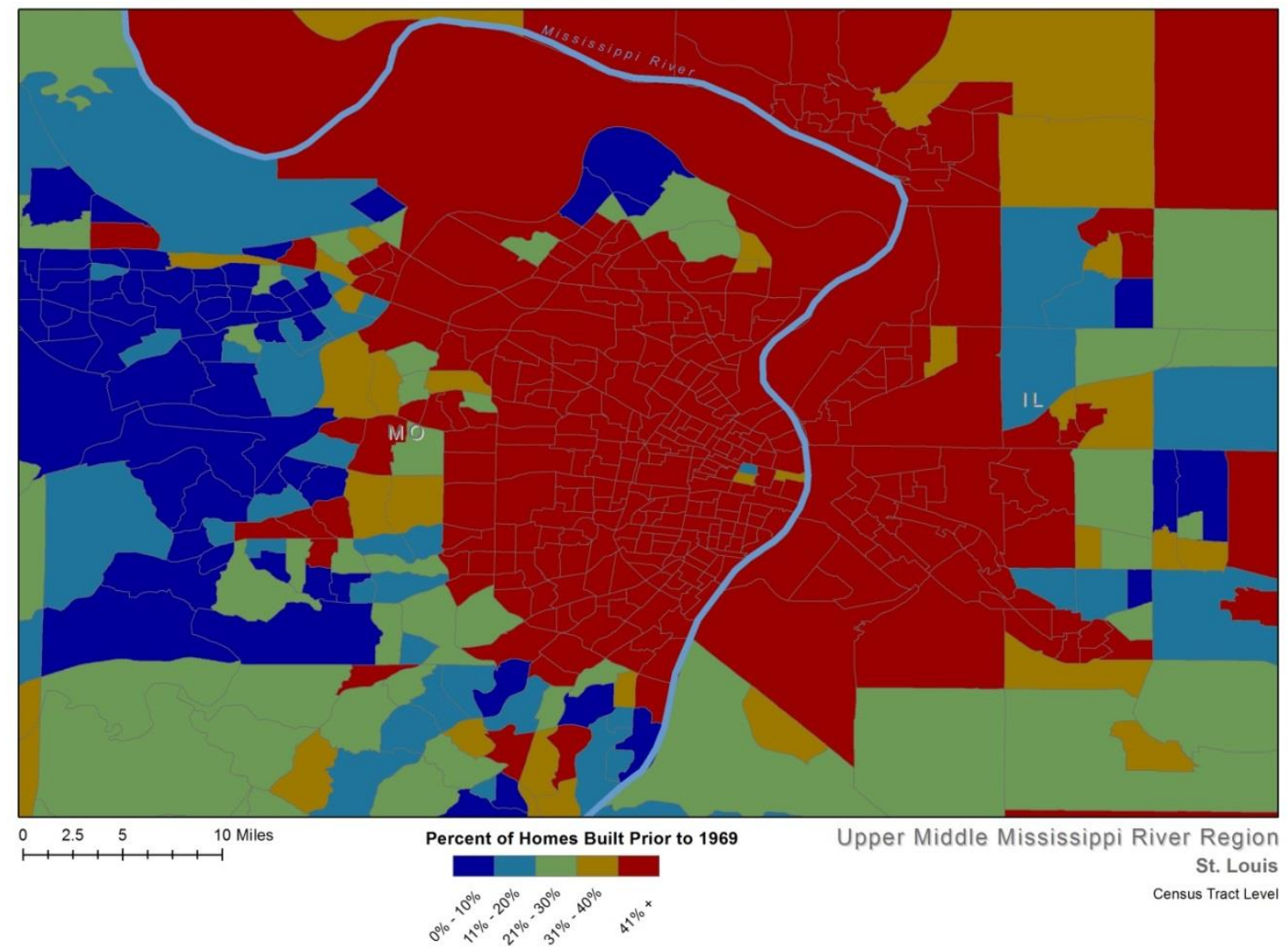

American Community Survey 2012 (5 year estimates) county and census tract data mapped using ArcGIS ${ }^{\circledR}$ software by Esri. ArcGIS ${ }^{\circledR}$ and $\operatorname{ArcMap}^{\mathrm{TM}}$ are the intellectual property of Esri and are used herein under license. 


\section{Figure 5.83}

Memphis, TN: Housing Built Prior to 1969

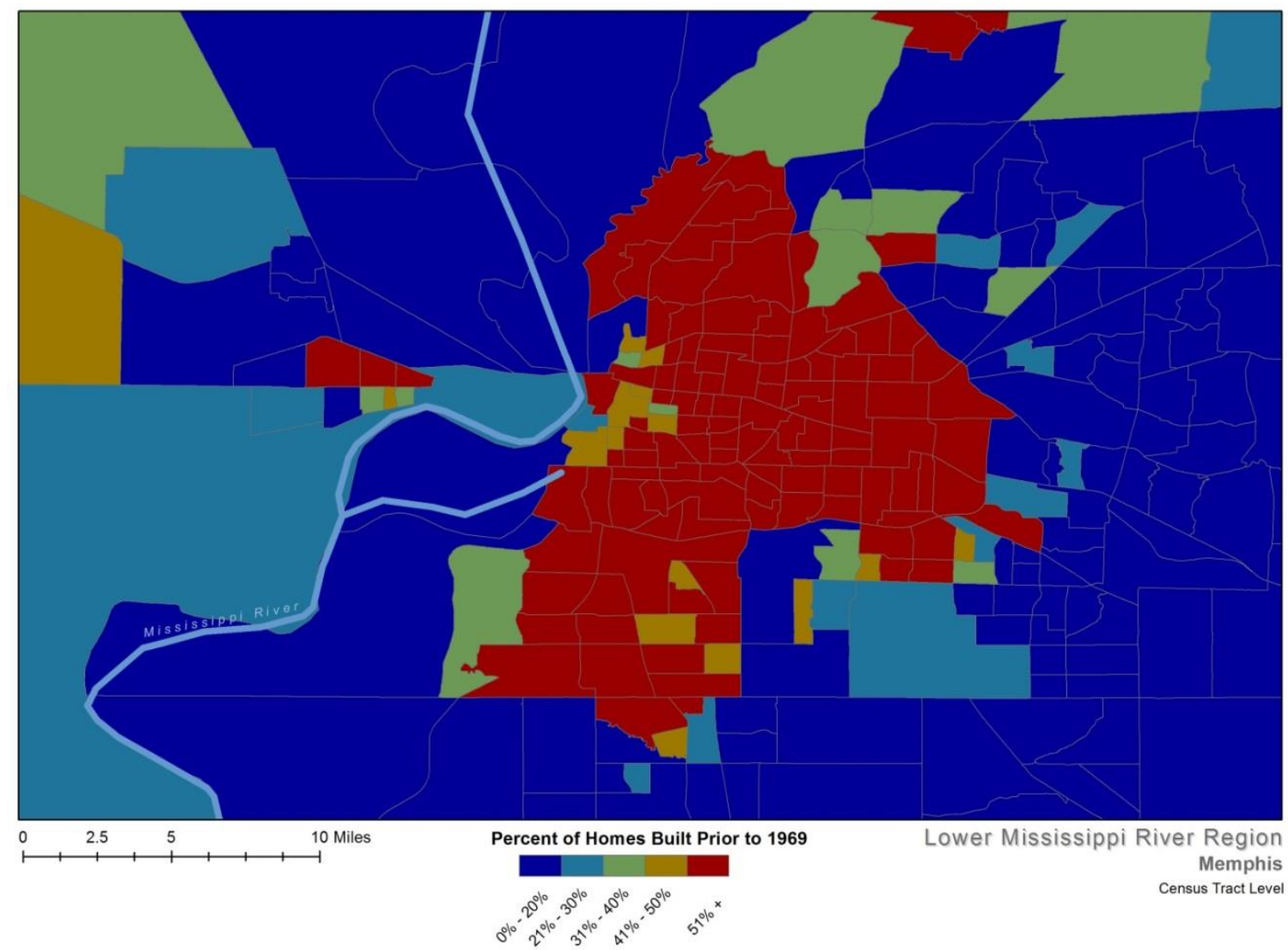

American Community Survey 2012 (5 year estimates) county and census tract data mapped using ArcGIS ${ }^{\circledR}$ software by Esri. ArcGIS ${ }^{\circledR}$ and ArcMap $^{\mathrm{TM}}$ are the intellectual property of Esri and are used herein under license. 


\section{Figure 5.84}

Baton Rouge, LA: Housing Built Prior to 1969

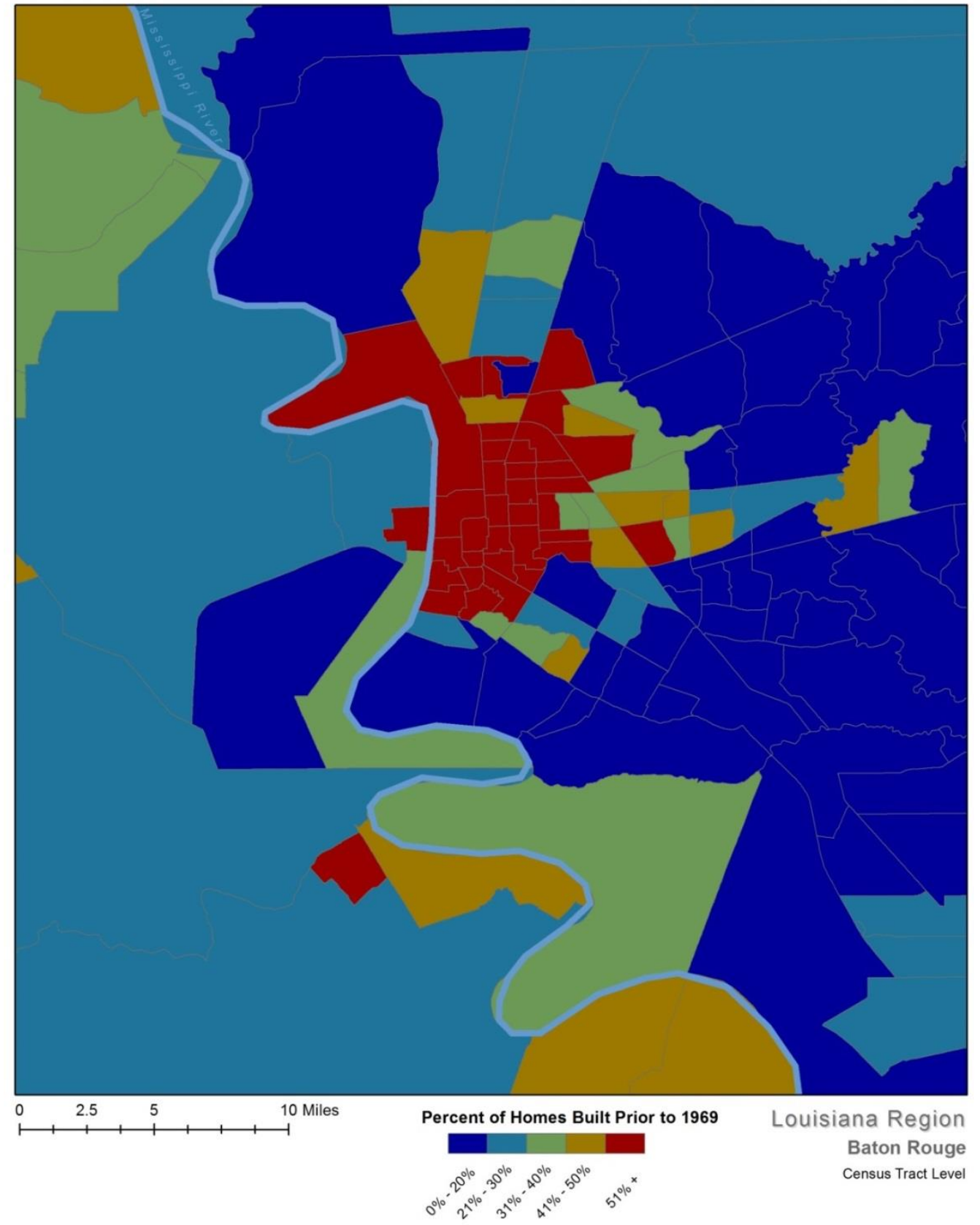

American Community Survey 2012 (5 year estimates) county and census tract data mapped using ArcGIS ${ }^{\circledR}$ software by Esri. ArcGIS ${ }^{\circledR}$ and ArcMap $^{\mathrm{TM}}$ are the intellectual property of Esri and are used herein under license. 


\section{Figure 5.85}

New Orleans, LA: Housing Built Prior to 1969

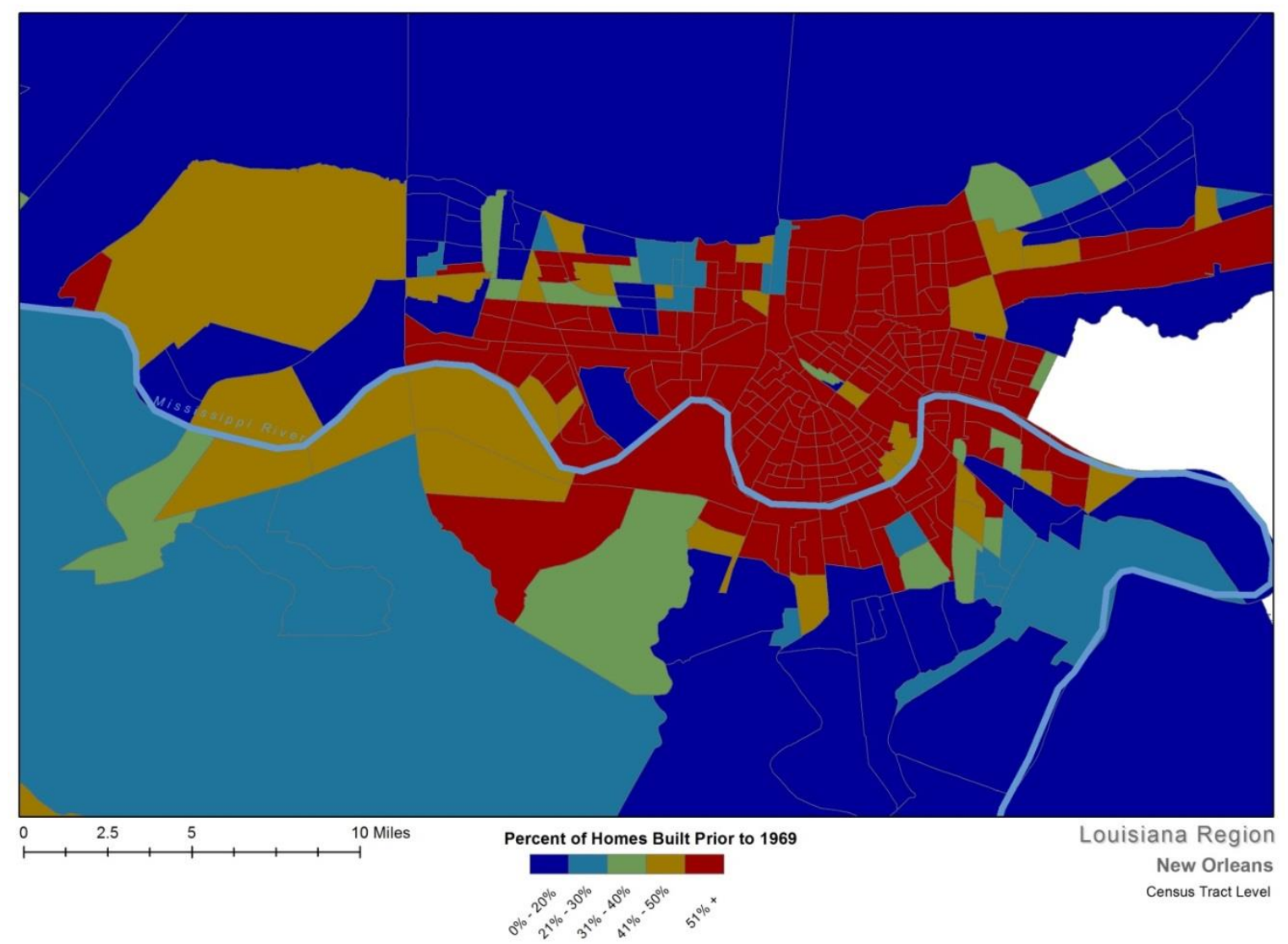

American Community Survey 2012 (5 year estimates) county and census tract data mapped using ArcGIS ${ }^{\circledR}$ software by Esri. ArcGIS ${ }^{\circledR}$ and ArcMap $^{\mathrm{TM}}$ are the intellectual property of Esri and are used herein under license. 


\title{
CURRICULUM VITA
}

NAME: $\quad$ Linda Kay Bailey

ADDRESS: 840 Pimlico Drive 1C

Dayton, OH 45459

DOB: $\quad$ Evansville, Indiana - May 8, 1964

\section{EDUCATION}

\& TRAINING:

\author{
B.S., Psychology \\ University of Southern Indiana \\ 2000-2004 \\ Master in Public Administration \\ University of Southern Indiana \\ 2005-2008 \\ Master in Liberal Studies \\ University of Southern Indiana \\ 2008-2010 \\ Ph.D., Urban Affairs \\ University of Louisville \\ 2010-2017
}

PROFESSIONAL EXPERIENCE:

University of Dayton: One year lecturer in Political Science and MPA Program (Fall, 2016 - Spring, 2017)

University of Southern Indiana: Adjunct Professor in Political Science and Psychology (Fall, 2014 - Spring, 2016)

Ivy Tech Community College: Adjunct Professor in Political Science (Fall, 2015 - Spring, 2016)

Planning Consultant:

Warrick County Solid Waste District (November, 2015 - February, 2016) 
University of Louisville Center for Hazards Research: Business Continuity Coordinator (August, 2010 - December, 2014)

Metropolitan Evansville Transit System Efficiency Study (September, 2008 - October, 2009)

Lead Research Asst. for Dr. Mary T. Hallock-Morris, Chair Political Science Dept. Under the auspices of USI Center for Applied Research for City of Evansville and Mayor Jonathon Weinzapfel and William Brodwater IV, Director of METS

Indiana Political Science Journal (May, 2009 - May, 2010)

Co-editor under the supervision of Mary T. Hallock-Morris, Editor

Community Disaster Preparedness Mitigation Study (Nov., 2009 - May 2010)

Primary Researcher; Supervisor: Dr. Mary T. Hallock-Morris, Chair Public Admin.

Grant support: USI Graduate Studies Dept.

The Greenway Path Project (October, 2006 - July, 2007)

Co-Author; Lead Assistant to Dr. U. Kwon

Supervision: Dr. U. Kwon, Associate Professor, Public Administration Dept. in

collaboration with USI Center for Applied Research for City of Evansville and Parks

Board

AWARDS:

Psi Chi National Honor Society (Inductee 02; President 04; Service Award 04)

Alpha Chi National Honor Society (Inductee 03)

Genarro Palladino Memorial Scholarship in Psychology (Honors Day 03)

Kappa Delta Pi Scholarship (Honors Day 03)

Academic Achievement Award for top G.P.A. (Honors Day 04)

U.S. Army Commendation Medal (outstanding performance) 1986

U.S. Army Achievement Medal (heroic duty) 1987

\title{
PROFESSIONAL SOCIETIES:
}

\author{
APSA \\ American Planning Association \\ Indiana Political Science Association \\ National Association of Contingency Planning \\ Kentuckiana Association of Contingency Planners -Program Director, board member \\ Yes for Unity, Evansville IN- consultant \\ Kentucky Emergency Management- private sector focus group \\ SUPA Ph.D. Association- Vice President 2011-2012 \\ 2009 USI Graduate School Advisory Board Council -elected student \\ SW Indiana Disaster Resistant Community Organization \\ PUBLICATIONS:
}


Indiana Political Science Journal (2009/2010) Volume 12 pp. 69-76. Research Note Publication "Toxic Cultures and Organizations: NASA and the Columbia Shuttle Disaster"

\section{PRESENTATIONS:}

6th Annual Louisiana Studies Conference, Natchitoches, LA (September, 2014) "Mitigation Issues in Mississippi River Flooding" 2014 Policy History Conference, Columbus, OH (June, 2014)

"Political Feasibility and Comprehensive Flood Mitigation Planning for the Mississippi River Region"

University of Louisville Sustainability Scholars Roundtable Workshop (February, 2014) "Communities Under Stress and Resilient Communities"

Kentuckiana Association of Contingency Planners Speaker Series (October, 2013) "Community Networking in Contingency Planning"

Indiana Political Science Association Annual Conference (April, 2013) "Incorporating Systems Theory Analysis of Hazards and Hazard Mitigation on the Lower Mississippi River"

Yes for Unity Evansville Indiana Expert Panel Discussion and Media Event (October, 2012) Evansville Metropolis and Vanderburgh County Consolidation "Weighing the Outcomes of City/County Consolidation"

Kentuckiana Association of Contingency Planners Speaker Series (September, 2012) "Lessons in Contingency Planning: Disaster plans, organizational structures, and the problem of aporia"

Environmental Hazards Guest Lecture at School of Urban Policy and Affairs (April, 2012) "Human Stampedes: Crowd behaviors and averting disaster"

Center for Hazards Research, University of Louisville (February, 2012)

"Private Sector Contingency Planning: A meta review of the literature and the future recommendations"

Indiana Academy of Social Sciences 80th Annual Meeting (October, 2009)

"Riding the Bus: Poverty, Polycentricity, and Other Challenges Associated with Public Transportation in Midsized Cities"

Presentation to Evansville County Commissioners, Board of Public Works and Local Media on behalf of University of Southern Indiana Center for Applied Research (July, 2007) "Greenway Path Usage Study- Final Report" 
Indiana Political Science Annual Meeting (March, 2007)

"Group Decision Making: Ethical Challenges and Considerations for Small Groups" 